QUANTITATIVE REMOTE SENSING OF VEGETATION PROPERTIES AND FUNCTIONING UNDER NORMAL AND DRY CONDITIONS 
Graduation committee:

\section{Chairman/Secretary}

Prof.dr.ir. A. Veldkamp University of Twente

\section{Supervisor}

Prof.dr.ing. W. Verhoef University of Twente

\section{Co-supervisor}

Dr.ir. C. van der Tol University of Twente

\section{Members}

Prof.dr. R. Zurita-Milla University of Twente

Prof.dr. F.D. van der Meer University of Twente

Prof.dr. U. Rascher

Dr. J.G.P.W. Clevers

Dr. M. Migliavacca

Forschungszentrum Jülich, Germany

Wageningen University

Max Plank Institute for

Biogeochemistry, Jena, Germany

ITC dissertation number 339

ITC, P.O. Box 217, 7500 AE Enschede, The Netherlands

ISBN: $978-90-365-4687-4$

DOI: $\quad 10.3990 / 1.9789036546874$

Printed by: ITC Printing Department

Copyright (C) 2018 by Bagher Bayat, Enschede, The Netherlands Cover designed by Bagher Bayat and Job Duim

All rights reserved. No part of this publication may be reported without the prior written permission of the author (bagher.bayat@gmail.com). 


\title{
QUANTITATIVE REMOTE SENSING OF VEGETATION PROPERTIES AND FUNCTIONING UNDER NORMAL AND DRY CONDITIONS
}

\author{
DISSERTATION \\ to obtain \\ the degree of doctor at the University of Twente, \\ on the authority of the rector magnificus, \\ prof.dr. T.T.M. Palstra, \\ on account of the decision of the graduation committee, \\ to be publicly defended \\ on Wednesday December 5, 2018 at 16:45
}

by

Bagher Bayat

born on November 21, 1984

in Malayer, Iran 
This thesis has been approved by

Prof.dr.ing. W. Verhoef (supervisor)

Dr.ir. C van der Tol (co-supervisor) 
"A journey of a thousand miles begins with a single step" Lao Tzu 
To my family 


\section{Acknowledgments}

First and foremost, I would like to deeply thank God almighty for giving me the power, knowledge, ability and opportunity to start this research and to persevere and complete it in a proper way. Without his blessings, this achievement would not have been possible.

Let's continue with my hands-on experience, that a completion of a $\mathrm{PhD}$ research requires a great interest, considerable commitment, lots of hard work, innovation and time management. However, while all of these factors are a requirement, they alone are not sufficient. You must also be lucky with your supervision team to receive scientific support to secure a good starting point, to move forward with enough knowledge, to stay in the line and to keep the right direction towards your destination. I would consider myself very lucky to be a part of the best and most unique research teams at ITC during this socalled "journey".

I would like to express my special appreciation and thanks to my main supervisor (promotor) Prof. Wouter Verhoef, who provided me with the opportunity to do my PhD in his research group at ITC, and from that moment till the end, supported me mainly in everything: helping me to shape innovative scientific research, observing my progress closely, conducting fruitful discussions, giving brilliant suggestions to improve the work and encouraging my research. His open office policy for my questions, being so quick response for my emails even during holidays and weekends, generous in sharing his knowledge, work, and experience are all greatly appreciated. His advice on both research as well as on my career have been priceless. If I ever get a chance for supervising students, all lessons I have learned from him during the course of my PhD will indeed be guiding me.

My sincere thanks go to my co-supervisor, Dr. Christiaan van der Tol, who has always supported me since the beginning of my PhD. He has always been there supporting me from the proposal development, papers publications, and thesis writing. I am deeply grateful for all his technical support and scientific advice during my research. Especially at the beginning of my PhD study, he fully supported my idea of conducting a controlled laboratory experiment as the first, and the most important, step of my research. He shared his knowledge and experience generously with me to set up an interesting and innovative laboratory drought experiment. I remember that he put in a great deal of effort and time in the laboratory to help me figure things out and answered my basic questions patiently and provided all the help he could to get me through the obstacles. Further, during my research in the last four years whenever I had difficulties, no matter if they were about facilities, research set-up, data collection, image analysis, modeling set-up, and results interpretation, I could always drop by his office and seek professional help from him. His logical thinking, constructive comments, smart suggestions, effective solutions and close observations of my progress have always helped me 
through the PhD study. I am also grateful for the fruitful discussions we shared during our individual meetings and our regular group meetings (usually once per two weeks) during my PhD study. In my opinion, although Wouter's retirement made a big scientific gap for new upcoming PhD students in WRS department at ITC, Christiaan's expertise could reconcile such a gap significantly. I could not have imagined having a better supervisor and cosupervisor for my PhD study and no words can express my gratitude, pride, and honor of being a PhD student in their unique research group!

Well, that was the core starting team, and it has expanded smoothly over time. In this regard, the first persons to mention are Marijke van der Tol and Josip Završki who gave me generous help during the laboratory experiment, particularly during all spectral samplings and destructive measurements in the laboratory. They were totally positive to follow the tight schedule of my experiment step by step just to help me to have such a successful experiment. Thanks Marijke and Josip for your engagement in my laboratory experiment which might sometimes be boring for both of you!

At this point, I also would like to mention the key local expert, Dr. Siyan $\mathrm{Ma}$, from the University of California, Berkeley, USA. She supported me in preparation of the needed ground data and the better understanding of the measurements at Vaira Ranch Fluxnet site (Var-US). In addition, Dr. Ma has reviewed the second, the third and the fourth papers and provided me with insightful comments and suggestions. I appreciate all the inputs she has given which helped me to improve the quality of my work.

I am also thankful to ITC which provided me with a nice working environment and facilities. Most importantly, I would like to thank Prof. Bob Su for all the support at WRS department. Many thanks Bob for insightful discussions we shared during my research. Further, Bob supported our idea of organizing advanced courses for PhDs in our department based on their needs through PhD-WPW events. Some of those courses were directly related to my research and, therefore, very useful for me. Thanks Bob! Also, I would like to acknowledge all the support received from the ITC Geoscience and Remote Sensing Laboratory staff, especially Boudewijn de Smeth, Watse Siderius and Murat Uçer. They facilitated my laboratory experiment dramatically. I am grateful to our department secretaries, Anke, Tina and Lindy, for being always so kind, supportive and helpful during my PhD. I would like to express my gratitude to Loes Colenbrander for the assistance of my PhD application and the support during my stay at ITC. I would like to thank Benno and Job for the assistance in making a few nice posters and helping me with the thesis cover design. I would like to thank ITC student affairs, especially Theresa van den Boogaard, for the assistance of my Visa, residence permit and health insurance applications. Big thanks go to all the colleagues and friends in ITC WRS department for their support and company during these years, especially Zoltan, Suhyb, Chris, Peiqi, Harm-Jan, Megan, Jan, Yasser, Cesar, Vahid, and Qiang. Especial thanks to Megan who reviewed the second paper and Peiqi who 
engaged in a fruitful discussion about the fourth paper. I also would like to extend my deepest gratitude to all my Iranian friends in Enschede for all the enjoyable moments we shared during the last five years and for all our weekend gatherings.

Apart from the Netherlands life and people, I would like to acknowledge and thanks my family. This dissertation would not have been possible without their encouragements and support, undoubtedly. Words cannot express how grateful I am to my family, especially to my father and mother for all of the sacrifices that they've made on my behalf. They prayer for me was what sustained me thus far.

Last but not least, I would like to express appreciation to my wife who was always my great support in the moments when there was no one to answer my queries. She always stands next to me in all the ups and downs of both the life and PhD! Thanks for your care, understanding, endless support and unconditional love. 


\section{Table of Contents}

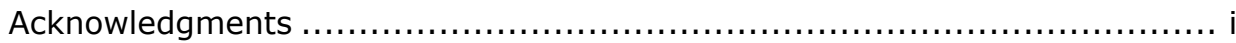

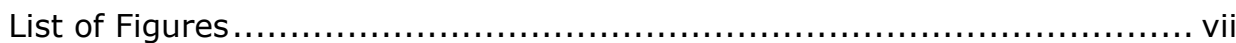

List of Tables ....................................................................... vii

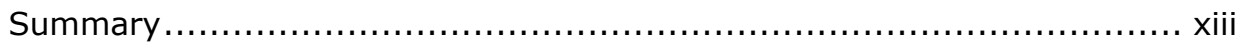

Samenvatting ......................................................................

Chapter 1 General Introduction .................................................. 1

1.1. Why estimating vegetation functioning .................................

1.2. Drought effects on vegetation functioning ...............................

1.3. How to estimate vegetation functioning ................................ 4

1.4. Remote sensing observations ............................................

1.5. Coupled modeling approach ........................................... 6

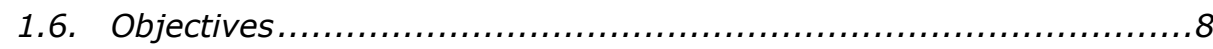

1.7. Dissertation outline ............................................... 9

Chapter 2 Exploiting hyperspectral reflectance observations using statistical and physical models ......................................................11

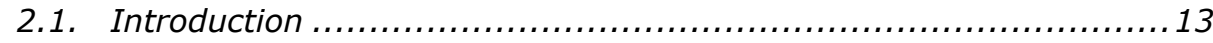

2.2. Materials and methods ............................................. 15

2.2.1. Experimental design/setup ...................................... 15

2.2.2. Instrumentation and measurements ............................. 16

2.2.3. Spectral acquisition ................................................. 19

2.2.4. Water stress-related vegetation indices........................... 19

2.2.5. Radiative transfer (RT) models ................................. 20

2.2.6. Local sensitivity analysis of RTMo ............................... 21

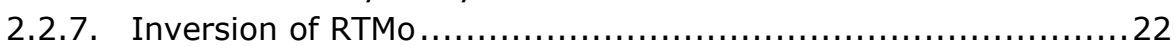

2.2.8. Inversion performance evaluation (statistics of errors) ........... 23

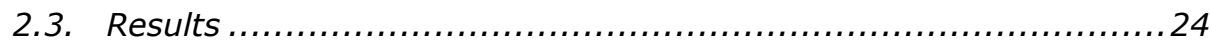

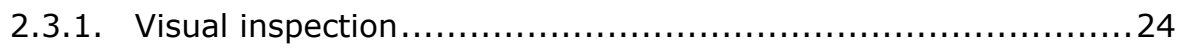

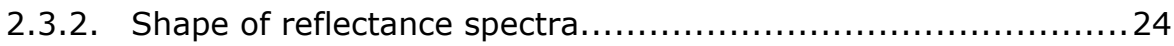

2.3.3. Spectral indices ..................................................... 26

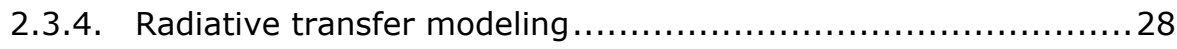

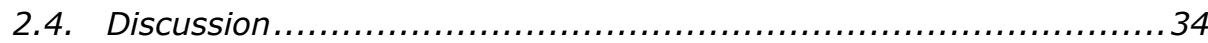

2.4.1. Visual interpretation of the stress effects.......................... 34

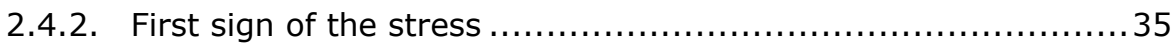

2.4.3. Water stress-related vegetation indices........................... 35

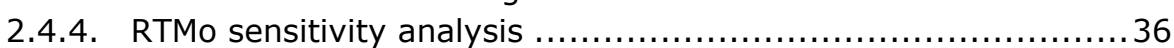

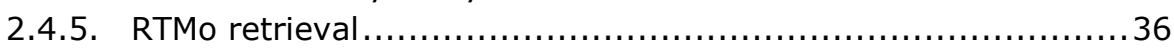

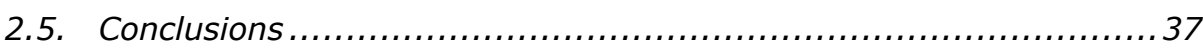

Chapter 3 Exploiting multispectral satellite radiance observations by

coupling radiative transfer models................................................. 39

3.1. Introduction ............................................................ 41

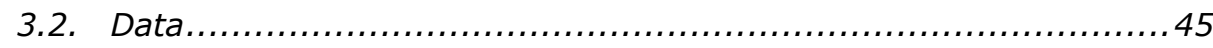

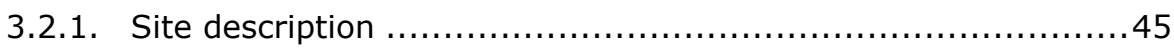


3.2.2. Vegetation characteristics at the site $\ldots \ldots \ldots \ldots \ldots \ldots \ldots \ldots \ldots \ldots \ldots$

3.2.3. Remote sensing observations ................................... 46

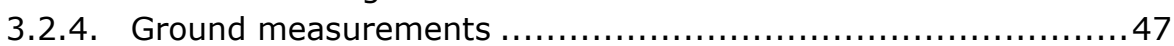

3.3. Methods............................................................. 47

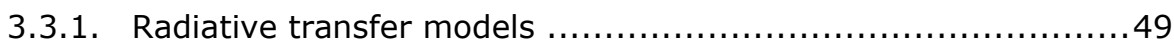

3.3.2. Parameter retrieval from TOA radiance spectra ................... 54

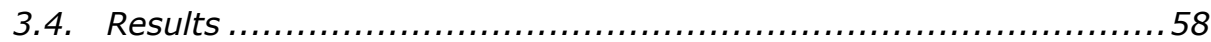

3.4.1. Landsat observed TOA radiance variations over time............ 58

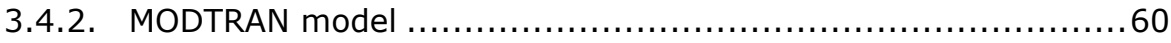

3.4.3. Coupled model inversion against TOA radiance.................6 64

3.4.4. Retrieved properties variations during the episode $\ldots \ldots \ldots \ldots \ldots . \ldots 70$

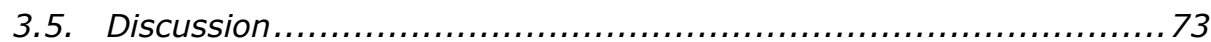

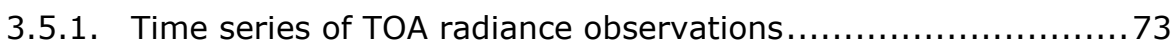

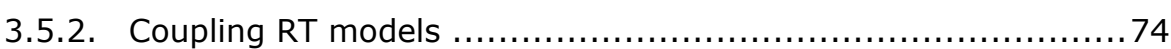

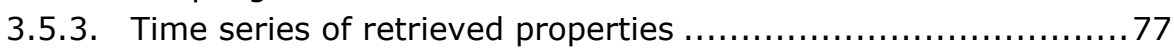

3.5.4. Implications for multi-sensor time series synergy studies........78

3.6. Conclusions ...................................................... 79

Chapter 4 Integrating satellite optical and thermal radiance

observations using the SCOPE model .......................................... 83

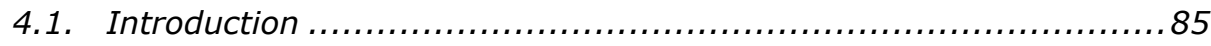

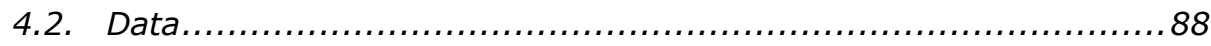

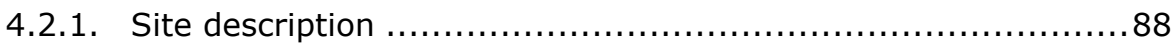

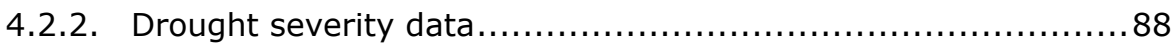

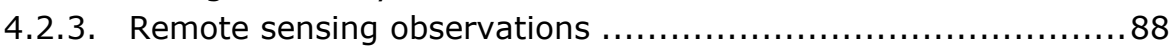

4.2.4. Ground measurements .......................................... 89

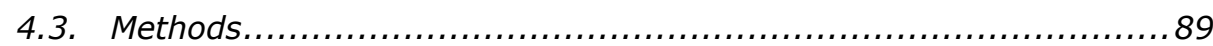

4.3.1. Atmospheric correction of TIR band ......................... 92

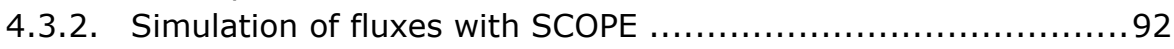

4.3.3. Crop factors ............................................... 94

4.3.4. Model performance evaluation ................................ 95

4.4. Results ......................................................... 96

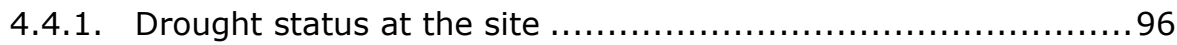

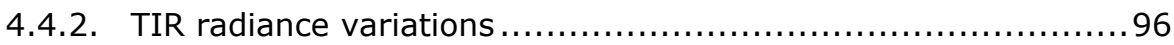

4.4.3. Vegetation functioning (GPP and ET) variations ................. 97

4.4.4. SCOPE (RTMt + energy balance) inversion against TIR spectra.97

4.4.5. TIR domain retrieved properties variations ..................... 98

4.4.6. Vegetation daily functioning simulation ............................ 99

4.4.7. Intercomparison (GPP, ET and Kc) .......................... 104

4.4.8. Spatio-temporal variations of GPP and ET .................. 107

4.5. Discussion...................................................... 110

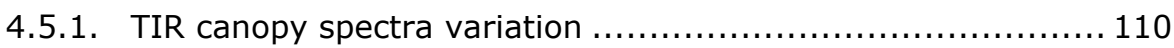

4.5.2. Canopy properties and functioning variations ................ 111

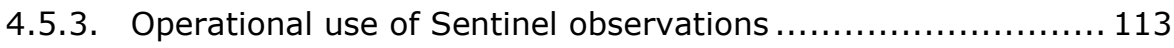

4.6. Conclusions .................................................. 113 


\section{Chapter 5 Combined use of optical reflectance and soil moisture}

observations using SCOPE-SM model ................................... 115

5.1. Introduction .................................................... 117

5.2. Model description ................................................ 120

5.2.1. SCOPE model brief overview.............................. 120

5.2.2. SCOPE-SM model........................................... 121

5.3. Evaluation of the model......................................... 126

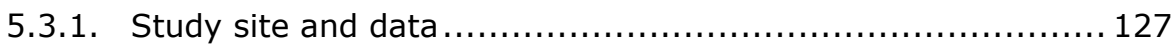

5.3.2. Error statistics .............................................. 128

5.3.3. Information content of optical, thermal and soil moisture

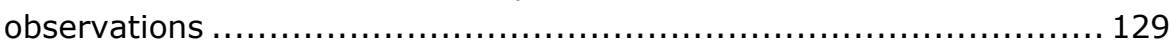

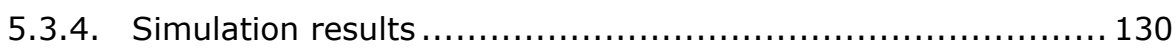

5.4. Discussion and conclusions ................................... 137

Chapter 6 Concluding remarks and prospects ............................ 145

6.1. Summary of conclusions............................................ 146

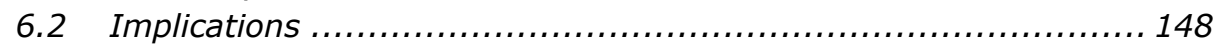

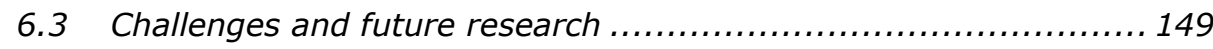

هكيده

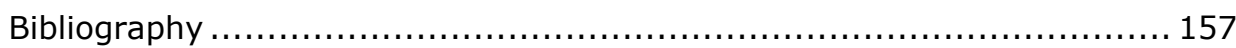

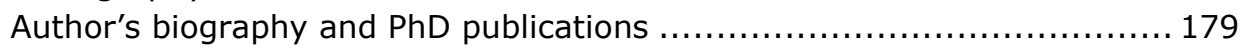




\section{List of Figures}

Figure 1.1. Stomatal control of photosynthesis and transpiration (source:

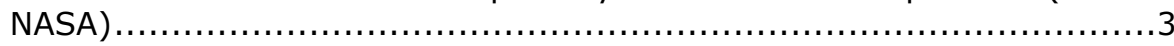

Figure 2.1. Experimental setup. (a) Plant pots, soil moisture sensors and data loggers to record soil moisture status continuously; (b) Closed greenhouse during the night and rainfall events. .................................. 16

Figure 2.2. Experimental laboratory setup for canopy and soil reflectance measurement. (a) One of the grass sample pots; (b) Close-up photo of camera and ASD fiber-optic cable (placed in a pistol grip) mounted on the stand.

Figure 2.3. Conceptualization of the iterative optimization technique used in this study. 22

Figure 2.4. The changes in the shape of reflectance spectra in responses to drought. (a) Canopy spectra change at different levels of soil moisture (SM) deficit; (b) Soil reflectance changes under different soil moisture conditions................................................................ 25

Figure 2.5. Spectral changes due to soil moisture deficit. (a) Pearson's correlation of the mean spectra taken at the beginning of the experiment and those of the measurements during the experiment over time in both stressed and control treatments; (b) Relative changes (\%) between the first measured spectra at day 4 and the spectra measured at day 11 ...26

Figure 2.6. Normalized changes of vegetation indices in the stressed group (compared to the control group). (a) At day 11 (short-term stress); (b) At day 36 (long-term stress). ........................................ 27

Figure 2.7. Trend of the best indices during the stress episode. (a) NDWI_1241 at day 11 ; (b) RATIO1200 at day 11 ; (c) PRI_norm at day 36; (d) CTR2 at day 36.

Figure 2.8 . The partial derivative of canopy reflectance simulated by RTMo to change of each input parameters (by one percent of their total range). (a) $C_{\mathrm{ab}}$; (b) $C_{\mathrm{w}}$; (c) $C_{\mathrm{dm}}$; (d) $C_{\mathrm{s}}$ (e) $L A I$; (f) $L I D F_{\mathrm{a}}$.

29

Figure 2.9. Left panels show the goodness of fit for the spectra obtained between measured reflectance (shown as red solid lines) and the simulated reflectance spectra (shown as blue dashed lines) on different days of the experiment; (a) day 11 and (c) day 36, and right panels show the difference between two simulated and measured reflectance spectra at (b) day $11 ;(d)$ day 36.

30

Figure 2.10.The distribution of RMSE between measured and simulated spectra for all simulations.

Figure 2.11. Retrieved versus measured vegetation parameters. (a) $C_{a b}$; (b) $L A I$.

Figure 2.12. Trend of the retrieved properties. (a) $C_{a b}$, (b) $C_{w}$, (c) $C_{d m}$ (d) $C_{s}$, (e) $L A I$ changes over time. Further, the normalized differences and relative changes of the properties is shown during the experiment ( $f$ ). The normalized values account for the variability in the control group. .......33

Figure 3.1. Quantitative modeling approach for mapping spatio-temporal variations of vegetation properties. The hatched boxes represent the approach adapted in this study.

Figure 3.2. Study site (Vaira Ranch, in California) representing the footprint of Landsat images (WRS-2 path/row: 043/033). The Landsat image acquired 
on 15 March 2004 (color composite of red = band 5, green = band 4 and blue $=$ band 3 ) is shown in the right panel in which the Vaira site location is indicated by a red square. The Vaira site and its surroundings, exported from the Google Earth images, is also shown in the bottom left panel...45

Figure 3.3. Satellite overpass during the soil moisture deficit episode. Landsat TM5 (thick red lines from top) and Landsat ETM7 (thick blue lines from top) observations covering a soil moisture deficit (black curve) episode at the Vaira site. The episode is divided into four periods (separated by dotted green lines) indicating normal, mild stress, moderate stress, and severe stress conditions. These periods within the time series are based on the Palmer Drought Severity Index (PDSI) data set published by NOAA's National Centers for Environmental Information (NCEI) ................47

Figure 3.4. Flowchart of the TOA approach used in this study to show how various RT models were coupled to retrieve and map vegetation properties during the drought episode from Landsat TOA radiance data ..............49

Figure 3.5. TOA radiance images observed by Landsat TM5 (red = band 5 , green $=$ band 4 , blue $=$ band 3 ) for $(a)$ DOY $59($ SM $=26 \%)$ (b) DOY 75 $(\mathrm{SM}=19 \%)$ and $(\mathrm{c})$ DOY $203(\mathrm{SM}=2.2 \%)$ in 2004. The white circle shows the location of the Vaira site.

Figure 3.6. Time series of Landsat TOA radiance spectra observed at the Vaira site during the 2004 drought episode. Radiance variations observed on (a) different days as a function of wavelength and (b) different bands as a function of time (DOYs). The logarithms of Landsat TOA radiance variations are shown (c) as a function of time (DOYs) to better detect the relative changes.

Figure 3.7. MODTRAN parameters spectra variations at a fixed visibility of 25 $\mathrm{km}$ over various aerosol types over the Vaira site for DOY 107 in 2004. (a) Path radiance $\left(L_{0}\right)$, (b) Gain factor $(G)$ and $(c)$ Spherical albedo $(S)$ for DOY

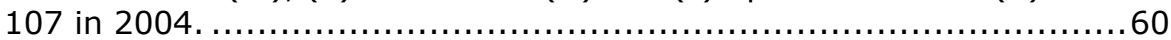

Figure 3.8. MODTRAN parameters (i.e., path radiance (L0), gain factor (G) and spherical albedo (S)) spectra variations at various visibilities $(5,15,30$ and $100 \mathrm{~km}$ ) and aerosol types (rural, maritime and urban cases) for DOY 107 at Vaira site. Left panels $(a, d, g)$ show the rural case. Middle panels (b, e, $h$ ) show the maritime case and right panels (c, $f, i)$ show the urban case.

Figure 3.9. Atmospheric spectral transfer functions $T_{2}-T_{14}$ generated for (a) DOY 66 (Vis = $65 \mathrm{~km}$ and aerosol type = urban) and (b) DOY 107 (Vis = $25 \mathrm{~km}$ and aerosol type $=$ maritime) in 2004 at the Vaira site. 64

Figure 3.10. Simulated TOA radiance images (red $=$ band 5 , green $=$ band 4 , blue = band 3) by RTMo model for (a) DOY 59, (b) DOY 75, (c) DOY 203 in 2004 and the residual maps of spectral fitting (i.e., the differences between the observed TOA radiance and the simulated TOA radiance over the spectra) for (d) DOY 59, (e) DOY 75, (f) DOY 203. The white circle shows the location of the Vaira site.

Figure 3.11. The goodness of fit for the spectra obtained between observed TOA radiances (at Landsat optical bands; shown as red solid lines) and the simulated TOA radiances (resampled to Landsat optical bands by Landsat SRFs; shown as blue dashed lines) on 24 different days at the Vaira site during the 2004 drought episode. ........................................66 66

Figure 3.12. Soil reflectance simulations with BSM model. The dry soil reflectance (at Landsat optical bands; shown as red solid lines) were scaled 
to obtain realistic spectra (at Landsat optical bands; shown as blue dashed lines) on different days at the Vaira site during the episode. Dry soil spectrum provides a realistic case for DOYs $\geq 98$.

.67

Figure 3.13. Anisotropy index computed from the best simulated reflectance factors on different days at the Vaira site during the episode. It should be noted that the vertical axis range varies for different time periods. ......68

Figure 3.14. Anisotropy index computed from the best simulated reflectance factors for all days at the Vaira site during the episode. It should be noted that 4 subplots (each row) of Fig. 3.13 are shown by an identical color but with different line styles.

69

Figure 3.15. The measured and retrieved LAI during the episode at the Vaira site in 2004. An ellipse is containing "too low" $L A I$ values. ................69

Figure 3.16. Landsat maps of retrieved properties for three days during this drought episode: $(\mathrm{a}, \mathrm{b}, \mathrm{c}) \operatorname{LAI} ;(\mathrm{d}, \mathrm{e}, \mathrm{f}) C_{\mathrm{ab}} ;(\mathrm{g}, \mathrm{h}, \mathrm{i}) C_{\mathrm{w}} ;(\mathrm{j}, \mathrm{k}, \mathrm{l}) C_{\mathrm{dm}} ;(\mathrm{m}, \mathrm{n}, \mathrm{o})$ $C_{s} ;(p, q, r) L I D F_{a}$. Left panels $(a, d, g, j, m, p)$ show the retrieved properties maps for DOY 59; middle panels ( $b, e, h, k, n, q)$ show the retrieved properties maps for DOY 75 and right panels (c, f, i, l, o, r) show the retrieved properties maps for DOY 203 in 2004. The black circle shows the location of the Vaira site. The reader is referred to Table 3.2 for the definitions of the surface properties. 71

Figure 3.17. Landsat retrieved properties variations at the Vaira site during the selected drought episode: (a) $L A I$; (b) $C_{a b}$; (c) $C_{\mathrm{w}}$; (d) $C_{\mathrm{dm}}$; (e) $C_{\mathrm{s}}$; (f) $L I D F_{a}$. Error areas show the uncertainty (standard deviation) in the vegetation properties caused by the uncertainty of the Landsat-observed TOA radiance. Various drought conditions (i.e., normal, mild stress, moderate stress and severe stress) are separated by the color dotted lines.

Figure 4.1 . Daily time series of the surface soil moisture at the study site in 2004. The red lines show the imaging times of Landsat TIR observations.

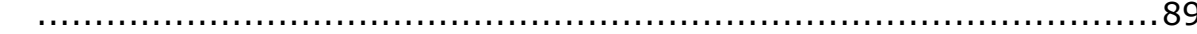

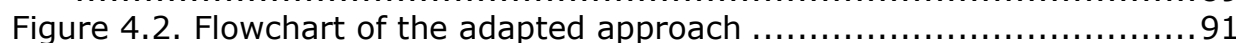

Figure 4.3. Landsat TOC radiance changes during drought episode as a function of time. .97

Figure 4.4. Vegetation functioning variations during the selected episode ... 97

Figure 4.5. SCOPE simulated and Landsat observed TIR band at a $3 \times 3$ window around the flux tower at the site on different DOYs......................98

Figure 4.6. Landsat TIR domain retrieved properties variations during selected drought episode: (a) $\mathrm{V}_{\text {cmax }}$; (b) $\mathrm{m}$; (c) $\mathrm{r}_{\mathrm{ss}}$; and (d) $\mathrm{r}_{\mathrm{bs}} \ldots \ldots \ldots \ldots \ldots \ldots . \ldots 9$

Figure 4.7. Time series of measured and simulated GPPs (actual and reference) at the site. 100

Figure 4.8. Time series of measured and simulated ET (actual and reference) at the site 101

Figure 4.9. Time series of $T_{\text {Ref, }} T, E_{\text {Ref }}$ and $E$; (a) Simulated $T$, (b) Simulated $E$.

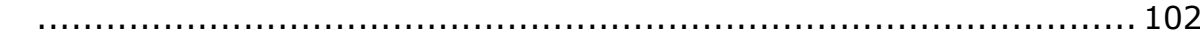

Figure 4.10. Time series of measured and simulated daily $K_{c}$ GPP........... 103

Figure 4.11. Time series of measured and simulated $\mathrm{K}_{\mathrm{c}}$ in drought conditions. (a) Measured and simulated $\mathrm{K}_{\mathrm{c}}$ ET; (b) Measured $\mathrm{K}_{\mathrm{c}}$ ET and simulated $\mathrm{K}_{\mathrm{cb}}$

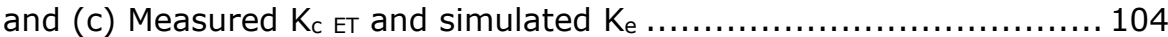

Figure 4.12. Taylor diagram illustrating the statistics between the observed (measured) and the simulated GPP, ET and $\mathrm{K}_{\mathrm{c}}$ during drought episode; (a) 
Measured and simulated GPP; (b) Measured and simulated $\mathrm{K}_{\mathrm{c}}$ GPP; (c) Measured and simulated ET; (d) Measured and simulated $\mathrm{K}_{\mathrm{c}}$ ET.......... 106

Figure 4.13. Daily GPP maps generated by use of optical and TIR information through SCOPE model during the selected episode on DOYs 59 (a, b), 75 (c, d) and 203 (e, f) at Vaira site in 2004. The left panels (a, c, e) show GPP maps generated from optical information in SCOPE and the right panels ( $b, d, f)$ show GPP maps generated from optical and TIR information in SCOPE. The black circle inside the maps show the location of Vaira Fluxnet site........................................................... 109

Figure 4.14. Daily ET maps generated by use of optical and TIR information through SCOPE model during the selected episode on DOYs 59 (a, b), 75 (c, d) and 203 (e, f) at Vaira site in 2004. The left panels (a, c, e) show ET maps generated from optical information in SCOPE and the right panels $(b$, $d, f)$ show ET maps generated from optical and TIR information in SCOPE. The black circle inside the maps show the location of Vaira Fluxnet site. 110

Figure 5.1. Simple Soil-Plant-Atmosphere Continuum (SPAC) scheme. The $\psi_{\mathrm{s}}$ is soil water potential $(\mathrm{m}), r_{\mathrm{s}}$ is soil hydraulic resistance $\left(\mathrm{s} \mathrm{m}^{-1}\right), r_{r}$ is resistance to water flow radially across the roots $\left(\mathrm{s} \mathrm{m}^{-1}\right), r_{\mathrm{x}}$ is plant axial resistance to flow from the soil to the leaves $\left(\mathrm{s} \mathrm{m}^{-1}\right), e_{i}$ is leaf (soil) vapor pressure ( $\mathrm{hPa}), r_{\mathrm{c}}$ is leaf stomatal (soil surface) resistance $\left(\mathrm{s} \mathrm{m}^{-1}\right), r_{\mathrm{a}}$ is aerodynamic resistance $\left(\mathrm{s} \mathrm{m}^{-1}\right)$ and $e_{a}$ is atmospheric vapor pressure (hPa). 123

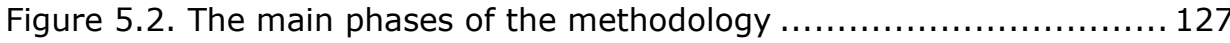

Figure 5.3. Model simulated and Fluxnet measured daily GPP at the Vaira site during the drought episode in 2004; (a) GPP simulated by original SCOPE using only Landsat retrieved vegetation properties, (b) GPP simulated by SCOPE-SM using Landsat retrieved properties and updated vapor pressure information, (c) GPP simulated by SCOPE-SM using Landsat retrieved properties, updated vapor pressure and $V_{\text {cmax }}$ information, and (d) GPP simulated by SCOPE-SM using Landsat retrieved vegetation properties, updated vapor pressure, updated $V_{\text {cmax }}$ and updated $r_{\text {ss }}$ information. Figure insets represent the scatter plot between simulated and measured GPP for each case (for more details of error statistics see section 5.3.4.3). ... 130

Figure 5.4. Model simulated and Fluxnet measured daily ET at the Vaira site during the drought episode in 2004; (a) ET simulated by original SCOPE using only Landsat retrieved vegetation properties, (b) ET simulated by SCOPE-SM using Landsat retrieved vegetation properties and updated vapor pressure information, (c) ET simulated by SCOPE-SM using Landsat retrieved vegetation properties, updated vapor pressure and $V_{\text {cmax }}$ information, and (d) ET simulated by SCOPE-SM using Landsat retrieved vegetation properties, updated vapor pressure, updated $V_{\mathrm{cmax}}$ and updated $r_{\text {ss }}$ information. Figure insets represent the scatter plot between simulated and measured ET for each case (for more details of error statistics see section 5.3.4.3) 131

Figure 5.5. Model simulated soil $E$ and canopy $T$ at the Vaira site during the drought episode in 2004; (a) $E$ and $T$ simulated by original SCOPE using only Landsat retrieved vegetation properties, (b) $E$ and $T$ simulated by SCOPE-SM using Landsat retrieved vegetation properties and updated vapor pressure information, (c) $E$ and $T$ simulated by SCOPE-SM using Landsat retrieved vegetation properties, updated vapor pressure and $V_{\text {cmax }}$ 
information, and (d) $E$ and $T$ simulated by SCOPE-SM using Landsat retrieved vegetation properties, updated vapor pressure, updated $V_{\text {cmax }}$ and updated $r_{\mathrm{ss}}$ information.

Figure 5.6. Time series of measured and simulated $K_{c}$ GPP and $\Delta K_{c}$ GPP in drought conditions. (a) Simulated and measured $K_{c}$ GPP comparing the information content provided by each observation; (b) The difference between simulated and measured Kc GPP computed for each observation. 136

Figure 5.7. Time series of measured and simulated $\mathrm{K}_{\mathrm{C}}$ ET and $\Delta \mathrm{K}_{\mathrm{C}}$ ET in drought conditions. (a) Simulated and measured $\mathrm{K}_{\mathrm{c}} \mathrm{ET}$ comparing the information content provided by each observation; (b) The difference between simulated and measured $\mathrm{K}_{\mathrm{c}}$ ET computed for each observation. .......... 137 


\section{List of Tables}

Table 2.1. List of the widely used water stress-related vegetation indices reviewed from the literature and used throughout this study. Rxxx indicates the reflectance at a specific wavelength .......................20

Table 2.2. Initial guess of parameters for retrieval and their status in the model

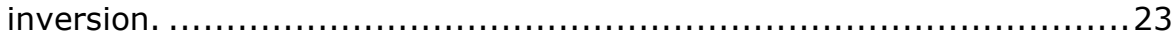

Table 2.3. Statistical measures used for evaluation of RTMo model inversion

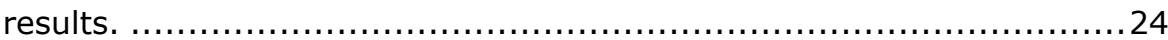

Table 2.4. Variation range of parameters for sensitivity analysis and the

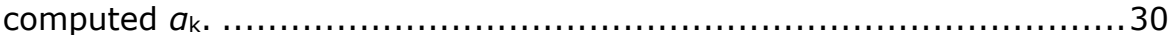

Table 2.5. Evaluation of RTMo model inversion results for LAI $(n=8)$ and Cab

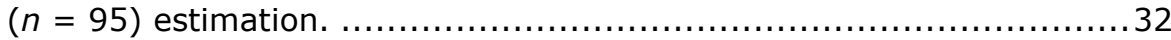

Table 3.1. Input parameters used to construct separate LUTs in this study for

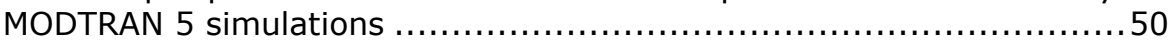

Table 3.2. Input parameters needed for the RTMo model. .................... 52

Table 3.3. Tuned vegetation properties, their lower boundaries (LB), upper boundaries (UB), initial guess (IG), a priori values $(\mu)$ and assumed standard deviation $\left(\sigma_{p 0}\right)$ used in this study for the retrieval. ............. 55

Table 3.4. Digitization noise in Landsat TM5 and ETM7 and assumed standard deviation $(\sigma)$ used in this study for different bands.

Table 3.5.The reflectance in various bands extracted by a window of 5 by 5 pixels from USGS Landsat surface reflectance products over a water body during this drought episode for (a) DOY 59, (b) DOY 75 and (c) DOY 203 in 2004.

Table 3.6. Input parameters used in this study to describe the real atmospheric and sensor geometric conditions for MODTRAN 5 simulations. 81

Table 4.1. Vegetation properties obtained from literature to simulate daily GPP and ET for "Reference" scenario. ....................................... 94

Table 4.2. PDSI variation for the selected episode at Vaira site ...............96

Table 4.3. Statistical measures used for evaluation of simulation results .. 107

Table 5.1. MSE components, RMSE, NRMSE and $\mathrm{R}^{2}$ comparison between the original SCOPE and SCOPE-SM performance for simulating daily GPP and ET. Model simulation results were compared with Vaira Fluxnet GPP and ET measurements. The table values without parentheses present the statistics only for drought conditions (from DOY 60 to 220) while the values within parentheses present the statistics for the whole episode (i.e., from DOY 1 to 220) covering both near normal and drought conditions. Different configurations of SCOPE-SM are shown as (C1: Landsat information plus updated $\left.e_{i}\right)$, (C2: Landsat information, updated $e_{\mathrm{i}}$, updated $\left.V_{\mathrm{cmax}}\right)$ and (C3: Landsat information, updated $e_{i}$, updated $V_{\text {cmax }}$ and updated $r_{\mathrm{ss}}$ ). The original SCOPE and SCOPE-SM (C3) statistics are shown in bold ........ 133

Table 5.2. Comparison of the information content of various observations to simulate GPP and ET using the SCOPE model. The statistical measures are obtained compared to the ground measured values of GPP and ET at the Vaira site. 


\section{Summary}

Time series of optical, thermal and soil moisture observations contain valuable information about vegetation properties and functioning (i.e., canopy photosynthesis and evapotranspiration). This study investigates how this information can be retrieved from such time series observations by means of quantitative approach in order to estimate vegetation properties and functioning under normal and dry conditions. This is important to better understand the potential of multiple observations to quantify plant carbon and water cycle feedback to climate change.

The dissertation is composed of six chapters. Chapter 1 is introductory and describes the importance of plant functioning, drought effects, the applications of remote sensing observations, the soil moisture dataset, methods for plant functioning assessment, the proposed coupled modeling approach and the subobjectives of this research.

Chapter 2 explores the information content of hyperspectral optical reflectance observations in the context of an artificial laboratory drought experiment. The chapter first focuses on visual signs of water stress on grass properties and top-of-canopy reflectance spectra. Second, it investigates some of the widely-used water stress related vegetation indices to examine their performance to detect drought effects and trends in their changes during the course of the experiment. In addition, the chapter addresses the application of a radiative transfer model (i.e., the optical radiative transfer routine RTMo) in the 'Soil-Canopy Observation of Photosynthesis and Energy fluxes' (SCOPE) model and its inversion against hyperspectral data collected during the experiment to retrieve vegetation biophysical and biochemical properties (i.e., Leaf Area Index, leaf chlorophyll content, leaf water content, leaf dry matter content, senescent material content and the leaf inclination distribution function) and analyze their trends within two groups (i.e., a well-watered control group and a group subjected to water stress). Overall, it is shown that the spectroscopic techniques, statistical methods, and RTMo model inversion have a promising potential to exploit hyperspectral observations in the optical domain and detect water stress effects on the spectral reflectance and vegetation properties. Spectroscopic techniques can assist to identify the time and location where the first stress signs take place. Statistical methods can be useful to identify the most promising water stress-related vegetation indices for early stress detection. RTMo model inversion can be of great help to retrieve vegetation properties information and, therefore, follow their evolution during a drought episode.

Chapter 3 describes an approach to exploit Landsat satellite (TM5 and ETM7) optical information to full extent under normal and dry conditions, and provides an outline of the relevant up-scaling from the laboratory experiment discussed in Chapter 2 into a regional scale grassland ecosystem using multispectral optical observations in a Mediterranian type annual C3 grassland 
site, called the Vaira site (US-Var), located in California. The chapter first describes a proposed forward modeling top of the atmosphere radiance approach to accurately simulate an annual time series of Landsat optical data. Verifying the performance of different components of the coupled set of models (i.e., the brightness - shape - moisture (BSM) soil reflectance model, RTMo, and the 'MODerate resolution atmospheric TRANsmission' (MODTRAN) atmosphere model) it is proven that together they can fairly well reproduce moist soil reflectance, anisotropic vegetation reflectance spectra and the observed top of atmosphere radiance spectra during a normal-to-dry episode. We accommodated the surface anisotropic reflection in the coupled modeling and also for the first time defined a novel anisotropy index to quantitatively express the importance of this phenomenon in satellite image analysis. Finally, the chapter investigates the inversion of the proposed set of coupled models to retrieve vegetation properties from the optical domain during the episode by means of a numerical optimization technique and analyzes their evolution during the episode. It is shown that the coupled use of radiative transfer models, in a "bottom-up" approach, can be considered as a proper tool to simulate time series of satellite optical radiance observations under normal and dry conditions. Further, the inversion of the coupled system is suitable for successful retrieval of vegetation properties from time series of satellite top of atmosphere radiance data to produce maps of land surface properties. This is a step forward to monitor vegetation properties variations in an operational way. The approach can also be easily adapted for conducting multi-sensor time series studies.

Chapter 4 concentrates on integrating satellite optical and thermal observations to maximize the information one can obtain for estimating vegetation functioning under normal and dry conditions. The chapter first describes an inversion of the energy balance and thermal radiative transfer routine RTMt in the SCOPE model by means of a look-up table approach against Landsat satellite thermal observations. This resulted in the retrieval of extra information about vegetation (i.e., the maximum carboxylation capacity and stomatal conductance) and soil (soil surface resistances and soil boundary resistance) properties during a normal-to-dry episode. Second, the chapter focuses on estimating vegetation daily functioning by integrating vegetation properties information retrieved from the optical and thermal domains, including soil information obtained from the thermal domain, together with locally measured weather variables, through forward modeling with SCOPE. Comparison between model estimations and Vaira site measurements shows that most drought effects on photosynthesis and transpiration are 'visible' in the Landsat optical bands. However, the accurate estimation of stomatal effects and soil evaporation requires thermal information. Overall, the results indicate that the combined use of optical and thermal radiative transfer models, in addition to an energy balance model, provides a useful tool to exploit satellite optical and thermal observations to full extent under normal and dry 
conditions. Optical radiative transfer model inversion assists to obtain vegetation properties from radiance data in the optical domain. Further, inverting thermal and energy balance models can offer valuable information regarding soil surface resistance and carboxylation capacity from radiance data in the thermal domain. Integrating all retrieved information from both optical and thermal domains could capture drought effects on the vegetation canopy in terms of reductions in daily vegetation functioning.

Chapter 5 investigates the added value of combining optical and soil moisture observations for estimating vegetation functioning under water stress condition. The chapter first proposes a simple extension to the SCOPE model which allows combining optical and soil moisture observations. This resulted in a soil moisture integrated version of the model, called SCOPE-SM. The extended model simulates additional state variables: vapor pressure both in the soil pore space and the leaf stomata in equilibrium with liquid water potential, maximum carboxylation capacity by a soil moisture dependent stress factor and soil surface resistance through approximation by a soil moisture dependent hydraulic conductivity. Second, the chapter focuses on the assessment of the SCOPE-SM model performance to estimate vegetation functioning at the Vaira site in 2004. Assessing vegetation functioning using the SCOPE-SM model, in which Landsat retrieved optical properties, modeled vapor pressure, maximum carboxylation capacity and soil surface resistance are used, constitutes a significant improvement. Finally, the chapter compares vegetation functioning assessments in which thermal and soil moisture data are used separately. For evapotranspiration estimations, the results show that there is more information embedded in the soil moisture dataset in comparison to the thermal information. The results reveal that the combined modeling of optical radiative transfer and soil moisture in SCOPE provides a useful tool to exploit optical radiance and soil moisture observations under normal and dry conditions. Optical radiance data carry valuable information about canopy transpiration and photosynthesis processes. In addition, soil moisture contains significant information that can be used to better estimate soil evaporation and carboxylation capacity during a normal-to-dry episode. Combining these two sources of information has a great potential to estimate daily vegetation functioning in water limited regions.

In Chapter 6, the main objective of this dissertation and how it was achieved is discussed. Four suitable approaches are discussed to exploit hyperspectral and multispectral satellite observations, to integrate optical and thermal data, and to combine optical and soil moisture observations for monitoring vegetation functioning variations in a normal-to-dry episode. This makes it possible to combine various observations from multiple sensors (e.g., satellite optical/thermal observations and in-situ data) in a consistent way, avoiding empirical approaches (e.g., utilizing only a few spectral bands in vegetation indices), and to eventually improve the remote assessment of vegetation functioning. The obvious way forward recommended by the author is to use 
optical, thermal as well as soil moisture data in a synergistic and complementary way, supported by coupled RT models in time-series studies using data from multiple sensors, thus creating a much denser temporal sampling than would be possible for separate single sensors. 


\section{Samenvatting}

Tijdreeksen van optische, thermische en bodemvochtwaarnemingen bevatten informatie over vegetatieeigenschappen en het functioneren van de vegetatie (de fotosynthese en de gewasverdamping). In deze studie is onderzocht hoe die informatie uit de tijdreeksen gehaald kan worden, om zo de vegetatieeigenschappen te kunnen volgen tijdens een periode van droogte. Dit is van belang voor een beter begrip van de potentie van veelsoortige waarnemingen voor het kwantificeren van de cycli van koolstof en water en hun terugkoppeling naar klimaatverandering.

De dissertatie bestaat uit zes hoofdstukken. Hoofdstuk 1 is een inleiding en beschrijft het belang van gewasfunctioneren, droogte-effecten, remote sensing waarnemingen, de bodemvocht gegevens, methoden voor het bepalen van de gewasgesteldheid, de voorgestelde benadering om modellen te koppelen en tenslotte de subdoelen van dit onderzoek.

Hoofdstuk 2 verkent de informatie-inhoud van hyperspectrale optische reflectiewaarnemingen binnen de context van een kunstmatig droogteexperiment in het lab. Eerst worden de tekenen van watergebrek op de zichtbare eigenschappen van gras en de bijbehorende reflectiespectra belicht. Ten tweede wordt onderzocht hoe een aantal veelgebruikte vegetatie-indices die wijzen op watergebrek presteren in het detecteren van droogte-effecten en wat hun trends zijn gedurende het verloop van het experiment. Bovendien behandelt dit hoofdstuk de toepassing van een gewasreflectiemodel ( $\mathrm{nl}$. de optische stralingstransportmodule RTMo) in het 'Soil-Canopy Observation of Photosynthesis and Energy fluxes' (SCOPE) model en het inverteren hiervan tegen hyperspectrale data verzameld gedurende het experiment voor het schatten van biofysische en biochemische eigenschappen van het gewas ( $\mathrm{nl}$. de 'leaf area index' LAI, bladchlorofyl, bladwatergehalte, drogestofgehalte, bruine pigmenten en de bladstandverdeling) en voor het analyseren van hun trends binnen twee groepen (een goedbewaterde controlegroep en een groep met watergebrek). Samengevat wordt getoond dat spectroscopische technieken, statistische methoden en RTMo modelinversie veelbelovende hulpmiddelen zijn voor een effectief gebruik van hyperspectrale metingen in het optische domein en voor het detecteren van de effecten van watergebrek op de spectrale reflectie en de gewaseigenschappen. Spectroscopische technieken kunnen de tijd en de locatie van de eerste tekenen van stress helpen vaststellen. Statistische methoden kan men gebruiken om de meestbelovende watergebrek-gerelateerde vegetatie-indices voor vroege stressdetectie te identificeren. RTMo modelinversie kan van grote waarde zijn voor het bepalen van gewaseigenschappen en daardoor ook voor het volgen van hun evolutie gedurende een droogteperiode.

Hoofdstuk 3 beschrijft een benadering om optische informatie van de Landsat satellieten (TM5 and ETM7) ten volle te benutten onder normale en droge omstandigheden, en schetst een draaiboek voor het opschalen van het 
laboratoriumexperiment uit Hoofdtuk 2 naar de regionale schaal van een grasland ecosysteem door het gebruik van multispectrale optische waarnemingen van een mediterraan type meetveld met éénjarig C3 grasland, nl. op de Vaira site in Californië. Eerst wordt beschreven hoe een voorgestelde voorwaartse modeleringsaanpak die resulteert in top-of-atmosphere (TOA) radianties kan worden ingezet om een tijdreeks van optische Landsatbeelden nauwkeurig te simuleren. Door het bevestigen van de prestaties van de verschillende modelcomponenten ( $\mathrm{nl}$. het 'brightness-shape-moisture' (BSM) bodemreflectiemodel, RTMo en het atmosfeermodel MODTRAN) wordt aangetoond dat zij tezamen de reflectie van vochtige bodems, de anisotropie van gewasreflectiespectra en de gemeten TOA radiantiespectra behoorlijk goed kunnen reproduceren gedurerende een periode met een overgang van normale naar droge condities. De anisotrope reflectie van het oppervlak is hierbij meegenomen in de voorwaartse modelering, en ook is voor het eerst een nieuwe index voor deze anisotropie gedefinieerd om het belang van dit verschijnsel voor de analyse van satellietbeelden kwantitatief tot uitdrukking te brengen. Tenslotte onderzoekt dit hoofdstuk de inversie van de voorgestelde keten van modellen om gewaseigenschappen af te leiden uit optische data gedurende de episode van droogte door middel van een numerieke optimalisatietechniek, en wordt hun evolutie gevolgd. Getoond wordt dat men met gekoppelde stralingsinteractiemodellen, in een 'bottom-up' benadering, een geschikt gereedschap in handen heeft om tijdreeksen van satellietwaarnemingen in het optische domein te simuleren onder zowel normale als droge omstandigheden. Verder is de inversie van de hele modelketen geschikt voor het succesvol afleiden van gewaseigenschappen uit tijdseries van TOA radiantiedata afkomstig van satellietbeelden en voor het in kaart brengen van de eigenschappen van het landoppervlak. Dit is een stap voorwaarts naar het operationeel monitoren van variaties in vegetatieeigenschappen. Deze benadering kan ook gemakkelijk worden aangepast voor het uitvoeren van tijdserie-analyses met meerdere sensoren.

Hoofdstuk 4 concentreert zich op het integreren van optische en thermische satellietdata om de hoeveelheid informatie over het functioneren van de vegetatie onder natte en droge condities te maximaliseren. Eerst wordt de inversie met opzoektabellen van de SCOPE routines voor de energiebalans en voor thermische straling (RTMt) op basis van Landsat thermische beelden beschreven. Dit resulteerde in het afleiden van extra informatie over de vegetatie ( $\mathrm{nl}$. de maximale carboxylatiesnelheid en de huidmondjesgeleiding) en de bodem (bodem oppervlakteweerstand en bodem grensweerstand) gedurende een overgang van normale naar droge omstandigheden. Ten tweede richt dit hoofdstuk zich op het inschatten van het dagelijks functioneren van de vegetatie door het integreren van infomatie over gewaseigenschappen afgeleid uit optische metingen, inclusief bodeminformatie verkregen uit thermische metingen, en met ter plekke gemeten weervariabelen, via voorwaarste modelering met SCOPE. Vergelijking tussen modelvoorspellingen 
en de Vaira site veldmetingen laat zien dat de meeste droogte-effecten op de fotosynthese en transpiratie 'zichtbaar' zijn in de Landsat optische spectrale banden. Echter, een nauwkeurige schatting van stomatale effecten en bodemverdamping vereist thermische informatie. Over het algemeen geven de resultaten aan dat het gecombineerde gebruik van optische en thermische stralingsinteractiemodellen, samen met een energiebalansmode, bruikbaar gereedschap verschaft voor het volledig exploiteren van optische en thermische satellietwaarnemingen onder normale en droge omstandigheden. Inversie van een optisch reflectiemodel helpt bij het verkrijgen van gewaseigenschappen uit radiantiegegevens in het optische domein. Verder kan inversie van thermische en energiebalansmodellen waardevolle informatie verschaffen over de bodemweerstand en de carboxylatiesnelheid uit thermische radiantiedata. Door het integreren van alle afgeleide informatie uit het optische en het thermische domein kunnen droogte-effecten op gewassen en op de achteruitgang in hun dagelijks functioneren goed worden vastgelegd.

Hoofdstuk 5 onderzoekt de toegevoegde waarde van het combineren van optische en bodemvochtmetingen voor het bepalen van het vegetatiefunctioneren onder droogtegebrek. Er wordt eerst een eenvoudige uitbreiding in het SCOPE model voorgesteld die het combineren van optische en bodemvochtwaarenemingen toestaat. Dit resulteeerde in een bodemvochtgeïntegreerde versie van het model, geheten SCOPE-SM. Het uitgebreide model simuleert additionele toestandsvariabelen: de dampdruk, zowel in de bodemporiën als in de bladhuidmondjes, in evenwicht met de waterpotentiaal, maximum carboxylatiesnelheid via een bodemvochtafhankelijke stressfactor en de bodemoppervlakteweerstand, door het benaderen hiervan via een bodemvochtafhankelijke hydraulische geleiding. Daarnaast richt dit hoofdstuk zich op het bepalen van de modelprestaties van SCOPE-SM t.a.v. het inschatten van het functioneren van de vegetatie op de Vaira site in 2004. Het onderzoeken van het functioneren van de vegetatie met het SCOPPE-SM model, waarbij met uit Landsat afgeleide optische eigenschappen, gemodeleerde dampdruk, Vcmax, en de bodemoppervlakteweerstand worden gebruikt, betekent een significante verbetering. Tenslotte worden in dit hoofdstuk methoden vergeleken voor het bepalen van vegetatiefunctioneren op grond van thermische en bodenvochtgegevens apart. Voor het schatten van evapotranspiratie laten de resultaten zien dat er in bodemvochtgegevens meer informatie zit dan in thermische informatie. De resultaten onthullen dat het gecombineerd modeleren van optisch stralingstransport en bodemvocht in SCOPE een bruikbaar gereedschap oplevert voor het beter exploiteren van optische radiantie en bodemvochtgegevens onder normale en droge condities. Optische radiantiegegevens bevatten waardevolle informatie over gewastranspiratie en het proces van de fotosynthese. Bovendien bevat bodemvocht significante informatie die kan worden gebruikt om de bodemverdamping en de carboylatiesnelheid beter te kunnen bepalen gedurende een overgang van normale naar droge omstandigheden. Het 
combineren van deze twee bronnen van informatie houdt een groot potentieel in voor het inschatten van het functioneren van de vegetatie in gebieden met watertekort.

In hoofdstuk 6 wordt het voornaamste doel van deze dissertatie, en hoe dat is bereikt, besproken. Vier geschikte benaderingen om hyperspectrale en multispectrale satellietwaarnemingen te exploiteren, om optische en thermische data te integreren, en om optische en bodemvochtmetingen te combineren voor het monitoren van variaties in het functioneren van de vegetatie, worden er besproken. Dit maakt het mogelijk om allerlei waarnemingen gedaan door een veelvoud van sensoren (bijv. optische/thermische satellietwaarnemingen en in situ data) op een consistente manier te combineren, waarbij empirische benaderingen (die bijv. maar enkele spectrale banden gebruiken in de vorm van een vegetatie-index) worden vermeden, en om uiteindelijk het onderzoeken op afstand van het functioneren van de vegetatie te verbeteren. De voor de hand liggende weg vooruit die wordt aanbevolen door de auteur ligt in het gebruik van optische, thermische, alsmede bodemvochtgegevens op een synergistische en complementaire wijze, ondersteund door gekoppelde stralingsinteractiemodellen in tijdserieanalyses met data van meerdere sensoren, waardoor een veel dichtere bemonstering in de tijd mogelijk wordt dan met afzonderlijke sensoren. 
Chapter 1 General Introduction 
The core idea of this dissertation is to exploit multiple observations including time-series of optical, thermal (TIR) and soil moisture data for remote sensing of vegetation properties and functioning under normal and dry conditions. It is significant to investigate the information content of such observations and quantify the impact of their synergistic use to explain drought effects on vegetation functioning. Therefore, understanding how much information one can get from different sensors (e.g., optical, TIR and soil moisture) to see vegetation (here for annual C3 grasses) properties and functioning (notably canopy photosynthesis [gross primary production (GPP)] and evapotranspiration (ET)) variations during a drought episode and whether combined use of this information can enhance vegetation functioning estimations is of great interest. This chapter gives a short general introduction and describes the importance of plant functioning, drought effects, application of remote sensing and in-situ observations, methods for plant functioning assessment, the proposed coupled modeling approach and the sub-objectives of this dissertation.

\subsection{Why estimating vegetation functioning}

Plants are key components of nearly all terrestrial ecosystems. Water and carbon exchanges between plants and the atmosphere are two fundamental traits of vegetation functioning (Y. Zhang et al., 2016), which support life on our planet. On the one hand, gross primary productivity GPP, as a primary driver of the carbon cycle, is the initial carbon fixed by vegetation through photosynthesis (Anav et al., 2015; Y. Zhang et al., 2016). GPP controls some of the crucial functions in the ecosystem, such as respiration and growth. It demonstrates the efficiency of the exchange of carbon dioxide (Running et al., 1989) and sustains the food web by providing the total carbohydrate matter (Beer et al., 2010; Running, 2012) and, therefore, plays an essential role for human life. On the other hand, ET, as the main component of the water cycle, contains plant transpiration $(T)$, soil evaporation ( $E$ ) and evaporation of intercepted precipitation (Fang et al., 2016; Wilcox, 2010). ET provides the primary linkage between energy and hydrologic flux in the ecosystem. It controls basin surface water sources (Bosch and Hewlett, 1982; Sun et al., 2011) and affects regional rainfall patterns (Koster et al., 2004; Seneviratne et al., 2006a) due to the fact that it is the source of water for the atmosphere. 


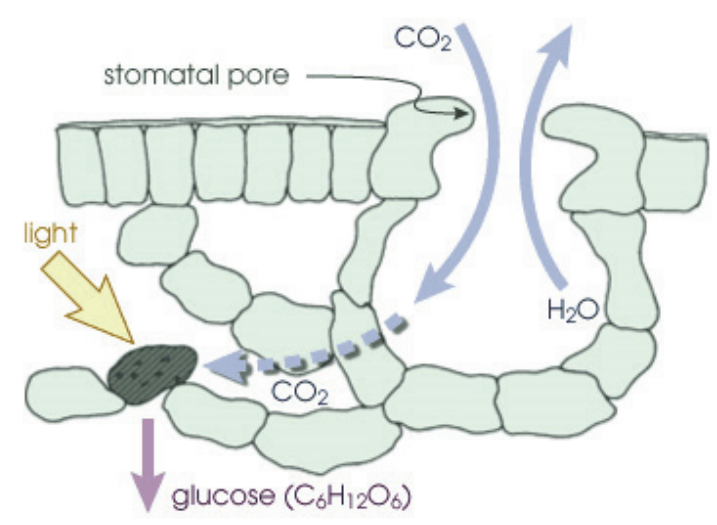

Figure 1.1. Stomatal control of photosynthesis and transpiration (source: NASA)

The two processes of GPP and T are linked through the plant stomata (Fig. 1.1). The plant takes in the $\mathrm{CO}_{2}$ needed for photosynthesis by opening the stomata (Sadava et al., 2009). Such an opening will release $\mathrm{H}_{2} \mathrm{O}$ from the tissue around the stomata to the atmosphere as a side-effect of photosynthesis (Sadava et al., 2009). The carbon and water cycles are thus very closely linked via stomatal gas exchange. Particularly relevant is how vegetation regulates the $\mathrm{CO}_{2}$ assimilation and its transpiration, and the atmospheric feedbacks. Not only climate influences this vegetation functioning, but the plant also affects the climate through these processes. For instance, the climate controls rainfall patterns, solar radiation, and $\mathrm{CO}_{2}$ concentration, which considerably influence the vegetation community (Bonan, 2015). However, vegetation can affect the fluxes of water, carbon, and heat to the atmosphere through vegetation processes (Adams, 2009; Bonan, 2015). Although much research has been carried out to study GPP and ET as two separate processes, monitoring both of them (as plant functioning) together can help to better understand landatmosphere interactions in earth system dynamics, and provide insights into climate change effects on the ecosystems and vegetation response to climate variations. In addition, the partitioning of net radiation into canopy transpiration, soil evaporation, and canopy photosynthesis is crucial for the accurate representation in climate and crop models.

\subsection{Drought effects on vegetation functioning}

Drought events are expected to increase in both frequency and severity in nearly all ecosystems especially in arid and semi-arid regions (Wolf et al., 2013; Zhou et al., 2013). The term 'drought' does not have a unique definition. In this study we adopted the definition of ecological drought as "an interval of time, generally of the order of months or years in duration, during which the 
actual moisture supply at a given place rather consistently falls short of the climatically expected or climatically appropriate moisture supply" quantified by the widely-used Palmer Drought Severity Index, PDSI, (Alley, 1984; Palmer, 1965). Ecological drought or soil moisture deficit is the result of either belowaverage rainfall or above-average evaporation (Dai, 2011). Although extensive research has been conducted to quantify the severity of droughts (Dai, 2011; Heim, 2005, 2000; Sheffield et al., 2009; Sheffield and Wood, 2008), their impacts on vegetation functioning, especially at daily basis, are not well understood yet (Gang et al., 2016) and, therefore, our knowledge about those aspects is still limited (Vicca et al., 2016). Thus, a detailed understanding of drought effects on vegetation daily functioning is required by both social and academic sectors (Lewinska et al., 2016).

Vegetation in the ecosystem copes with and responds to drought. Therefore, vegetation canopy properties become altered and, as a consequence, both GPP and ET will be affected. In a drought episode, the vegetation tends to close its stomata in order to prevent internal water lose, e.g., T reduction, which in turn interferes with the carbon flux and causes GPP reduction (Lee et al., 2016). In fact, drought influences vegetation in several ways: (1) stomatal effects which change the intrinsic water use efficiency and, therefore, the ratio of photosynthesis to transpiration, and (2) non-stomatal effects which change the photosynthetic capacity of the vegetation (Zhou et al., 2013). Both of these effects have been modeled and understood well using local experimental data sets (Egea et al., 2011; Keenan et al., 2010a; Zhou et al., 2013). However, a joint effort is still needed to understand such drought effects at larger scales (i.e., regional and ecosystem levels) during a prolonged soil moisture deficit episode.

\subsection{How to estimate vegetation functioning}

Traditionally, GPP and ET are measured using various direct and indirect techniques. Regarding GPP, there is no direct measurement method to follow since there are no observation techniques to quantify GPP at the right scale (Anav et al., 2015). GPP can only be estimated from measurements of net carbon exchange between terrestrial ecosystem and the atmosphere (Aubinet et al., 2012; Reichstein et al., 2005). However, applying such methods (such as leaf cuvettes and whole-plant chamber) to obtain net carbon exchange may cause some biases and artifacts since physical placement of tools and controlling environmental conditions of gas exchange chambers are difficult tasks (Baldocchi, 2003). Moreover, ground-based measurements of ET include various methods such as water balance, energy balance, and Bowen ratio, weighing lysimeters, aerodynamic methods, sap flow method and chamber systems (Rana and Katerji, 2000). Rana and Katerji (2000) discussed the advantages and disadvantages of these methods in details. Further, detailed reviews of ground-based measurement (direct or indirect) methods of GPP and 
ET can be found in the studies of Anav et al (2015) and Allen et al (2011), respectively.

The method that is nowadays the standard, the eddy covariance techniques, enables the quantification of both GPP and ET processes. The eddy covariance enables the estimation of net carbon exchange (NPP), from which GPP can be derived after flux partitioning, and latent heat flux (LE), from which ET can be derived. Flux tower networks consist of more than 600 stations (Anav et al., 2015), that are measuring carbon dioxide, water vapor, and energy fluxes between vegetation and the atmosphere over time (Baldocchi et al., 2001). The eddy covariance technique provides a direct measurement of ecosystem functioning, multi-temporal resolution observations (from hour to year) and a reasonable representation of the flux footprint, just to name a few advantages. However, the eddy covariance method has also some limitations. The applicability of the method is limited to flat terrains and steady-state environmental conditions (Baldocchi, 2003), and the equipment and field work required for long-term measurements of water flux (ET) and carbon flux (GPP) is expensive. This limits the size of the network and thus the spatial coverage. The measured GPP and ET usually represent small samples in space and time (Anav et al., 2015) and, therefore, scaling up beyond the sample area to a regional and global scale is still challenging.

The spatio-temporal coverage provided by remote sensing observations can considerably overcome the majority of these deficits. When monitoring vegetation processes and their responses to stressors (e.g., drought) at different scales is of interest, satellite observations provide cost-efficient information. Satellite observations can offer a unique opportunity to estimate spatial variations of optical properties which are directly related to vegetation status and environmental conditions. The question is: Can we detect these effects of drought on GPP and transpiration ( $T$ ), but also on soil evaporation $(E)$, by means of satellite optical observations? What would be the added value of extra information (e.g., TIR and soil moisture observations)? We assume that in vegetation most of the non-stomatal effects are due to browning and defoliation (Vicca et al., 2016), which are visible in the optical spectra. However, stomatal effects and soil evaporation become manifest in the TIR domain (Anderson et al., 2007a, 2007b; Crow et al., 2008) and soil moisture data.

\subsection{Remote sensing observations}

Nowadays, eco-hydrology is progressively entering the new era of satellite "big data" (Reichstein et al., 2014). Exploring the information content of such valuable remote sensing datasets at various time and space scales can open new opportunities for vegetation functioning estimations. Vegetation appearance (i.e., canopy radiance) contains useful information related to energy and mass transfer (Olioso et al., 1999). The observed spectra have 
valuable information about the biophysical and biochemical properties of the leaf composition and the canopy structure (Barton, 2011). Acquisition of canopy spectra to assess their patterns over time and translating them into the time series of biophysical and biochemical properties of interest, which are linked to GPP and ET, are main aspects of vegetation remote sensing (Meroni et al., 2004). During a drought episode, while it is progressing and, therefore, the soil is drying, gradual changes take place in vegetation biophysical and biochemical properties. Drought can cause loss of water content in leaves and the whole canopy, resulting in a change in spectral signatures. Thus, radiometric observations might be a valuable tool in assessing drought-induced changes on vegetation properties (Barton., 2011; De Jong et al., 2012; Suárez et al., 2009) and linking them to vegetation processes.

Although remote sensing can make spatially-temporally distributed and cost-efficient measurements of various vegetation appearance, it cannot provide direct information on the vegetation properties, the total fluxes and physical processes using radiation alone. In order to fully exploit and make effective use of the available remote sensing dataset, coherent algorithms and models are needed for (1) translating the observed top-of-atmosphere (TOA) radiance spectra into biophysical and biochemical properties on the one hand and (2) simulating water and carbon fluxes (ET and GPP) as a function of estimated vegetation properties on the other.

\subsection{Coupled modeling approach}

For exploring remote sensing observations, the ideal case is to exploit all available spectral data together (in optical/TIR domains) through detailed radiative transfer (RT) models (Dorigo et al., 2009; Jacquemoud et al., 1995; Kuusk, 1998; Verhoef and Bach, 2007, 2003a). However, using only RT models is insufficient to estimate vegetation biophysical and biochemical processes (like GPP and ET). In addition, so-called the Surface-Vegetation-Atmosphere Transfer (SVAT) models are needed (Norman, 1979) to represent the physical processes involved in GPP and ET. SVAT models make it possible to model the coupled transport of radiation, heat, and carbon within the vegetation canopy (Brunsell and Gillies, 2003; Sellers et al., 1997; Tuzet et al., 2003; Verhoef and Allen, 2000). Therefore, the coupled use of detailed RT models, biochemical and energy balance through SVAT models seems to be a feasible avenue to exploit time series of various satellite observations to the full extent and unlocking the informative power of combined earth observation data regarding vegetation properties and processes in different environmental conditions.

SVAT models usually do not include a detailed RT scheme. This means using those SVAT models without a RT link, one cannot utilize all available and up-coming satellite datasets effectively. The model CUPID (Kustas et al., 2007; Norman, 1979) is the first proposed SVAT model in which a reasonable RT 
model is implemented, although it only distinguishes between the VIS, NIR and TIR radiation domains. Since different biophysical and biochemical properties of vegetation contribute to the canopy reflectance (Asner, 1998), a detailed RT scheme is required to retrieve such properties from optical and thermal remote sensing. Regarding the choice of RT models, using complex models, like Discrete Anisotropic Radiative Transfer (DART) (Gastellu-Etchegorry, 2008; Gastellu-Etchegorry et al., 1996, 2004), may generate more accurate results due to a higher level of realism, they require a large number of input parameters, and this limits their applicability. Medium complexity RT models (e.g., PROSPECT (Jacquemoud and Baret, 1990) leaf and SAIL (Verhoef et al., 2007; Verhoef, 1984, 1985) canopy models) coupled in a SVAT model can be considered proper candidates to enable estimation of GPP and ET from remote sensing observations. One of such SVAT models we selected for this research is the Soil-Canopy-Observation of Photosynthesis and the Energy fluxes (SCOPE) model (Van der Tol et al., 2009b). SCOPE includes relatively simple RT models at high spectral resolution and broad coverage, making it possible to use hyperspectral observations.

SCOPE is a vertical (1-D) integrated model of soil-canopy spectral radiances, photochemistry and energy balance which is based on radiative transfer theory, plant physiology science, and micro-meteorology. It includes three radiative transfer models, one photosynthesis model and one energy balance model. The radiative transfer models of the SCOPE cover the complete 0.4 to $50 \mu \mathrm{m}$ wavelength range. RTMo, which is mainly based on the Fluspect (Vilfan et al., 2016) and SAIL (Verhoef, 1984, 1985) models, is the radiative transfer model in the optical domain $(0.4-2.5 \mu \mathrm{m})$ and it simulates canopy reflectance and radiation distribution inside a canopy. RTMt is the radiative transfer model in the thermal domain $(2.5-50 \mu \mathrm{m})$. Another radiative transfer model is RTMf that simulates canopy fluorescence $(0.64-0.85 \mu \mathrm{m})$.

SCOPE spectral outputs have sampling intervals of $0.001 \mu \mathrm{m}$ in the optical domain, $0.1 \mu \mathrm{m}$ in the thermal domain, and $1 \mu \mathrm{m}$ in the longwave domain.

Further, in SCOPE, a canopy is divided into 60 leaf layers assuming a maximum LAI of 0.1 per layer, and one soil surface is defined under the vegetation layers. There are 468 classes of leaf orientation, composed of all combinations of 13 leaf zenith angles and 36 leaf azimuth angles. The leaf orientations are of great importance because solar flux interception and scattering by leaves is a function of their orientation relative to the sun's position.

RTMo computes the radiation that interacts with each leaf and the scattered and absorbed radiation. Likewise, RTMt simulates the distribution of thermal emitted radiation within the canopy. The net radiation outputs of RTMo and RTMt are used as an input to the energy balance module to estimate skin temperature, while the computed skin temperature from the energy balance is in turn an input of RTMt. The final skin temperature is solved by iteration of 
RTMt and the energy balance module. Such an iteration continues until the energy balance is closed for all the elements described above.

Both the aerodynamic and stomatal resistances are modified during the iteration due to the fact that atmospheric stability and vegetation photosynthesis are influenced by leaf temperatures. The aerodynamic resistance depends on the LAI, canopy height, wind speed and the atmospheric stability (Wallace and Verhoef, 2000), whereas the stomatal resistance depends on net assimilation rate of the leaves, vapor pressure deficit in the ambient air and air pressure. Furthermore, the photosynthesis of C3 (Farquhar et al., 1980), C4 vegetation (Collatz et al., 1992), stomatal resistance (Collatz et al., 1992, 1991) and chlorophyll fluorescence (Van der Tol et al., 2009a) are computed by the biochemical routine of the model.

The primary purpose of the model was to provide a tool that connects different parts of optical and thermal radiation ranging from visible to infrared domain $(0.4-50 \mu \mathrm{m})$ with the purpose of estimating land surface processes (mainly ET, GPP, and chlorophyll fluorescence). The main advantages of SCOPE model are: (1) it is a suitable option to fill the observational gaps between satellite and flight overpasses to monitor carbon and water fluxes, (2) it has a great potential for validation of energy balance models as a ground truth (for instance validation of SEBS (Timmermans et al., 2013)) and (3) it can be used to derive chlorophyll fluorescence from visible parts of the spectrum (Van der Tol et al., 2009b). To the best of our knowledge, the potential of SCOPE model to estimate daily GPP and ET in a wet-to-dry episode has not been explored before. This thesis encompasses efforts to constrain the SCOPE model with optical/TIR and soil moisture observations to simulate vegetation functioning variations over a prolonged drought episode and evaluate the model performance.

\subsection{Objectives}

The main objective of this dissertation is to exploit the information contained in the optical and TIR domains of remote sensing data and additional soil moisture observations to detect daily vegetation functioning (i.e., GPP and ET) variations under normal and dry conditions.

To achieve this main objective, four sub-objectives have been defined, as listed below. Further, each of these sub-objectives is tackled in various chapters of this dissertation.

1. Exploiting hyperspectral measurements in a laboratory drought treatment to detect vegetation responses to stress by using statistical and physical models (Chapter 2)

2. Exploiting multispectral Landsat satellite observations in a drought episode to detect vegetation properties changes by coupling radiative transfer models (Chapter 3 ) 
3. Integrating Landsat satellite optical and thermal observations for improving ecosystem functioning estimations in a drought episode by using the SCOPE model (Chapter 4)

4. Extending the SCOPE model to combine optical reflectance and soil moisture observations to detect ecosystem functioning variations during a drought episode (Chapter 5)

\subsection{Dissertation outline}

This dissertation consists of six chapters following the objectives. Besides the "general introduction (Chapter $\mathbf{1}$ )" and "concluding remarks and prospects (Chapter 6)", four chapters are published in peer-reviewed ISI journals as four papers. Moreover, all these four chapters have been presented in four international remote sensing related conferences. Each of the published chapters addresses one of the research sub-objectives described above.

In Chapter 2, the RTMo model is inverted against time series of canopy hyperspectral measurements collected in a laboratory drought experiment to retrieve vegetation properties [notably Leaf Area Index $(L A I)$, leaf chlorophyll content $\left(C_{\mathrm{ab}}\right)$, leaf water content $\left(C_{\mathrm{w}}\right)$, leaf dry matter content $\left(C_{\mathrm{dm}}\right)$, the leaf inclination distribution function $(L I D F)$ and the senescent material content $\left(C_{s}\right)$ ]. Further, the trends of vegetation properties changes in two groups, control and unstressed treats, are investigated, and the first signal of water stress in both spectra and vegetation properties is detected. Moreover, widelyused vegetation indices are computed to better understand the water stress effects.

In Chapter 3, a forward modeling TOA radiance approach is proposed to accurately simulate an annual time series of Landsat (TM5 and ETM7) data and to retrieve vegetation properties during a drought episode in space and time. Various RT models are coupled to describe the surface-atmosphere system. Inversion of such coupled models resulted in detecting vegetation properties variations during a drought episode in a Mediterranean grassland.

In Chapter 4, Landsat optical and TIR observations are integrated to improve vegetation functioning estimations in a drought episode in a Mediterranean grassland. To this end, we used the retrieved vegetation properties of optical bands (from chapter 3) and inverted RTMt and the energy balance model of SCOPE through a look-up table approach against Landsat TIR radiance data.

In Chapter 5, a simple extension for the SCOPE model, SCOPE-SM, is proposed which combines optical reflectance observations and soil moisture data for improving daily GPP and ET estimations in water-limited ecosystems. This is significant since relying on optical information in the original SCOPE model will lead to significant bias of estimates when water availability becomes the primary limiting factor for vegetation. 
In Chapter 6, concluding remarks and prospects related to this dissertation are described. It provides the main conclusions, implications, and recommendations for further research. 


\section{Chapter 2 Exploiting hyperspectral reflectance observations using statistical and physical models*}

\footnotetext{
* This chapter is based on:

Bayat, B., Van der Tol, C., Verhoef, W., 2016. Remote Sensing of Grass Response to Drought Stress Using Spectroscopic Techniques and Canopy Reflectance Model Inversion. Remote Sensing, 2016, 8, 557, https://doi.org/10.3390/rs8070557.

Bayat, B., Van der Tol, C., Verhoef, W., 2016. Monitoring Soil Moisture Deficit Effects on Vegetation Parameters Using Radiative Transfer Models Inversion and Hyperspectral Measurements under Controlled Conditions. Living Planet Symposium 2016, Prague, Czech Republic, 9-13 May 2016.
} 


\begin{abstract}
The aim of this study was to follow the response to drought stress in a Poa pratensis canopy exposed to various levels of soil moisture deficit. We tracked the changes in the canopy reflectance $(450-2450 \mathrm{~nm})$ and retrieved vegetation properties [Leaf Area Index $(L A I)$, leaf chlorophyll content $\left(C_{a b}\right)$, leaf water content $\left(C_{w}\right)$, leaf dry matter content $\left(C_{\mathrm{dm}}\right)$ and senescent material $\left(C_{S}\right)$ ] during a drought episode. Spectroscopic techniques and radiative transfer model (RTM) inversion were employed to monitor the gradual manifestation of drought effects in a laboratory setting. Plots of $21 \mathrm{~cm} \times 14.5$ $\mathrm{cm}$ surface area with Poa pratensis plants that formed a closed canopy were divided into a well-watered control group and a group subjected to water stress for 36 days. In a regular weekly schedule, canopy reflectance and destructive measurements of $L A I$ and $C_{a b}$ were taken. Spectral analysis indicated the first sign of stress after 4-5 days from the start of the experiment near the water absorption bands (at $1930 \mathrm{~nm}, 1440 \mathrm{~nm}$ ) and in the red (at $675 \mathrm{~nm}$ ). Spectroscopic techniques revealed plant stress up to 6 days earlier than visual inspection. Of the water stress-related vegetation indices, the response of Normalized Difference Water Index (NDWI_1241) and Normalized Photochemical Reflectance Index (PRI_norm) were significantly stronger in the stressed group than the control for short and long-term effects detection, respectively. To observe the effects of stress on grass properties during the drought episode, we used the RTMo (RTM of solar and sky radiation) model inversion by means of an iterative optimization approach. The performance of the model inversion was assessed by calculating coefficient of determination $\left(R^{2}\right)$ and the Normalized Root Mean Square Error (NRMSE) between retrieved and measured $L A I\left(R^{2}=0.87\right.$, NRMSE $=0.18)$ and $C_{\mathrm{ab}}\left(R^{2}=0.74, \mathrm{NRMSE}=0.15\right)$. All properties retrieved by model inversion co-varied with soil moisture deficit. However, the first strong sign of water stress on the retrieved grass properties was detected as a change of $C_{\mathrm{w}}$ followed by $C_{\mathrm{ab}}$ and $C_{\mathrm{dm}}$ in the earlier stages. The results from this study indicate that the spectroscopic techniques and RTMo model inversion have a promising potential of detecting stress on the spectral reflectance and grass properties before they become visibly apparent.
\end{abstract}




\subsection{Introduction}

Plants are subjected to various harsh environmental conditions (i.e., abiotic stresses) in their ecosystems, which affect vegetation structure, functioning, growth and yield (Reddy et al., 2004; Zhang et al., 2013). Thus, environmental stresses trigger various plant responses. Among such stresses, prolonged soil moisture deficit or "ecological drought" is the most important one in many ecosystems-especially in arid and semi-arid regions (Lidon and Cebola, 2012; Wolf et al., 2013). In these ecosystems, plants often suffer from moistureinduced stress. Although there might be other stressors in the ecosystem, their impacts are frequently modulated by the effect of soil moisture deficit (Laio et al., 2001). For instance, heat or radiation stress usually appears after the cooling effect of transpiration has been reduced as a result of soil moisture deficit (Laio et al., 2001; Larcher, 2003). Drought stress is a complex feature and it has a significant impact on plant growth. Three main mechanisms that alter plant growth, and therefore reduce crop yields by soil moisture deficit in a drought episode, are: (1) reducing canopy absorption of incident photosynthetically active radiation (PAR); (2) reducing light use efficiency (LUE), and (3) reducing harvest index (HI) (Earl and Davis, 2003). It is quite important to monitor water stress impacts on vegetation community over time in a drought episode (Dorman et al., 2015, 2013; Zhao et al., 2015).

Traditionally, stress-induced changes in plants have been mainly investigated by visual inspection or detected after extensive analysis of destructive samplings during the growth period (Chaerle and van der Straeten, 2001; Fedotov et al., 2016). However, effective remote detection methods and spectroscopic techniques which allow near real-time detection of stress impacts, even before visual symptoms appear and adverse effects take place, are emerging as promising tools. There is valuable information in the reflectance spectra which relates to the biophysical and biochemical parameters of both the leaf composition and the canopy properties (Barton, 2011). Collecting vegetation canopy spectra to monitor their changes over time, translating them into biophysical and biochemical parameters of interest, and relating these parameters to environmental limiting factors are three main aspects of vegetation remote sensing (Meroni et al., 2004).

While drought is progressing and, therefore, the soil is drying, changes gradually take place in vegetation biophysical and biochemical properties. Drought can cause loss of water content in leaves and canopy, resulting in a change in spectral signatures. Thus, radiometric observations in the optical domain and spectroscopic techniques are valuable tools in assessing droughtinduced changes on plants (Barton, 2011; De Jong et al., 2012; Suárez et al., 2009), especially when the early detection of stress signs is desirable.

Among radiometric observations, hyperspectral measurements have capabilities for estimating vegetation's biophysical and biochemical properties (Serbin et al., 2015, 2014; Ustin et al., 2009). These capabilities give 
hyperspectral data potential for monitoring drought impacts on vegetation (Asner et al., 2004; Coates et al., 2015). To translate hyperspectral remote sensing data into information about vegetation biophysical and biochemical properties, specialized algorithms and approaches are needed. Two common approaches are the statistical approach (Ceccato et al., 2002; Chávez et al., 2013; Darvishzadeh et al., 2011; Houborg et al., 2007; Verrelst et al., 2008; Zarco-Tejada et al., 2013) and physical modeling (Berjón et al., 2013; Bicheron and Leroy, 1999; Clevers et al., 2010; Darvishzadeh et al., 2008; Dorigo et al., 2009; Duan et al., 2014; Houborg et al., 2007; Jacquemoud et al., 1995; Laurent et al., 2011a; Schaepman-Strub et al., 2006; Verhoef, 1984, 1985; Verhoef and Bach, 2007, 2003a). Statistical approaches include spectral vegetation indices computation and regression model application. In many studies, plant stress effects have been analyzed by regression against vegetation indices (De Jong et al., 2012; Govender et al., 2009; Yi et al., 2012; Zhang et al., 2013). The physical approach consists of applying radiative transfer (RT) models that are based on physical laws. They are highly suited for studying the relationship between biophysical variables and reflectance spectral data (Atzberger et al., 2011; Clevers et al., 2010) since they are not site-, sensor- and species-specific and offer an explicit relationship between spectral signature and vegetation properties. Physical approaches have been widely used to retrieve vegetation properties from various types of remote sensing data. Physically based models of vegetation remote sensing signals provide the links that exist between vegetation biophysical and biochemical properties on the one hand and the leaf and canopy spectral reflectance on the other.

In this study, analysis of collected spectra during a drought episode was performed to understand drought-induced impacts on different parts of the spectrum over time. We investigated some of the widely used water stressrelated vegetation indices to follow their behavior in the stress period and to identify the most sensitive one(s). Afterwards, physical approaches have been employed to retrieve the biophysical and biochemical properties of grass (Leaf Area Index $(L A I)$, leaf chlorophyll content $\left(C_{a b}\right)$, leaf water content $\left(C_{w}\right)$, leaf dry matter content $\left(C_{\mathrm{dm}}\right)$ and senescent material $\left(C_{\mathrm{s}}\right)$ ) from hyperspectral measurements by inversion of RTMo module in the Soil Canopy Observation of Photosynthesis and the Energy balance (SCOPE) model (Van der Tol et al., 2009b). RTMo includes the widely used PROSPECT (Jacquemoud and Baret, 1990) and SAIL (Scattering by Arbitrarily Inclined Leaves) (Verhoef, 1984, 1985) models. This assisted in estimation of grass properties, following their changes over time, finding the first signs of stress on grass properties. To our knowledge, this study is the first to use spectroscopic techniques and radiative transfer model inversion to quantify drought impacts on grass canopy reflectance, as well as biophysical and biochemical properties in a controlled laboratory experiment. The main advantage of conducting such a controlled experiment is that error sources could be narrowed down considerably, 
resulting in a greater confidence in the measurements. Uncontrollable events (e.g., rainfalls) could be prevented and the need for pre-processing of observations (e.g., performing atmospheric correction) could be eliminated. The specific objectives of this study were:

(1) To follow the spectral $(450-2450 \mathrm{~nm}$ ) signs of canopy exposed to various levels of water stress in different parts of the spectrum (from visible (VIS), near-infrared (NIR) to short-wave infrared (SWIR)) over time to identify the time and spectral location of the first change.

(2) To compute widely used water stress-related vegetation indices to identify the most sensitive ones for water stress detection during the drought episode.

(3) To execute a sensitivity analysis of the RTMo model to quantify the sensitivity of canopy reflectance to input parameters.

(4) To estimate grass biophysical and biochemical properties by RTMo inversion using an iterative optimization approach.

(5) To follow the estimated grass properties changes over time to identify the first sign of stress on grass properties.

To meet these objectives, we conducted a laboratory experiment in which 20 pots with a Poa pratensis grass canopy equipped with recording soil moisture sensors were monitored with frequent spectroradiometer measurements at the canopy level.

\subsection{Materials and methods}

\subsubsection{Experimental design/setup}

A greenhouse experiment was conducted from 10 August 2014 until 27 October 2014 in the garden of the ITC Faculty of the University of Twente, the Netherlands. A commercially grown grass lawn (of Poa pratensis) was cut into 50 rectangles and transplanted into $21 \mathrm{~cm} \times 14.5 \mathrm{~cm}$ pots with a depth of 12 $\mathrm{cm}$, all filled with an organic soil. All 50 pots were watered regularly until the canopy height was about $15 \mathrm{~cm}$ (on 14 September 2014), after which they were placed in a greenhouse. The greenhouse shielded the vegetation from rainfall, but temperature, irradiance and humidity were not controlled. We selected grass for our experiments because of its rapid response to soil moisture deficit, and because the requirements for applying a 1-D turbid medium model like SAIL (Verhoef, 1984, 1985) are more easily met for relatively small canopies. The pots were divided into two equally sized groups: (1) a group under the well-watered condition and (2) a group that was not irrigated at all. Ten pots in each group were equipped with calibrated soil moisture sensors (Em50 Series, Decagon Devices, Inc., Hopkins Court Pullman, WA, USA). The well-watered pots were irrigated weekly with 200-250 $\mathrm{mL}$ water, such that the volumetric soil moisture content fluctuated around $30 \%-40 \%$. The pots subject to no water treatment were not irrigated at all 
(started from 14 September 2014) to expose them to maximum water stress conditions. The greenhouse was fitted with removable plastic covers as walls, which were left open during daytime and closed during the night and rainfall events. Figure 2.1 shows the greenhouse setup for the experiment, plants in the groups and soil moisture sensors connected to the data loggers.

(a)

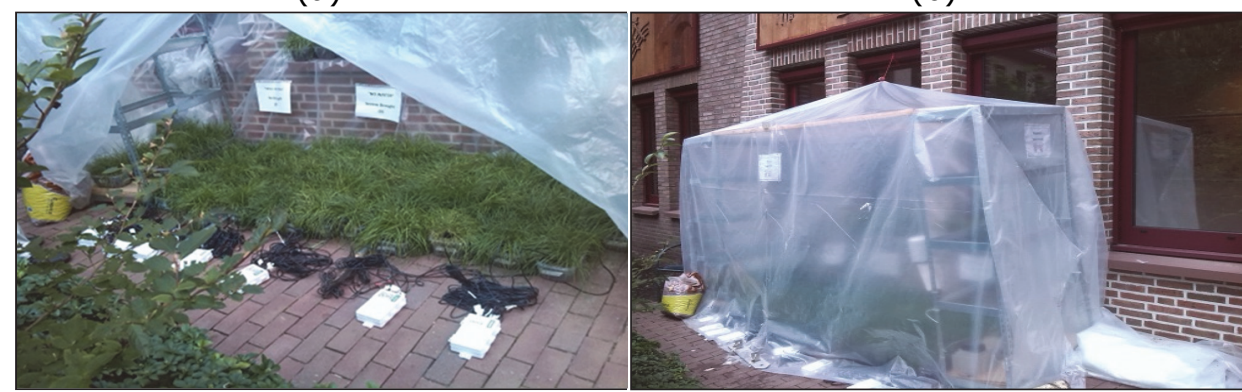

Figure 2.1. Experimental setup. (a) Plant pots, soil moisture sensors and data loggers to record soil moisture status continuously; (b) Closed greenhouse during the night and rainfall events.

\subsubsection{Instrumentation and measurements}

\subsubsection{Canopy and soil spectral measurements}

Canopy spectra of all pots were measured in a dark room located in a remote sensing laboratory using the Analytical Spectral Devices (ASD), FieldSpec ${ }^{\circledR} 3 \mathrm{Hi}$-Res Portable Spectroradiometer in Full Range (ASD Inc., Boulder, CO, USA) that acquires continuous spectra in the VIS, NIR and SWIR regions ( 350 to $2500 \mathrm{~nm}$ ). The plants were illuminated by four tungsten halogen quartz lamps of $100 \mathrm{~W}$, each installed to be pointing in four azimuth directions, each under a $45^{\circ}$ zenith incidence angle. These lamps were mounted about $80 \mathrm{~cm}$ above the plants (Figure 2.2a) to provide sufficient light to receive significant signal for accurate spectral measurements but without doing heat damage to the plant during the short measurement time. In this manner, we achieved a constant illumination. Measurements were done at the sampling intervals of the instrument (1.4 nm-VIS and NIR; $2 \mathrm{~nm}-$ SWIR) and were resampled by the instrument automatically into $1 \mathrm{~nm}$ intervals using linear and polynomial interpolations (Borzuchowski and Schulz, 2010). The fiber-optic cable was placed in a pistol and mounted on a stand (Figure 2.2b). In the setting, under $22.55 \mathrm{~cm}$ height and $25^{\circ}$ field of view (FOV), the spectrometer scanned a diameter of $10 \mathrm{~cm}$ on the pot surface with the nadir point at the center of the circle. We made sure that the FOV of the sensor was fully covered by the plants. Every start of the measurements was preceded by a warming up time of the ASD for about $60 \mathrm{~min}$ (as recommended by the manuals). Before every target measurement, the ASD spectroradiometer was optimized for the illumination conditions using a spectralon white (BaSO4) 
reference panel. The ASD spectrometer was set to take 60 samples and compute the average value before storing these data (to reduce the noise in the spectral measurements). Each sample was transferred from greenhouse to the laboratory and placed in the measurement setup. After each measurement of spectral reflectance from the target sample pot, a photo was also taken by a digital camera (EOS 400D, Digital Rebel XTi, Melville, NY, USA) installed on the stand in the setup (Figure 2.2). Finally, the pot was moved back to the greenhouse.

(a)

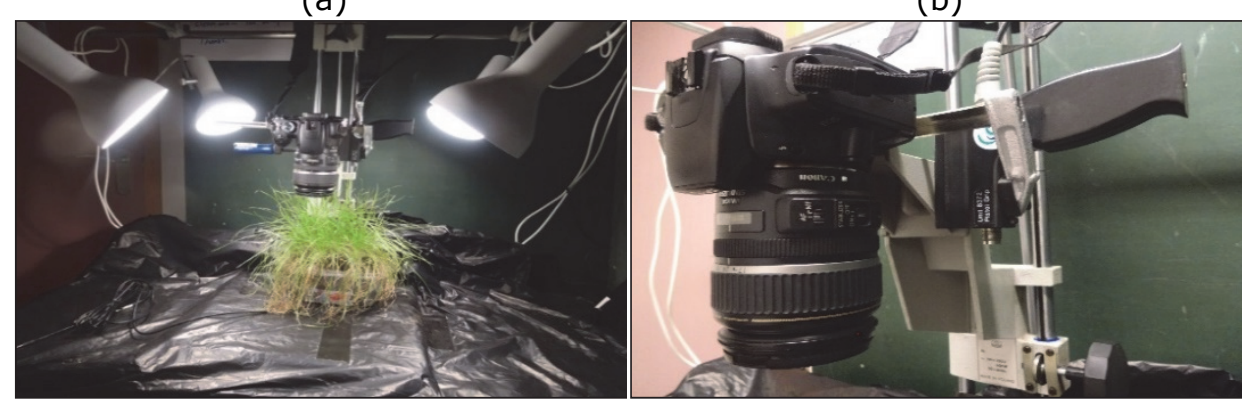

Figure 2.2. Experimental laboratory setup for canopy and soil reflectance measurement. (a) One of the grass sample pots; (b) Close-up photo of camera and ASD fiber-optic cable (placed in a pistol grip) mounted on the stand.

Since the measurement of soil spectra is needed to be used as the background reflectance of the grass target samples in the RT model inversion (Bach and Verhoef, 2003), the reflectance of the background soil containing various values of soil moisture content was also measured. At the end of the experiment, the biomass of 10 samples was completely harvested to take soil reflectance measurements on a set of soil samples having a range of soil moisture (from dried soil to completely saturated soil). To measure volumetric soil moisture content of each sample, the pots were weighed in the laboratory both before and after drying ( $48 \mathrm{~h}, 45^{\circ}$ Celsius), the difference being the mass of water originally in the sample. Then, volumetric soil moisture of soil samples was calculated by Equation (2.1):

$$
\theta_{v}=\theta_{g} \times\left(\frac{\rho_{b}}{\rho_{w}}\right)
$$

where $\theta_{v}$ is volumetric soil moisture $\left(\mathrm{m}^{3} \mathrm{~m}^{-3}\right), \theta_{g}$ is gravimetric soil moisture (wet mass of soil-dry mass of soil/dry mass of soil) $\left(\mathrm{g} \mathrm{g}^{-1}\right), \rho_{b}$ is soil bulk density and $\rho_{w}$ is the density of water $\left(\mathrm{g} \mathrm{cm}^{-3}\right)$.

In this experiment, in addition to canopy and soil reflectance measurements, some direct measurements of $L A I$ and $C_{a b}$ of the grass were measured in the laboratory during the stress episode for model validation purposes. This enabled the comparison of the destructive laboratory measurements of parameters with corresponding properties as retrieved from 
spectral readings. The measured parameters are described in the following subsection.

\subsubsection{Leaf area index and leaf chlorophyll content}

$L A I$ was measured directly during the experiment at different dates (having various soil moisture contents) by harvesting the pot samples which did not have a soil moisture sensor. Leaf area was measured at a representative subsample in the pot and related to its dry mass (oven dried at $65^{\circ} \mathrm{C}$ for $48 \mathrm{~h}$ ). To determine the leaf area, leaf samples were placed carefully on a sheet of paper and then were scanned with a flatbed scanner (the Xerox ColorQube 9301, Woerden, The Netherlands). The projected area was calculated using the Image] (the National Institutes of Health, Montgomery, AL, USA) software program. In all cases, we made sure that the leaves were not curled up or overlapping and tried to position the leaves to be as flat as possible in the position. We calibrated the area meter by using pieces of known area before measuring leaves and always checked that the whole leaves were positioned within the scanning area. The ratio of leaf area to leaf dry mass, known as specific leaf area (Vile et al., 2005), was calculated in $\mathrm{cm}^{2} \mathrm{~g}^{-1}$. Finally, the total dry mass of leaves collected within the pot surface area was converted into $L A I$ by multiplying by the specific leaf area.

To take measurements of leaf chlorophyll content, we used the SPAD 502Plus leaf chlorophyll meter (Konica Minolta Sensing, Inc., Sakai, Osaka, Japan). We took ten chlorophyll samples from each pot during one measurement located in the field of view of the canopy reflectance measurements and used the average value. The relative values of the SPAD were converted into absolute amount of chlorophyll using a widely used calibration curve (Equation (2.2)) from the literature (Markwell et al., 1995):

$$
C h l=10^{S^{0.0265}} R^{2}=0.94
$$

where $\mathrm{Chl}$ is the absolute amount of chlorophyll in $\mu \mathrm{mol} \mathrm{m} \mathrm{m}^{-2}$ and $S$ is the unitless value of the SPAD readings. Then, by considering the molecular mass of Chla and Chlb, unit conversions were made from $\mu \mathrm{mol} \mathrm{m}-2$ to $\mu \mathrm{g} \mathrm{cm}^{-2}$.

\subsubsection{Visual inspection}

To monitor visible changes in the plants undergoing various treatments, we installed a digital camera on the stand (Figure 2.2) to take a photo of each sample after measurement of target spectral reflectance. In this manner, we could follow the changes of plant status over time by naked eye. The most important changes might be detected by visual observation including the decoloration of the leaves, the shape of the leaves and the openness of the canopy (De Jong et al., 2012). 


\subsubsection{Spectral acquisition}

The grass spectra were measured six times during the experiment. There were ten pots in each measurement. In total, 108 spectra were collected in the stressed and control group. They were averaged to reduce noise and to enhance the representativeness of spectra for a specific day of measurement. As a result, six average spectra for the stressed and control group were investigated. To analyze the impacts of moisture deficit on different parts of the spectra, canopy spectral changes to different levels of moisture deficit during the experiment were plotted. To find the time of the first signs of stress in the reflectance spectra, we followed (De Jong et al., 2012), and Pearson's correlations were computed between the averaged spectra measured at the beginning and those of the measurements during the experiment over time, i.e., the other five averaged spectra, in each group. This indicated the degree of changes in the shape of the reflectance spectra over time. Afterwards, the ratio was computed between the averaged spectra measured at the beginning and those of the measurements during the experiment to find the relative changes as a function of the spectral position and time.

\subsubsection{Water stress-related vegetation indices}

Some of the widely used water stress-related vegetation indices were computed for the stressed and control group over time. Computed vegetation indices were categorized in three groups depending on the spectral information they use (Table 2.1). They can provide valuable information about water stress using just a few individual wavelengths. Normalized differences were found between the stressed and control groups for each of the computed indices. We performed a linear regression over the time series of the control group, then calculated the standard deviation of the residual of the data of the control group and the regression line, and used this standard deviation to normalize the differences between the two groups (control and stressed). The normalized values account for the variability in the control group. Selected vegetation indices were investigated during the drought episode to find the most sensitive indices for the stress detection in the early stages. A selection of the stress indices was made based on the literature. 
Table 2.1. List of the widely used water stress-related vegetation indices reviewed from the literature and used throughout this study. Rxxx indicates the reflectance at a specific wavelength

\begin{tabular}{|c|c|c|c|}
\hline Spectral Index & Equation & Eq. & Reference \\
\hline \multicolumn{4}{|l|}{ 1.VIS region (450-700) } \\
\hline Blue/Red pigment Index 2 & $B R I 2=R 450 / R 550$ & (2.3) & $\begin{array}{l}\text { (Zarco- } \\
\text { Tejada et } \\
\text { al., 2005) }\end{array}$ \\
\hline Blue/green pigment Index & $R G I=R 690 / R 550$ & (2.4) & $\begin{array}{l}\text { (Zarco- } \\
\text { Tejada et } \\
\text { al., 2005) }\end{array}$ \\
\hline $\begin{array}{l}\text { Photochemical Reflectance } \\
\text { Index }\end{array}$ & $P R I=(R 570-R 531) /(R 570+R 531)$ & $(2.5)$ & $\begin{array}{l}\text { (Gamon et } \\
\text { al., 1992) }\end{array}$ \\
\hline $\begin{array}{l}\text { Normalized Photochemical } \\
\text { Reflectance Index }\end{array}$ & $\begin{array}{c}P R I(\text { norm })=P R I /[((R 800- \\
R 670) / s q r t(R 800+R 670)) \\
R 700 / R 670]\end{array}$ & (2.6) & $\begin{array}{l}\text { (Zarco- } \\
\text { Tejada et } \\
\text { al., 2013) }\end{array}$ \\
\hline \multicolumn{4}{|l|}{ 2.NIR region $(700-1300)$} \\
\hline Normalized Water Index 1 & $N W I 1=(R 970-R 900) /(R 970+R 900)$ & $(2.7)$ & $\begin{array}{l}\text { (Babar et } \\
\text { al., 2006) }\end{array}$ \\
\hline Carter Index 2 & $C T R 2=R 695 / R 760$ & $(2.8)$ & $\begin{array}{l}\text { (Carter, } \\
1994)\end{array}$ \\
\hline $\begin{array}{l}\text { Normalized Difference Water } \\
\text { Index } 1241\end{array}$ & $\begin{array}{c}N D W I 1241=(R 857-R 1241) /(R 857+ \\
R 1241)\end{array}$ & $(2.9)$ & $\begin{array}{l}\text { (Gao, } \\
\text { 1996) } \\
\text { (Penuelas }\end{array}$ \\
\hline Water Band Index & $W B I=R 900 / R 970$ & $(2.10)$ & $\begin{array}{l}\text { et al., } \\
1995)\end{array}$ \\
\hline Three-band ratio 975 & $\begin{array}{c}\text { RATIO975 = } 2 \sum(R 960: R 990) /( \\
\left.\Sigma(R 920: R 940)+\sum(R 1090: R 1110)\right)\end{array}$ & $(2.11)$ & $\begin{array}{l}\text { (Pu et al., } \\
\text { 2003) }\end{array}$ \\
\hline Three-band ratio 1200 & $\begin{array}{c}R A T I O 1200= \\
2 \sum(R 1180: R 1220) /( \\
\Sigma(R 1090: R 1110)+\Sigma(R 1265: R 1285))\end{array}$ & $(2.12)$ & $\begin{array}{l}\text { (Pu et al., } \\
\text { 2003) }\end{array}$ \\
\hline \multicolumn{4}{|l|}{$\begin{array}{l}\text { 3.NIR/SWIR region (1300- } \\
2450)\end{array}$} \\
\hline $\begin{array}{l}\text { Normalized Difference Water } \\
\text { Index } 1640\end{array}$ & $\begin{array}{c}N D W I 1640=(R 857-R 1640) /(R 857+ \\
R 1640)\end{array}$ & $(2.13)$ & $\begin{array}{l}\text { (Chen et } \\
\text { al., 2005) }\end{array}$ \\
\hline $\begin{array}{l}\text { Normalized Difference Water } \\
\text { Index } 2130\end{array}$ & 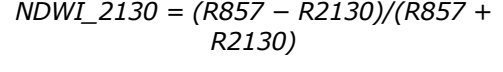 & $(2.14)$ & $\begin{array}{l}\text { (Chen et } \\
\text { al., 2005) }\end{array}$ \\
\hline Moisture Stress Index & $M S I=R 1599 / R 819$ & $(2.15)$ & $\begin{array}{c}\text { (Ceccato } \\
\text { et al., } \\
2001 ; \\
\text { Hunt Jr } \\
\text { and Rock, } \\
1989 \text { ) }\end{array}$ \\
\hline $\begin{array}{l}\text { Normalized Difference } \\
\text { Infrared Index }\end{array}$ & $\begin{array}{c}N D I I=(R 819-R 1649) /(R 819+ \\
R 1649)\end{array}$ & $(2.16)$ & $\begin{array}{l}\text { (Jackson et } \\
\text { al., 2004) }\end{array}$ \\
\hline
\end{tabular}

\subsubsection{Radiative transfer (RT) models}

Implementations of the well-known and widely used PROSPECT (Jacquemoud and Baret, 1990) and SAIL (Verhoef, 1984, 1985) radiative transfer models were selected for physically based leaf and canopy parameter retrieval. We used the RTMo model, which is a version of the four-stream SAIL model for the radiative transfer of incident light in canopies as used in the SCOPE model (Van der Tol et al., 2009b). RTMo is a combination of the "4SAIL" model (Verhoef et al., 2007), with a few additions, and the leaf radiative transfer model "Fluspect" which is basically the "PROSPECT5" model with a few modifications and additions. The main differences between RTMo (4SAIL + 
Fluspect) and PROSAIL (SAILH + PROSPECT4) are: (1) The leaf angle distribution in RTMo is described with two parameters; the mean leaf inclination parameter (LIDFa) and the bimodality of the leaf inclination distribution (LIDFb), while PROSAIL uses only the Mean Leaf Inclination Angle (MLA); (2) the fraction of diffuse incoming solar radiation in RTMo is spectrally dependent, whereas in PROSAIL it is considered as a constant value. Retrieval of canopy parameters from hyperspectral canopy level measurements was performed by inverting the RTMo model. The PROSPECT5 model (Jacquemoud et al., 1996; Jacquemoud and Baret, 1990) calculates the leaf hemispherical reflectance and transmittance as a function of four input parameters: (1) the leaf structural parameter $N$ (unitless); (2) the leaf chlorophyll $\mathrm{a}+\mathrm{b}$ concentration $C_{\mathrm{ab}}$ ( $\mu \mathrm{g}$ $\left.\mathrm{cm}^{-2}\right)$; (3) the dry matter content $C_{\mathrm{dm}}\left(\mathrm{g} \mathrm{cm}^{-2}\right)$; and (4) the water concentration of the leaves $C_{w}\left(\mathrm{~g} \mathrm{~cm}^{-2}\right)$. In Fluspect, also brown pigment concentration, i.e., $C_{s}$ (arbitrary unit), is included. The 4SAIL model (Verhoef, 1984,1985 ) is a one-dimensional bidirectional quasi-turbid medium radiative transfer model since leaf size is considered for the hot-spot effect. It defines the canopy as a horizontally homogeneous layer that consists of small, flat leaves. In addition to leaf reflectance and transmittance, the RTMo model requires some other input parameters to simulate the top-of-canopy bidirectional reflectance. These are the sun zenith angle, $\theta_{\mathrm{s}}$ (deg); the sensor viewing angle, $\theta_{0}(\mathrm{deg})$; the relative azimuth angle between sensor and sun, $\psi$ (deg); spectra of solar irradiance, $E_{\text {sun }}$; sky irradiance, $E_{\text {sky, }}$ background reflectance (soil reflectance), $r_{\mathrm{sl}} ; L A I\left(\mathrm{~m}^{2} \mathrm{~m}^{-2}\right)$; the hot-spot size parameter, defined as the ratio between the average width of the leaves and the canopy height (Verhoef and Bach, 2007), and the leaf inclination distribution function (LIDF).

\subsubsection{Local sensitivity analysis of RTMo}

By performing a sensitivity analysis for a model, the most (and least) important input parameters and, therefore, their roles in explaining the variance in the model output can be identified (Bowyer and Danson, 2004; Saltelli et al., 2000). At the canopy level, local sensitivity analysis (LSA) was executed to find the influence of small changes in RTMo input parameters on different parts of the reflectance spectrum. In this study, LSA relies on the Jacobian J, which is the matrix of first partial derivatives of the relative model output. To improve the comparability of the various model parameters, the Jacobian was calculated by varying each parameter by $1 \%$ of its range and recording the corresponding reflectance difference. This reflectance difference equals:

$$
\Delta r=J \frac{P_{\max }-P_{\min }}{100}
$$

where $J$ is the corresponding element of the Jacobian matrix. $P_{\max }$ is the maximum and $P_{\min }$ is the minimum value of input parameter $P$. To evaluate the 
influence of the parameters $k$ over the entire spectrum and to find the most (and least) influential parameters, the indicator $a_{k}$ was defined as:

$$
\alpha k=\sqrt{\frac{1}{n} \sum_{i=1}^{n} J_{i, k}^{2}}
$$

\subsubsection{Inversion of RTMo}

Inversion of a physical reflectance model aims at finding the set of input parameters which leads to the best match between simulated spectra by the model and observed spectra by the sensor. We used an iterative optimization technique for model inversion. The iterative optimization technique searches for the best fit between the simulated and the measured reflectance spectra by iteratively running the canopy reflectance model (Figure 2.3) for different values of the input variables. The minimization of a cost function that accounts for the differences between the simulated and the measured reflectance spectra is used as a stopping criterion for this optimization problem. There are several studies that used different mathematical and statistical approaches to find the minimum (Dorigo et al., 2007).

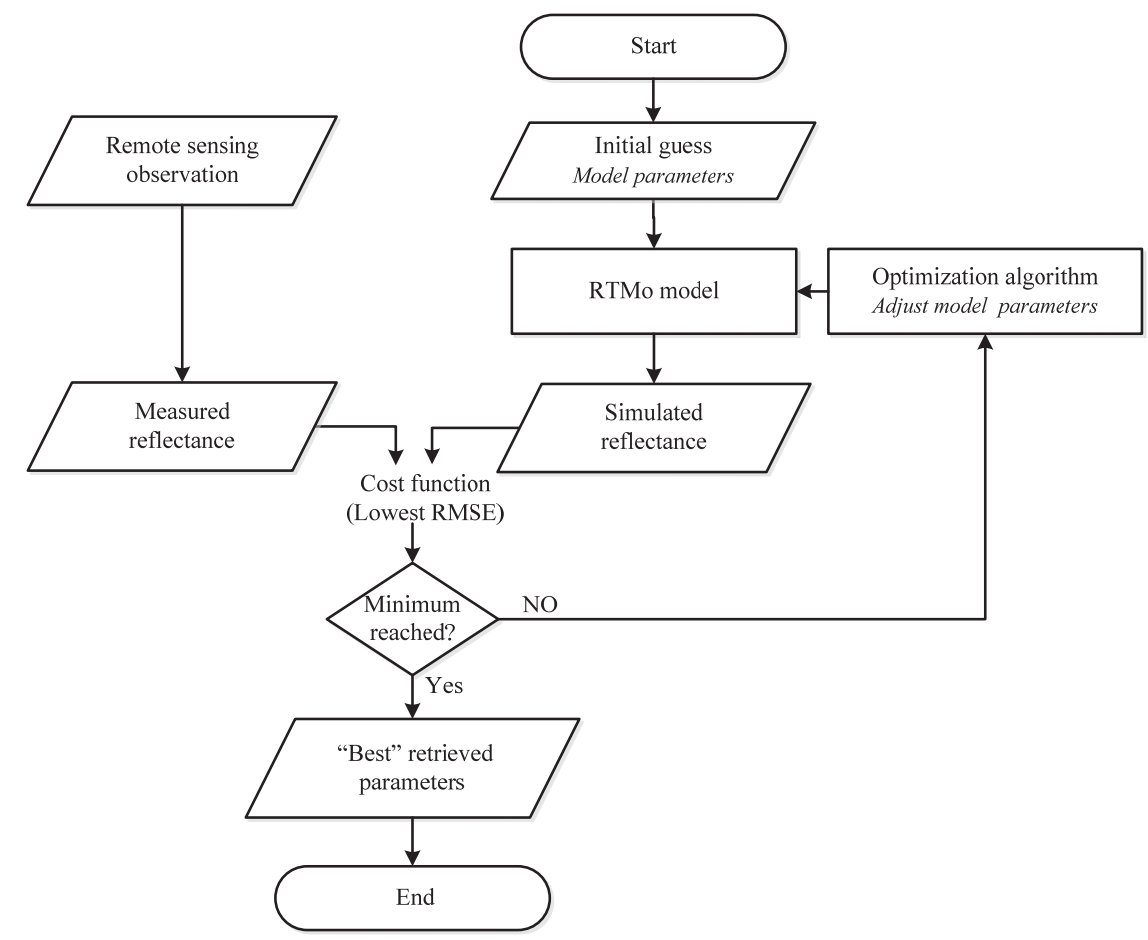

Figure 2.3. Conceptualization of the iterative optimization technique used in this study. 
Table 2.2 shows the initial guesses of input parameters used during the model inversion. To consider the contribution of the background soil reflectance in the model inversion, we changed the model soil spectra based on the value of soil moisture recorded in the pot for which canopy reflectance was taken.

Table 2.2. Initial guess of parameters for retrieval and their status in the model inversion.

\begin{tabular}{lcccc}
\hline Parameter & $\begin{array}{c}\text { Abbr. in } \\
\text { Model }\end{array}$ & Unit & $\begin{array}{c}\text { Initial } \\
\text { Guess }\end{array}$ & $\begin{array}{c}\text { Parameter } \\
\text { Status }\end{array}$ \\
\hline Leaf chlorophyll content & $C_{\mathrm{ab}}$ & $\mu \mathrm{g} \mathrm{cm}^{-2}$ & 40 & Tuned \\
Leaf water content & $C_{\mathrm{w}}$ & $\mathrm{g} \mathrm{cm}^{-2}$ & 0.009 & Tuned \\
Carotenoids & $C_{\mathrm{ca}}$ & $\mu \mathrm{g} \mathrm{cm}^{-2}$ & 5 & Fixed \\
Leaf dry matter content & $C_{\mathrm{dm}}$ & $\mathrm{g} \mathrm{cm}^{-2}$ & 0.012 & Tuned \\
Senescent material & $C_{\mathrm{s}}$ & - & 0 & Tuned \\
Leaf structural parameter & $N$ & - & 1.5 & Fixed \\
Leaf area index & $L A I$ & $\mathrm{~m}^{2} \mathrm{~m}^{-2}$ & 1 & Tuned \\
Leaf inclination distribution & $L I D F_{\mathrm{a}}$ & - & -0.35 & Tuned \\
function & & & & Tuned \\
Bimodality of the leaf & $L I D F_{\mathrm{b}}$ & - & -0.15 & Fixed \\
inclination & $h o t$ & $\mathrm{~m} \mathrm{~m}$ & 0.05 & Fixed \\
Hot-spot size parameter & $\theta_{\mathrm{s}}$ & $\mathrm{deg}$ & 45 & Fixed \\
Solar zenith angle & $\theta_{0}$ & $\mathrm{deg}$ & 0 & Fixed \\
Observation zenith angle & $\psi$ & $\mathrm{deg}$ & 0 & \\
Relative Azimuth Angle & & & & \\
\hline
\end{tabular}

The "Trust Region" algorithm implemented in the MATLAB (the MathWorks, Inc. Natick, MA, USA) function "Isqnonlin" was used to minimize the cost function. The cost function calculated was simply the sum of the squared differences over the whole wavelength range of the measured reflectance. From the result, the Root Mean Square Error (RMSE) between measured and simulated spectra was calculated. To avoid local minima, we did the minimization in numerous loops starting with various initial values. We changed the model initial values and simulated the canopy spectra. The results (data not shown) showed no significant effects of initial value choices on the retrieved properties and the calculated RMSE between measured and simulated spectra.

\subsubsection{Inversion performance evaluation (statistics of errors)}

Table 2.3 presents a list of goodness-of-fit measures used in this research to indicate the agreement between simulated and observed values of LAI and $C_{a b}$. Error indices (category 1 in Table 2.3) quantify the deviation of modeled from observed values. The statistics therefore describe the departure of model estimations from the one-to-one line (Richter et al., 2012). The main advantage of calculating these error indices is that they represent the simple or squared differences between observed and simulated data. Correlationbased measures (category 2 in Table 2.3), have the advantage of being bounded (for $R^{2}$ between 0 and 1 ), and, therefore, are independent of the unit 
of the parameter. The two most often used and traditional measures from category 1 and 2 (i.e., RMSE and $R^{2}$, respectively) are often seen as insufficient for model validation purposes (Atkinson et al., 2012; Richter et al., 2012). Instead, there are some dimensionless statistics (category 3 ) proposed in many studies, such as relative and normalized variations of the RMSE (i.e., RRMSE and NRMSE, respectively). The particular advantage of RRMSE and NRMSE is that the actual error can be calculated without being affected by the data unit.

Table 2.3. Statistical measures used for evaluation of RTMo model inversion results.

\begin{tabular}{|c|c|c|c|}
\hline Statistical Measure & Equation & Eq. & Unit/Range \\
\hline \multicolumn{4}{|l|}{ (1) Error Indices } \\
\hline $\begin{array}{l}\text { Root Mean Square } \\
\text { Error }\end{array}$ & $R M S E=\sqrt{\frac{1}{n} \sum_{i=1}^{n}\left(V_{e s t}^{i}-V_{o b s}^{i}\right)^{2}}$ & $(2-19)$ & Data unit \\
\hline \multicolumn{4}{|l|}{$\begin{array}{l}\text { (2) Correlation- } \\
\text { Based Measure }\end{array}$} \\
\hline $\begin{array}{l}\text { Coefficient of } \\
\text { Determination }\end{array}$ & $R^{2}=1-\frac{\sum_{i=1}^{n}\left(V_{o b s}^{i}-V_{e s t}^{i}\right)^{2}}{\sum_{i=1}^{n}\left(V_{o b s}^{i}-\bar{V}_{o b s}\right)^{2}}$ & $(2-20)$ & 0 to 1 \\
\hline \multicolumn{4}{|l|}{$\begin{array}{l}\text { (3) Dimensionless } \\
\text { Error Indices }\end{array}$} \\
\hline Normalized RMSE & $N R M S E=\frac{R M S E}{\text { Range }(o b s)}$ & $(2-21)$ & 0 to $\infty$ \\
\hline Relative RMSE & $R R M S E=100 \times \frac{R M S E}{\text { Mean }(\text { obs })}$ & $(2-22)$ & 0 to $\infty$ \\
\hline
\end{tabular}

\subsection{Results}

\subsubsection{Visual inspection}

Grass responses to soil moisture deficit were tracked visually during the drought episode by analysis of their pictures. The visible signs of stress were increasing with time when moisture deficit progressed. The leaves turned from shiny to dull, decoloring to brown at the first signs of stress on day 10-11 of the experiment. Afterwards, by progress of stress, leaves started curling, shrinking, losing their color, allowing the brown leaves to dominate. At the end of the experiment in severe water stress, plants permanently wilted, all the leaves were discolored and the plants dried out completely and died.

\subsubsection{Shape of reflectance spectra}

The changes in the shape of reflectance spectra for the selected grass, Poa pratensis, in response to the soil moisture deficit is illustrated in various ways. First, we visualized the effects of specific moisture deficit on the collected spectra to interpret the moisture-induced impacts on the shape of the reflectance curve on both canopy and soil from $450-2450 \mathrm{~nm}$. Then, relative changes of the canopy reflectance values over time were analyzed to find the position and the time of the first sign of stress. Figure $2.4 a$ shows selected 
measured spectra collected over the experiment in different soil moisture content. This result confirms that the stress affected all parts of the spectrum (either directly or indirectly) at the canopy level. Some parts of the spectrum, like $800-1100 \mathrm{~nm}$, show a distinct decrease of reflectance values during the drought episode in case the plant is under stress. However, this is not the case under normal conditions in which the plant is not under stress (e.g., soil moisture contents $\geq 0.3$, in the first days of the experiment). For instance, the reflectance in the region $800-1100 \mathrm{~nm}$ at a soil moisture of $0.02 \mathrm{~m}^{3} \mathrm{~m}^{-3}$ is lower than the canopy reflectance collected under other stress conditions (e.g., soil moisture contents $0.2,0.15,0.10$ and $0.05 \mathrm{~m}^{3} \mathrm{~m}^{-3}$ ). The water absorption bands at 1450 and $1940 \mathrm{~nm}$ showed the strongest response by an increase of the reflectance. The visible green and visible red show smaller albeit distinct changes.

(a)

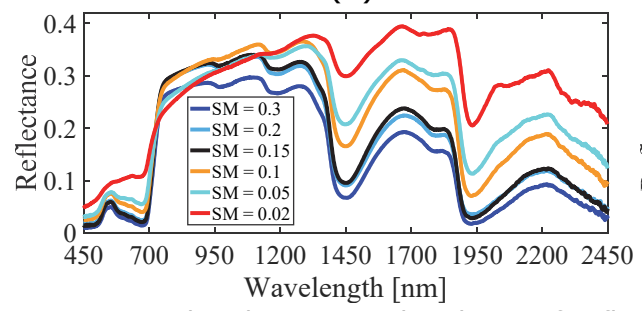

(b)

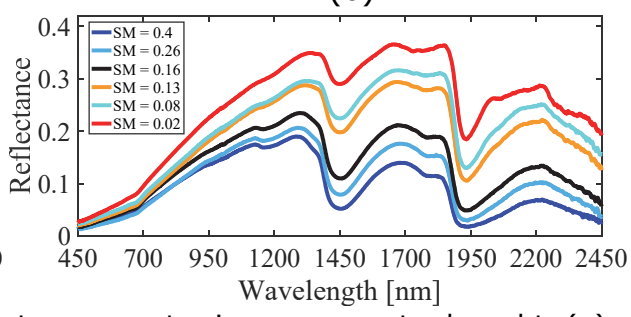

Figure 2.4. The changes in the shape of reflectance spectra in responses to drought. (a) Canopy spectra change at different levels of soil moisture (SM) deficit; (b) Soil reflectance changes under different soil moisture conditions.

The spectra collected in the first stages of the drought episode (with soil moisture content of $0.3\left(\mathrm{~m}^{3} \mathrm{~m}^{-3}\right)$ ) had low reflectance values in the visible part of the spectrum due to high concentrations of leaf chlorophyll. However, a decrease in chlorophyll concentration as a result of water stress increased the visible reflectance. Canopy reflectance of vegetation also depends on the reflectance properties of the underlying soil (Huete, 1987). Figure 2.4b illustrates how soil reflectance changed due to different soil moisture contents in the experiment.

To find the time when the first drought-induced changes take place, we computed Pearson's correlation [as in (De Jong et al., 2012)] between the mean spectrum taken at the beginning of the experiment and those of the measurements during the experiment over time in both stressed and control treatments (Figure 2.5a). Values smaller than 1.0 indicate that the shape of the spectral curve changed compared to the first measurement taken at the beginning of the experiment in the stressed and control groups. This analysis showed that on 17 September 2014 the first sign of stress occurred since the reflectance of Poa pratensis started deviating from the first measurement as early as day 4 and, therefore, the correlation of the stressed group started declining at this time. To identify the spectral position in which the first signs of stress could be detected, we calculated the ratio between reflectance values 
collected at day 11 and day 4 for the stressed group expressed as a percentage change (Figure 2.5b). The first considerable responses could be seen at the major water absorption bands, especially at $1930 \mathrm{~nm}(62 \%)$ and $1440 \mathrm{~nm}$ (29\%). Furthermore, distinct changes were detected around 550-700 nm with a maximum at $675 \mathrm{~nm}(31 \%)$. However, the minor water absorption bands around $970 \mathrm{~nm}$ and $1200 \mathrm{~nm}$ did not show different responses from the surrounding wavelengths and were not recognizable in the graph.

(a)

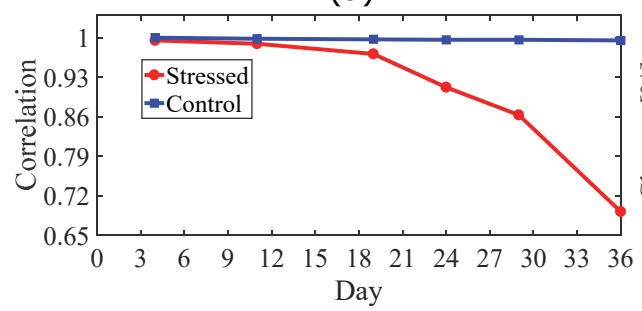

(b)

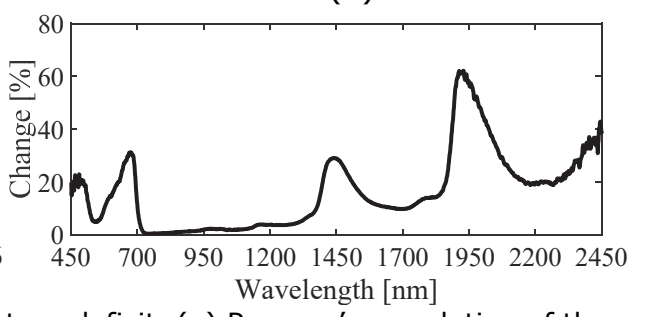

Figure 2.5. Spectral changes due to soil moisture deficit. (a) Pearson's correlation of the mean spectra taken at the beginning of the experiment and those of the measurements during the experiment over time in both stressed and control treatments; (b) Relative changes (\%) between the first measured spectra at day 4 and the spectra measured at day 11 .

\subsubsection{Spectral indices}

To find the most sensitive spectral indices for detection of water stress in the early stages, we computed the widely used indices related to water stress. The selected indices showed different behaviors over time during the experiment. The normalized differences of the index values in the stressed group compared to the control group are displayed in Figure 2.6. To find the normalized differences of the index values, first a linear regression was performed over the time series of the control group. Second, the standard deviation of the residual of the data of the control group with respect to the regression line was calculated, as a measure for the variability in the control group. This standard deviation was used to normalize the differences between the two groups (control and stressed). The threshold of two times the response of the control group, suggested in previous studies (De Jong et al., 2012), was used to decide whether the stress index actually detected the stress or not. Based on this threshold, the majority of selected indices could detect the stress in the early stages (Figure 2.6a). The results showed that the NDWI_1241 was the best stress detector by exceeding the threshold. The response of the NDWI_1241, RATIO1200, BGI2 and NDWI_2130 were 10, 8.7, 8.6 and 8.2 times stronger for the stressed group than for the control group, respectively (Figure 2.6a).

The MSI, NDII, NWI_1, and WBI indices also showed a stronger response (greater than six times the one of the control group) to the stress in the early stages. However, PRI_norm showed no detectable response to the stress since 
its response stayed below the defined threshold. The vegetation indices responses to long-term stress, at the end of the experiment, showed that all of the selected indices detected the stress (Figure 2.6b). The results showed that the PRI_norm was the best detector of long-term stress conditions. The response of the PRI_norm, CTR2, BGI2 and NDWI_1241 to long-term stress were 76, 53, 51 and 44 times stronger for the stressed group than for the control group respectively (Figure $2.6 \mathrm{~b}$ ).

(a)

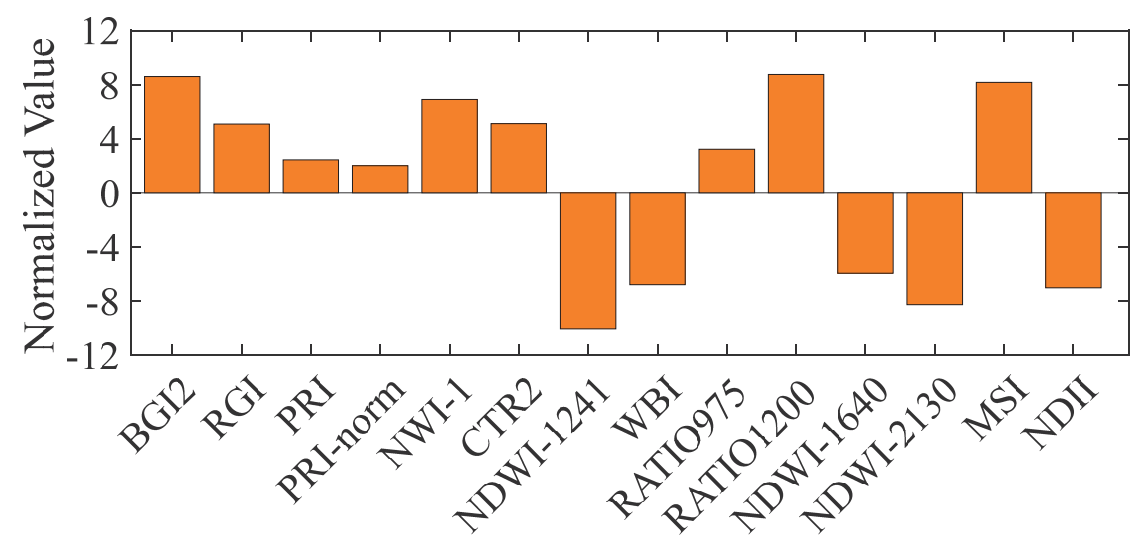

(b)

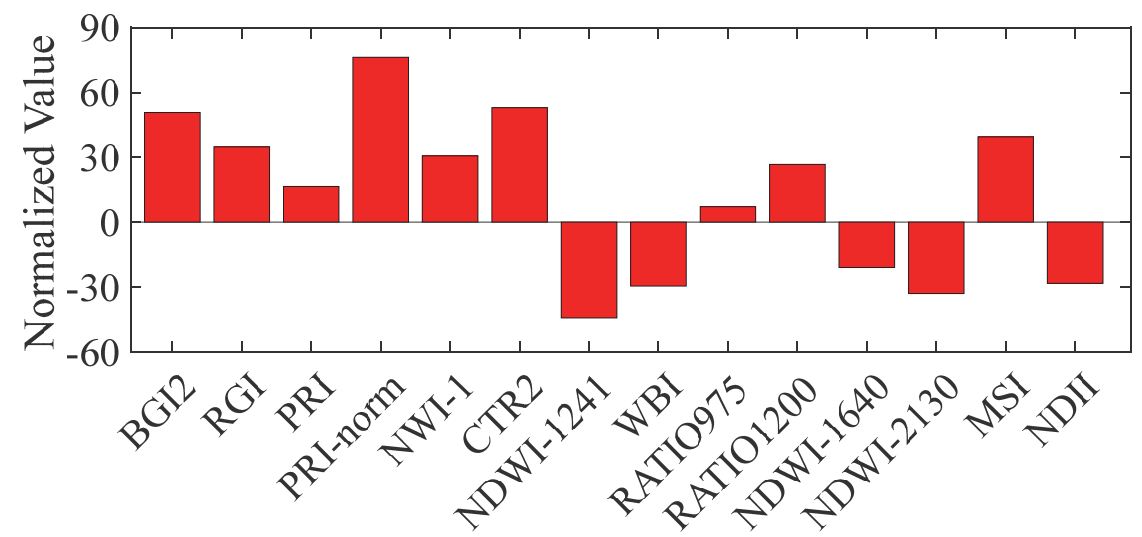

Figure 2.6. Normalized changes of vegetation indices in the stressed group (compared to the control group). (a) At day 11 (short-term stress); (b) At day 36 (long-term stress).

Figure 2.7a,b shows the development over time for the two bestperforming stress indices (NDWI_1241 and RATIO1200) in response to shortterm stress (at day 11). Figure 2.7c,d shows the development over time for the two best-performing stress indices (PRI_norm and CTR2) in response to long-term stress (at day 36). As expected, indices in the control group did not 
change over time, except for small variations that might be explained by the noise level of the index (De Jong et al., 2012).

(a)

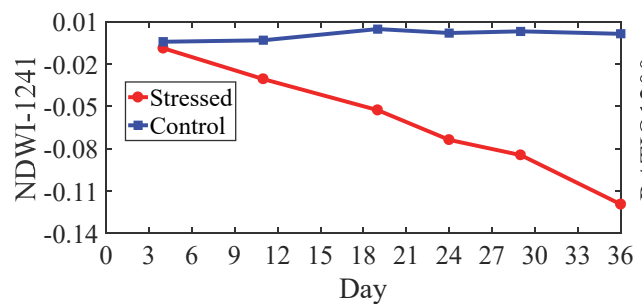

(c)

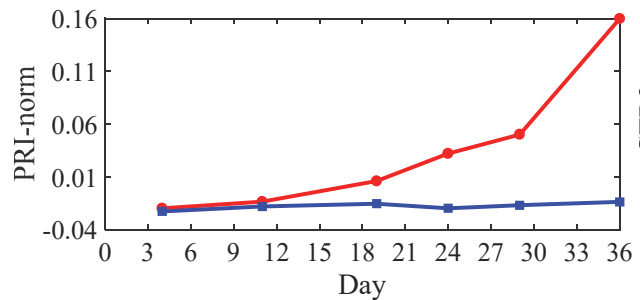

(b)

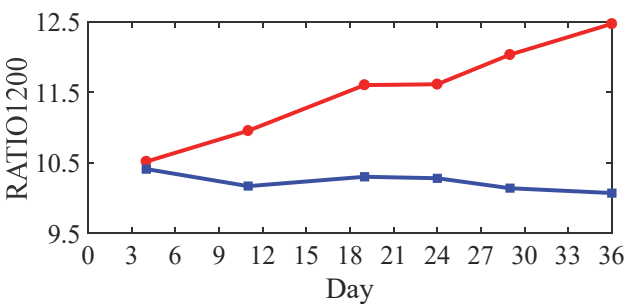

(d)

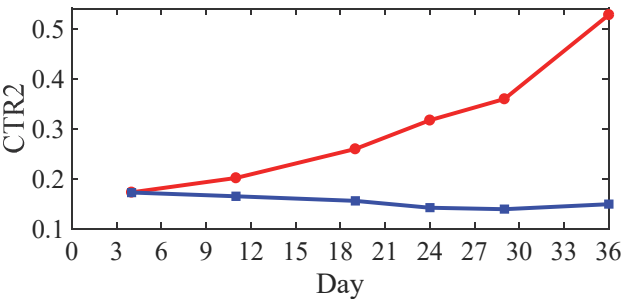

Figure 2.7. Trend of the best indices during the stress episode. (a) NDWI_1241 at day 11; (b) RATIO1200 at day 11; (c) PRI_norm at day 36; (d) CTR2 at day 36.

NDWI_1241, the best performing index for short-term stress (at day 11) showed a downward trend over time during the experiment, whereas RATIO1200, PRI_norm and CTR2 showed upward trends. In addition, we found that BGI2 and NDWI_1241 had detectable and strong responses for both shortterm and long-term stress.

\subsubsection{Radiative transfer modeling}

\subsubsection{RTMo sensitivity analysis results}

We changed all the parameters ( $C_{\mathrm{ab}}, C_{\mathrm{dm}}, C_{\mathrm{w}}, C_{\mathrm{s}}, L A I$, and $\left.L I D F_{\mathrm{a}}\right)$ by $1 \%$ of their total range (Table 2.4) and then determined the reflectance differences (Figure 2.8). This shows the influence of each parameter in a comparable way. The normalized derivative demonstrated two clearly indicated peaks in the reflectance response to $C_{a b}$ change at $557 \mathrm{~nm}$ and $710 \mathrm{~nm}$ (Figure 2.8a). The second peak was the most sensitive one of the entire spectrum and the visible region was indicated as the most sensitive to $C_{a b}$ change. In contrary, the small variation in $C_{w}$ was expressed most strongly in the SWIR (Figure 2.8b). The greatest sensitivity to variation in $C_{w}$ was exhibited at 1400, 1870, 1516, 2225 $\mathrm{nm}$. Variation in $C_{\mathrm{w}}$ also contributes significantly in the NIR, especially at 1198 and $976 \mathrm{~nm}$. Variation in the $C_{\mathrm{dm}}$ was expressed most strongly in both the NIR and the SWIR (Figure 2.8c). It showed pronounced peaks at 916, 1075, 1272, 1719, 2182 and $2273 \mathrm{~nm}$. Two clearly indicated peaks are observed in the 
reflectance response to $C_{\mathrm{s}}$ change at $551 \mathrm{~nm}$ and $748 \mathrm{~nm}$. However, the NIR and SWIR parts did not respond to changes of the $C_{s}$ parameter (Figure $2.8 \mathrm{~d}$ ). Although variations in $L A I$ and $L I D F$ triggered the reflectance response at similar spectral wavelengths (910, 1081, 1279, 1681, 1827 and $2221 \mathrm{~nm}$ ), the $L I D F$ response was quite weak compared to the one of $L A I$ (Figure $2.8 \mathrm{e}, \mathrm{f}$ ).

(a)

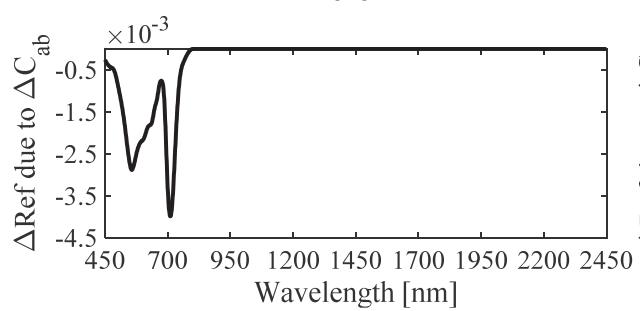

(c)

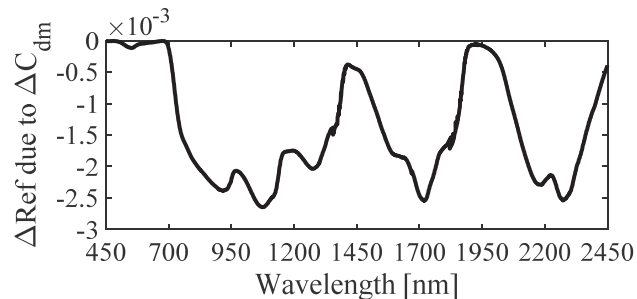

(e)

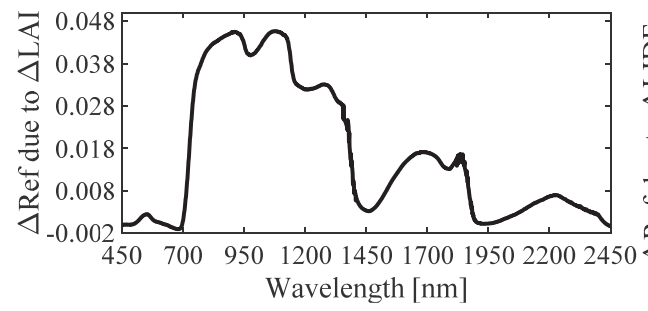

(b)

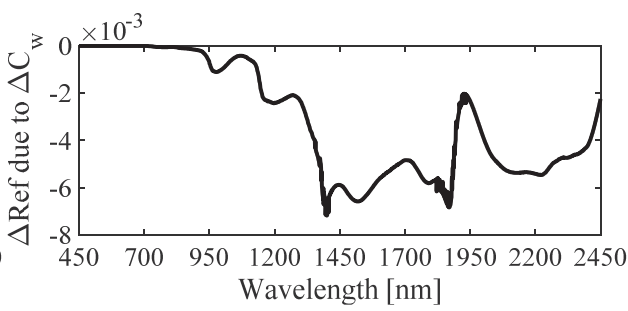

(d)

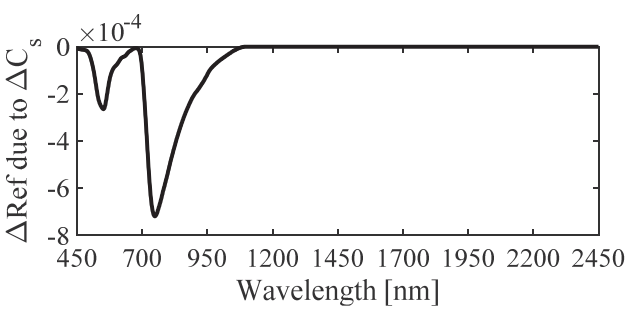

(f)

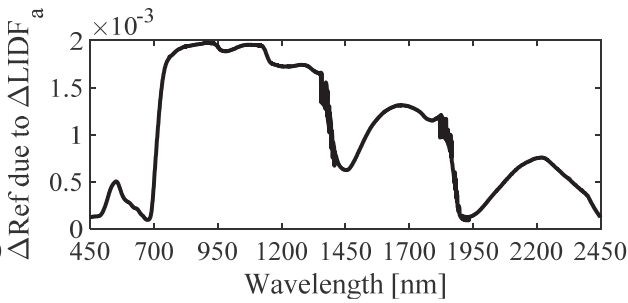

Figure 2.8. The partial derivative of canopy reflectance simulated by RTMo to change of each input parameters (by one percent of their total range). (a) $C_{a b}$; (b) $C_{w}$; (c) $C_{d m}$; (d) $C_{\mathrm{s}}$ (e) $L A I$; (f) $L I D F_{\mathrm{a}}$.

The computed $a_{\mathrm{k}}$ values (Table 2.4) showed that the most influential parameters over the entire spectrum were $L A I$ and $C_{\mathrm{w}}$ with $a L A I$ and $a C_{\mathrm{w}}$ values of 0.0231 and 0.0039 . Thus, by having a small change in these parameters, the reflectance will respond relatively stronger in comparison to the other ones. The least influential parameters identified were $C_{a b}$ and $C_{s}$. 
Table 2.4. Variation range of parameters for sensitivity analysis and the computed $a_{\mathrm{k}}$.

\begin{tabular}{ccccc}
\hline Parameter & $\begin{array}{c}\text { Abbreviation in } \\
\text { Model }\end{array}$ & Unit & $\begin{array}{c}\text { Variation } \\
\text { Range }\end{array}$ & $a_{\mathrm{k}}$ \\
\hline Leaf chlorophyll content & $C_{\mathrm{ab}}$ & $\mathrm{mg}^{-2}$ & $0-100$ & 0.0008 \\
Leaf water content & $C_{\mathrm{w}}$ & $\mathrm{g} \mathrm{cm}^{-2}$ & $0-0.05$ & 0.0039 \\
Leaf dry matter content & $C_{\mathrm{dm}}$ & $\mathrm{g} \mathrm{cm}^{-2}$ & $0-0.02$ & 0.0016 \\
Senescent material & $C_{\mathrm{s}}$ & - & $0-0.3$ & 0.0002 \\
Leaf area index & $L A I$ & $\mathrm{~m}^{2} \mathrm{~m}^{-2}$ & $0-6$ & 0.0231 \\
Leaf inclination distribution & $L I D F_{\mathrm{a}}$ & - & $-1-+1$ & 0.0012 \\
function & & & &
\end{tabular}

\subsubsection{RTMo inversion results}

The RMSE of measured and simulated spectra was employed as the criterion of the RTMo model inversion performance. Figure 2.9a,c shows two representative examples (at days 11 and 36) for spectra goodness of fit. Further, the difference between two simulated and measured canopy spectra on different days (days 11 and 36) of the experiment is shown in Fig. 2.9b,d. These examples represent the performance of the inversion since good quality of spectral fit achieved.

(a)

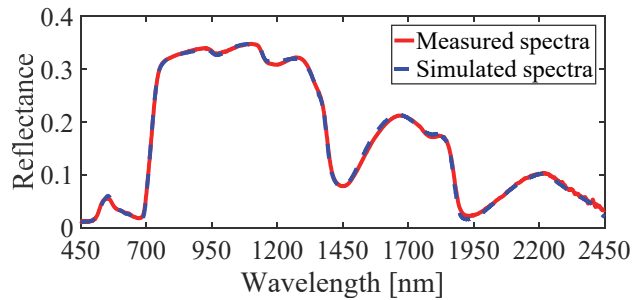

(c)

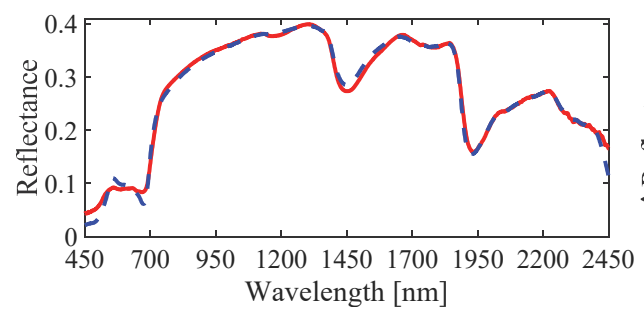

(b)

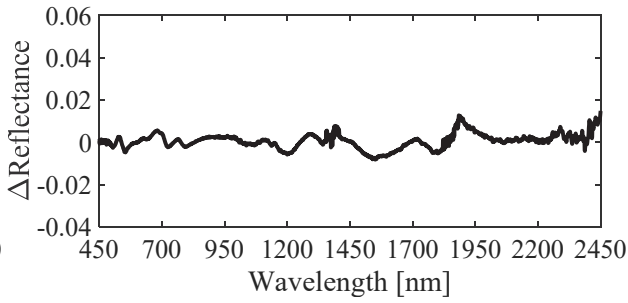

(d)

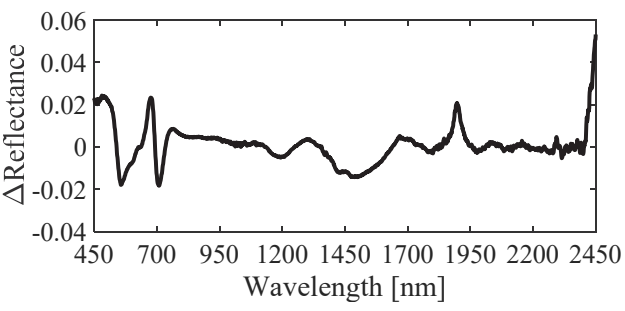

Figure 2.9. Left panels show the goodness of fit for the spectra obtained between measured reflectance (shown as red solid lines) and the simulated reflectance spectra (shown as blue dashed lines) on different days of the experiment; (a) day 11 and (c) day 36, and right panels show the difference between two simulated and measured reflectance spectra at (b) day $11 ;$ (d) day 36.

Furthermore, the distribution of RMSE between measured and simulated canopy reflectance spectra during the drought experiment for all simulations (under various soil moisture conditions) is presented in Figure 2.10. The small error in the model inversion $(0.002<$ RMSE < 0.009) showed that the model 
was able to accurately reproduce all observed reflectance spectra under different soil moisture contents during the experiment.

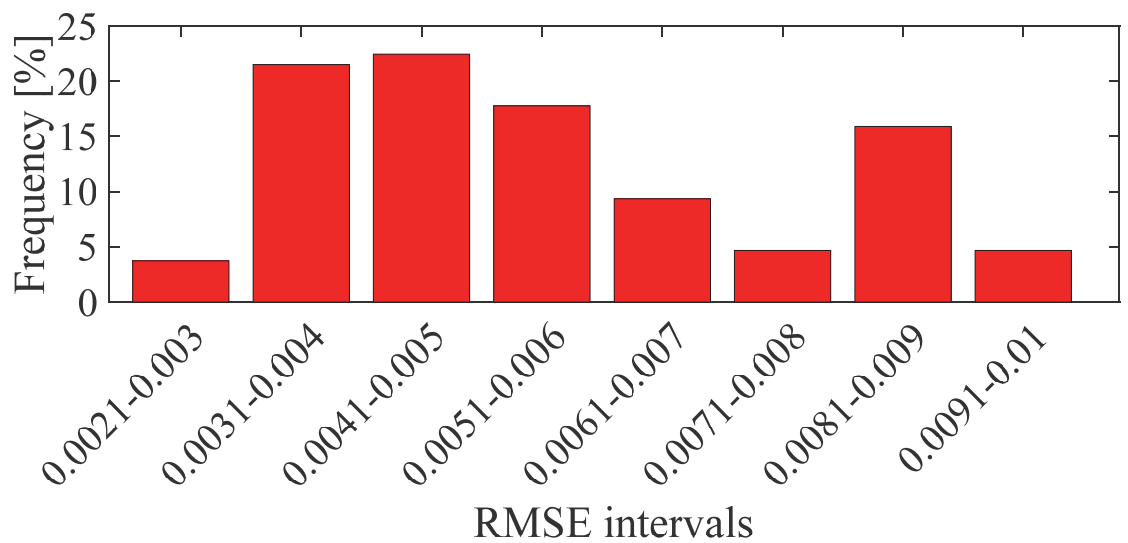

Figure 2.10.The distribution of RMSE between measured and simulated spectra for all simulations.

In addition, the inversion results were also evaluated in their accuracy (deviations from the measured parameter values). In Figure 2.11, the retrieved and measured $L A I$ and $C_{a b}$ are illustrated in the form of scatter plots and deviations from the one-to-one line.

For the retrieved and measured properties, statistical measures were calculated. Varying statistical performances are given for the two variables (i.e., $L A I$ and $C_{a b}$; Table 2.5). RMSE and $\mathrm{R}^{2}$ calculated $0.75\left(\mathrm{~m}^{2} \mathrm{~m}^{-2}\right), 0.87$ for $L A I$ and $4.61\left(\mu \mathrm{g} \mathrm{cm}^{-2}\right), 0.74$ for $C_{a b}$ estimation. Because of the different units, we also calculated NRMSE and RRMSE, which are dimensionless and suitable measures for comparisons between $L A I$ and $C_{a b}$ variables. The calculated NRMSE (LAI: 0.18, $\left.C_{\mathrm{ab}}: 0.15\right)$ and RRMSE (LAI: 24.8\%, $C_{\mathrm{ab}}: 19.8 \%$ ) are presented in Table 2.5. 
(a)

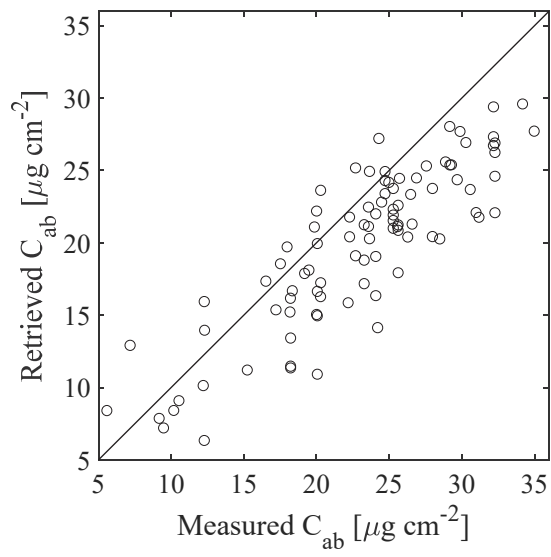

(b)

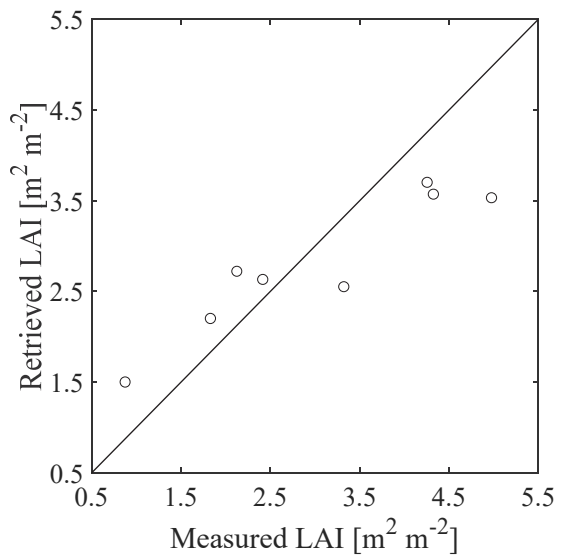

Figure 2.11. Retrieved versus measured vegetation parameters. (a) $C_{a b}$; (b) $L A I$.

Table 2.5. Evaluation of RTMo model inversion results for LAI $(n=8)$ and Cab $(n=$ 95) estimation.

\begin{tabular}{ccccc}
\hline Statistical Measure & $L A I$ & Unit & Cab & Unit \\
\hline RMSE & 0.75 & $\mathrm{~m}^{2} \mathrm{~m}^{-2}$ & 4.61 & $\mu \mathrm{cm}^{-2}$ \\
$\mathrm{R}^{2}$ & 0.87 & - & 0.74 & - \\
NRMSE & 0.18 & - & 0.15 & - \\
RRMSE & 24.8 & $\%$ & 19.8 & $\%$ \\
\hline
\end{tabular}

\subsubsection{Trend of the retrieved grass properties}

Retrieved properties variations over time during the experiment are plotted in Figure 2.12. This way, we could follow the trend of changes and detect water stress impacts on the retrieved properties. We presented the properties changes over time in separated stressed and control groups derived from the averaged spectra of all measurements from the same day. In almost all cases, the value of the control group displayed, as expected, a horizontal course indicating that vegetation properties did not change much during the measurement period. However, water stress affected all grass properties in the stressed group during the drought episode. The maximum value retrieved for the $C_{a b}$ at the first measurement (day 4) was about $22\left(\mathrm{ug} \mathrm{cm}^{-2}\right)$, which then decreased during the experiment and reached the minimum value of 3.6 on the last measurement (day 36). The $C_{w}$ changed from 0.006 to $0.001\left(\mathrm{~g} \mathrm{~cm}^{-2}\right)$ from the beginning of the experiment to the end. Following the responses of $C_{\mathrm{dm}}$ and $C_{\mathrm{s}}$ to the stress over time showed a different trend in comparison to the other properties since they deviated away from the horizontal control line upward. The minimum value for $C_{s}$ was retrieved on day 4 while the maximum value recorded at the end of experiment on day 36 . LAI responded to the stress during the experiment and decreased from $2.3\left(\mathrm{~m}^{2} \mathrm{~m}^{-2}\right)$ at the beginning to $1.5\left(\mathrm{~m}^{2} \mathrm{~m}^{-2}\right)$ at the end of the experiment. In addition, the results showed that $L A I$ and $C_{s}$ responded to the stress relatively late (after day 11 ) compared to 
the other properties such as $C_{\mathrm{w}}, C_{\mathrm{dm}}$ and $C_{\mathrm{ab}}$ which responded in the early stages (day 4).

(a)

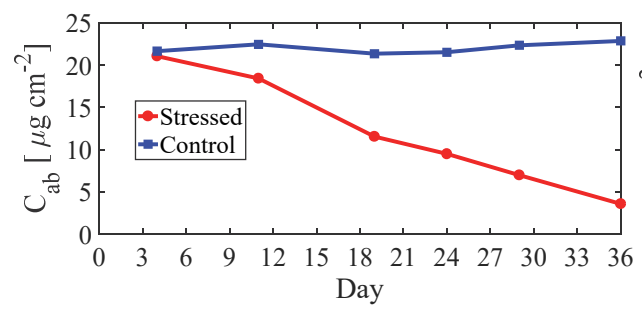

(c)

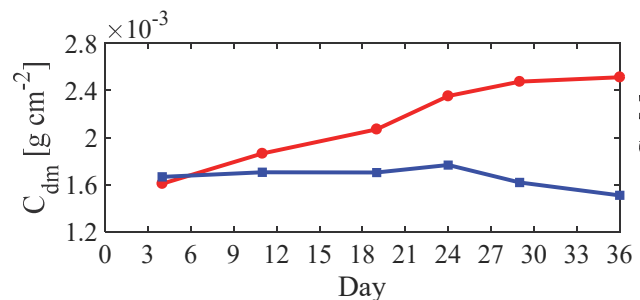

(e)

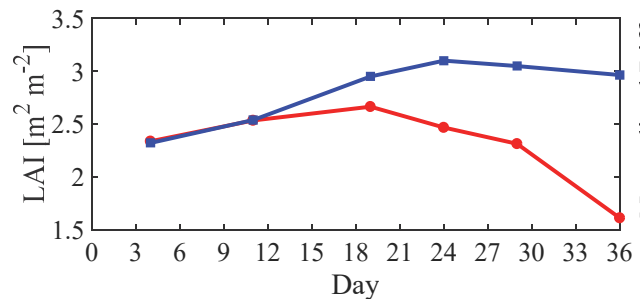

(b)

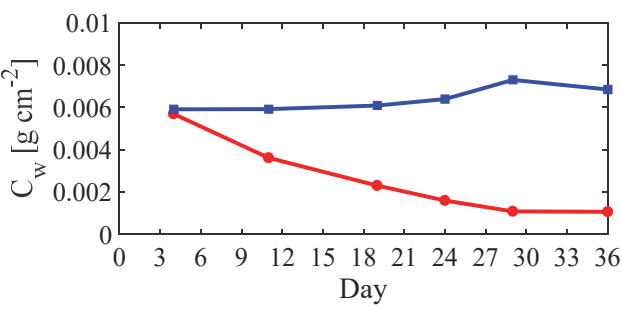

(d)

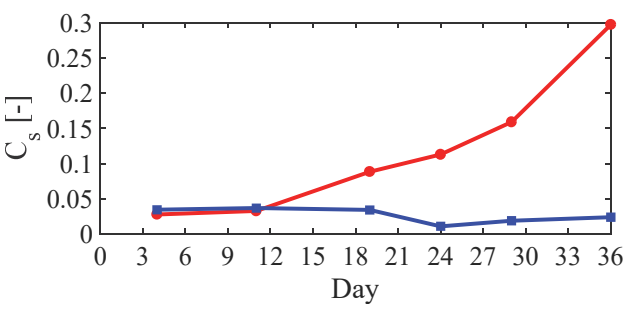

(f)

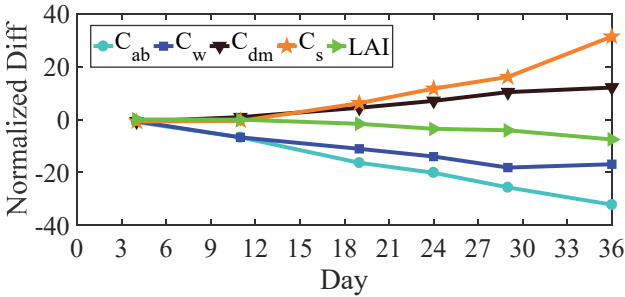

Figure 2.12. Trend of the retrieved properties. (a) $C_{a b}$, (b) $C_{w}$, (c) $C_{d m}$ (d) $C_{s}$, (e) $L A I$ changes over time. Further, the normalized differences and relative changes of the properties is shown during the experiment (f). The normalized values account for the variability in the control group.

To compare the effects of stress on various retrieved properties and detect the order of grass responses during the experiment, we normalized the differences for each of the properties between the stressed and the control group. The normalized values account for the variability in the control group. The relative changes of the properties in early stages of the stress (Fig. 2.12f) demonstrate that the first effects of stress on the grass properties are the change of $C_{\mathrm{w}}$ and $C_{\mathrm{ab}}$, followed by $C_{\mathrm{dm}}$ and $C_{\mathrm{s}}$. These properties started responding to stress in the earlier stages of stress. $L A I$ and $C_{s}$ did not respond to the stress until 15 days after the start of the experiment. Almost all grass properties responded to the stress at the end of the experiment. The strongest response at the end of the experiment compared to the control group was the change of $C_{\mathrm{s}}$, followed by $C_{\mathrm{ab}}, C_{\mathrm{w}}, C_{\mathrm{dm}}$ and $L A I$, respectively. 


\subsection{Discussion}

We conducted a drought experiment to follow water stress impacts on grass reflectance and properties over time. This experiment lasted for 80 (35 $+36+9$ ) days. In the first 35 days, all plants were watered regularly until the canopy height was about $15 \mathrm{~cm}$ and the maximum growth reached. In the next 36 days, the canopy spectral measurements were collected in the stressed and control group. In addition, direct measurements of $L A I$ and $C_{a b}$ were taken during this period. In the last nine days, soil reflectance measurements under various moisture conditions were taken. After the experiment, all of the plants ultimately died except for the control group.

\subsubsection{Visual interpretation of the stress effects}

The visible signs of stress on the plants, including curling and shrinking of the leaves, becoming fragile, turning from shiny to dull and finally some leaves decoloring, were observed first after 10-11 days from the start of the drought. From day 19 onwards the proportion of dry leaves increased rapidly. The visible signs of stress were increasing by the time the moisture deficit progressed. This confirms other studies revealing similar results. For instance, De Jong et al reported the first visible sign of different stresses (water saturation, light deprivation, water deprivation, heat and chlorine poisoning) for Buxus sempervirens on average after 15 days for all stresses and after 13 days for water deprivation (De Jong et al., 2012). They also found that the analysis of the infrared photos collected during the stress did not provide additional information after the visual inspection of the plants. An interpretation of the canopy reflectance responses to soil moisture deficit revealed that the stress affected all parts of the spectrum. In particular, changes were detected in the $450-700 \mathrm{~nm}$ and $1300-2500 \mathrm{~nm}$ ranges (Figure 2.4 ), which can be explained by the role of the concentrations of pigments and water, respectively. These findings are in full agreement with Carter (Carter, 1991), Zarco-Tejada et al (Zarco-Tejada et al., 2003) and Chavez et al (Chávez et al., 2013), who demonstrated two effects of water stress on the reflectance spectra; direct (primary) effects and indirect (secondary) ones. "Direct effects" are the primary impacts of water stress (dehydration) on vegetation which resulted solely from the spectral properties of water (this gives changes of the reflectance in the range of 1300-2500 nm because of less absorption by water). The "indirect effects" are secondary impacts that could not be explained solely by the spectral properties of water (manifested by changes of the reflectance in the range of $400-700 \mathrm{~nm}$ because of more cell wall-air interfaces within the leaf tissue as well as the effect of dehydration on the concentrations of pigments). Canopy spectral reflectance in the NIR region (750-1300 nm) initially increased but, in later stages of water stress, it decreased. This pattern can be explained by the consequence of the deterioration of cell walls (Knipling, 1970), loss of leaves and the changes in 
LIDF (Asner, 1998). Our findings of NIR responses to water stress support previous studies (Chávez et al., 2013; Clevers et al., 2010; Hunt Jr and Rock, 1989).

\subsubsection{First sign of the stress}

The analysis of the collected spectra over time showed that the first considerable responses could be seen near the major water absorption bands especially at $1930 \mathrm{~nm}$ and $1440 \mathrm{~nm}$ (Figure 2.5b). In addition, distinct changes were detected around $550-700 \mathrm{~nm}$ with a peak value located at $675 \mathrm{~nm}$. We did not detect significant changes at the location of the minor water absorption bands at 970,1200, and $1770 \mathrm{~nm}$, which is in agreement with previous studies (De Jong et al., 2012). Based on Pearson's correlation analysis, the correlation of the stressed group started declining from day 4, thereby showing the first sign of the stress visible in the spectra. Pearson's correlation computation between the spectra proved a valuable way to detect subtle spectral changes and to identify the moment in time of the stress-induced spectral changes of the plant. The spectroscopic signs of stress were detectable 6 days before the visible signs. Thus the use of spectroscopic techniques allows a much earlier detection of plant stress than visible inspection.

\subsubsection{Water stress-related vegetation indices}

The vegetation indices that best illustrated the stress effects in the earlier stages in our experiment were the NDWI_1241 and RATIO1200. These two spectral indices, using the reflectance in NIR and SWIR around 857, 1241, $1180-1220,1090-1110,1265-1285 \mathrm{~nm}$, were the most sensitive ones among the examined indices. This is in agreement with Ceccato et al (Ceccato et al., 2001) who concluded that a combination of SWIR and NIR is necessary to improve the accuracy in estimating vegetation water content at the leaf level from optical observations. Our study showed that the response of the NDWI_1214 was ten times as strong for the stress group as for the control in the early stages of the stress. This index is a measure of liquid water molecules in vegetation canopies that interacted with the incoming solar radiation. This is in agreement with Gao (Gao, 1996) who demonstrated the sensitivity of NDWI to the total amounts of liquid water in stacked leaves. He explained the reasons of sensitivity of NDWI by the location of the selected channels, their negligible or weak absorption properties and less sensitivity to atmosphere effects, although atmospheric effects are not relevant in the present study. The spectral indices that best illustrated the development of water stress over time during the experiment were PRI_norm and CTR2. PRI_norm is normalized by both structure and by the red edge chlorophyll-related index. Zarco-Tejada et al (Zarco-Tejada et al., 2013) concluded that PRI_norm is a more linearly related index for reading canopy chlorophyll content levels than the standard PRI index, due to its good performance. CTR2 uses the wavelength 760 (NIR 
shoulder) in combination with a spectral band in the red edge at $695 \mathrm{~nm}$, which is sensitive to chlorophyll, to compute the index value. Our results match other studies which identified CTR2 as one of the best stress indicators (Carter and Miller, 1994; De Jong et al., 2012; Noomen et al., 2008).

\subsubsection{RTMo sensitivity analysis}

Local sensitivity analysis provided useful insights about the parameter changes' influences on the simulated reflectance. The results showed the ability of the RTMo model to link variations of reflectance to variations of grass properties. Small changes in $C_{w}$ resulted into strong responses in the SWIR part of the spectrum. The importance of $C_{w}$ in accounting for variance in the SWIR supports previous studies (Ceccato et al., 2002, 2001; Tucker, 1980). The variation in $C_{\mathrm{dm}}$ showed significant responses in the SWIR and NIR part. This is in agreement with other studies as well (Bowyer and Danson, 2004; Ceccato, 2002). The main cause of the strong response in the NIR part might be explained by the absorption of $C_{\mathrm{dm}}$ since it is the only absorber in most of the NIR region and tends to increase with the age of the leaf (Merzlyak et al., 2002). The response of reflectance to a small variation in $L A I$ and LIDF was detected at similar wavelengths in the NIR and SWIR. This is in agreement with other studies which reported similar effects of $L A I$ and LIDF in PROSAIL model sensitivity analysis (Jacquemoud et al., 2009). Reflectance in the green $(557 \mathrm{~nm})$ and red edge $(710 \mathrm{~nm})$ responded clearly to changes of $C_{\mathrm{ab}}$. This result confirms other studies explaining the relationship between reflectance and Cab (Daughtry, 2000).

\subsubsection{RTMo retrieval}

A physical approach was adopted in this research to retrieve grass properties from spectroradiometer measurements. This has many advantages, as it is based on physical laws, use of all spectral bands, the least reliance on in-situ measurements and it gives generalizable results, just to name a few (Atzberger et al., 2015, 2011). However, use of this approach (i.e., radiative transfer models) is more complex than a simple statistical method (i.e., vegetation indices). Several studies have demonstrated that vegetation properties retrieval using radiative transfer models yields more accurate results compared to that of vegetation indices. For instance, Atzberger et al compared physical and statistical-based retrieval methods to map grassland LAI using airborne imaging spectroscopy (Atzberger et al., 2015). They concluded that RTM inversion based on a look-up table approach and predictive equations yields a higher accuracy with a normalized RMSE of 0.18 and 0.38 respectively for $L A I$ estimation. In our experiment, although we inverted the RTMo model by means of an optimization algorithm, the results for $L A I$ retrieval are in good agreement with the findings of Atzberger et al. The calculated 
normalized RMSE for $L A I$ retrieval in our experiment is 0.18 (Table 2.5) which is in agreement with their studies (Atzberger et al., 2015).

Simulated spectra fitted well with measured spectra collected at different soil moisture deficit conditions during the drought experiment. Low RMSE between measured and simulated spectra (ranging from 0.002 to 0.009 ) for a variety of soil moisture conditions confirmed that the inversion was successful for all spectra collected in the entire episode. We conclude that there was a positive significant relationship between retrieved and measured properties. Nevertheless, the variation in properties, (i.e., the range of values) especially in $C_{a b}$, showed that retrieved values had a smaller range than the destructive measurements. This might be explained by two facts: (1) the RTMo model uses one $C_{a b}$ value for all leaves in the pot, but measurements taken from individual leaves are more variable; and (2) to convert the relative values of the measured chlorophyll by SPAD 502 into the absolute values we used a calibration curve from the literature (Markwell et al., 1995). Changes of $C_{w}$ and $C_{a b}$ were found as the first signs of stress on vegetation properties. Other researchers concluded that changes in canopy reflectance due to water stress were mostly explained by equivalent water thickness and LAI (Chávez et al., 2013). We found that all vegetation properties responded to stress at the end of the experiment. The strongest response at the end of the experiment compared to the control group was the change of $C_{\mathrm{s}}$, followed by $C_{\mathrm{ab}}, C_{\mathrm{w}}, C_{\mathrm{dm}}$ and $L A I$. Our experiment shows that soil moisture deficit stress impacts can be tracked in a drought episode over time using remote sensing methods. Spectroscopy is a valuable technique to detect stress effects on the reflectance spectra in an early stage.

\subsection{Conclusions}

In this study, we investigated in the laboratory the grass response to water stress in a Poa pratensis canopy exposed to various levels of soil moisture deficit. We used spectroscopic techniques, to observe the stress impacts on canopy reflectance, and radiative transfer model inversion, to detect stress effects on grass properties. These techniques have a promising potential of detecting the drought-induced effects on grass reflectance and properties during a drought episode. Sensitivity analysis of simulated reflectance to a small change of its input parameters shows that changes in $L A I, C_{w}$ and $C_{d m}$ trigger a stronger response in the reflectance compared to the other parameters. The RTMo inversion shows that $C_{\mathrm{w}}, C_{\mathrm{ab}}$ and $C_{\mathrm{dm}}$ respond strongly to short-term moisture-deficit stress, while $L A I$ and $C_{s}$ changes are the main responses of vegetation to long-term stress. Spectral measurements allow moisture stress detection up to six days earlier than visual naked-eye observations. The first spectral signs of stress are detectable near the major water absorption bands. Among grass properties, the first signs of moisture stress are changes of $C_{w}$ and $C_{a b}$. The most promising water stress-related 
vegetation indices for early stress detection are NDWI_1241 and RATIO1200 since their responses to the stress were significantly stronger in the early stages for the stressed group. In addition, for the entire drought episode, PRI_norm and CTR2 are identified as the best ones for stress detection. This research demonstrated that spectroscopic techniques and RTMo inversion allow presymptomatic monitoring (early detection) of changes in the canopy reflectance and biophysical properties non-destructively. Beyond the scale and plant species of this study, it is unclear how broadly applicable this approach will be and to what extent these findings could be generalized, since this would require applying the proposed approach in the "real world" using satellite observations. It is currently under investigation by the authors to upscale the results obtained in this study to field conditions. We expect that spectral analysis and the RTMo model inversion against satellite images would enable the detection of water stress impacts on vegetation properties in the ecosystem. 


\section{Chapter 3 Exploiting multispectral satellite radiance observations by coupling radiative transfer models}

\footnotetext{
* This chapter is based on:

Bayat, B., Van der Tol, C., Verhoef, W., 2018. Retrieval of Land Surface Properties from an Annual Time Series of Landsat TOA Radiances during a Drought Episode using Coupled Radiative Transfer Models. Remote Sensing of Environment, 2018, https://doi.org/10.1016/j.rse.2018.09.030.
}

Bayat, B., Verhoef, W., Van der Tol, C., 2017. MOD-PROSAIL: a Coupled Atmospherecanopy Radiative Transfer Model for the Retrieval of Vegetation Properties from Remote Sensing Observations with Application to Drought Effects Detection. The $5^{\text {th }}$ International Symposium on Recent Advances in Quantitative Remote Sensing RAQRS'V 2017, Valencia, Spain, 18-22 September 2017. 


\begin{abstract}
The accurate retrieval of land surface vegetation properties under varying environmental conditions from time series of moderately high spatial resolution satellite observations is challenging. By coupling various Radiative Transfer (RT) models one can describe the soil, vegetation and the atmosphere contributions in a "bottom-up" approach and, thereby, simulate top-ofatmosphere (TOA) spectral radiance data comparable to satellite-observed TOA radiances. This makes it possible to retrieve vegetation properties directly from TOA radiances rather than from atmospherically corrected top-of-canopy (TOC) reflectance data. The advantages of this approach are that a separate atmospheric correction of the satellite images is not necessary, and that the anisotropic surface reflection can also be taken into account effectively. In this study, we coupled various RT models, including the brightness - shape moisture (BSM) reflectance model of the soil, the optical radiative transfer (RTMo) model of vegetation and the 'MODerate resolution atmospheric TRANsmission' (MODTRAN) model of the atmosphere, to simulate an annual time series of Landsat satellite TOA radiances observed during a drought episode in California Mediterranean grasslands in 2004. The inversion of this coupled system through an optimization technique against Landsat TOA radiances resulted in direct retrieval of vegetation properties. We accommodated the surface anisotropic reflection in our coupled modeling and also defined a novel anisotropy index to quantitatively express the importance of this phenomenon in satellite image analysis for the first time. Our study showed that the coupled use of RT models was able to accurately reproduce the time series of observed TOA radiances collected under varying soil moisture contents during drought episode. The proposed coupling approach is useful for successful retrieval of vegetation properties from time series of satellite TOA radiance data to produce maps of land surface properties and monitor vegetation properties variations in an operational straightforward way. The approach can also be easily adapted for conducting multi-sensor time series studies, creating a much denser temporal sampling than would be possible for separate single sensors.
\end{abstract}




\subsection{Introduction}

Satellite time series observations, when combined in a quantitative modeling approach, can provide a unique opportunity for operational monitoring of land surface (i.e., vegetation) properties under various environmental and atmospheric conditions. There are mainly two quantitative data processing approaches which have been employed for translating satellite observations into vegetation properties information (as shown in Fig. 3.1). The first is to use vegetation indices (VIs) in a statistical approach (Ceccato, 2002; Chávez et al., 2013; Darvishzadeh et al., 2011; Houborg et al., 2007; ZarcoTejada et al., 2013) and the second is to use a vegetation radiative transfer (RT) model in a physical modeling approach (Bayat et al., 2016b, 2016a; Bicheron and Leroy, 1999; Clevers et al., 2010; Darvishzadeh et al., 2008; Dorigo et al., 2009; Duan et al., 2014; Houborg et al., 2007; Jacquemoud et al., 1995; Laurent et al., 2011a; Schaepman-Strub et al., 2006; Verhoef and Bach, 2007, 2003b; Zhang et al., 2005). VIs have the advantage that they can be applied very easily and that they can have a reasonable correlation with vegetation properties, such as leaf area index ( $L A I)$ and leaf chlorophyll content $\left(C_{a b}\right)$ (Darvishzadeh et al., 2011). However, VIs may be affected by several factors simultaneously, which implies that the explored relationships between VIs and surface properties are species and observation specific and thus cannot be applied universally. In addition, computation of VIs is based on employing only a few of the available bands. As a consequence, valuable pieces of information embedded in the other bands are ignored. The alternative of using physical vegetation RT models has the advantages that; (1) they offer explicit relationships between the whole spectrum and vegetation properties (Atzberger et al., 2011; Clevers et al., 2010), (2) often yield a more accurate estimation of vegetation properties compared to VIs (Le Maire et al., 2011) and, (3) produce more generalizable outputs while being less dependent on in situ measurements (Atzberger et al., 2011; Baret and Buis, 2008). Thus, using a canopy RT model, albeit more complicated, is considered a better way to explore satellite observations efficiently and retrieve vegetation properties more accurately.

Most vegetation RT models produce surface or top of canopy (TOC) reflectance, and are therefore suitable to retrieve vegetation properties from TOC observations (the 'TOC approach'). This approach has been applied in many studies successfully, resulting in the retrieval of vegetation properties with acceptable accuracy. However, satellite observations are originally recorded at the top of the atmosphere (TOA), so that still an atmospheric correction is required to obtain the TOC reflectance from the observed TOA radiances. Applying a reliable atmospheric correction to satellite observations to obtain the TOC reflectance, however, is still a challenging and cumbersome task (Laurent et al., 2011b), posing considerable limitations especially when the analysis of time series of images is desired. Further, the retrieval of 
vegetation properties might be subject to errors not only due to modeling uncertainty but also to errors in the computed TOC reflectance caused by inaccurate atmospheric correction assumptions. On the other hand, Level-2 surface reflectance products, which are already corrected atmospherically, are not commonly (or at least not freely) available for new sensors, and the fact remains that the quality of such products is still questionable since they are based on the assumption that both target and surroundings are Lambertian (isotropic) reflectors, which is inconsistent with what is known about the anisotropy in the reflectances of vegetation, bare soil and water bodies.

Since considerable limitations of the TOC approach are related to performing the atmospheric correction to convert TOA radiance to TOC reflectance, this appears to be unsuitable as a feasible and operational set-up for time series analysis. An alternative is to use the TOA radiance data directly for the retrieval (Verhoef et al., 2018; Verhoef and Bach, 2003a). This requires simulation of the surface - atmosphere system by coupling a set of physical RT models describing various objects from soil, to leaf, canopy, and to the atmosphere. Such a coupling approach has the crucial advantage that one can also take the anisotropic surface reflection into account in the forward RT modeling. This is important due to the fact that the majority of vegetation canopies are clearly non-Lambertian (Verhoef et al., 2018). Therefore, the forward modeling of this coupled RT system will produce more accurate TOA radiance results. Further, since the coupled system produces the TOA radiance, which is indeed the same physical quantity as observed by the satellite sensors, justice is done to the actual physics of the observations. By including specific information about particular satellite sensors (e.g., spectral bands, spectral response function, spectral resolution) in the modeling, the simulated TOA radiance data are directly comparable to the ones observed by the satellite sensor (Verhoef and Bach, 2003b). Thus, by the coupled use of an atmospheric RT with a vegetation RT and a soil reflectance model, one may simulate TOA radiance and retrieve land surface properties directly by inversion of such a coupled model (Verhoef et al., 2018). 


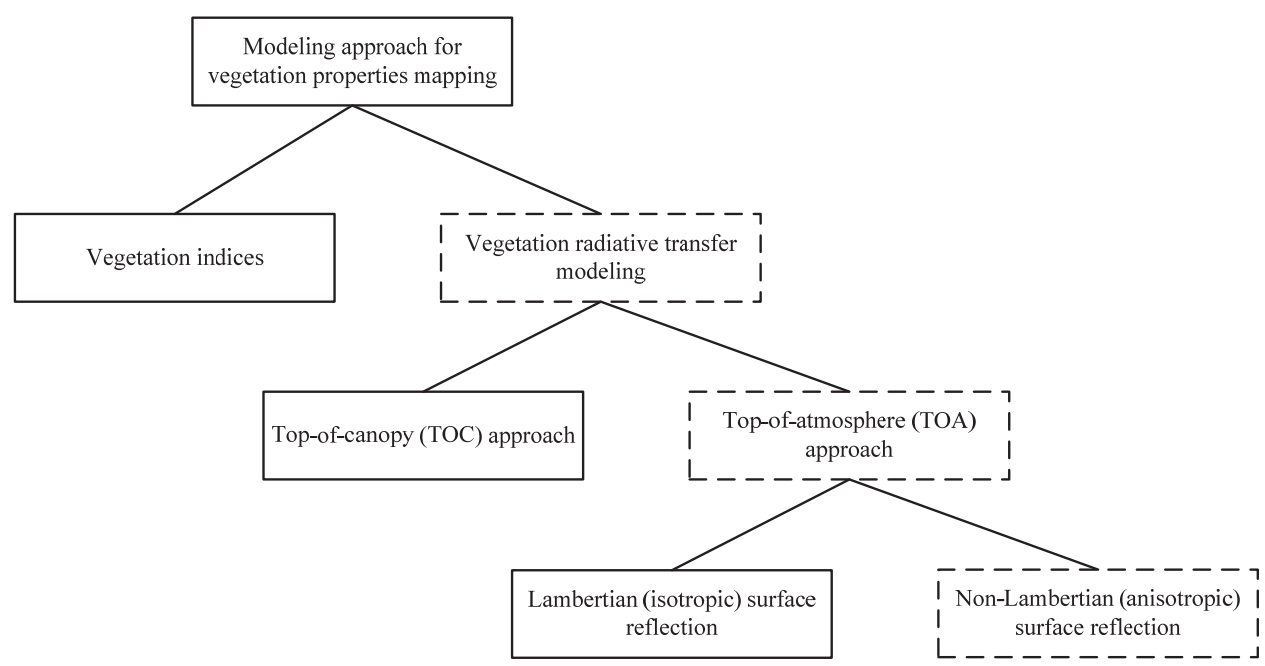

Figure 3.1. Quantitative modeling approach for mapping spatio-temporal variations of vegetation properties. The hatched boxes represent the approach adapted in this study.

Several efforts have been made towards accomplishing such a coupling approach to simulate TOA radiance images for different sensors (Börner et al., 2001; Faurtyot and Baret, 1997; Gastellu-Etchegorry et al., 2004; Laurent et al., 2011b, 2011a; Rahman et al., 1993; Verhoef et al., 2018; Verhoef and Bach, 2012, 2007, 2003b). Among them, Verhoef and Bach (2003b) coupled a leaf model (PROSPECT), a canopy two-layer model (GeoSAIL) and the MODerate resolution atmospheric TRANsmission (MODTRAN) model to simulate hyperspectral and directional radiance images over vegetated areas and bare fields (Verhoef and Bach, 2003b). Similarly, Verhoef and Bach (2007) coupled the soil-leaf-canopy (SLC) model to MODTRAN4 in order to simulate the hyperspectral multi-angular surface reflectance and TOA radiance for the multi-angular CHRIS sensor (Verhoef and Bach, 2007). They compared the simulated surface reflectances with the ones observed with the CHRIS sensor for soil, maize, dense and less dense forest pixels, and concluded that spectraldirectional observations of CHRIS could be reproduced by the SLC model with good accuracy. Furthermore, Verhoef and Bach (2012) coupled the models SLC (for modeling soil and vegetated pixels), WASI (for modeling inland water pixels) and MODTRAN4 (for modeling atmospheric effects) to simulate TOA radiance spectra of Sentinel-3 observations (Verhoef and Bach, 2012). A similar combination of SLC and MODTRAN was inverted against CHRIS multiangular TOA radiances on three Norway spruce stands (Czech Republic) to retrieve forest variables in 2006 (Laurent et al., 2011a). Most recently, Verhoef et al (2018) used a novel set of coupled RT models of the soil (brightness shape - moisture (BSM) model), canopy (the Soil-Canopy Observation Photosynthesis and Energy fluxes (SCOPE) model) and atmosphere (MODTRAN model) to simulate TOA radiance data of several optical sensors of the 
Fluorescence Explorer (FLEX)/ Sentinel-3 (S3) tandem mission (Verhoef et al., 2018). They concluded that one can retrieve surface fluorescence and vegetation biophysical properties simultaneously and with remarkable accuracy from TOA radiance data.

The main focus of the described studies was to chain different RT models to simulate the TOA directional radiance of an image at a specific time (as a snapshot) and, therefore, (1) the background soil reflectance contribution was considered relatively stable, and did not vary due to the fact that soil properties (e.g., soil moisture content) were fixed, (2) the input parameters of the vegetation RT models were obtained either from a land cover map plus ground measurements at the desired time (day), or by running RT models in forward mode and making a database of reflectance, (3) the atmospheric properties (e.g., visibility, water vapor and aerosol models) did not vary much because of the relatively stable atmospheric conditions over a short period (one day) and (4) the radiance of an airborne hyperspectral image or future planned satellite mission could be simulated. Therefore, in the majority of the previous studies, the coupled models were applied to simulate a specific satellite or airborne hyperspectral image for a single flight path. However, the potential of such a coupled model for wider and operational applications is still unexplored and has not been dealt with in depth. Monitoring the effects of soil moisture deficit on vegetation properties during a prolonged drought episode, for example, requires time series of high spatial resolution observations over a relatively long period. In this situation, not only environmental (soil and vegetation properties) but also atmospheric conditions [visibility (Vis) and aerosol models (Aer)] may vary day by day, which consequently stresses the need to consider soil, vegetation, and atmospheric variations, sufficiently. In other words, there is still an interest in exploring this TOA coupling approach for analyzing time series of available satellite observations, acquired during a longer episode in which the soil, vegetation, and atmospheric properties are all changing. The current study is focused particularly on this aspect.

We examine the ability of coupled RT models to capture changes in the soil-vegetation-atmosphere system over time to produce accurate and consistent results during a longer episode. Furthermore, we intend to investigate the importance of taking surface anisotropic reflection into account since more recent evidence (Verhoef et al., 2018) demonstrates the importance of non-Lambertian surface reflection. In this context, not only have we considered surface anisotropic reflection in our coupled model, but we also defined a novel anisotropy index to express the importance of this phenomenon. We incorporate this anisotropy effect in time series image analysis quantitatively applied to satellite data for the first time. The combination of RT models we used to describe the soil - vegetation atmosphere system in a bottom-up approach, comprises the BSM soil reflectance model, the vegetation optical radiative transfer (RTMo) model of the SCOPE and the MODTRAN version 5.2.1 atmospheric RT model. The canopy 
RT model produces four anisotropic surface reflectance factors, and the sensor's spectral sampling is incorporated in the forward RT modeling as well. The best match obtained between simulated TOA radiances and satelliteobserved TOA radiances resulted in the direct retrieval of vegetation properties [notably $L A I, C_{\mathrm{ab}}$, leaf water content $\left(C_{\mathrm{w}}\right)$, leaf dry matter content $\left(C_{\mathrm{dm}}\right)$, the senescent material content $\left(C_{s}\right)$ and the leaf inclination distribution function $(L I D F)$ ] by model inversion through optimization. We applied this approach to a time series of twenty-four Landsat (TM5 and ETM7) observations acquired during a prolonged drought episode in California Mediterranean grasslands in 2004 to map spatio-temporal variations of vegetation properties and explore the trend of retrieved properties during this episode.

\subsection{Data}

\subsubsection{Site description}

The study focused on the Vaira Ranch (US-Var) Fluxnet site (Fig. 3.2), hereafter called Vaira site, in the United States of America (Baldocchi et al., 2004; Ma et al., 2011; Xu and Baldocchi, 2004), which is an open grassland, in a Mediterranean climate at $129 \mathrm{~m}$ altitude near the foothills of the Sierra Nevada mountain range in California $\left(38.4133^{\circ} \mathrm{N} ; 120.9508^{\circ} \mathrm{W}\right)$.

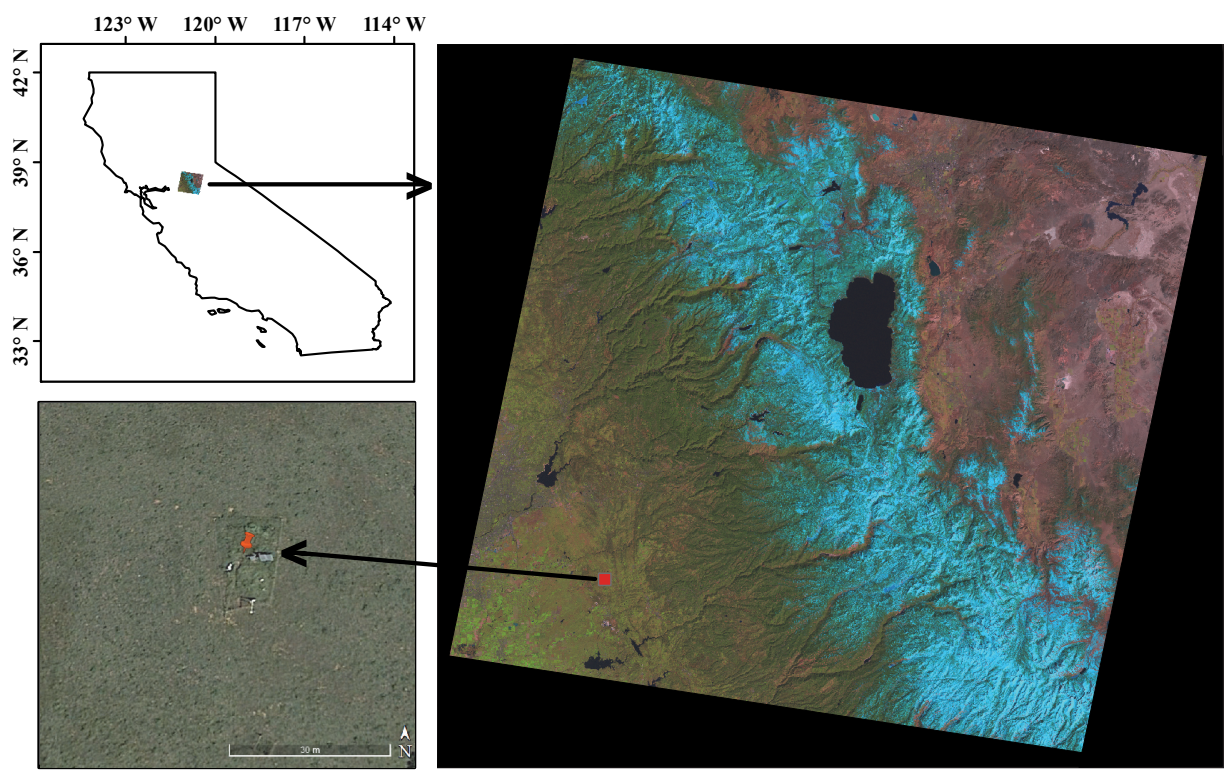

Figure 3.2. Study site (Vaira Ranch, in California) representing the footprint of Landsat images (WRS-2 path/row: 043/033). The Landsat image acquired on 15 March 2004 (color composite of red $=$ band 5 , green $=$ band 4 and blue $=$ band 3 ) is shown in the right panel in which the Vaira site location is indicated by a red square. The Vaira site and its surroundings, exported from the Google Earth images, is also shown in the bottom left panel. 
The mean annual temperature and precipitation in the region are $16.6^{\circ} \mathrm{C}$ and $559 \mathrm{~mm}$, respectively. A prolonged drought occurred at the site in 2004, and it was reported as one of the driest years there (Ma et al., 2007). The soil moisture content declined 10 -fold from 0.3 to $0.03 \mathrm{~m}^{3} \mathrm{~m}^{-3}$ during a period of 220 days (Fig. 3.3). Further, The NOAA's National Centers for Environmental Information (NCEI) reported variations from 0.44 to 3.25 for the Palmer Drought Severity Index (PDSI) at the Vaira site in 2004 (www.ncdc.noaa.gov/temp-and-precip/drought/historical-palmers). PDSI values suggest near-normal conditions at the site from the first of January (DOY 1) until the end of February (DOY 60), while drought levels with increasingly higher severity, i.e., mild, moderate and severe, were recorded from the first of March (DOY 61) till the end of August (DOY 220), as shown in Fig. 3.3.

\subsubsection{Vegetation characteristics at the site}

The land cover of the Vaira site is cool-season C3 (corresponding to the 3carbon photosynthetic pathways) grass with the dominant species of Brachypodium distachyon, Erodium cicutarium, Bromus hordeaceous, Hypochaeris glabra, Trifolium dubium Sibth, Trifolium hirtum, Erodium botrys and Dichelostemma volubile (Xu and Baldocchi, 2004). The grass species composition might vary slightly from one year to another based on the climatic conditions (i.e., precipitation and temperature) of the area (Heady, 1958; Jackson, 1985; Pitt and Heady, 1978). The grassland is physiologically functioning from the autumn (e.g., November) to the next spring (e.g., May), with the peak growth period in late February to early April. In this period, the Vaira site contains multiple species belonging to various functional groups (i.e., grasses, forbs and nitrogen fixers) (McNaughton, 1968) which make up a closed canopy (Baldocchi et al., 2004). The average height of the grass during the season was recorded as $0.3 \mathrm{~m}$ from 2001 to 2004, while, the maximum grass height may reach $0.55 \pm 0.12 \mathrm{~m}$.

\subsubsection{Remote sensing observations}

Twenty Landsat TM5 and four Landsat ETM7 observations (WRS-2 path/row: 043/033), hereafter all termed Landsat, were selected such that a soil moisture deficit episode was covered (Fig. 3.3). The cloud-free Landsat data used in this study were standard L1T products in DN format obtained from the US Geological Survey (USGS) website (https://glovis.usgs.gov/). 


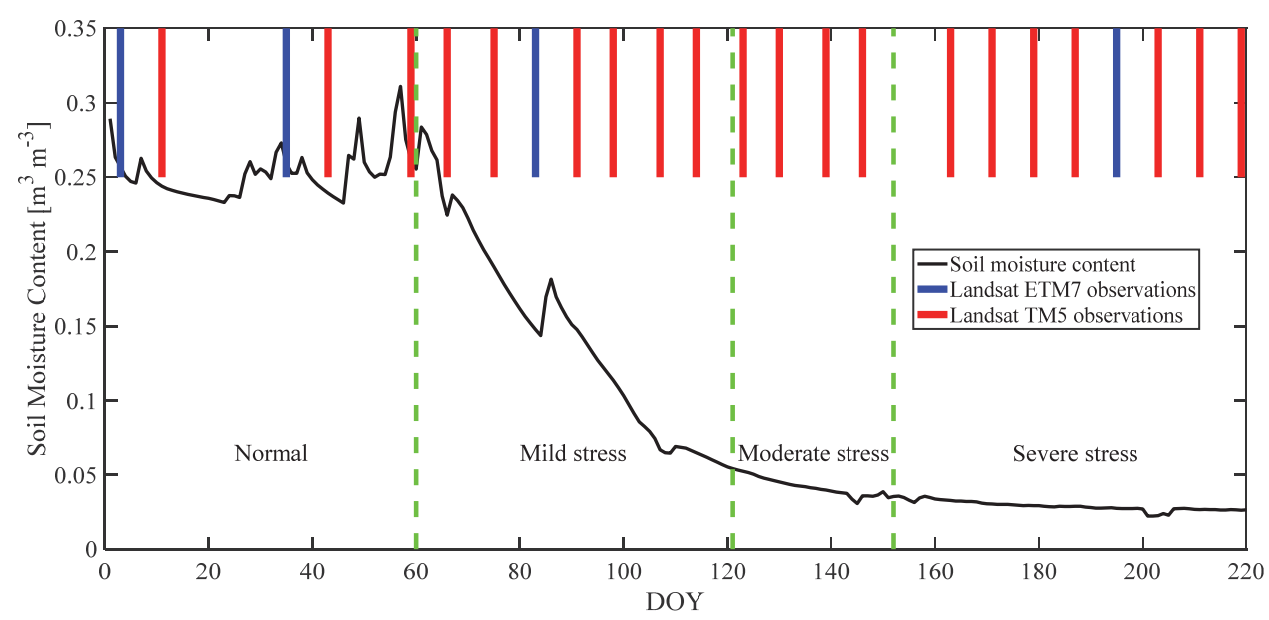

Figure 3.3. Satellite overpass during the soil moisture deficit episode. Landsat TM5 (thick red lines from top) and Landsat ETM7 (thick blue lines from top) observations covering a soil moisture deficit (black curve) episode at the Vaira site. The episode is divided into four periods (separated by dotted green lines) indicating normal, mild stress, moderate stress, and severe stress conditions. These periods within the time series are based on the Palmer Drought Severity Index (PDSI) data set published by NOAA's National Centers for Environmental Information (NCEI).

\subsubsection{Ground measurements}

\subsubsection{Soil moisture measurements}

Volumetric soil moisture (SM) was measured at the site with a frequencydomain reflectometer probe (ML2x, Delta-T Devices, Burwell, Cambridge, UK) at 2,10 and $20 \mathrm{~cm}$ depths. These sensors were automatically sampled by data loggers (CR10X or CR23, Campbell Scientific, Inc., Logan, Utah, USA) every 10 seconds, and their half-hour averages were recorded. In this study, we used time series of soil moisture content measured at $2 \mathrm{~cm}$ depth.

\subsubsection{LAl measurements}

LAI was measured destructively with intervals of $2-3$ weeks during this drought episode. Grass was collected from three sample plots $(0.2 \mathrm{~m} \times 0.2 \mathrm{~m})$ in the prevailing direction of the eddy covariance flux system. All grass leaves were separated from the stem and litter components, and the green areas were measured by running through a leaf area meter (Li-Cor 3100, Lincoln, NE, USA) (Ma et al., 2017).

\subsection{Methods}

Fig. 3.4 shows schematically how various RT models were coupled in order to retrieve and map vegetation properties during this drought episode from Landsat TOA radiance data. There were four main steps in our study. First, we 
made use of MODTRAN to obtain the best fitting atmospheric properties over a lake nearby the study site. This resulted in finding the best visibility and aerosol model for various conditions by means of a look-up table (LUT). Second, we ran MODTRAN with the retrieved best fitting properties of the atmosphere beside the other needed inputs one more time to generate the time series of atmospheric transfer functions (for all overpass days). In parallel and as the third step, we used the BSM model to scale the dry soil spectrum using measured soil moisture contents during the episode in order to obtain realistic soil reflectance spectra over time. This scaled soil reflectance was used as an input besides the other needed ones to RTMo to generate surface reflectance factors. Fourth, we coupled the MODTRAN generated atmospheric transfer functions with the RTMo generated surface reflectance factors to simulate Landsat TOA radiances during the episode. This assisted in mapping vegetation properties through model inversion by means of numerical optimization. We explain all the applied models with sufficient details including the needed input values in the following sections. 


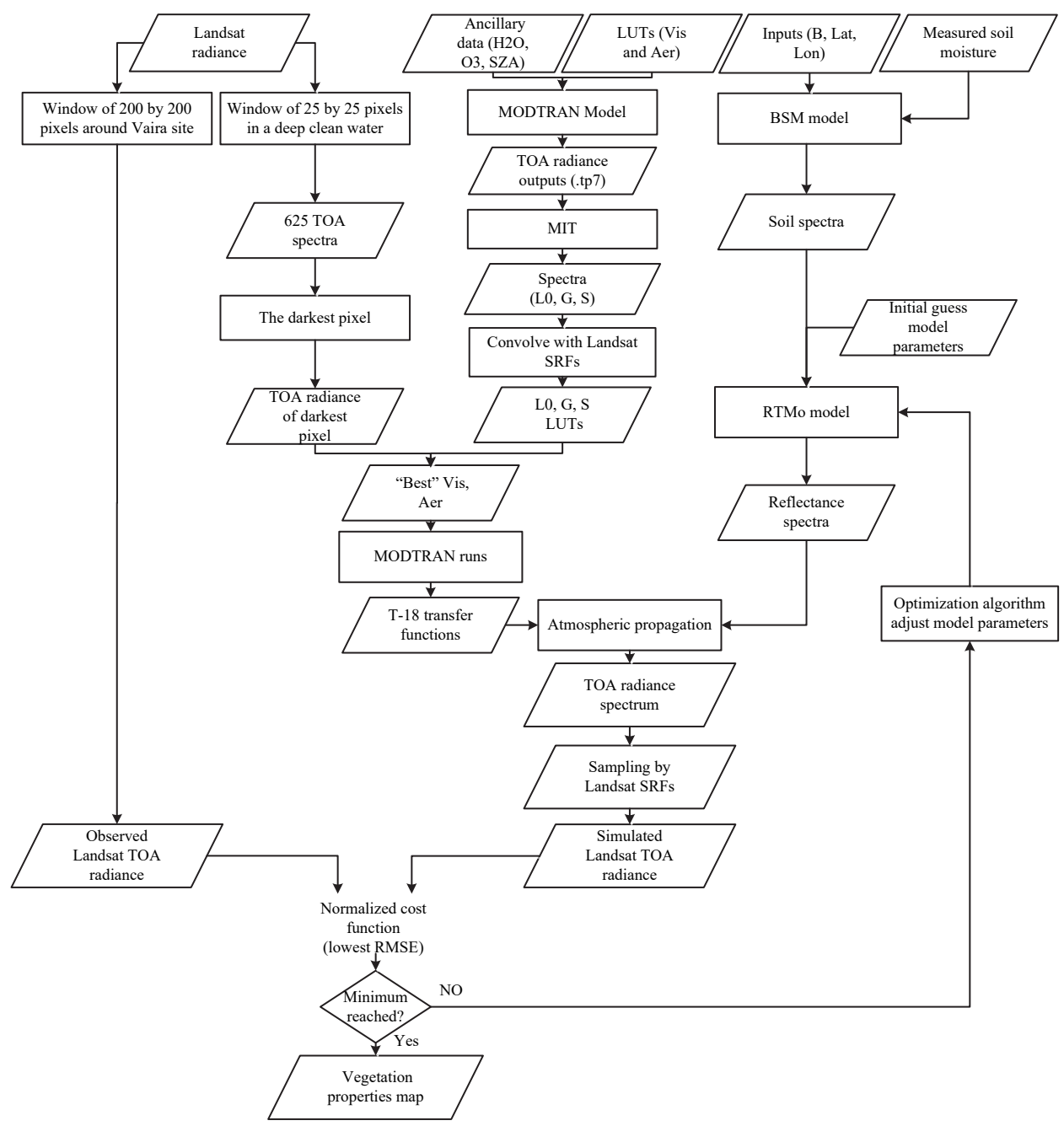

Figure 3.4. Flowchart of the TOA approach used in this study to show how various RT models were coupled to retrieve and map vegetation properties during the drought episode from Landsat TOA radiance data

\subsubsection{Radiative transfer models}

\subsubsection{MODTRAN model}

MODTRAN is an atmospheric RT model and the successor of the LOWTRAN model (Kneizys et al., 1988). MODTRAN includes a detailed spectral database of solar irradiance plus the absorption of all important atmospheric gases at a fine spectral resolution (Verhoef and Bach, 2003b). In our study, we used MODTRAN version 5.1.2 (Berk et al., 2008). To run MODTRAN, several input parameters describing the real atmospheric and sensor geometric conditions should be prepared (Table 3.1). In this study we used MODTRAN mainly for 
two purposes: first to construct a Look up Table (LUT) by varying the aerosol types ( 3 cases as rural, maritime and urban) and visibility ( 5 to $100 \mathrm{~km}$ with a step of $5 \mathrm{~km}$ ) for all days (Table 3.1) to compute surface reflectance over a water body. For every Landsat image a separate input file was prepared by adjusting the local atmospheric conditions, geometric variables and a LUT containing 60 scenarios for various visibility and aerosol models for that specific run of MODTRAN. This resulted in obtaining the best combinations of visibility and aerosol model for all days during this drought episode. Second, we executed MODTRAN for each day separately by preparing an input file including the best visibility and aerosol model (obtained in the previous step) with two runs at the bottom of atmosphere for albedo values of 0.5 and 1 , and two runs at TOA for albedo values of 0 and 1 . This resulted in obtaining the socalled T-18 atmospheric transfer functions (Verhoef et al., 2018), using the latest version of the MODTRAN Interrogation Technique (MIT) (Verhoef and Bach, 2012) to convert reflectance factors simulated by the RTMo canopy model to TOA radiances. We obtained one set of T-18 transfer functions for each day and $24 \mathrm{~T}-18$ files in total during the episode. Table 3.1 presents the most important inputs used for such MODTRAN runs.

Table 3.1. Input parameters used to construct separate LUTs in this study for MODTRAN 5 simulations

\begin{tabular}{|c|c|c|c|}
\hline Parameter & Unit & Value/Range & $\begin{array}{l}\text { Parameter } \\
\text { Status }\end{array}$ \\
\hline Aerosol Model & - & $\begin{array}{l}\text { Rural, Maritime, } \\
\text { Urban }\end{array}$ & $\begin{array}{l}\text { Varied (per } \\
\text { image) }\end{array}$ \\
\hline Visibility & $\mathrm{km}$ & $\begin{array}{l}5-100(5 \mathrm{~km} \\
\text { increment) }\end{array}$ & $\begin{array}{l}\text { Varied (per } \\
\text { image) }\end{array}$ \\
\hline Atmospheric profile & - & $\begin{array}{l}\text { Mid Latitude } \\
\text { Summer }\end{array}$ & Fixed \\
\hline $\begin{array}{l}\text { DISORT number of } \\
\text { streams }\end{array}$ & - & 8 & Fixed \\
\hline Concentration of $\mathrm{CO}_{2}$ & $\mathrm{ppm}$ & 390 & Fixed \\
\hline water vapor column & $\mathrm{cm}^{-2}$ & Appendix A. & Fixed \\
\hline ozone & DU & Appendix A. & Fixed \\
\hline sun zenith angle & ee $e^{\text {degr }}$ & Appendix A. & Fixed \\
\hline sun azimuth angle & ee $e^{\text {degr }}$ & Appendix A. & Fixed \\
\hline Surface height & m & 129 & Fixed \\
\hline Sensor Height & $\mathrm{km}$ & 705 & Fixed \\
\hline $\begin{array}{l}\text { Molecular band model } \\
\text { resolution }\end{array}$ & $\mathrm{cm}^{-1}$ & 1 & Fixed \\
\hline Start, ending wavelength & $\mathrm{nm}$ & $\begin{array}{l}400-2400 \\
\text { (optical) }\end{array}$ & Fixed \\
\hline
\end{tabular}

The atmospheric water vapor column $\left(\mathrm{H}_{2} \mathrm{O}\right)$ data were obtained from the NASA Giovanni platform (http://giovanni.sci.gsfc.nasa.gov/), the ozone $\left(\mathrm{O}_{3}\right)$ data obtained from NASA ozone products 
(https://ozoneaq.gsfc.nasa.gov/data/ozone/). Geometric variables (i.e., sun zenith angle [SZA] and sun azimuth angle [SAA]) are extracted from satellite image metadata. It is shown that the difference between calculated geometric variables at the Vaira site (representing a pixel) and those extracted from the image metadata (representing the whole image) was quite small for a specific day at the time of satellite overpass (see Appendix A).

In the first phase of the MODTRAN simulations, to obtain the best visibility and aerosol model above a lake, the MIT was applied for each scenario by using surface albedo values of 0.0, 0.5 and 1.0 (Verhoef and Bach, 2003b). The MODTRAN .tp7 output file can be used in the MIT to derive three relevant MODTRAN parameters [i.e., path radiance $\left(L_{0}\right)$, gain factor $(G)$ and spherical albedo $(S)$ ]. These three parameters are spectrally variable and changing with atmospheric conditions (Verhoef and Bach, 2003b). The spectral response functions (SRFs) of the Landsat bands were convolved with spectra of the MODTRAN parameters to compute the mean path radiance, gain factor and spherical albedo for every Landsat band in the optical domain.

To collect path radiance, gain factor, and spherical albedo, we need mainly two outputs of the MODTRAN .tp7 file. These are called "SOL_SCAT" (the solar multiple-scattered radiance term of the path radiance) and "GRND_ RFLT" (the total ground reflected radiance).

After obtaining $G, L$, and $S$ for all cases in the LUT, we employed deep water bodies present in the study area and computed water reflectances (at bottom of atmosphere) for all cases in the LUT as follows (Berk et al., 2008; Verhoef and Bach, 2012):

$$
R=\frac{L^{\mathrm{TOAm}}-L_{0}}{G+S\left(L^{\mathrm{TOAm}}-L_{0}\right)}
$$

where $R$ is the water reflectance, $L^{\text {TOAm }}$ is the TOA radiance $\left(\mathrm{Wm}^{-2} \mathrm{sr}^{-1}\right.$ $\mu \mathrm{m}^{-1}$ ) observed by the sensor for the darkest pixel in a window of 25 by 25 pixels extracted from the deepest part of the clear water of the biggest nearby lake, located in the south part of the image and with a distance of about 25 $\mathrm{km}$ from the Vaira site.

We retrieved the best atmospheric properties $\left(L_{0}, G\right.$ and $\left.S\right)$ and, therefore, obtained the corresponding visibility and aerosol model, by selecting the path radiance which gave a reflectance closest to zero from the LUT, since we assumed that the reflectance of clear water is negligible in all visible bands.

To collect the T-18 atmospheric functions, we need seven outputs of the MODTRAN .tp7 file called "TOT_TRANS" (total transmittance), "PTH_THRML" (thermal emission), "SURF_EMIS" (surface emission directly transmitted to the sensor), "SOL_SCAT" (the solar multiple-scattered radiance term of the path radiance), "GRND_RFLT" (the total ground reflected radiance), "DRCT_RFLT" (the direct solar contribution) and "TOASUN" (top-of-the-atmosphere solar 
irradiance). The white reference solar radiance spectrum at TOA is placed in $T_{1}$, while $T_{2}-T_{14}$ describe the optical transfer functions of the atmosphere and $\mathrm{T}_{15}-\mathrm{T}_{18}$ describe four thermal transfer functions of the atmosphere. In our study, we used $T_{1}-T_{14}$ in order to reproduce the TOA radiances from RTMo simulated TOC reflectance factors considering the anisotropic surface reflection. More details about using these transfer functions are provided in the next section.

\subsubsection{RTMo model}

The optical radiative transfer routine (RTMo), taken from the SCOPE model (Van der Tol et al., 2009b), is basically a combination of the PROSPECT5 leaf model (Jacquemoud and Baret, 1990) and the 4SAIL canopy reflectance model (Verhoef et al., 2007; Verhoef, 1984, 1985). Table 3.2 shows the input parameters of the RTMo model.

Table 3.2. Input parameters needed for the RTMo model.

\begin{tabular}{|c|c|c|}
\hline Parameters & $\begin{array}{l}\text { Abbr. in } \\
\text { model }\end{array}$ & Unit \\
\hline Leaf chlorophyll content & $C_{a b}$ & $\mu \mathrm{g} \mathrm{cm}{ }^{-2}$ \\
\hline Leaf water content & $C_{\mathrm{w}}$ & $\mathrm{g} \mathrm{cm}^{-2}$ \\
\hline Leaf dry matter content & $C_{\mathrm{dm}}$ & $\mathrm{g} \mathrm{cm}^{-2}$ \\
\hline Senescent material & $C_{\mathrm{s}}$ & - \\
\hline Leaf area index & $L A I$ & $m^{2} m^{-2}$ \\
\hline Leaf inclination distribution function ${ }^{a}$ & $L I D F_{\mathrm{a}}$ & - \\
\hline Bimodality of the leaf inclination ${ }^{b}$ & $L I D F_{\mathrm{b}}$ & - \\
\hline Carotenoids & $C_{\mathrm{ca}}$ & $\mu \mathrm{g} \mathrm{cm}^{-2}$ \\
\hline Leaf structural parameter & $N$ & - \\
\hline Hot-spot size parameter ${ }^{c}$ & hot & $\mathrm{m} \mathrm{m}^{-1}$ \\
\hline Solar zenith angle & $\theta_{\mathrm{s}}$ & deg \\
\hline Observation zenith angle & $\theta_{0}$ & deg \\
\hline Relative Azimuth Angle & $\psi$ & deg \\
\hline Spectra of solar irradiance & $E_{\text {sun }}$ & $W m^{-2} \mu m^{-1}$ \\
\hline Spectra of sky irradiance & $E_{\text {sky }}$ & $W m^{-2} \mu m^{-1}$ \\
\hline \multicolumn{3}{|c|}{$\begin{array}{l}\text { a,b These two parameters of the LIDF (i.e., LIDFa and LIDFb) are utilized to describe the } \\
\text { (cumulative) probability distribution function of leaf inclination angles mathematically } \\
\text { (Verhoef, 1998). LIDFa describes the average leaf inclination, where a value of } 1 \text { indicates } \\
\text { the erectophile (mean leaf angle MLA of } 81.48^{\circ} \text { ) and a value of }+1 \text { indicates the planophile } \\
\left(M L A=8.52^{\circ} \text { ) distribution, while LIDFb describes the bimodality of the distribution, and is }\right. \\
\text { proportional to the standard deviation of the distribution. } \\
\text { c This parameter is approximated as the ratio between the average width of the leaves and the } \\
\text { canopy height (Verhoef and Bach, 2007) }\end{array}$} \\
\hline
\end{tabular}


The anisotropic reflectance factors generated by the RTMo model are coupled with the T-18 atmospheric functions generated by MODTRAN to obtain the TOA radiance as follows:

$$
L^{\mathrm{TOAs}}=T_{1}\left[T_{2}+T_{8} r_{s o}+\frac{\left(T_{9}+T_{14} \overline{r_{s d}}\right) r_{d o}+T_{10} \overline{r_{s d}}+T_{11} \overline{r_{d d}}}{1-\overline{r_{d d}} T_{3}}\right]
$$

where $r_{s o}$ is the directional reflectance factor for direct solar incidence (or the bi-directional reflectance factor, BRF), $r_{\mathrm{do}}$ is the directional reflectance factor for diffuse incidence, $r_{\mathrm{sd}}$ is the hemispherical reflectance factor for direct solar incidence and $r_{\text {dd }}$ is hemispherical reflectance factor for diffuse incidence, all simulated by the RTMo model.

The $T_{i}$ are components of the $T-18$ atmospheric transfer functions derived from the MODTRAN5 .tp7 output file using the MIT technique: one of the most important ones, $\mathrm{T}_{1}$ describes the extraterrestrial solar irradiance $\left(\mathrm{Wm}^{-2} \mathrm{sr}^{-1}\right.$ $\left.\mu \mathrm{m}^{-1}\right), \mathrm{T}_{2}$ the bidirectional atmospheric reflectance at the top of the atmosphere (for a black earth surface) and $T_{3}$ the bi-hemispherical reflectance at the bottom of the atmosphere (spherical albedo). For more details on these atmospheric transfer functions, the reader is referred to Table 3.3 in (Verhoef et al., 2018). The over bars in Eq. 3.2 indicate a spatial filtering over the surrounding areas of the target pixel (about $1 \mathrm{~km}$ radius, with a kernel that is strongly peaked in the center) to describe the adjacency effect. In this study, we ignored the over bars and used the output of RTMo ( $r_{\mathrm{sd}}$ and $r_{\mathrm{dd}}$ ) directly since we assumed that the Landsat pixel was taken from a relatively homogeneous area.

To quantify the surface anisotropy effect and demonstrate its importance, we proposed and computed a novel simple index for the first time, called Anisotropy Index (AI). This index, which is based on the RTMo simulated reflectance factors, is defined as:

$$
A I=\frac{r_{s o}-\frac{\left(r_{d o}+r_{d d}+r_{s d}\right)}{3}}{r_{s o}+\frac{\left(r_{d o}+r_{d d}+r_{s d}\right)}{3}}
$$

The index works similar to a normalized vegetation index (difference over sum), and it can be computed for all wavelengths. It should be noted that the second terms in Eq. 3.3 compute the average of three reflectance factors. In this study, we computed the AI from $400-2400 \mathrm{~nm}$. In case of a Lambertian surface, the anisotropy index would be zero at all wavelengths, since all four reflectance factors are equal for a Lambertian surface. However, if the surface is non-Lambertian, which is usually the case for vegetation canopies, then the 
reflectance factors are not equal anymore and, therefore, the anisotropy index would not be zero. Due to the fact that most canopies are non-Lambertian, it is crucial to differentiate among these four reflectance factors and consider the anisotropy effect in the RT modeling.

\subsubsection{BSM model}

To consider the effects of the soil background on the simulated spectra, we incorporated the BSM soil reflectance model. The BSM model is based on the library of global soil vectors (GSV) proposed by (Chongya and Hongliang, 2012), extended with a brightness-shape transformation and a soil moisture effect to describe soil spectra. The model contains the following parameters: (1) the soil brightness parameter, $B$ (dimensionless); (2) the spectral shape "latitude", Lat (deg); (3) the spectral shape "longitude", Lon (deg); and (4) the soil's moisture volume percentage, SMp (\%). This model can be used as an alternative for providing a measured soil's spectrum as input. However, if the dry soil reflectance is available, which was the case in our study, one can invert the BSM model and derive the BSM parameters ( $B$, Lat and Lon) from the given soil reflectance spectrum. In the BSM model, one can also scale the dry soil spectrum by the measured soil moisture value and produce realistic soil reflectance spectra for wet soils up to $55 \%$ soil moisture content in the top soil layer. For more details on the BSM model, the reader is referred to (Verhoef et al., 2018).

\subsubsection{Parameter retrieval from TOA radiance spectra}

\subsubsection{An overview of the algorithm}

The observed TOA radiance by Landsat can be compared to the simulated TOA spectra by the coupled RT model. We used Numerical Optimization (NO) to invert the coupled model, similar to (Bayat et al., 2016a; Van der Tol et al., 2016; Verhoef et al., 2018), against the time series of Landsat-observed TOA radiance and, consequently, to retrieve one set of vegetation properties separately for each of the observation days during the episode. We ran the model in MATLAB iteratively, with specific vegetation properties (see Table 3.3) in order to minimize a normalized cost function $C$ as:

$$
C=\sum_{i=1}^{N b a n d s}\left(\frac{L_{i}^{\mathrm{TOAm}}-L_{i}^{\mathrm{TOAs}}}{\sigma_{i}}\right)^{2}+\sum_{j=1}^{N p a r}\left(\frac{p_{j}-\mu_{j}}{\sigma_{p_{0} j}}\right)^{2}
$$

where $\mathrm{L}^{\text {TOAm }}$ is the Landsat-observed TOA radiance $\left(\mathrm{Wm}^{-2} \mathrm{sr}^{-1} \mu \mathrm{m}^{-1}\right)$, the $\mathrm{L}^{\text {TOAs }}$ is the model simulated TOA radiance $\left(\mathrm{Wm}^{-2} \mathrm{sr}^{-1} \mu \mathrm{m}^{-1}\right)$, the $\sigma$ is uncertainty (i.e., standard deviation) of the observed TOA radiance (see section 3.2.4), $i$ indicates the Landsat optical band number (ranges from 1 to 
$6)$, the $p$ are the current and $\mu$ are the priori values of the vegetation properties, the $\sigma_{\mathrm{po}}$ is the assumed uncertainty of the a priori values of each property (see section 3.2.3) and the $j$ indicates the 7 retrieved parameters (Table 3.3).

We made use of the MATLAB built-in function "Isqnonlin" from the optimization toolbox, selecting a Trust Region algorithm in order to update the values of properties after each iteration step. The stopping criterion for the iteration was fulfilled when the improvement of the cost function was less than $10^{-3}$, similar to (Van der Tol et al., 2016; Vilfan et al., 2016). The starting values, also called the initial guess (IG), the a priori values $(\mu)$ and their uncertainties $\left(\sigma_{\mathrm{p}}\right)$ of the input parameters for the retrieval algorithm are presented in Table 3.3.

Table 3.3. Tuned vegetation properties, their lower boundaries (LB), upper boundaries $(\mathrm{UB})$, initial guess (IG), a priori values $(\mu)$ and assumed standard deviation $\left(\sigma_{\mathrm{p} 0}\right)$ used in this study for the retrieval.

\begin{tabular}{lccccc}
\hline Parameter & LB & UB & IG & $\mu$ & $\sigma_{\mathrm{p} 0}$ \\
\hline $\mathrm{C}_{\mathrm{ab}}$ & 0 & 100 & 40 & 50 & 28.8 \\
$\mathrm{C}_{\mathrm{dm}}$ & 0 & 0.02 & 0.005 & 0.01 & 0.01 \\
$\mathrm{C}_{\mathrm{w}}$ & 0 & 0.05 & 0.02 & 0.025 & 0.01 \\
$\mathrm{C} \mathrm{ca}$ & 0 & 25 & 10 & 12.5 & 7.22 \\
$\mathrm{C}$ & 0 & 1.5 & 0.1 & 0.75 & 0.43 \\
Transformed LAI $^{a}$ & 0 & 0.7 & 0.4 & Measured & Measured \\
LIDFa $_{\mathrm{a}}+\operatorname{LIDF}_{\mathrm{b}}{ }^{a}$ & -1 & +1 & -0.5 & 0 & 0.58 \\
LIDF $_{\mathrm{a}}-$ LIDF $^{a}$ & -1 & +1 & -0.2 & 0 & 0.58 \\
\hline
\end{tabular}

a These parameters are transformed to new ones (see section 3.2.2)

The choice of values for LB, UB and IG were adapted from the previous studies (Bayat et al., 2016a; Van der Tol et al., 2016; Verhoef et al., 2018). Although the IG is necessary for NO as the starting point, the choice of their values is subjective but does not affect the results (Bayat et al., 2016a; Vilfan et al., 2016). The use of uncertainties [i.e., standard deviations ( $\sigma_{\mathrm{p} 0}$ and $\sigma$ )] to normalize the cost function and the a priori values is an effective regularization approach applied in NO (Dorigo et al., 2007; Verhoef et al., 2018) to reduce numeric ill-posedness [i.e., multiple solutions yielding the same spectrum (Combal et al., 2003)], since in the case of ill-posedness the solution is automatically driven in the direction of the a priori values. In addition, for the $N$ and hot parameters we considered fixed values of 1.5 and 0.05 based on previous studies (Bayat et al., 2016a; Haboudane et al., 2004; Houborg et al., 2007). The dry soil parameters for the BSM soil reflectance model were obtained by their retrieval from a nearby bare soil pixel (as $B=$ 0.55 , Lat $=19.50$ and $L o n=49.46$ ) at the end of the episode when the soil was completely dry. For the rest of the time series, we used the measured surface soil moisture values collected on various days as a priori information to scale the dry soil spectra for moist conditions during the episode and, 
therefore, to take into account the soil moisture effects on dry soil spectra, keeping $B$, Lat and Lon at the above mentioned values.

\subsubsection{Transformed parameters}

Some input parameters in RTMo were transformed in the inversion process, notably $L A I, L I D F_{\mathrm{a}}$ and $L I D F_{\mathrm{b}}$. $L A I$ was transformed to a new parameter $1-\exp$ $(-0.2 L A I)$ to improve the linearity of the model. The value of 0.2 ensures a more linear response of the reflectance in near-infrared part, which is the most sensitive part of the spectrum to high values of $L A I$ (Verhoef et al., 2018). Moreover, $L I D F$ parameters were transformed because $L I D F_{\mathrm{a}}$ and $L I D F_{\mathrm{b}}$ are restricted by the condition $\left|L I D F_{\mathrm{a}}\right|+\left|L I D F_{\mathrm{b}}\right|<=1$. By constructing two transformed variables, via summation $\left(L I D F_{\mathrm{a}}+L I D F_{\mathrm{b}}\right)$ and subtraction $\left(L I D F_{\mathrm{a}}\right.$ - $L I D F_{b}$ ) and attaching -1 and +1 as their $L B$ and $U B$, one can ensure that the constraint of $\left|L I D F_{\mathrm{a}}\right|+\left|L I D F_{\mathrm{b}}\right|<=1$ is effectively fulfilled in an automatic way (Verhoef, 1998).

\subsubsection{Including the a priori information and uncertainties}

For the a priori values, we used measured $L A I$ information during this drought episode for the case of $L A I$ in the retrieval. This is useful to constrain the inversion and to reduce the volume of parameter space. However, we did not know any a priori values for the other properties ( $C_{\mathrm{ab}}, C_{\mathrm{w}}, C_{\mathrm{dm}}, C_{\mathrm{s}}$ and LIDF) on the ground during the episode. Thus, for these cases, we used the mid of the total range [i.e., $(\mathrm{LB}+\mathrm{UB}) / 2$ ] as the a priori values, similar to (Verhoef et al., 2018). Furthermore, for the a priori uncertainties, we assumed uniform (a priori) distributions over the range between LB and UB of the vegetation properties. Assuming uniform prior distributions over LB and UB resulted in values of uncertainties equal to $1 / \sqrt{12} \approx 0.3$ times the range of each property. Moreover, we used measured SM values as a priori information to scale the dry soil spectra for moist conditions during this drought episode.

\subsubsection{Sensor noise}

We considered the digitization noise as a rough estimate of sensor noise and, therefore, the source of uncertainty for Landsat-observed TOA radiances. It is necessary to obtain reasonable estimates for sensor noise in different Landsat bands, and one may assume that digitization noise in each band has been designed to be in proportion to actual sensor noise. Maximum digitization noise may be considered equal to $1 \mathrm{DN}$ count in each band of Landsat, because the maximum amplitude of the coherent noise in Landsat sensor is equal to 1 DN (USGS, 1998). Consequently, assuming uniform (a priori) distributions over range of $0-1 \mathrm{DN}$ leads to the uncertainty of $0.3 \mathrm{DN}$ for each band of Landsat. Thus, we converted $1 \mathrm{DN}$ in each band of Landsat into TOA radiance values and computed their uncertainties as shown in Table 3.4. 
Table 3.4. Digitization noise in Landsat TM5 and ETM7 and assumed standard deviation $(\sigma)$ used in this study for different bands.

\begin{tabular}{ccccc}
\hline \multirow{2}{*}{ bands } & \multicolumn{2}{c}{ Digitization noise } & \multicolumn{2}{c}{$\sigma$} \\
& TM5 & ETM7 & TM5 & ETM7 \\
\hline 1 & 0.766 & 0.779 & 0.230 & 0.234 \\
2 & 1.448 & 0.799 & 0.434 & 0.240 \\
3 & 1.044 & 0.622 & 0.313 & 0.186 \\
4 & 0.876 & 0.640 & 0.263 & 0.192 \\
5 & 0.120 & 0.126 & 0.036 & 0.038 \\
7 & 0.066 & 0.044 & 0.020 & 0.013 \\
\hline
\end{tabular}

\subsubsection{Error propagation analysis}

The propagation of sensor noise in the Landsat-observed TOA radiances into errors in the retrieval of vegetation properties is estimated by:

$$
\sigma_{P}=\left(J_{L}^{\mathrm{T}} J_{L}\right)^{-1} J_{L}^{\mathrm{T}} \sigma_{i}
$$

The $\sigma_{\mathrm{p}}$ is the uncertainty in the vegetation properties propagated from the sensor noise $\left(\sigma_{\mathrm{i}}\right)$ and $J_{\mathrm{L}}$ is the Jacobian of the model computed for each set of optimized vegetation properties expressed by:

$$
J_{L}=\left(\begin{array}{ccc}
\partial L_{\lambda 1} / \partial_{P 1} & \ldots & \partial L_{\lambda 1} / \partial_{P 7} \\
\ldots & \ldots & \ldots \\
\partial L_{\lambda 6} / \partial_{P 1} & \ldots & \partial L_{\lambda 6} / \partial_{P 7}
\end{array}\right)
$$

The Jacobian $J_{L}$ is a matrix containing the first partial derivatives of the relative model output (Bowyer and Danson, 2004; Saltelli et al., 2000). We changed vegetation properties by a small step $\left(10^{-6}\right)$ and recorded the response in the simulated TOA radiances to such a small change. This is basically the local sensitivity analysis of the radiance $L$ at each wavelength $\lambda_{i}$ of the 6 Landsat optical spectral bands (rows, Table 3.4) to each of the 7 input parameters (columns, Table 3.3). The computed Jacobian was then utilized to relate the observed spectra (Table 3.4) to uncertainty in the retrieved properties (Figure 3.17). 


\subsection{Results}

\subsubsection{Landsat observed TOA radiance variations over time}

Three representative examples (on DOYs $=59,75$ and 203) of the TOA radiance observed by Landsat (in various soil moisture conditions) during this drought episode are presented in Fig. 3.5. These images clearly highlight that not only the vegetation properties are changing significantly during the developing drought episode, but that the background soil contribution varies over time as well. For instance, there is more contribution from the vegetation at DOY 75 (the middle of the episode (Figure 3.5b)), whereas there is more contribution from the soil at DOYs 59 (early in the episode (Figure 3.5a)) and 203 (the end of the episode (Figure 3.5c)).

(a)

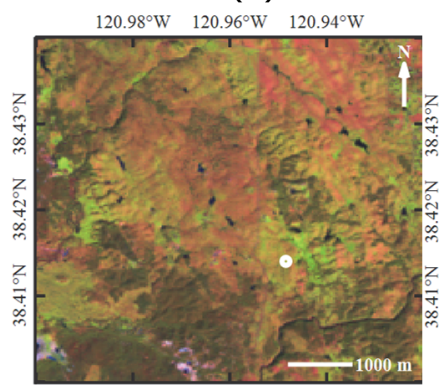

(b)

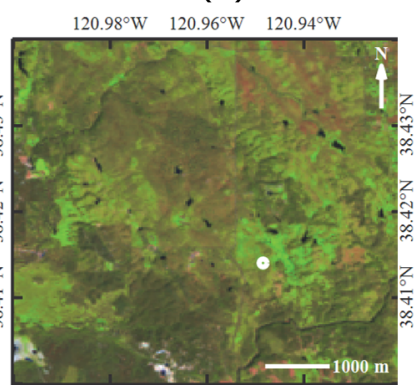

(c)

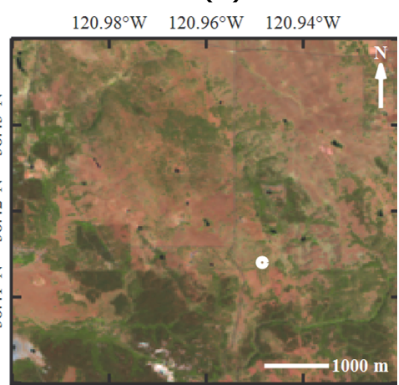

Figure 3.5. TOA radiance images observed by Landsat TM5 ( red $=$ band 5 , green $=$ band 4, blue = band 3) for (a) DOY $59($ SM = 26\%) (b) DOY $75(\mathrm{SM}=19 \%)$ and (c) DOY 203 $(\mathrm{SM}=2.2 \%)$ in 2004 . The white circle shows the location of the Vaira site.

To better understand the trends in the observed radiances during this drought episode, we analyzed the radiance changes at the Vaira site over time (Fig. 3.6). The radiance in bands $1,2,3,5$ and 7 increased over time (Fig. $3.6 \mathrm{bc}$ ). However, the radiance in band 4 initially increased considerably (until DOY 80), decreased in the middle period (DOY 80 - 112) and was almost stable afterwards ( $\geq$ DOY 112) (Fig. 3.6bc). Radiance increase of the red band (band 3) was the strongest, the difference between the radiance spectra at the highest (DOY 3) and the lowest soil moisture (219) was significant for almost all bands (Fig. 3.6a). All bands showed mid-event fluctuations (between DOYs $90-120)$. 
(a)

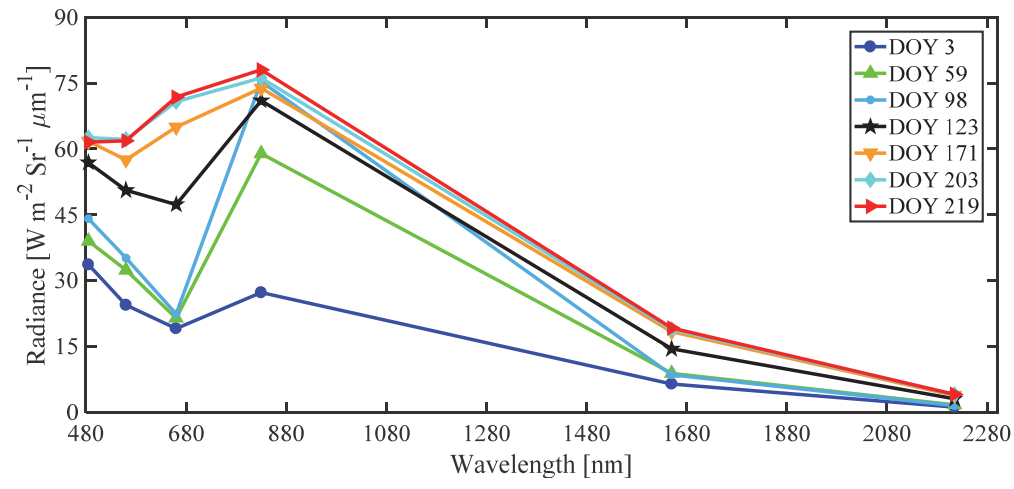

(b)

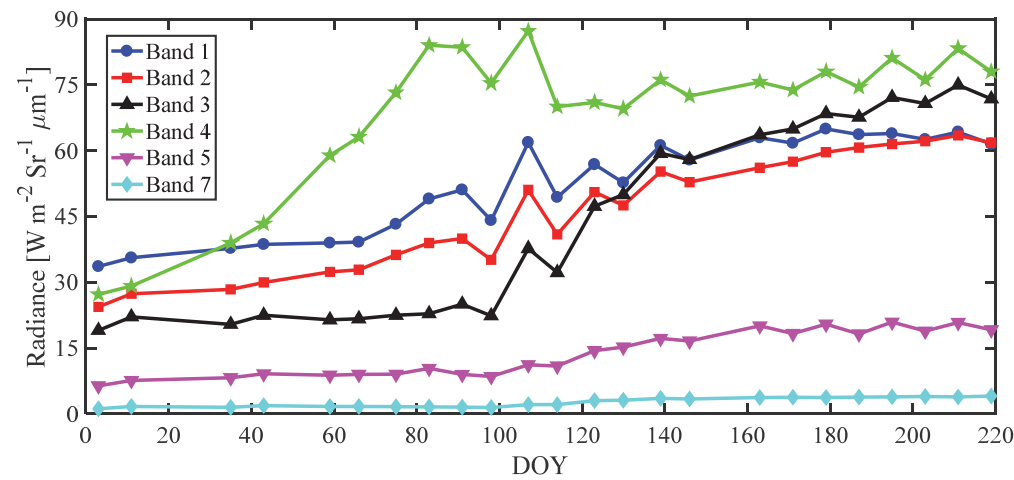

(c)

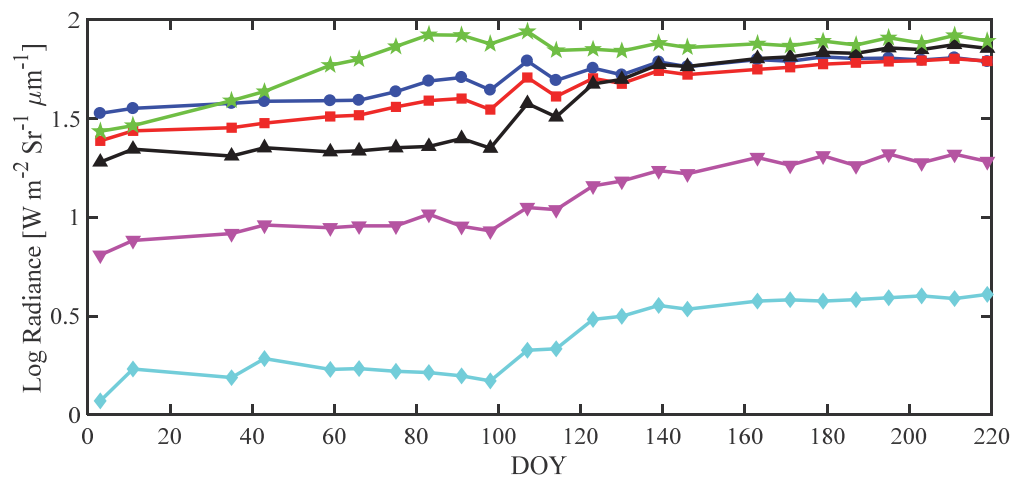

Figure 3.6. Time series of Landsat TOA radiance spectra observed at the Vaira site during the 2004 drought episode. Radiance variations observed on (a) different days as a function of wavelength and (b) different bands as a function of time (DOYs). The logarithms of Landsat TOA radiance variations are shown (c) as a function of time (DOYs) to better detect the relative changes. 


\subsubsection{MODTRAN model}

\subsubsection{MODTRAN parameter variations}

MODTRAN parameters (i.e., $L_{0}, G$ and $S$ ) resampled to the Landsat bands shown for various atmospheric aerosol types (rural, maritime and urban) for a fixed visibility of $25 \mathrm{~km}$ on 16 April 2004 (DOY 107) are presented in Fig. 3.7. The atmospheric $L_{0}$ shows the case when there is no reflectance from the surface and, therefore, the total radiance comes from atmospheric scattering alone. As Fig. 3.7 shows, Lo follows a downward trend with wavelength in the solar reflective domain. This is due to the fact that the atmosphere scatters much more at shorter wavelengths (band 1) than at longer wavelengths (band 7). The $G$, which includes the extraterrestrial solar irradiance and the total twoway transmittance in the atmosphere, roughly follows the shape of the solar irradiance spectrum. However, similar to the $L_{0}$, the $S$ shows a smooth downward trend over wavelength. The $L_{0}, G$ and $S$ variations are not only a function of wavelength and visibility, but also of the aerosol type. In general, the urban aerosol model had a stronger absorption and, therefore, in all cases showed lower values compared to the other two aerosol models. Moreover, the $L_{0}, G$ and $S$ variations show a stronger spectral slope for the rural case compared to the maritime.

(a)

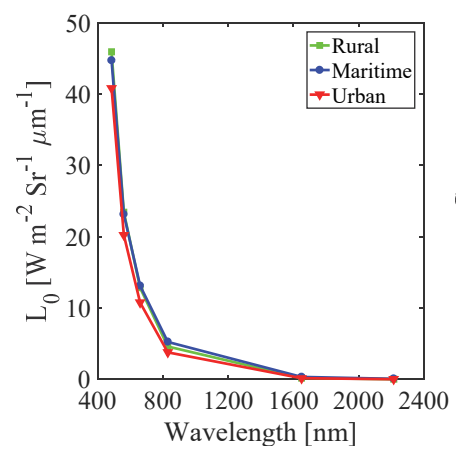

(b)

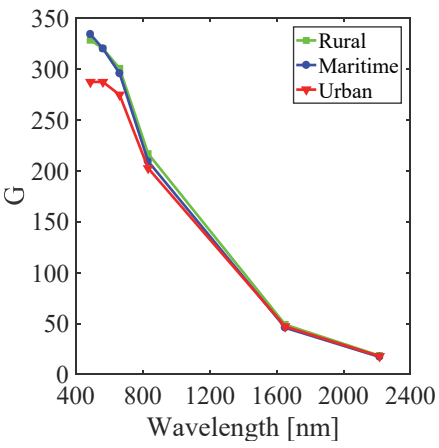

(c)

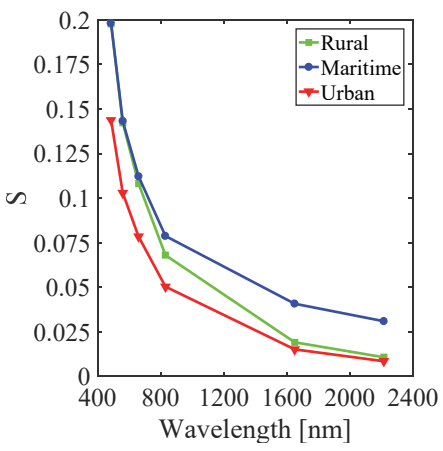

Figure 3.7. MODTRAN parameters spectra variations at a fixed visibility of $25 \mathrm{~km}$ over various aerosol types over the Vaira site for DOY 107 in 2004. (a) Path radiance $\left(L_{0}\right)$, (b) Gain factor (G) and (c) Spherical albedo (S) for DOY 107 in 2004.

The variations of the $L_{0}, G$ and $S$ on 16 April 2004 (DOY 107), for a range of haze conditions (i.e., visibilities of 5, 15, 30 and $100 \mathrm{~km}$ ) and three aerosol models (rural, maritime and urban) are presented in Fig. 3.8.

As Fig. 3.8a-c shows, the atmospheric $L_{0}$ for the rural (Fig. 3.8a) and maritime (Fig. 3.8b) aerosol cases had higher ranges of variation than that of the urban aerosol case (Fig. 3.8c). In addition to the dependency of the Lo on aerosol types, the results show the effects of visibility: the lower visibility, the higher $L_{0}$, and vice versa. Fig. $3.8 \mathrm{~d}$-f show that the $G$ in rural (Fig. 3.8d) and maritime (Fig. 3.8e) aerosol had a higher range of variations compared to that 
of urban aerosol case (Fig. 3.8f), similar to the atmospheric $L_{0}$. In addition, the $G$ spectra in the urban aerosol case respond more strongly to increasing visibilities compared to rural and maritime aerosol types. The $G$ changes directly with visibility conditions: the lower visibility, the lower $G$, and vice versa. Fig. 3.8g-i shows that the $S$ in rural (Fig. 3.8g) and maritime (Fig. $3.8 \mathrm{~h}$ ) aerosol had a higher range of variations compared to that of urban aerosol case (Fig. 3.8i), similar to the atmospheric Lo. Moreover, the $S$ spectra in the rural and maritime aerosol case, corresponding to various visibilities showed larger deviations compared to the urban aerosol type. In addition to the dependency of the $S$ to aerosol types, the results show again the effect of visibility: the lower visibility, the higher $S$ and vice versa.

Rural case

(a)

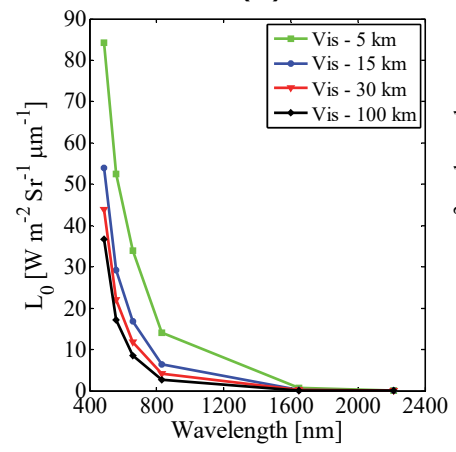

(d)

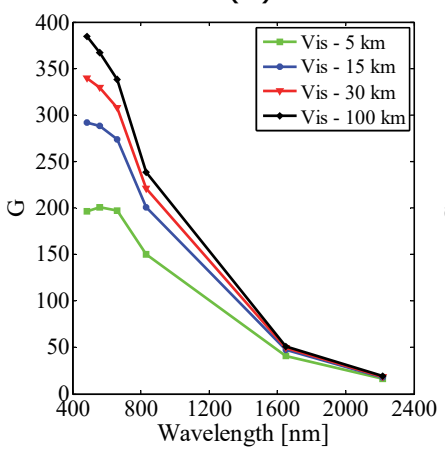

Maritime case

(b)

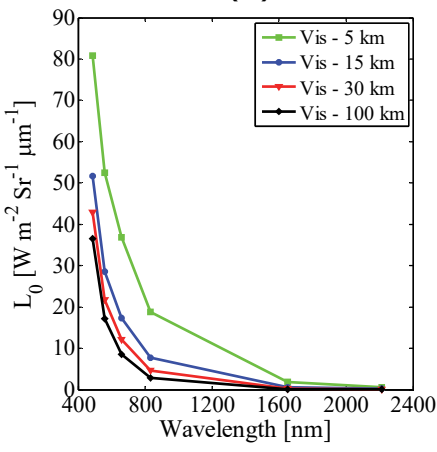

(e)

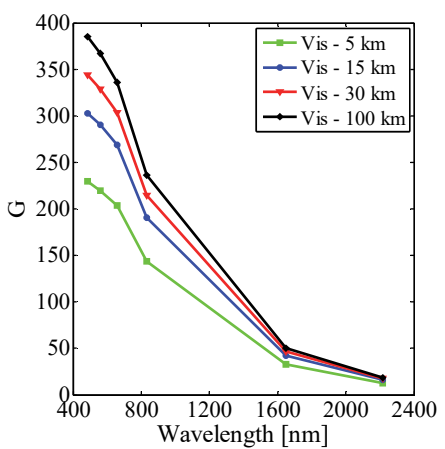

Urban case

(c)

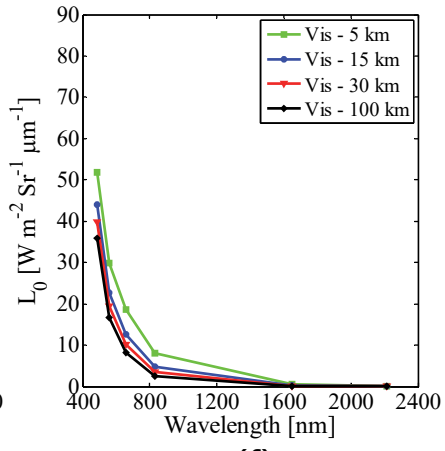

(f)

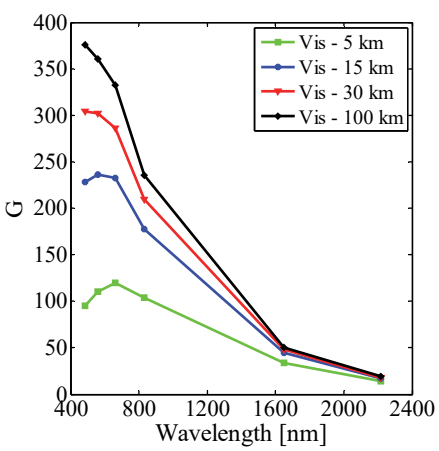


(g)

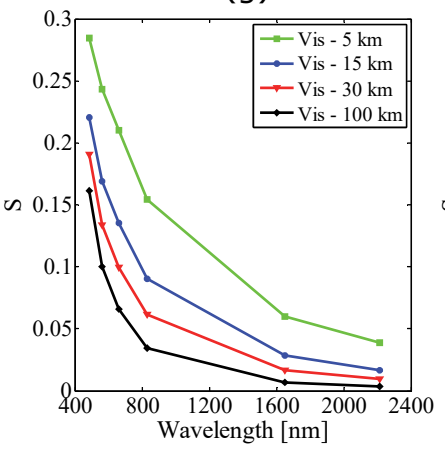

(h)

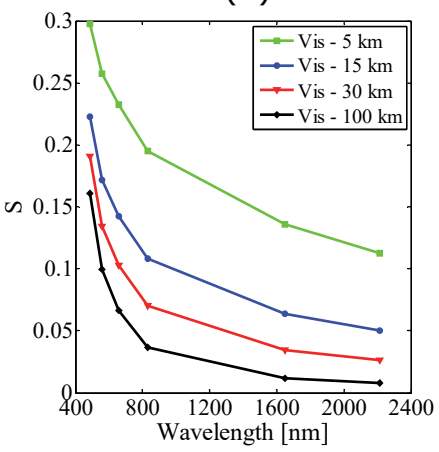

(i)

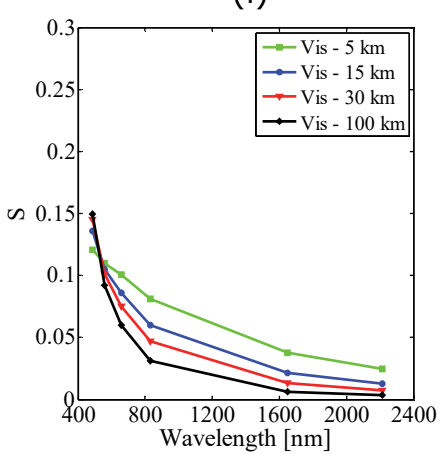

Figure 3.8. MODTRAN parameters (i.e., path radiance (LO), gain factor ( $G$ ) and spherical albedo (S)) spectra variations at various visibilities $(5,15,30$ and $100 \mathrm{~km})$ and aerosol types (rural, maritime and urban cases) for DOY 107 at Vaira site. Left panels $(a, d, g)$ show the rural case. Middle panels $(b, e, h)$ show the maritime case and right panels (c, $f, i)$ show the urban case.

A wrong assumption on visibility or aerosol type will produce a wrong computation of the TOA radiances and consequently, vegetation properties retrieval will be biased, especially for urban $(G, S)$, rural $(S)$ and maritime $(S)$ cases.

\subsubsection{The best fitting atmospheric properties}

We compared the surface reflectance generated by the retrieved best atmospheric properties (MODTRAN generated reflectance) over a lake with the Landsat surface reflectance products obtained from USGS ESPA on-demand system (http://espa.cr.usgs.gov/) at the same dates (as for Landsat radiance data in Fig. 3.3) in our study site.

The results demonstrated that the extracted values from the USGS Landsat surface reflectance products were relatively far from zero over a clear water. Although slightly positive values are acceptable, negative reflectance values are definitely due to atmospheric correction errors in the USGS products and will cause problems in quantitative analysis. Three representative examples of the reflectance values extracted by a window of 5 by 5 pixels from USGS Landsat products over a deep water body on various days are presented in Table 3.5. Our MODTRAN best fitting parameters were forced to generate reflectances of zero over the same lake on the same dates. 
Table 3.5.The reflectance in various bands extracted by a window of 5 by 5 pixels from USGS Landsat surface reflectance products over a water body during this drought episode for (a) DOY 59, (b) DOY 75 and (c) DOY 203 in 2004.

\begin{tabular}{lcclllllll}
\hline & \multicolumn{2}{c}{ DOY 59} & \multicolumn{4}{c}{ DOY 75} & \multicolumn{4}{c}{ DOY 203} \\
Bands & $\begin{array}{c}\text { Darkest } \\
\text { pixel }\end{array}$ & mean & std & $\begin{array}{l}\text { darkest } \\
\text { pixel }\end{array}$ & mean & std & $\begin{array}{l}\text { darkest } \\
\text { pixel }\end{array}$ & mean & std \\
\hline 1 & 0.028 & 0.034 & 0.003 & 0.028 & 0.031 & 0.003 & 0.023 & 0.027 & 0.002 \\
2 & 0.009 & 0.019 & 0.004 & 0.014 & 0.020 & 0.003 & 0.014 & 0.015 & 0.002 \\
3 & 0.012 & 0.014 & 0.004 & 0.008 & 0.013 & 0.002 & 0.007 & 0.009 & 0.001 \\
4 & 0.011 & 0.012 & 0.002 & 0.011 & 0.013 & 0.002 & 0.008 & 0.011 & 0.001 \\
5 & -0.005 & 0.001 & 0.003 & -0.004 & 0.003 & 0.002 & -0.001 & 0.003 & 0.002 \\
7 & -0.007 & 0.001 & 0.004 & -0.001 & 0.002 & 0.003 & -0.001 & 0.003 & 0.002 \\
\hline
\end{tabular}

\subsubsection{T-18 atmospheric transfer functions}

Fig. 3.9 presents two representative examples of the spectra of the generated functions $\mathrm{T}_{2}-\mathrm{T}_{14}$ over the wavelength range of $400-2400 \mathrm{~nm}$ for DOY 66 (Fig. 3.9a, Vis $=65 \mathrm{~km}$ and aerosol type $=$ urban) and DOY 107 (Fig. $3.9 \mathrm{~b}, \mathrm{Vis}=25 \mathrm{~km}$ and aerosol type $=$ maritime). 
(a)

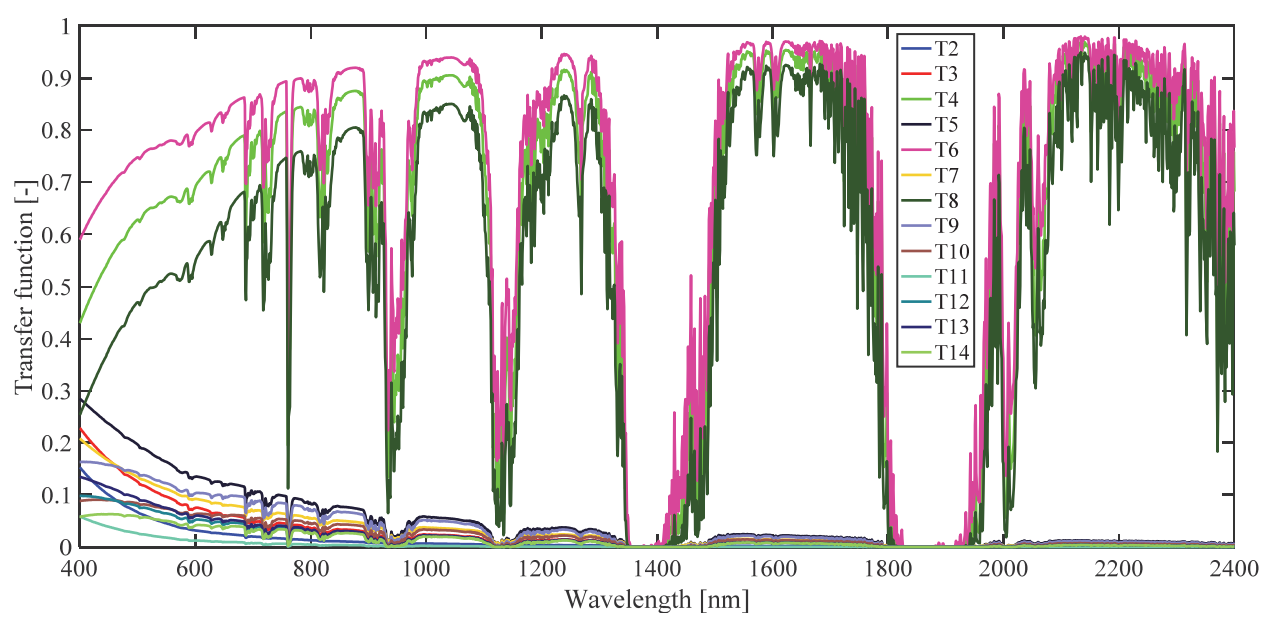

(b)

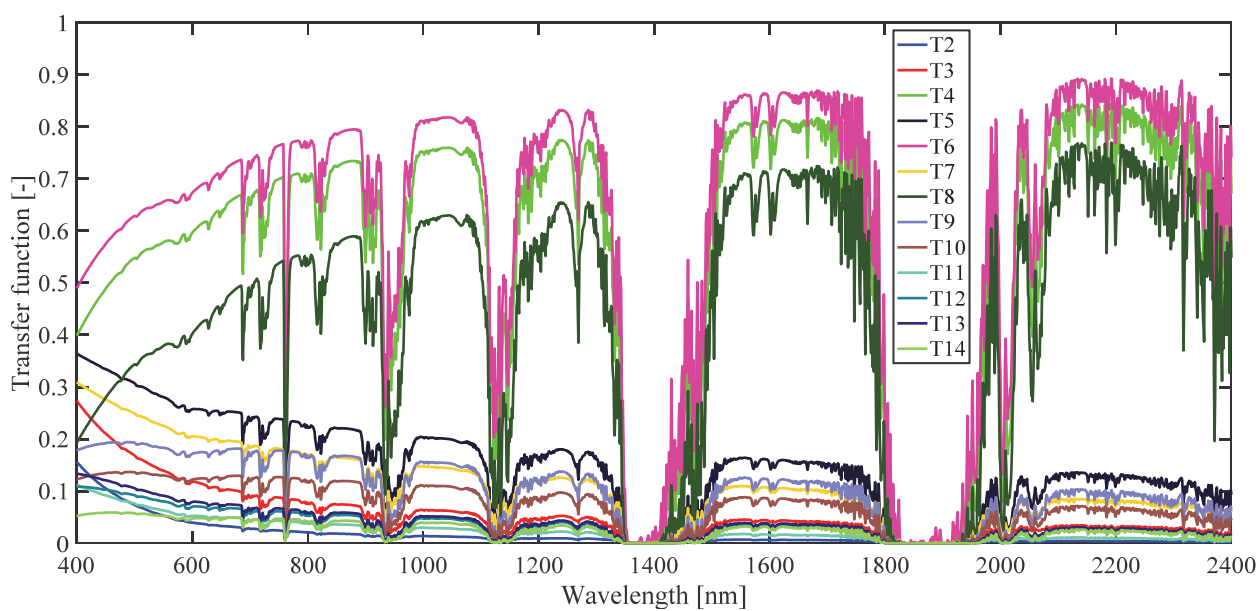

Figure 3.9. Atmospheric spectral transfer functions $T_{2}-T_{14}$ generated for (a) DOY 66 (Vis $=65 \mathrm{~km}$ and aerosol type $=$ urban) and (b) DOY 107 (Vis $=25 \mathrm{~km}$ and aerosol type $=$ maritime) in 2004 at the Vaira site.

Although almost similar spectral shapes were obtained for the $T_{2}-T_{14}$ system for DOYs 66 and 107, their magnitudes and range of variations were clearly different. The lower visibility on DOY 107 gives lower transmittances and higher scattering, which is confirmed by the lower levels of functions $T_{4}$, $T_{6}$ and $T_{8}$, and the higher levels of the other T-functions on DOY 107.

\subsubsection{Coupled model inversion against TOA radiance}

Three representative examples of simulated TOA radiance images by the coupled model and the residual maps of spectral fitting (i.e., the differences 
between the Landsat-observed TOA radiance and the simulated TOA radiance) are presented in Fig. 3.10.

(a)

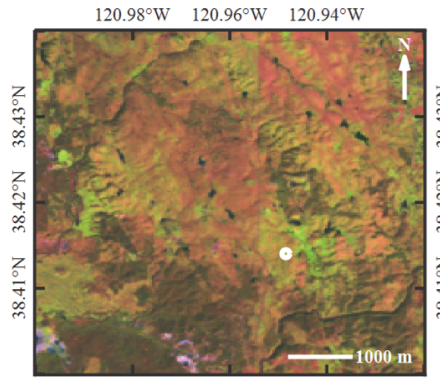

(d) (b)

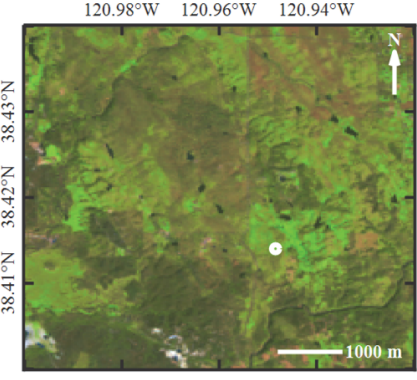

(e)

(c)

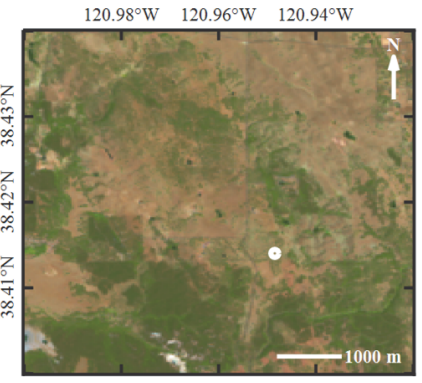

(f)

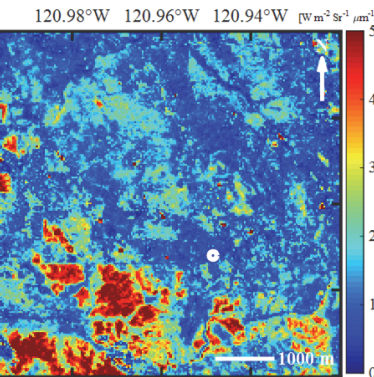

Figure 3.10. Simulated TOA radiance images ( $r e d=$ band 5 , green $=$ band 4 , blue $=$ band 3) by RTMo model for (a) DOY 59, (b) DOY 75, (c) DOY 203 in 2004 and the residual maps of spectral fitting (i.e., the differences between the observed TOA radiance and the simulated TOA radiance over the spectra) for (d) DOY 59, (e) DOY 75, (f) DOY 203. The white circle shows the location of the Vaira site.

The smallest error (RMSE) between observed and simulated TOA radiance was used as a measure of the model inversion performance. Fig. 3.11 illustrates the time series coupled model fittings at the Vaira site obtained through the optimization, between observed spectra (by Landsat) and simulated spectra (by model) in a window of three by three pixels around the flux tower at the site on various days. Overall, the small error in the model inversion $\left(0.006<\mathrm{RMSE}<2.2 \mathrm{Wm}^{-2} \mathrm{sr}^{-1} \mu \mathrm{m}^{-1}\right.$ ) shows that the model was able to accurately reproduce the observed optical spectra under different soil moisture conditions during the whole observation period. 


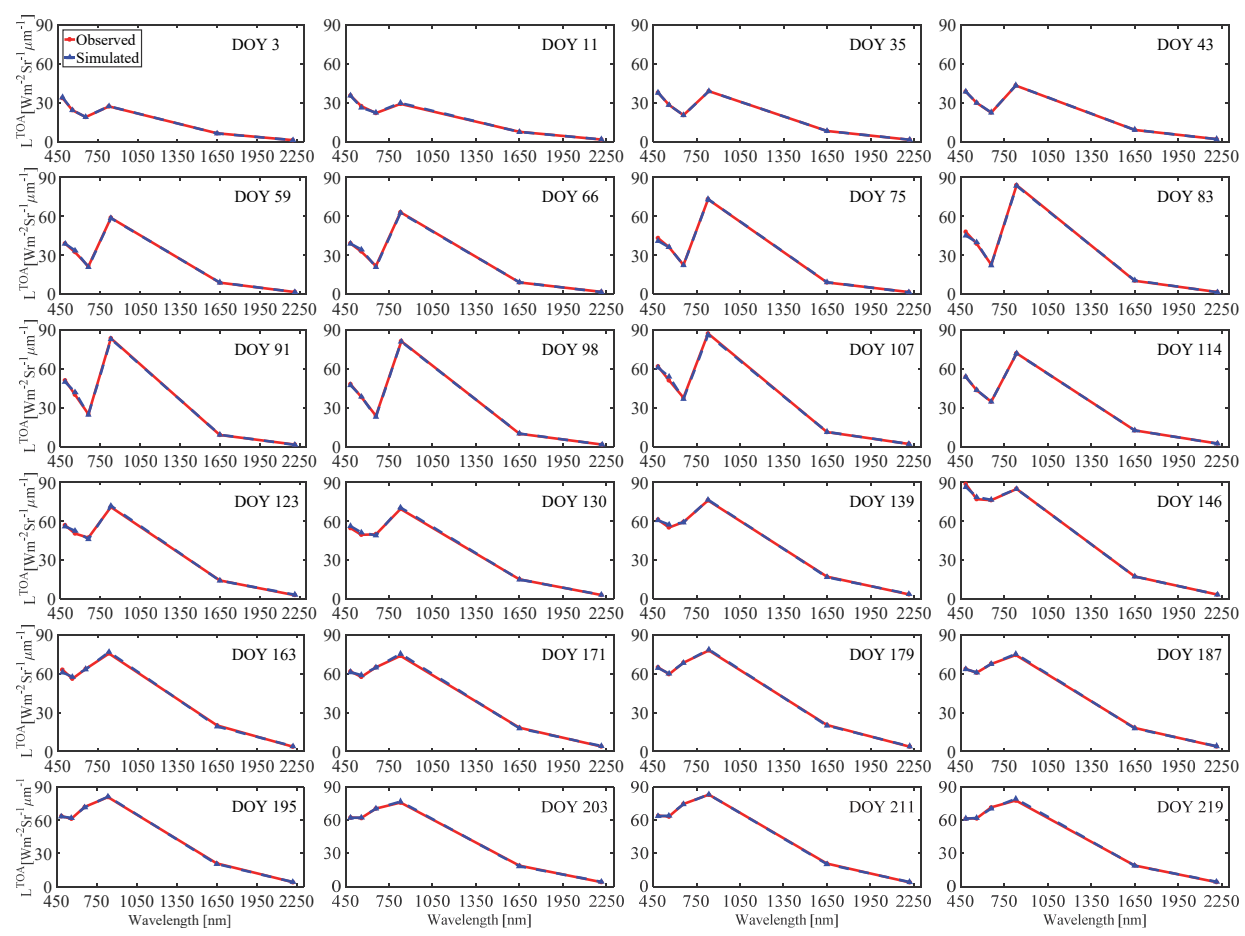

Figure 3.11. The goodness of fit for the spectra obtained between observed TOA radiances (at Landsat optical bands; shown as red solid lines) and the simulated TOA radiances (resampled to Landsat optical bands by Landsat SRFs; shown as blue dashed lines) on 24 different days at the Vaira site during the 2004 drought episode.

As discussed in section 3.2, we scaled the dry soil spectrum based on the measured surface soil moisture and used them in the RTMo model. Fig. 3.12 illustrates the fixed dry soil spectrum in red and the scaled soil reflectance for various days at the Vaira site in blue dashed lines. This results showed that the dry soil spectrum provides a realistic case for DOYs $\geq 98$. 

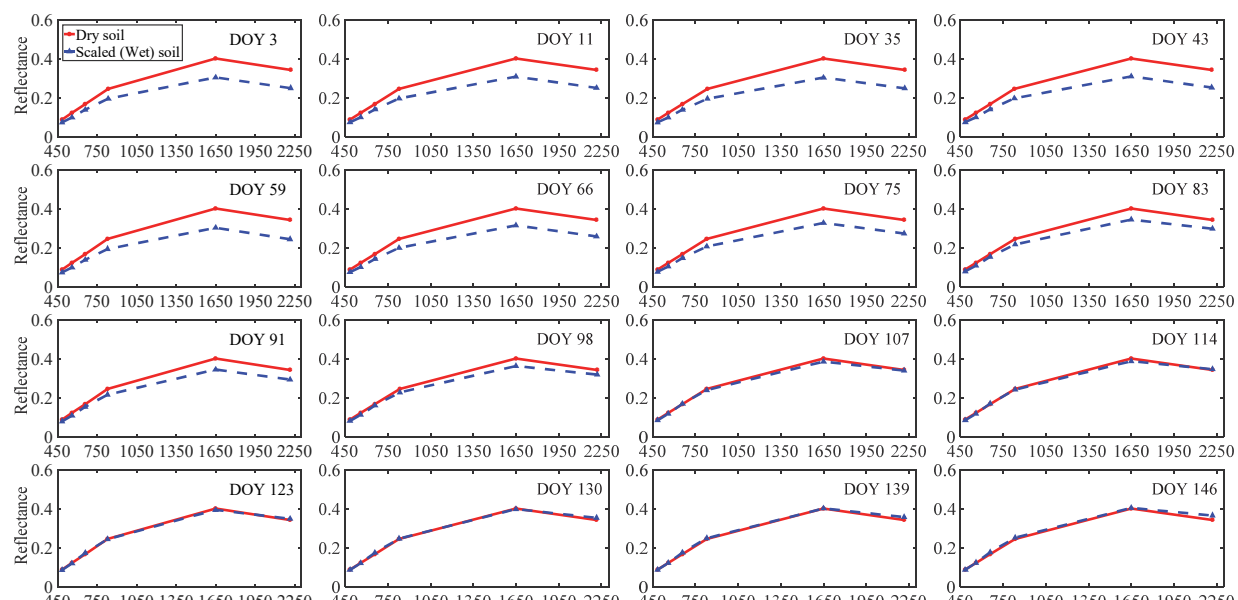

45075010501350165019502250
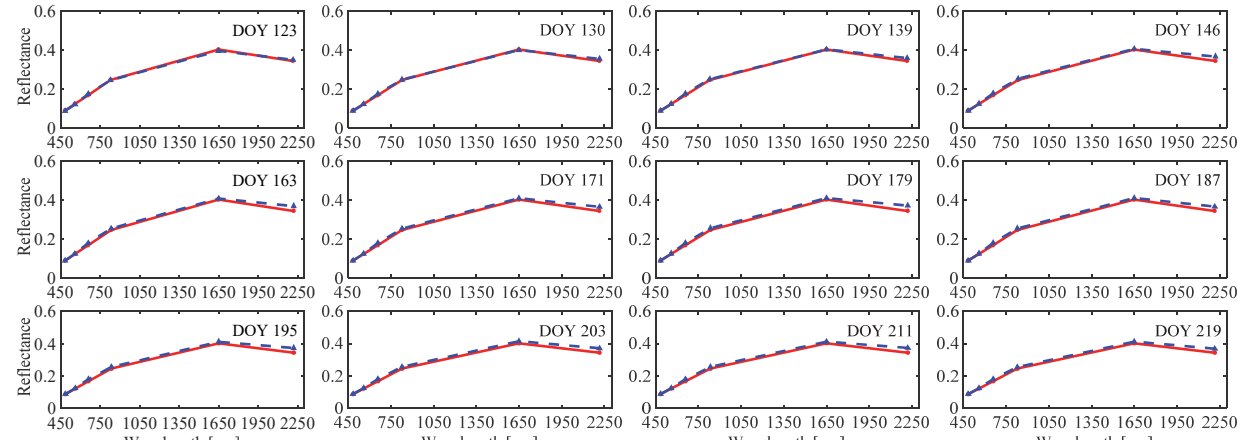

Figure 3.12. Soil reflectance simulations with BSM model. The dry soil reflectance (at Landsat optical bands; shown as red solid lines) were scaled to obtain realistic spectra (at Landsat optical bands; shown as blue dashed lines) on different days at the Vaira site during the episode. Dry soil spectrum provides a realistic case for DOYs $\geq 98$.

Fig. 3.13 illustrates the time series of computed anisotropy index spectra at the Vaira site on various days during the episode. Considering the variation of the computed index $(-0.1<\mathrm{AI}<0.28)$, it is clear that the grass canopy is non-Lambertian and, therefore, it is relevant to consider the anisotropy effect for simulating surface reflectance, TOA radiance and consequently for the retrieval of vegetation properties. As the anisotropy index spectra show, canopy anisotropy has to be taken into account in all parts of the spectrum during the whole episode from normal condition to severe stress. However, the largest effects of canopy anisotropy are observed from DOY 3 to DOY 123 (during the near normal and mild stress period). So, anisotropy appears to reduce under dry conditions. 

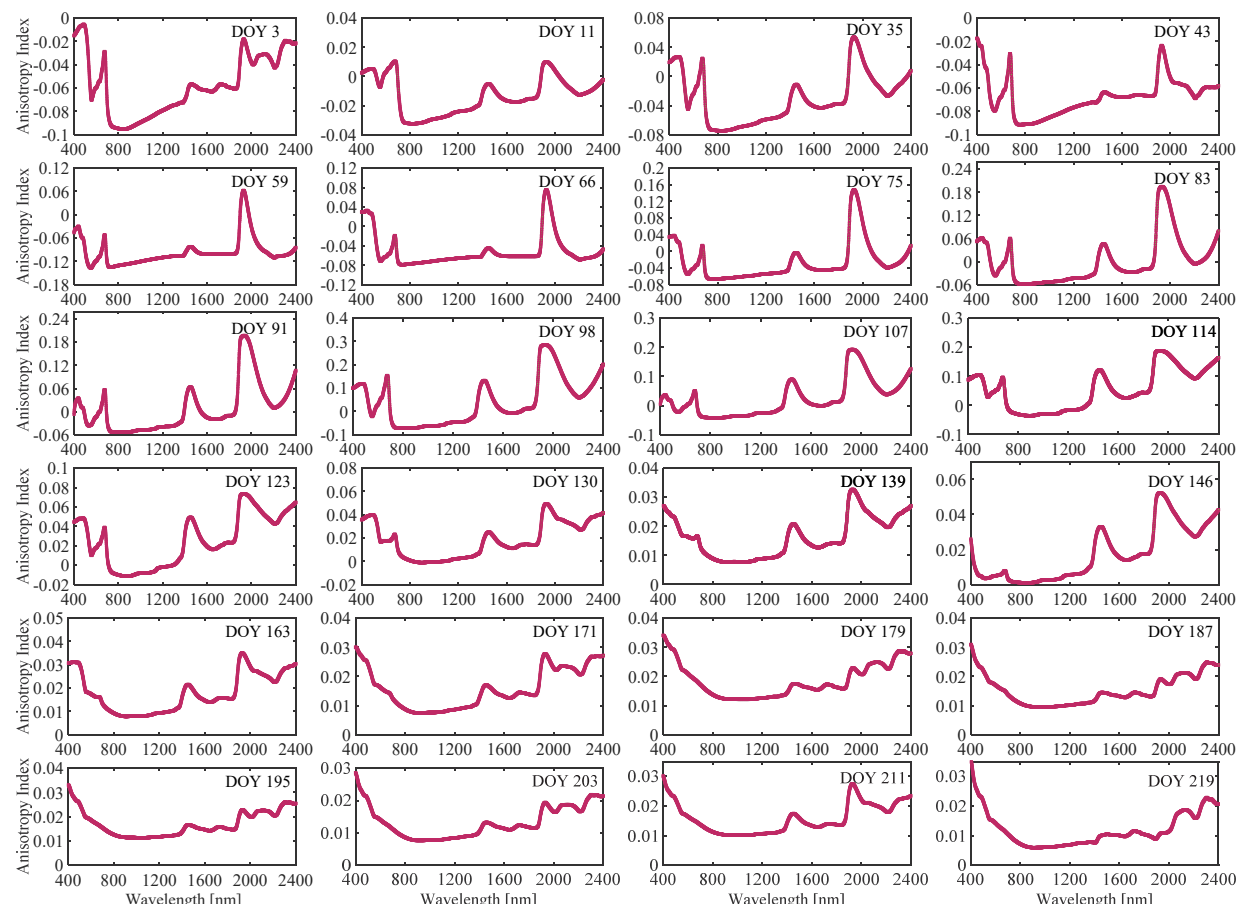

Figure 3.13. Anisotropy index computed from the best simulated reflectance factors on different days at the Vaira site during the episode. It should be noted that the vertical axis range varies for different time periods.

We present the anisotropy index variations for all DOYs together in Fig. 3.14. In general, from the middle of the episode, when soil moisture and vegetation coverage decreased, the surface anisotropy effect decreased as well. Considering that the RTMo model includes the assumption of a Lambertian soil background, it is not surprising that the modeled anisotropy decreases when more soil becomes exposed. 


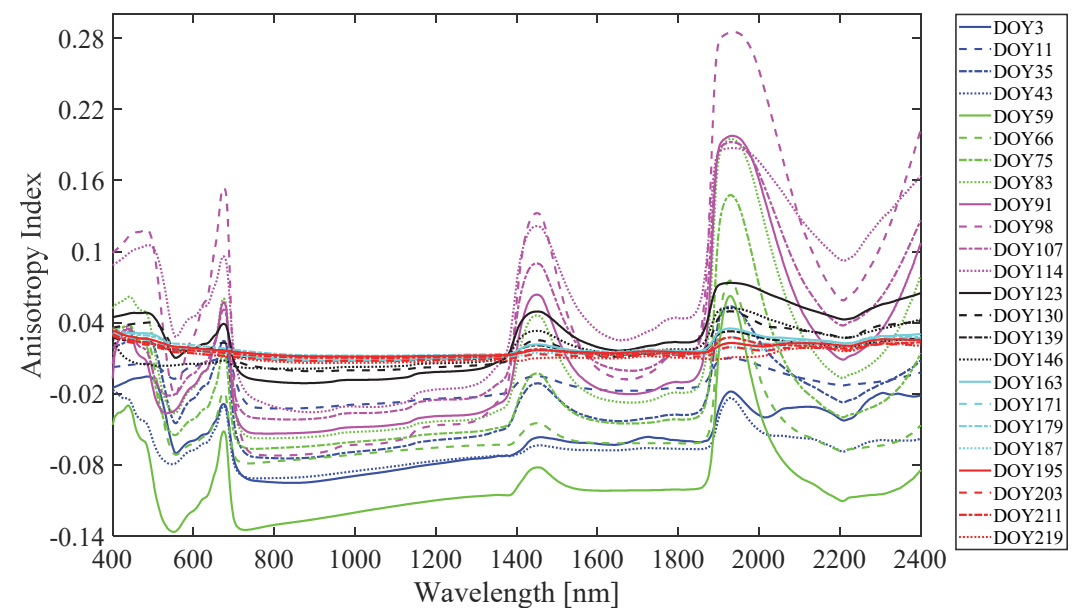

Figure 3.14. Anisotropy index computed from the best simulated reflectance factors for all days at the Vaira site during the episode. It should be noted that 4 subplots (each row) of Fig. 3.13 are shown by an identical color but with different line styles.

We compared the retrieved $L A I$ values with those of measured $L A I$ collected during this drought episode (Fig. 3.15). The model inversion gives a prediction of $L A I$ within the measured $L A I \pm$ the uncertainties. We expected the retrieved values to match with measured $L A I$ well since the measured $L A I$ was used to constrain the model inversion. Except for very low LAI values, the results fulfilled our expectations.

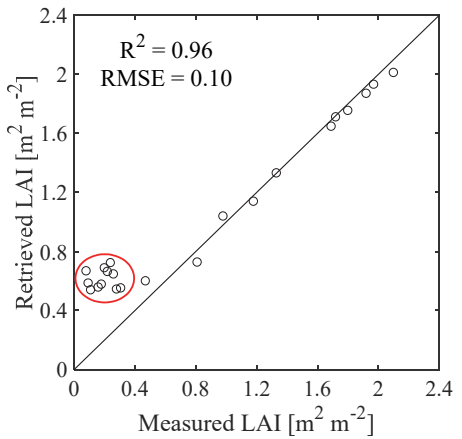

Figure 3.15. The measured and retrieved LAI during the episode at the Vaira site in 2004. An ellipse is containing "too low" $L A I$ values.

However, overestimation of $L A I$ at the end of the episode (for lower $L A I$ values) can be attributed to the fact that the measured $L A I$ only refers to the green $L A I$ and, therefore, the brown leaves inside the sample plots are ignored. In the RTMo model, only the effective (total) $L A I$ is considered, which results in higher values of $L A I$ at the end of episode where fewer green leaves, but still many brown leaves, are present. 


\subsubsection{Retrieved properties variations during the episode}

\subsubsection{Spatio-temporal changes}

Maps of the retrieved vegetation properties were generated for all the observations during the developing drought episode. Three representative examples of the retrieved maps for three days (DOY 59, 75 and 203) during the episode are presented in Fig. 3.16.

(a)

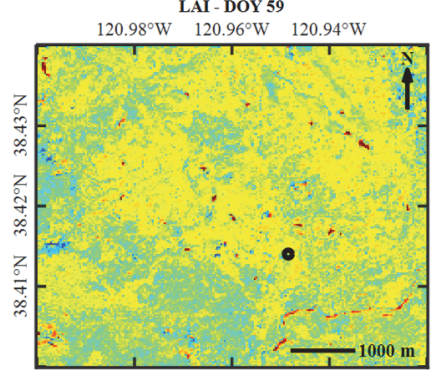

(d)

$120.98^{\circ} \mathrm{W} \quad 120.96^{\circ} \mathrm{W} \quad 120.94^{\circ} \mathrm{W}$

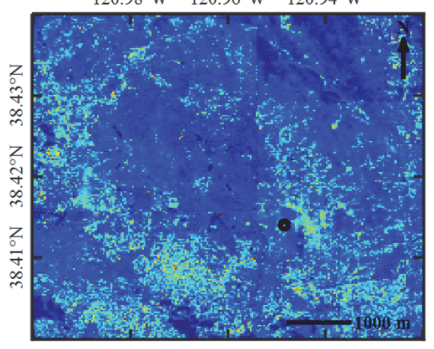

(g)

$120.98^{\circ} \mathrm{W} \quad 120.96^{\circ} \mathrm{W} \quad 120.94^{\circ} \mathrm{W}$

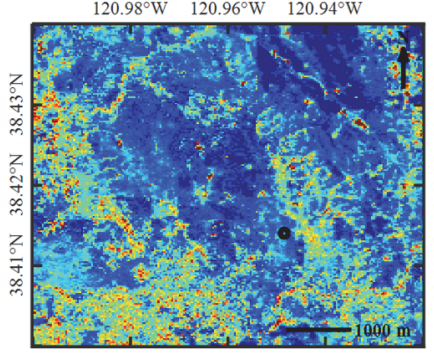

(b)

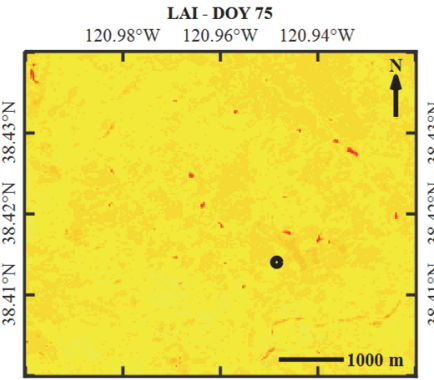

(e)

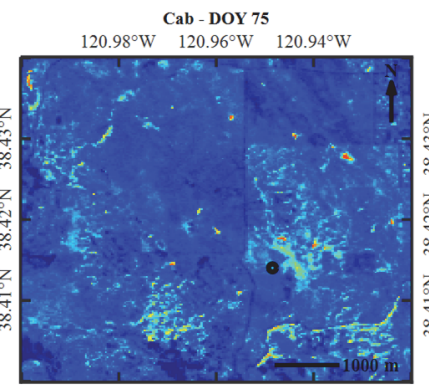

(h)

$120.98^{\circ} \mathrm{W} \quad \begin{aligned} & \text { CW - DOY } 75 \\ & 120.96^{\circ} \mathrm{W}\end{aligned} \quad 120.94^{\circ} \mathrm{W}$

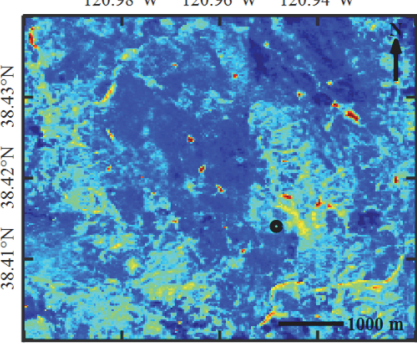

(c)

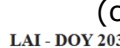

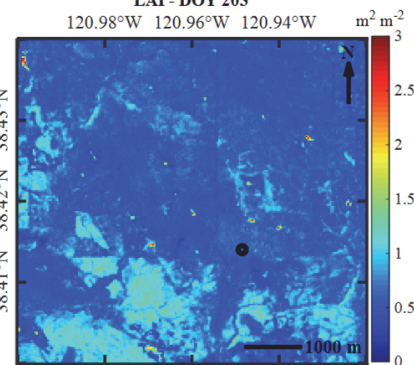

(f)

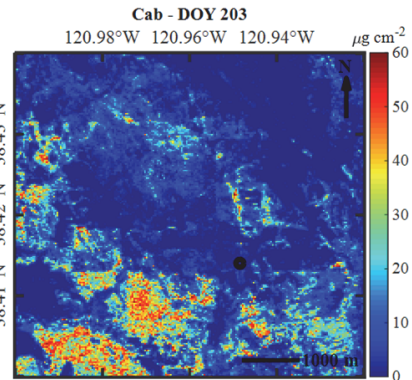

(i) Cw - DOY 203
$120.98^{\circ} \mathrm{W} 120.96^{\circ} \mathrm{W} 120.94^{\circ} \mathrm{W} \quad \mathrm{g} \mathrm{cm}^{-2}$

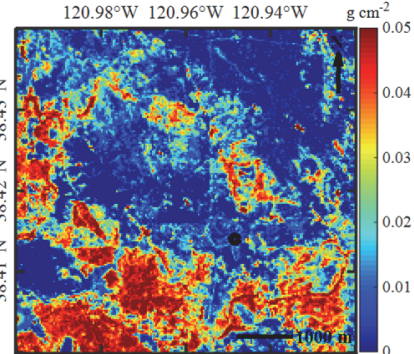


(j)

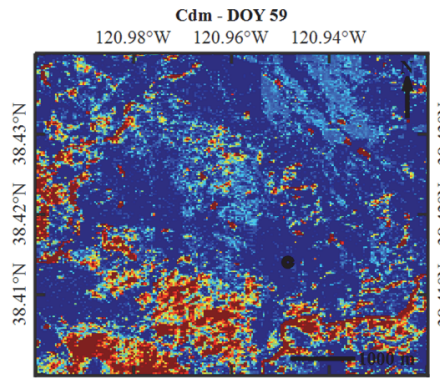

(m) $120.98^{\circ} \mathrm{W} \quad 120.96^{\circ} \mathrm{W} \quad 120.94^{\circ} \mathrm{W}$

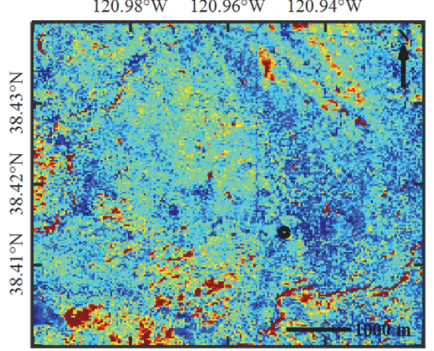

(p) $120.98^{\circ} \mathrm{W} \quad 120.96^{\circ} \mathrm{W} \quad 120.94^{\circ} \mathrm{W}$

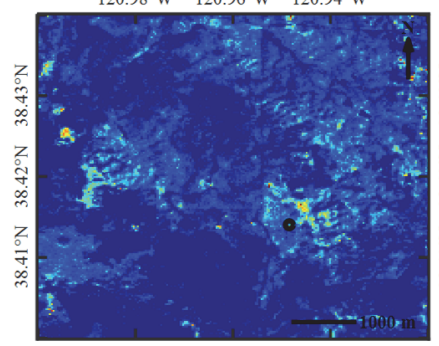

(k)

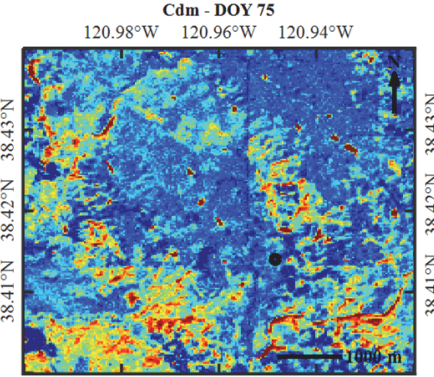

(n)

Cs - DOY 75

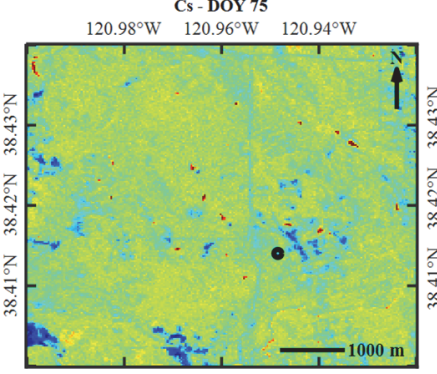

(q) LIDFa - DOY 75
$120.98^{\circ} \mathrm{W} \quad 120.96^{\circ} \mathrm{W} \quad 120.94^{\circ} \mathrm{W}$

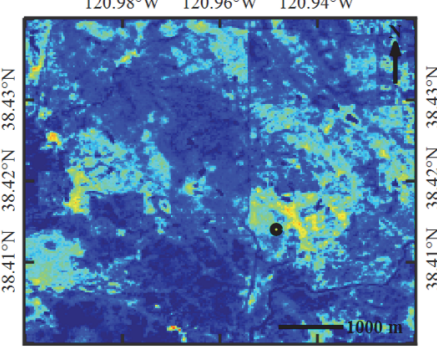

(I)

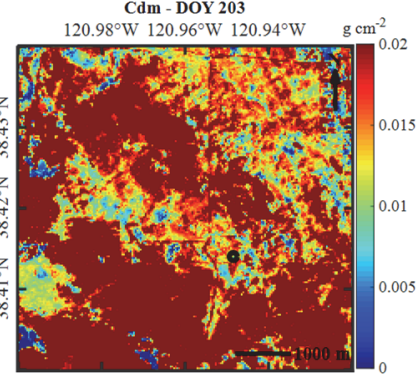

(0)

Cs - DOY 203
W $120.96^{\circ} \mathrm{W} 120.94^{\circ} \mathrm{W}$

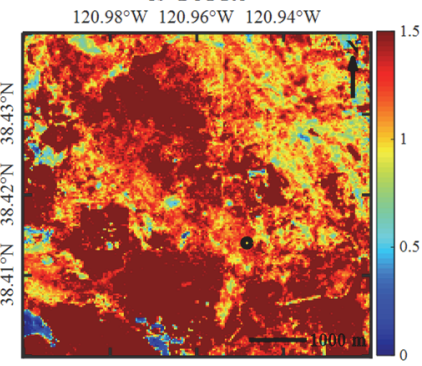

(r)

LIDFa - DOY 203

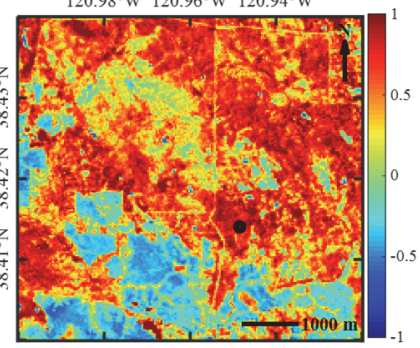

Figure 3.16. Landsat maps of retrieved properties for three days during this drought episode: $(\mathrm{a}, \mathrm{b}, \mathrm{c}) L A I ;(\mathrm{d}, \mathrm{e}, \mathrm{f}) C_{\mathrm{ab}} ;(\mathrm{g}, \mathrm{h}, \mathrm{i}) C_{\mathrm{w}} ;(\mathrm{j}, \mathrm{k}, \mathrm{l}) C_{\mathrm{dm}} ;(\mathrm{m}, \mathrm{n}, \mathrm{o}) C_{\mathrm{s}} ;(\mathrm{p}, \mathrm{q}, \mathrm{r})$ LIDF$_{\mathrm{a}}$. Left panels $(a, d, g, j, m, p)$ show the retrieved properties maps for DOY 59; middle panels (b, e, h, k, n, q) show the retrieved properties maps for DOY 75 and right panels (c, f, i, I, o, r) show the retrieved properties maps for DOY 203 in 2004. The black circle shows the location of the Vaira site. The reader is referred to Table 3.2 for the definitions of the surface properties.

To better understand the trend of retrieved vegetation properties during the drought episode, we analyzed their changes over time at the Vaira site (Fig. 3.17). $L A I, C_{a b}$, and $C_{w}$ showed an initial increase in normal conditions to the middle of mild stress period (DOY 90) during the episode, but a decrease afterwards (from the middle of mild stress period to severe stress). Maximum $L A I, C_{a b}$ and $C_{w}$ were retrieved at the middle of the mild stress period, as expected for the normal phenological cycle, while the minimum values for these properties were obtained both in the beginning (the normal period) and during the later severe stress period due to drought. 
$C_{\mathrm{dm}}$ and $C_{\mathrm{s}}$ showed the opposite trend compared to $L A I, C_{\mathrm{ab}}$ and $C_{\mathrm{w}}$ : they decreased first, reaching minimal values in the middle of mild stress period and increased later, reaching a maximum at the end of the episode when the stress was severe. The opposite trend of properties between the first group ( $L A I, C_{\mathrm{ab}}$ and $C_{\mathrm{w}}$ ) and the second group ( $C_{\mathrm{dm}}$ and $\left.C_{\mathrm{s}}\right)$ could be expected. When the vegetation is functioning well (i.e., photosynthesis rates are high), it produces more green leaves resulting in higher $L A I$ and, in general high $C_{a b}$ and $C_{w}$ values, while the opposite is true at the end of episode when the brown leaves are dominant and one can observe higher values for $C_{\mathrm{dm}}$ and $C_{\mathrm{s}}$. Despite a few local fluctuations in $L I D F_{a}$, it showed an overall declining trend during the early normal period of the episode indicating more erectophile leaves. However, an opposite trend (i.e., upward) in the mild and moderate period of the episode is observed which indicates more planophile leaves. The maximum values of $L I D F_{a}$ at the end of drought episode indicate that horizontallyoriented (planophile) leaves were dominant, while they were more verticallyoriented (erectophile) leaves in the middle of the episode, albeit with some fluctuations. 
(a)

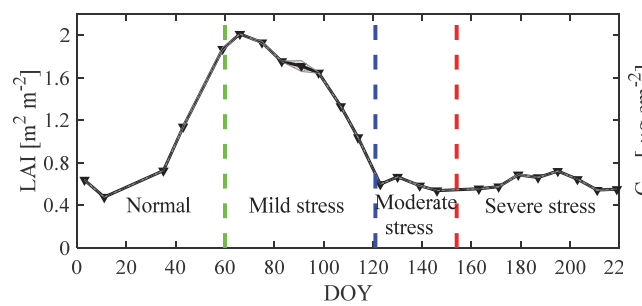

(c)

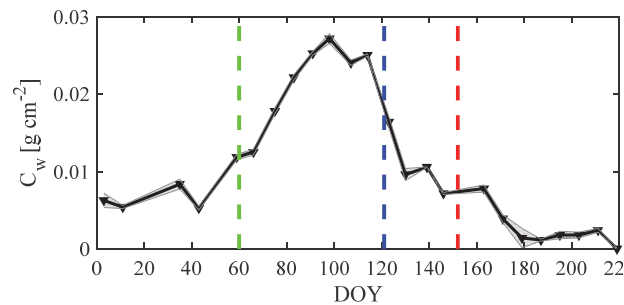

(e)

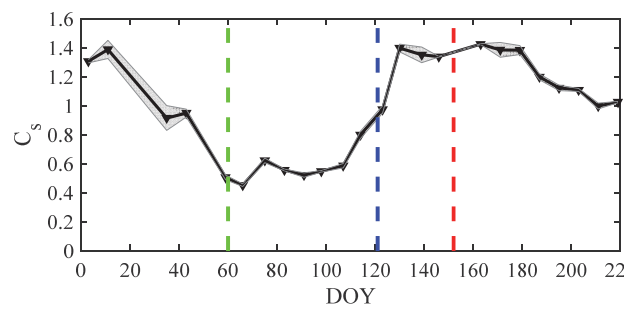

(b)

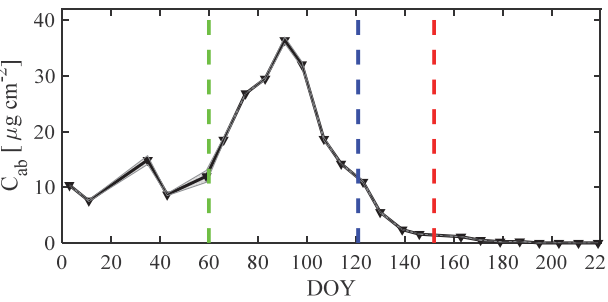

(d)

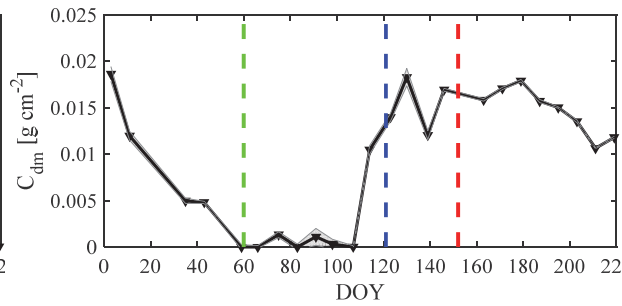

(f)

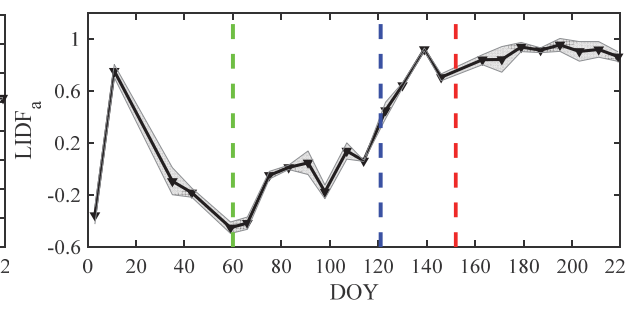

Figure 3.17. Landsat retrieved properties variations at the Vaira site during the selected drought episode: (a) $L A I$; (b) $C_{\mathrm{ab}}$; (c) $C_{\mathrm{w}}$; (d) $C_{\mathrm{dm}}$; (e) $C_{\mathrm{s}}$; (f) $L I D F_{\mathrm{a}}$. Error areas show the uncertainty (standard deviation) in the vegetation properties caused by the uncertainty of the Landsat-observed TOA radiance. Various drought conditions (i.e., normal, mild stress, moderate stress and severe stress) are separated by the color dotted lines.

As presented in section 3.2.5, we used the Jacobian $J$ of the model to investigate the error propagation of TOA radiance observations into the retrieved vegetation properties. The uncertainty in the retrieved properties $\left(L A I, C_{\mathrm{ab}}, C_{\mathrm{w}}, C_{\mathrm{dm}}, C_{\mathrm{s}}\right.$ and $\left.L I D F_{\mathrm{a}}\right)$ originating from the uncertainty in the radiance measurements and propagated to the properties, is small (error regions in Figure 3.17), which could be expected since $L A I$ was known from measurements.

\subsection{Discussion}

\subsubsection{Time series of TOA radiance observations}

The most striking result to emerge from the time series of the observed TOA radiance data is that all spectral bands of Landsat are sensitive to a soil 
moisture deficit (water stress) over time during the episode (Fig. 3.6), and therefore investigation of the whole spectrum, by means of RT modeling, is required to exploit the full potential of the spectral information (Bayat et al., 2016a; Carter, 1991; Chávez et al., 2013; Zarco-Tejada et al., 2003). This indicates that, although extracting the information content from parts of the spectrum by means of VIs can assist in detecting stress signals to some extent, it is more advantageous to exploit all the information in the spectra by using the RT modeling approach.

Water stress effects on TOA radiance spectra can be explained from two stages, notably direct effects, also termed primary impacts, and indirect effects, also termed secondary impacts. Direct effects are considered as the impacts of water shortage (dehydration) on vegetation properties related to the spectral properties of water (this gives an increasing reflectance mostly in the short wave infrared (SWIR) part because of less absorption by water). The indirect effects are considered as the impacts that cannot be explained by the spectral properties of water alone, but that are also related to other changes of canopy and leaf structure and the effects of dehydration on pigment concentrations and defoliation. Both types of impacts are observed in our study. Moreover, as Fig. 3.6 shows, the observations acquired in the first part of the episode show a low radiance in the visible (VIS) and SWIR parts of the spectrum, because of relatively high concentrations of $C_{a b}$ and $C_{w}$, respectively. Our findings are in agreement with the findings of previous studies at leaf (Genc et al., 2013) and canopy level (Bayat et al., 2016a; Elmetwalli et al., 2012). Canopy TOA spectral radiance in band 4 of Landsat [i.e., the near infrared (NIR)] initially increased, but in more severe stages of water stress it decreased. Such a pattern could be explained as a result of cell wall deterioration (Knipling, 1970), loss of plant leaves and the changes in the average leaf angle (Asner, 1998). Radiance increases in the VIS parts of the spectrum, i.e., in bands 1-3, could be well explained by $C_{a b}$ reductions due to the water stress. An increase in radiance in the SWIR parts of the spectrum, bands 5 and 7, occurred due to the decline of $C_{w}$. Our findings of various spectral changes due to water stress support previous studies (Asner, 1998; Chávez et al., 2013; Clevers et al., 2010; Hunt Jr and Rock, 1989). For detailed discussions about vegetation properties changes, radiance variation, and plant-water relations in various conditions (i.e., stressed and normal), the reader is referred to (Damm et al., 2018).

\subsubsection{Coupling RT models}

TOA radiance observations by satellites above a vegetated surface are basically influenced by three main factors: (1) atmospheric conditions, (2) canopy and leaf properties and (3) understory background or soil characteristics (Verhoef and Bach, 2007). Reliable models describing each of these three factors are required to simulate the atmosphere - surface system 
and to obtain accurate retrievals of vegetation properties. In our study, we considered all of these three contributions in our modeling effort.

We applied the MODTRAN atmospheric, RTMo canopy and BSM soil reflectance models as tools to describe the atmosphere - surface system to simulate TOA radiance observations in a time series and, therefore, to retrieve/map vegetation properties directly. Using this physically-based approach has many advantages, as it is based on physical laws, use of all spectral bands, the least reliance on in situ measurements, and it gives generalizable results (Atzberger et al., 2015, 2011). By combining the outputs of MODTRAN to the surface reflectance simulated by the RTMo and BSM models, one can simulate TOA radiance and eliminate the need to perform traditional atmospheric correction. This is significant since even in the best case of atmospheric correction performance, its result is a surface reflectance that is still dependent on atmospheric conditions and the solar zenith angle, unless the surface is both uniform and Lambertian over a large area, but this will never be the case in practice. The retrieval of surface properties by model inversion of TOA radiance data, instead of using surface reflectances obtained after atmospheric correction, is the best way to remove systematic effects related to the solar zenith angle and the atmospheric conditions, since RT models can take these effects implicitly into account. Thus, the proposed TOA approach can narrow down the error sources due to the atmospheric correction but also does justice to the actual physics of the satellite observations by simulating the same quantity as observed by the satellite. We used the combination of 3 RT models to retrieve vegetation properties directly from the time series of Landsat images observed during a prolonged drought episode in which soil moisture content declined 10 -fold from 0.3 to $0.03 \mathrm{~m}^{3} \mathrm{~m}^{-3}$ during a period of 220 days. This episode provided a suitable case to investigate the performance of MODTRAN - RTMo - BSM, since during this episode both atmospheric (different months) and environmental (drought and soil moisture deficit stress) conditions were affecting the vegetation canopy. We can attribute the success of the combined models to their capability of capturing variations of atmospheric conditions (considering various aerosol types and visibilities) and environmental conditions (considering various soil moisture and vegetation properties) using the Landsat optical bands. Landsat time series have been selected for this research mainly because of their great potential due to the spatial and spectral resolution, the foresighted acquisition and global image archive (Wulder et al., 2012), freely available archived and new data sets (Loveland and Irons, 2016), the continuity of the observations (Loveland and Dwyer, 2012) and the ever increasing range of users and applications (Wulder et al., 2008).

To find out the best fitting atmospheric properties one needs to compare the computed surface reflectance of the LUTs with the ground measured reflectance (as ground truth). Since we did not have such ground truth data for 2004, we employed lakes as dark pixels in the Landsat image near the 
study site. However, it would be possible to invert the coupled set of MODTRAN - RTMo - BSM models when more spectral data are available (e.g., hyperspectral images) as well. This would eliminate the need for either ground spectral measurements or dark water bodies in the image. The comparison of generated surface reflectance, from the MODTRAN best fitting parameters over a lake, with the USGS surface reflectance products (http://espa.cr.usgs.gov/) over a lake, has further strengthened our confidence in the atmospheric properties retrieval accuracy. We found negative water reflectances in the USGS surface reflectance products over a lake (Table 3.5), which indeed is due to possible errors in the atmospheric correction and can be attributed to overestimations of the local atmospheric path radiance. Negative reflectance values are physically impossible and can no longer be used as an input for model inversion to retrieve surface properties.

Despite the majority of atmospheric correction methods which assume a Lambertian surface for vegetation canopies, our results indicate that most vegetation canopies are non-Lambertian and this would affect the spectral radiance captured by a remote sensing instrument under different conditions, in particular solar zenith angles. Consequently, the retrieval of vegetation properties would be influenced considerably. Our findings of canopy surface reflectance anisotropy are in agreement with generally recognized nonLambertian characteristics of natural surfaces (Gerstl and Simmer, 1986). Further, the change of the computed anisotropy index during the course of this research (Fig. 3.13 and 3.14) reveals the fact that surface anisotropy has to be taken into account not only in normal periods, when vegetation components are dominant but also during drought conditions (from mild to moderate and severe stress), when the soil background and plant senescence materials are dominant in the field. However, the largest effects of surface anisotropy are observed when the vegetation is in maximum growth conditions in the middle of the episode. Later it decreased by the decline of soil moisture content and vegetation coverage. For instance, comparing the trends in retrieved vegetation properties (Fig. 3.17) and the computed anisotropy index (Fig. 3.14), one can follow how vegetation properties are related to the canopy anisotropy changes during the episode. For instance, the maximum values of $L A I, C_{a b}$, and $C_{w}$ were retrieved at the middle of the mild stress period when higher values of anisotropy index are observed, while the minimum values of $L A I, C_{\mathrm{ab}}$ and $C_{\mathrm{w}}$ were obtained later at severe stress period when lower values of the index are observed. From a modeling perspective, a canopy consisting solely of horizontal leaves is Lambertian if the soil is Lambertian as well, so the $L I D F_{\text {a }}$ parameter would generate the greatest anisotropy when it would become considerably less than unity. In Fig. 3.17 we observe that the retrieved LIDFa is minimum on DOY 60, at the beginning of the mild stress period when LAI, $C_{\mathrm{ab}}$ and $C_{\mathrm{w}}$ are still high.

Lower residuals after spectral fitting for TOA radiance $(0.006<$ RMSE $<$ $2.2 \mathrm{Wm}^{-2} \mathrm{sr}^{-1} \mu \mathrm{m}^{-1}$ for all cases) demonstrate the capability of the coupled 
model to reproduce the observed spectra under different environmental conditions (Fig. 3.11). Overall, a remarkable correspondence was observed between time series of simulated and observed TOA radiances during the episode. This can be explained by the fact that (1) we scaled the dry soil spectra by means of measured soil moisture values to give a realistic soil reflectance for different days (Fig. 3.12) and, therefore, the background contribution was effectively taken into account; (2) we used the a priori information (e.g., $L A I$ and soil moisture) to constrain the inversion, reducing the size of parameter space and ill-posedness; (3) we considered anisotropy effects in the forward modeling instead of assuming a Lambertian surface (Fig. 3.13 and Fig. 3.14), highlighting the anisotropy influence and canopy nonLambertian behavior. This offers indisputable and very powerful evidence for taking the anisotropic surface reflection into account in time series image analysis and RT modeling; and (4) we found the best fitting atmospheric properties during the episode for different days with different magnitudes of the atmospheric transfer functions ( $T-18$ system) for different atmospheric conditions (Fig. 3.9). A wrong assumption about atmospheric properties will result in the wrong computation of TOA radiance data and, consequently, possible errors in spectral fit and the biased retrieval.

\subsubsection{Time series of retrieved properties}

Visual inspection of the retrieved properties trend during this drought episode reveals that all vegetation properties responded to drought stress, but in different ways, with two general categories. For instance, retrieved $L A I, C_{a b}$ and $C_{w}$ showed upward trends from normal condition up to the middle of mild stress period during the episode, while downward trends were observed for the rest of the episode (i.e., moderate and severe stress period). This pattern was opposite for $C_{\mathrm{dm}}, C_{\mathrm{s}}$ and $L I D F$, which decreased initially in the normal condition up to the middle of mild stress, reached to minimal values in the middle and increased afterwards in moderate and severe stress period. The trend of vegetation properties observed during this episode is in agreement with a water stress laboratory experiment conducted by Bayat et al (Bayat et al., 2016a) who demonstrated similar responses of grass to drought stress and reported considerable grass response to a drought experiment as an increase of $C_{\mathrm{dm}}$ and $C_{\mathrm{s}}$, followed by a declining $C_{\mathrm{ab}}, C_{\mathrm{w}}$ and $L A I$. Moreover, the error propagation analysis demonstrated that the possible digitization (sensor) noise embedded in the TOA radiance data does not have significant effects on the retrieved properties. In other words, this analysis indicated that the retrieval results were reliable due to the small error propagated from the assumed sensor noise.

In addition, comparing the trend over time of the retrieved vegetation properties with the trend of measured soil moisture decline during the drought episode demonstrates that there was a time delay in vegetation response (i.e., 16 days for $L A I, 31$ days for $C_{a b}$ and 41 days for $C_{w}$ ) to the soil moisture deficit 
since the soil moisture started declining from DOY $=59$ while vegetation properties decline observed from DOY $75(L A I)$, DOY $90\left(C_{\mathrm{ab}}\right)$ and DOY 100 $\left(C_{\mathrm{w}}\right)$. Furthermore, the $C_{\mathrm{dm}}$ and $C_{\mathrm{s}}$ started increasing from DOY 100 (Fig. 3.17). This may be attributed to the fact that vegetation stress does not manifest when soil moisture deficit is below a certain limit or that water is available deeper in the root zone, but as water stress intensifies the plants will be affected.

It should be noted that the available dataset does not allow us to separate soil moisture deficit effects from those of senescence or the phenological cycle, following the natural vegetation growth cycle, since that seems not to be possible in the absence of a reliable reference (unstressed) case. Doing so would require repeating the analysis for multiple years and retrieving longterm time series of vegetation properties. In this way, one will be able to identify anomalies due to soil moisture deficit (water stress) from the "average" phenology.

\subsubsection{Implications for multi-sensor time series synergy studies}

We coupled various RT models in a bottom-up TOA approach in order to simulate time series of Landsat (TM5 and ETM7) TOA radiances and directly retrieve and map land surface properties. The results look promising and demonstrate the potential of our approach for simulation of time series of other satellite sensors data where the environment, atmospheric and canopy characteristics are varying. The coupled RT model could capture these effects from time series of the observations adequately. For instance, in our case the soil moisture deficit effects on TOA radiances and vegetation properties could be detected in a prolonged drought episode using the coupled RT models. However, there is potential to improve the resolution (spatial, temporal and spectral) and, therefore, to gain more information from the Sentinel missions using our approach. Sentinel-2 provides optical information in 13 bands (covering VIS, NIR and SWIR regions) with spatial resolutions of 10, 20 and $60 \mathrm{~m}$ and an average revisiting frequency of 5 days (Drusch et al., 2012). Thus, it offers a unique opportunity to use more of the information together by applying our coupled approach in an operational way to deliver high spatial resolution (of 10 and $20 \mathrm{~m}$ ) maps of water stress effects on vegetation properties over time. This can be beneficial for both academic (e.g., remote sensing, eco-hydrology, and plant physiology communities) and application oriented (e.g., agriculture and farming) sectors to understand vegetation response to climate change.

The proposed approach may seem to be complex for operational application at first glance. However, to ensure some levels of realism, one has to consider the surface - atmosphere system carefully by coupling a set of RT models to allow the retrieval of surface properties directly from TOA radiance data. The most important advantages of this approach are that (1) a separate 
atmospheric correction of the satellite images is not necessary, (2) the anisotropic surface reflection can be taken into account effectively and (3) the original observations of satellites (Level-1, which are freely available even for new sensors) can be utilized directly. From our point of view, these advantages can pave the way for the operational application of our approach for large multi-scene areas, albeit considering the computation time. The NO approach for the inversion of the proposed coupled model takes about four seconds per pixel on a normal PC. This computation time can be reduced considerably using supercomputer facilities.

In addition, our findings have an important implication for multi-sensor time series synergy studies. The coupled RT model used in this study produces the atmospheric transfer functions and surface reflectance factors in the optical domain from $400 \mathrm{~nm}$ to $2400 \mathrm{~nm}$ with a spectral resolution of 0.1 or $1 \mathrm{~cm}^{\text {घ1 }}$ in wavenumber units (determined by MODTRAN), which at $1000 \mathrm{~nm}$ means 0.01 $\mathrm{nm}$ or $0.1 \mathrm{~nm}$ in wavelength units, respectively. This provides the user with the opportunity to resample the spectra into multiple sensors bands based on known sensor's spectral response functions. In other words, there is no need to make major changes and apply a different modeling approach in case of using various sensor data sets. The only difference is in the last step where the user needs to resample the models outputs based on specific spectral response functions. We believe that this can be considerably beneficial for multi-sensor approaches as well as time series studies in different applications.

\subsection{Conclusions}

A forward modeling TOA radiance approach has been applied to accurately simulate an annual time series of Landsat (TM5 and ETM7) data and to retrieve vegetation properties during a drought episode in space and time. Verifying the performance of different components of the coupled model proves that BSM is able to fairly well reproduce the moist soil reflectance, RTMo is able to reproduce anisotropic TOC vegetation reflectance spectra and MODTRAN is able to accurately reproduce the observed TOA radiance spectra during this drought episode. Thus, it is concluded that the coupled use of these RT models, in a "bottom-up" approach, could be considered as a proper alternative for traditional "top-down" TOC approaches making use of atmospheric correction. The optimization approach for the inversion of the proposed coupled model takes about four seconds per pixel on a normal PC which can be reduced considerably using supercomputer facilities. The proposed approach is relevant for time series image analysis. Certainly in time series of satellite observations over a given target, the dependence of the target's reflectance on the solar zenith angle may interfere with the correct retrieval of true surface properties as a function of time. In addition, variations of the aerosol load in the atmosphere induce variable fractions of diffuse incident sky radiation, for which the target has its own reflectance, the hemispherical-directional reflectance 
factor (HDRF). This means that in time series analyses, also the atmospheric variability as a function of time has to be taken into account. Even with the best possible atmospheric correction, the assumption of isotropic surface reflectance would be inconsistent with RT models that predict anisotropic reflectance behavior. The computed anisotropy index highlights the importance of taking the surface anisotropic reflection into account for simulation of TOA radiance data and provides further evidence that the vegetation canopy is nonLambertian. Moreover, simulated TOA radiance spectra can be sampled by the spectral response functions of arbitrary hyperspectral and multispectral sensor in space. This means that a multitude of optical sensors can give their combined inputs for time series of retrieved biophysical surface properties, thus creating a much denser temporal sampling than would be possible for separate single sensors. This is a key requirement to enable exploring time series of various satellite observations to full extent, unlocking the informative power of combined earth observation data, expanding the number of potential earth observation data users, and allowing earth observation data to become an essential asset for environmental monitoring purposes. Overall, the proposed TOA approach lowers the barrier to time series analysis of satellite images and allows users to obtain desired surface information directly and quickly to support the utilization of the growing volume of earth observation data. From an operational point of view, our TOA approach can be of great help for embedding the time series of available (and also upcoming) satellite observations in operational programs to support management objectives, enable reporting, to inform decision (policy) makers and hopefully benefit our society. 
Appendix A. Atmospheric, sensor geometric and satellite image properties Table 3.6. Input parameters used in this study to describe the real atmospheric and sensor geometric conditions for MODTRAN 5 simulations.

\begin{tabular}{|c|c|c|c|c|c|c|c|}
\hline \multirow{2}{*}{ DOY } & \multirow{2}{*}{ Sensor } & \multirow{2}{*}{$\mathrm{H}_{2} \mathrm{O}\left[\mathrm{g} \mathrm{cm}^{-2}\right]$} & \multirow{2}{*}{$\mathrm{O}_{3}[\mathrm{DU}]$} & \multicolumn{2}{|c|}{ SZA [degree] } & \multicolumn{2}{|c|}{ SAA [degree] } \\
\hline & & & & Image $^{a}$ & Vaira $^{b}$ & Image $^{a}$ & Vaira $^{b}$ \\
\hline 3 & ETM7 & 0.58 & 0.29 & 65.7 & 65.6 & 155.5 & 154.8 \\
\hline 11 & TM5 & 1.7 & 0.29 & 65.9 & 64.9 & 151.9 & 153.4 \\
\hline 35 & ETM7 & 1.2 & 0.31 & 60.5 & 60.3 & 150.4 & 149.6 \\
\hline 43 & TM5 & 0.82 & 0.31 & 59.2 & 59.2 & 146.6 & 145.7 \\
\hline 59 & TM5 & 1.02 & 0.32 & 53.9 & 53.9 & 143.9 & 142.9 \\
\hline 66 & TM5 & 1.75 & 0.32 & 51.4 & 50.7 & 142.8 & 143.4 \\
\hline 75 & TM5 & 1.36 & 0.33 & 48.1 & 48.0 & 141.2 & 140.1 \\
\hline 83 & ETM7 & 1.37 & 0.33 & 43.3 & 43.6 & 142.9 & 141.8 \\
\hline 91 & TM5 & 1.37 & 0.34 & 41.9 & 41.9 & 138.3 & 137.5 \\
\hline 98 & TM5 & 2.01 & 0.34 & 39.4 & 58.7 & 136.9 & 137.0 \\
\hline 107 & TM5 & 1.19 & 0.34 & 36.7 & 36.9 & 134.9 & 133.3 \\
\hline 114 & TM5 & 0.85 & 0.34 & 34 & 33.4 & 133.1 & 133.6 \\
\hline 123 & TM5 & 1.44 & 0.34 & 31.6 & 31.7 & 130.5 & 128.7 \\
\hline 130 & TM5 & 1.8 & 0.34 & 29.9 & 29.3 & 128.4 & 128.8 \\
\hline 139 & TM5 & 1.62 & 0.33 & 28.3 & 28.5 & 125.6 & 123.6 \\
\hline 146 & TM5 & 2.02 & 0.33 & 27.4 & 26.6 & 123.4 & 123.7 \\
\hline 163 & TM5 & 1.67 & 0.32 & 25.1 & 25.3 & 122.0 & 120.2 \\
\hline 171 & TM5 & 1.35 & 0.32 & 26.4 & 26.7 & 118.4 & 116.5 \\
\hline 179 & ETM7 & 1.96 & 0.31 & 25.6 & 25.8 & 120.5 & 118.7 \\
\hline 187 & TM5 & 2.62 & 0.30 & 27.4 & 27.7 & 118.7 & 116.8 \\
\hline 195 & TM5 & 1.31 & 0.30 & 27.2 & 27.3 & 122.1 & 120.4 \\
\hline 203 & TM5 & 2.1 & 0.30 & 29.2 & 29.5 & 121.9 & 120.0 \\
\hline 211 & TM5 & 1.6 & 0.30 & 29.59 & 29.7 & 126.4 & 124.7 \\
\hline 219 & TM5 & 1.57 & 0.29 & 31.9 & 32.1 & 127.3 & 125.6 \\
\hline
\end{tabular}

${ }^{a}$ These values are extracted from Landsat image metadata file.

${ }^{b}$ These geometric variables are calculated for time of satellite overpass at the Vaira site by using NOAA Solar Calculator (https://www.esrl.noaa.gov/gmd/grad/solcalc/).

"This represents "best quality" in Landsat image metadata files. 


\section{Chapter 4 Integrating satellite optical and thermal radiance observations using the SCOPE model ${ }^{*}$}

* This chapter is based on:

Bayat, B., Van der Tol, C., Verhoef, W., 2018. Integrating Satellite Optical and Thermal Infrared Observations for Improving Daily Ecosystem Functioning Estimations during a Drought Episode. Remote Sensing of Environment, 2018, 209, 375-394, https://doi.org/10.1016/j.rse.2018.02.027.

Bayat, B., Van der Tol, C., Verhoef, W., 2018. Estimation of Vegetation Functioning in a Drought Episode from Optical and Thermal Remote Sensing. IEEE International Geoscience and Remote Sensing Symposium IGARSS 2018, Valencia, Spain, 22-27 July 2018. 


\begin{abstract}
Satellite optical and thermal infrared (TIR) spectra are linked to vegetation properties and, therefore, carry valuable information needed for estimating vegetation functioning as expressed in canopy photosynthesis [gross primary production (GPP)] and evapotranspiration (ET). Joint effort is required to fully exploit this satellite spectral information and to demonstrate its capability to reveal ecosystem functioning in various environmental conditions. We investigated the relationship between Landsat (TM5 and ETM7) optical/thermal data and canopy daily functioning of annual C3 grasses at a Fluxnet site (USVar) during a prolonged drought episode. By using the 'Soil-Canopy Observation of Photosynthesis and Energy fluxes' (SCOPE) model, reference GPP and ET were simulated via locally measured weather data, and then actual GPP and ET were simulated twice: first using the vegetation properties retrieved only from the optical bands, and second using information from both the optical and thermal domains. The output of last two simulations were compared to flux tower measurements. For the first simulation, we used the Landsat optical retrieved vegetation properties from Chapter 3 [notably Leaf Area Index $(L A I)$, leaf chlorophyll content $\left(C_{a b}\right)$, leaf water content $\left(C_{\mathrm{w}}\right)$, leaf dry matter content $\left(C_{\mathrm{dm}}\right)$, the leaf inclination distribution function (LIDF) and the senescent material content $\left(C_{S}\right)$ ] covering the period from January to August 2004. All the retrieved vegetation properties were linearly interpolated over time and were used, together with locally measured weather variables, to simulate GPP and ET at half-hourly time steps with SCOPE. For the second simulation, we additionally used TIR information to retrieve the maximum carboxylation capacity $\left(V_{c \max }\right)$, the Ball-Berry stomatal conductance parameter $(m)$ and soil surface and boundary resistances ( $r_{\mathrm{ss}}$ and $r_{\mathrm{bs}}$ ) by inversion of the energy balance and thermal radiative transfer routines of SCOPE, RTMt. The comparison between simulations and measurements shows that most drought effects on ET, GPP and transpiration are 'visible' in the Landsat optical bands. However, the accurate simulation of soil evaporation requires TIR information. The results from this study indicate that the integration of optical and TIR information has a great potential to capture the drought effects on the grass canopy in terms of reductions in daily GPP and ET. Further, it is found that integrating optical and TIR information not only could capture the lower values of GPP and ET during severe drought but also, mapped much higher spatial variability during mild drought.
\end{abstract}




\subsection{Introduction}

Exploiting information contained in both the optical and TIR domains of satellite observations to full extent can assist in detecting daily ecosystem functioning - canopy photosynthesis [gross primary production (GPP)] and evapotranspiration (ET) - variations during a drought episode. This is needed by both social and academic sectors (Lewinska et al., 2016) to better understand the carbon and water cycle feedbacks to climate change (Dong et al., 2015).

Drought influences vegetation in several ways: (1) stomatal effects which change the intrinsic water use efficiency and, therefore, the ratio of photosynthesis to transpiration, and (2) non-stomatal effects which change photosynthetic capacity of the vegetation (Zhou et al., 2013). Both of these effects have been modelled and understood well using experimental data sets (Egea et al., 2011; Keenan et al., 2010a; Zhou et al., 2013). However, the question is: can we detect these effects of drought on GPP and transpiration $(T)$, but also on soil evaporation $(E)$, by means of satellite observations? We assume that in grass most of the non-stomatal effects are due to browning and defoliation (Vicca et al., 2016), which are visible in the optical spectra. However, stomatal effects and soil evaporation become manifest in the TIR domain (Anderson et al., 2007a, 2007b; Crow et al., 2008).

Two approaches to estimate GPP from satellite data are widely used: (1) using the Monteith production efficiency concept (Monteith, 1972), in which GPP is linked to the absorbed amount of photosynthetically active radiation (APAR) and (2) using empirical models, in which the relationship is explored between ground measured GPP and satellite observed spectral information (Song et al., 2013). Regardless of the methodological differences between these approaches, the remote sensing information has been used in both by means of Vegetation Indices (VIs), mostly by, but not limited to, the Enhanced Vegetation Index (EVI) and Normalized Differences Vegetation Index (NDVI). For instance, Dong et al (2015) investigated the performance of four EVI-based models to estimate GPP in one grassland and two croplands (maize and soybean) in the US. They examined the relationship between two vegetation indices (NDVI and EVI) and measured GPP under two different conditions; nondrought and drought years. They concluded that satellite information, obtained as EVI and NDVI, could capture GPP changes at different sites, however, the EVI explained more variance of GPP in both non-drought and drought conditions (Dong et al., 2015). In another study, Vicca et al (2016) extracted the information content of MODerate-resolution Imaging Spectroradiometer (MODIS) reflectance spectra to identify drought effects on GPP. They examined MODIS-derived EVI, NDVI, Simple Ratio (SR), Global Environmental Monitoring Index (GEMI), Normalized Differences Water Index (NDWI) and Photochemical Reflectance Index (PRI) in detecting severe drought effects on annual GPP in a beech forest, an evergreen broadleaved oak forest and a grassland. They 
concluded that the majority of long-term drought effects on GPP could be detected by EVI and the normalized PRI at the beech forest site and the evergreen broadleaved oak forest, while all of the examined indices captured the drought effects at the grassland site. Overall, the above-mentioned and many more studies (Dong et al., 2015; Gitelson et al., 2014; Maselli et al., 2009; Peng et al., 2011; Verma et al., 2015; Wagle et al., 2015, 2014, Wu et al., 2011, 2009, Xiao et al., 2004a, 2004b) demonstrated the capability of information from optical bands to estimate GPP.

Similarly, two widely-used approaches to estimate ET using satellite information are (1) using the surface energy balance (SEB) approach, in which the land surface temperature (LST) information from TIR bands is used and (2) using empirical models, in which the statistical relationship is explored between ground measured ET and satellite observed optical bands (K. Zhang et al., 2016). The first approach (SEB) makes use of the fact that LST is determined by the partitioning of available energy into latent (LE) and sensible heat flux $(\mathrm{H})$. This approach has been widely used in previous studies to estimate ET. For instance, Su et al (2005) reported that the accuracy of The SEB System (SEBS) model in estimating ET could reach $10-15 \%$ of in-situ measurements for range of evaporation fraction from $0.5-0.9$ (Su et al., 2005). In addition, The SEB algorithm for land (SEBAL) has been applied to estimate ET under various climatic conditions at the field scale and good accuracy has been reported for daily (85\%) and seasonal (95\%) estimations (Bastiaanssen et al., 2005; Bastiaanssen, 2000). Based on the SEBAL method, Allen et al proposed the Mapping EvapoTranspiration with high Resolution and Internalized Calibration (METRIC) model in which ground-based ET is used to calibrate the SEB internally resulting in computational bias reduction (Allen et al., 2007). How to determine the hot and cold pixels, which are needed for both SEBAL and METRIC, are also discussed in previous studies (Long and Singh, 2012). In another study, Gonzalez-Dugo et al (2009) compared the performance of the Two-Source Model (TSMN), that proposed by Norman et al (Norman et al., 1995), with two one-source SEB model in estimating ET over rain-fed corn and soybean in central Iowa. They concluded that although all three models could estimate ET with reasonable accuracy, the TSMN model was performed the best (with the lowest RMSE) compared to the ground measurements (Gonzalez-Dugo et al., 2009). Considerable research has been conducted to improve the TSMN (Kustas and Norman, 1999, 1996; Li et al., 2005; Norman et al., 2000; Sánchez et al., 2008). Many more studies used the above-mentioned SEB models and, therefore, estimated ET variations from satellite TIR data with acceptable accuracy (as reviewed in (Glenn et al., 2007; Liou and Kar, 2014; K. Zhang et al., 2016)). In the second approach to estimate ET, the optical spectral bands are utilized to relate them to flux tower measurements of ET. For instance, Nagler et al (2005) established a relationship between MODIS-derived EVI, NDVI and ground measured ET collected at four flux towers at different riparian sites over 4 years located in 
New Mexico. They have demonstrated that EVI and NDVI were fairly correlated with ET (Nagler et al., 2005). In another study, Cleugh et al (2007) used MODIS-derived NDVI together with meteorological inputs to estimate ET in two various ecosystems in Australia. They established a relationship between remote sensing and ground measurements, showing their method's validity over regional scales (Cleugh et al., 2007). Overall, there are numerous similar studies using satellite optical data to estimate ET variations in croplands and natural environments (as reviewed in (Glenn et al., 2010)).

As described above in both cases (GPP and ET estimation), only a fraction of the available satellite data, either from optical or TIR domain, is employed in order to explain the changes in carbon and water fluxes. On the one hand, the models simulating GPP and ET from satellite optical data mostly use VIs. These are simple to compute and provide useful information about physiological processes (Glenn et al., 2008). However, there are three limitations for using such VIs; (1) They are only based on a few individual bands located in the optical domain and by adopting them, as a consequence, important pieces of information in the other bands is ignored; (2) the majority of VIs do not include information from the TIR domain and (3) the empirical models which are based on VIs have shown acceptable accuracy only at a time scale of weeks to years and, therefore, are unable to capture ecosystem functioning variations with acceptable accuracy at time scales of days or shorter (Glenn et al., 2007; Liou and Kar, 2014). On the other hand, although the models estimating ET from satellite TIR data through SEB approach showed acceptable performance, the lack of a one-to-one correspondence between the surface temperature and $H$ due to mainly the wind and aerodynamic resistance causes considerable uncertainty in the $L E$ flux derived with this method (Glenn et al., 2008).

Thus, the potential of utilizing the full spectral information, from the optical and TIR domains together, is still unexplored. An alternative method is to exploit the information from all available optical and TIR spectral bands in a consistent way by means of Radiative Transfer (RT) models and to simulate vegetation functioning by means of a Soil-Vegetation-Atmosphere Transfer (SVAT) model. Limited work has been done in this direction and we address this gap in our study.

Hence, this study intends to use Soil-Canopy Observation of Photosynthesis and Energy fluxes (SCOPE) (Van der Tol et al., 2009b) to exploit the information contained in Landsat optical and TIR images to full extent in order to estimate daily GPP and ET simultaneously in a drought episode. This way, it is possible to assess the information of all bands together, and to analyze which drought effects can be observed using optical information offered by a remote sensing satellite and what would be the added value of using TIR data. 


\subsection{Data}

\subsubsection{Site description}

The study focussed on the Vaira Ranch (US-Var) Fluxnet site, hereafter called Vaira site. It is an open grassland (see Fig. 3.2 in chapter 3), in a Mediterranean climate, at $129 \mathrm{~m}$ altitude at the foothills of the Sierra Nevada in California (38.4133 $\mathrm{N} ; 120.9508^{\circ} \mathrm{W}$ ), in the USA (Baldocchi et al., 2004; Ma et al., 2016, 2007; Xu and Baldocchi, 2004). Most rainfall events occur from October to May. The mean annual temperature and precipitation in the region are $16.6^{\circ} \mathrm{C}$ and $559 \mathrm{~mm}$, respectively. The species composition varies per year as a function of rainfall and air temperature (Ma et al., 2011). The grassland is physiologically functioning from September to May, with the peak growth period in late February to early April. In this period, the maximum grass height reaches $0.55 \pm 0.12 \mathrm{~m}$. The soil type is silty loam (30/57/13\% sand/silt/clay). A prolonged drought occurred at the site in 2004 and it was reported as one of the driest years at the site (Ma et al., 2007).

\subsubsection{Drought severity data}

We defined drought based on the Palmer Drought Severity Index (PDSI), in which drought is considered as a prolonged and abnormal soil moisture deficiency (Alley, 1984; Palmer, 1965).

In this study, the time series of the PDSI dataset were obtained from a monthly database of the NOAA's National Centers for Environmental Information (NCEI), (www.ncdc.noaa.gov/temp-andprecip/drought/historical-palmers), in which various drought conditions have been identified at the site using long-term PDSI. More details are presented in the results section.

\subsubsection{Remote sensing observations}

In the current study we used time series of Landsat-retrieved vegetation properties from optical domain (described in Chapter 3, Fig. 3.17) during the selected period at the Vaira site. In addition, Landsat TIR band information is used to constrain the SCOPE model. Fig. 4.1. shows the Landsat TIR images we used during the drought episode. For the days with a satellite overpass, the retrieved properties were used. For the other days during the episode in which Landsat observations were not available, a linear interpolation was applied and, therefore, a continuous set of needed vegetation properties obtained for all days during the episode. The Landsat data used in this study were contained in standard L1T files obtained from the US Geological Survey (USGS) website (http://glovis.usgs.gov/). 


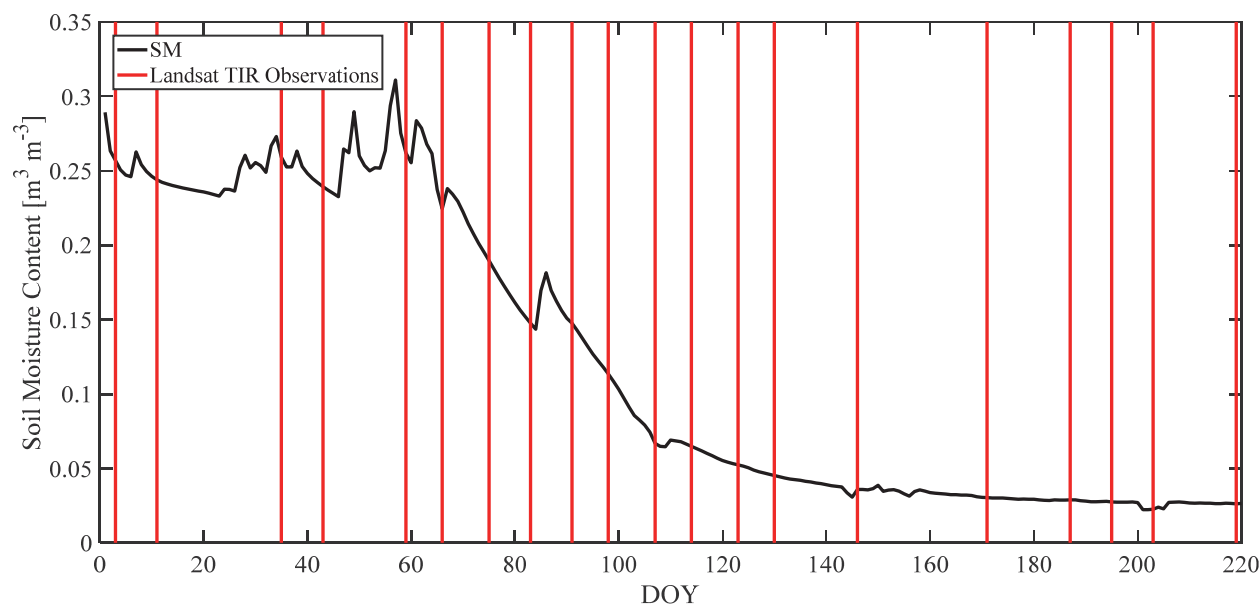

Figure 4.1. Daily time series of the surface soil moisture at the study site in 2004 . The red lines show the imaging times of Landsat TIR observations.

\subsubsection{Ground measurements}

We used half-hourly scale ground measurements of solar radiation fluxes, air temperature, relative humidity, air pressure, volumetric surface soil moisture content (at $2 \mathrm{~cm}$ depth) and wind speed. Radiation fluxes were measured above grass canopies using upward and downward facing quantum sensors; (PAR Lite, Kipp and Zonen, Delft, Netherlands), a pyranometer (CM 11, Kipp and Zonen, Delft, Netherlands), and one net radiometer (NR Lite, Kipp and Zonen, Delft, Netherlands). Temperature and relative humidity were collected using a resistance thermometer and solid-state humicap (model HMP45A, Vaisala, Helsinki, Finland). Air pressure was measured by capacitance barometers (model PTB101B, Vaisala, Helsinki, Finland). Volumetric soil moisture content was measured by an array of calibrated frequency domain reflectometry sensors at depths of surface, 2, 10 and $20 \mathrm{~cm}$ (Theta Probe model ML2-X, Delta-T Devices, Cambridge, UK), calibrated by gravimetric measurements. Fluxes were measured with an Eddy Covariance (EC) system (Wind master Pro, Gill Instruments, Lymington, UK plus LI-7500, LICOR, Lincoln, NE, USA), as reported by Baldocchi et al (2004) and Ma et al (2007). Moreover, $L A I$ was measured periodically from canopy peak growth to the end of the drought episode at intervals of 2-4 weeks. Grass was collected from three sample plots $(0.2 \mathrm{~m} \times 0.2 \mathrm{~m})$ in the prevailing direction of the eddy covariance flux system. Then all grass leaves were separated from the stem component and their green areas were measured by a leaf area meter ( $\mathrm{Li}-\mathrm{Cor}$ 3100, Lincoln, NE, USA).

\subsection{Methods}

There were four phases in this study. In the first phase, the best fitting atmospheric [notably Visibility (Vis), and Aerosol model (Aer)] and vegetation 
properties [notably Leaf Area Index $(L A I)$, leaf chlorophyll content $\left(C_{a b}\right)$, leaf water content $\left(C_{\mathrm{w}}\right)$, leaf dry matter content $\left(C_{\mathrm{dm}}\right)$, the leaf inclination distribution function ( $L I D F)$ and the senescent material content $\left(C_{s}\right)$ ] obtained by coupled use of the MODTRAN and RTMo models from optical domain of Landsat observations (this is described in Chapter 3 ). In the second phase, the retrieved vegetation properties were linearly interpolated over time and then used with half-hourly scale weather inputs in the SCOPE model to simulate daily time series of GPP and ET. The results were compared to the field measurements to assess the information content from the optical bands regarding drought effects on GPP and ET. In the third phase, we added new information from the TIR domain to the simulations. For this purpose, we inverted the energy balance and thermal radiative transfer routines of SCOPE, RTMt, and retrieved time series of the maximum carboxylation capacity $V_{\text {cmax }}$, the Ball-Berry stomatal parameter $m$, soil surface resistance for evaporation $r_{\text {ss }}$ and soil boundary resistance $r_{\text {bs }}$ during the episode. Next, by using the best fitting parameters from both optical and TIR domains, we simulated daily GPP and ET with the SCOPE model. To eliminate the effect of fluctuations in weather conditions, we normalized GPP and ET to reference GPP and ET of unstressed hypothetical green grass in order to obtain crop factor. The main phases of the methodology are shown in Fig. 4.2. 


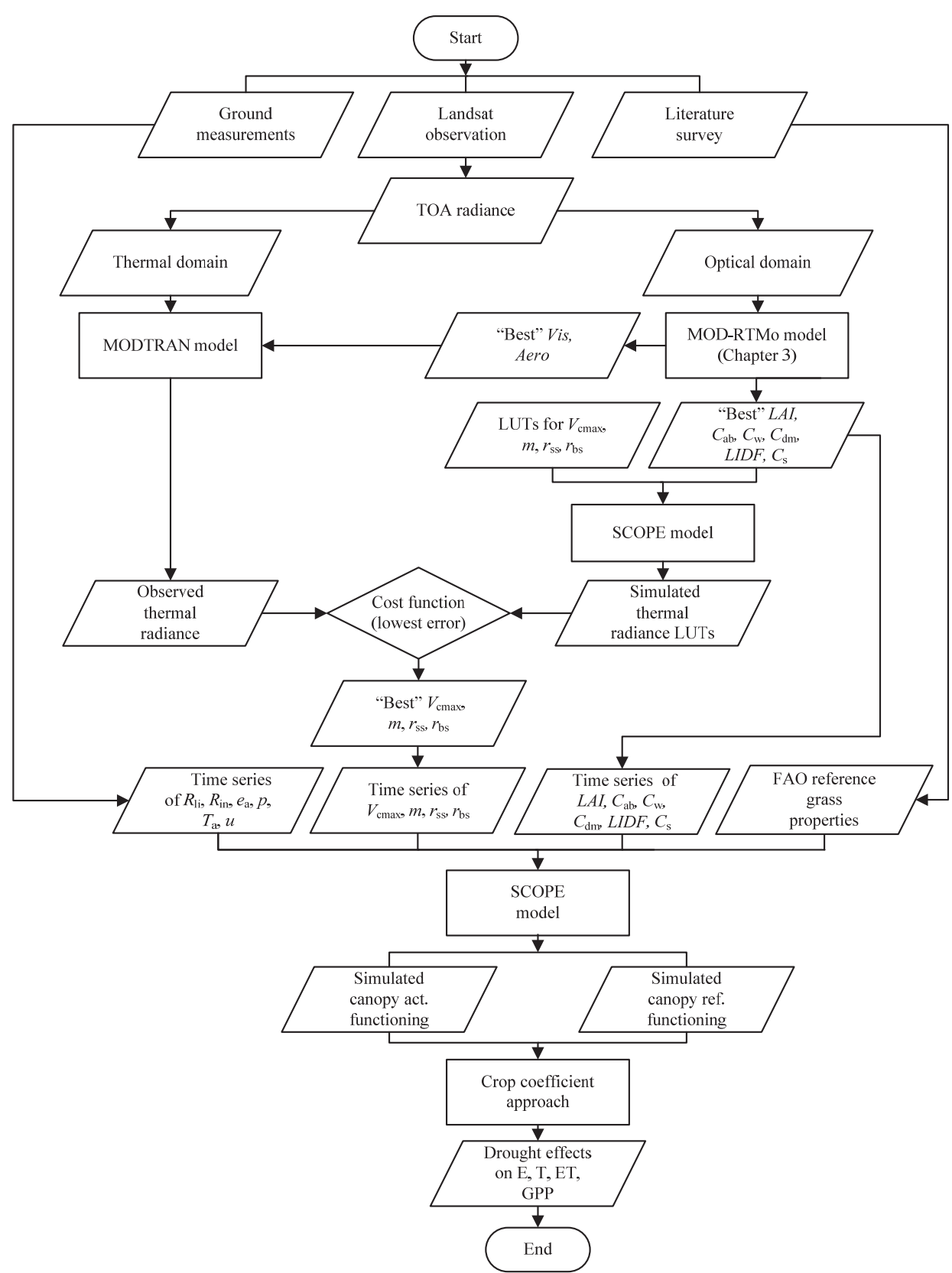

Figure 4.2. Flowchart of the adapted approach

The first phase, obtaining the best fitting atmospheric (Vis, Aer) and vegetation properties (LAI, Cab, Cw, Cdm, LIDF, Cs), is presented in chapter three of this dissertation in details. Before proceeding to the second, third and fourth phase to simulate fluxes with SCOPE model, it is required to perform atmospheric correction for the TIR band of Landsat. 


\subsubsection{Atmospheric correction of TIR band}

Atmospheric correction for the TIR domain (band 6 of Landsat), was carried out with MODTRAN simulations. The TOC surface radiance for the TIR band was computed as (Verhoef and Bach, 2012):

$$
L_{s}=\frac{L^{\mathrm{TOA}}-L_{a}(t)-(1-\varepsilon) L_{a}(b) \tau}{\varepsilon \tau}
$$

where $L_{s}$ is the TOC surface radiance $\left(\mathrm{Wm}^{-2} \mathrm{sr}^{-1} \mu \mathrm{m}^{-1}\right), L^{\text {TOA }}$ is the observed TOA radiance by the sensor $\left(\mathrm{Wm}^{-2} \mathrm{sr}^{-1} \mu \mathrm{m}^{-1}\right), L_{a}(t)$ is the TOA radiance for zero surface albedo $\left(\mathrm{Wm}^{-2} \mathrm{sr}^{-1} \mu \mathrm{m}^{-1}\right), L_{\mathrm{a}}(b)$ is the radiance from the bottom of the atmosphere for a surface albedo of one $\left(\mathrm{Wm}^{-2} \mathrm{sr}^{-1} \mu \mathrm{m}^{-1}\right), \tau$ is direct transmittance in the direction of observation, $\varepsilon$ is surface emissivity which was estimated for different days during the episode based on the NDVI Thresholds Method (Sobrino et al., 2008) as follows:

$$
\begin{aligned}
& \varepsilon=\varepsilon_{v} P_{v}+\varepsilon_{s}\left(1-P_{v}\right) \\
& P_{v}=\left(\frac{N D V I-N D V I_{S}}{N D V I_{V}-N D V I_{S}}\right)^{2}
\end{aligned}
$$

where $\varepsilon_{v}$ and $\varepsilon_{s}$ are vegetation and soil emissivity, respectively, $P_{v}$ is the proportion of vegetation which is also termed as fractional vegetation cover $(F V C), N D V I$ is the normalized difference vegetation index calculated from red and near infrared bands of Landsat, NDVIV and NDVIs are referred to as the NDVI of a vegetated pixel and a soil pixel. We considered $0.98,0.94$ for $\varepsilon_{v}$ and $\varepsilon_{s}$ in our study (Sobrino et al., 2008; Valor and Caselles, 1996). In addition, the maximum and minimum NDVI values computed for the selected episode (0.79 and 0.25 ) were used for $N D V I_{\mathrm{V}}$ and $N D V I_{\mathrm{s}}$.

\subsubsection{Simulation of fluxes with SCOPE}

The SCOPE model differentiates shaded and sunlit parts in 60 leaf layers and the soil. Leaf orientations are described by the zenith (with a distribution provided as input) and azimuthal angles (assumed uniformly distributed) of the leaf's normal. The wavelength range of radiative transfer computations in the model is from 0.4 to $50 \mu \mathrm{m}$, with different sampling intervals in the optical $(0.4-2.5 \mu \mathrm{m})$, thermal $(2.5-15 \mu \mathrm{m})$ and longwave regions $(15-50 \mu \mathrm{m})$ of, respectively, $0.001,0.1$ and $1 \mu \mathrm{m}$. In the energy balance module of the model, an energy budget and the surface temperature are solved for each sunlit leaf zenith and azimuth class in each layer, for each layer in the shaded parts, and for sunlit and shaded soil. SCOPE iterates between a RTM for thermal radiation, and a micro-meteorological scheme for turbulent fluxes until energy balance closure is achieved for all these elements. The model computes the leaf $\mathrm{CO}_{2}$ assimilation rate and gas exchange for $\mathrm{C} 3$ and $\mathrm{C} 4$ vegetation (Collatz et al., 
$1992,1991)$. The main parameters considered in calculating the aerodynamic resistance of the soil and the canopy are $L A I$, canopy height, wind speed and the atmospheric stability according to (Wallace and Verhoef, 2000).

In this study, the Landsat optical domain retrieved vegetation properties (Fig 3.17, chapter 3 ) and the half-hourly scale meteorological variables, i.e., TOC incoming shortwave radiation from 0.3 to $2.5 \mu \mathrm{m}(R$ in $)$, TOC incoming long wave radiation from 2.5 to $50 \mu \mathrm{m}\left(R_{\mathrm{li}}\right)$, air pressure $(p)$, air temperature $\left(T_{\mathrm{a}}\right)$, actual vapor pressure $\left(e_{a}\right)$, and wind speed $(u)$ were used as inputs for the SCOPE model to quantify the time series of canopy functioning (fluxes). In addition, the SCOPE partitions canopy transpiration $(T)$ and soil evaporation (E). Besides the retrieved vegetation properties from the Landsat optical bands, there are four other parameters relevant for the SCOPE model that cannot be retrieved from optical domain directly. These are the Ball-Berry stomatal parameter $m$, the maximum rate of carboxylation $V_{\mathrm{cmax}}\left(\mu \mathrm{mol} \mathrm{\textrm {m } ^ { - 2 } \mathrm { s }}\right.$ $\left.{ }^{1}\right)$, the soil resistance for evaporation from the pore space, $r_{s s}$; and soil boundary layer resistance, $r_{\text {bs }}$ (both in $\mathrm{s} \mathrm{m}^{-1}$ ). However, one can get an estimation for these parameters if the TIR domain information is also provided.

To analyze the added value of Landsat information from both domains, we ran SCOPE version 1.61 with four different scenarios. In the first scenario, called "Reference", we did not use the time series of retrieved properties from Landsat. Instead, we followed the "FAO-56" (Allen et al., 1998) definition for the hypothetical reference grass as much as possible to simulate canopy reference GPP and ET. Further, we consult with the literature to obtain other needed parameters (Table 4.1). This way, we can monitor vegetation functioning changes in an unstressed reference grass when the only limiting factor is irradiance and atmospheric demand. In the second scenario, called "Landsat Optical Info", we used all the retrieved vegetation properties from the optical bands, i.e. time series of $\angle A I, C_{\mathrm{w}}, C_{\mathrm{ab}}, C_{\mathrm{dm}}, C_{\mathrm{s}}$ and $L I D F$. In this scenario

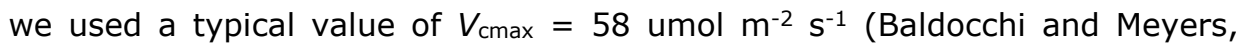
1998; Wullschleger, 1993); for $m$, a constant value of 10 (Wolf et al., 2006; $\mathrm{Xu}$ and Baldocchi, 2003); for $r_{\mathrm{ss}}$ and $r_{\mathrm{bs}}$, the default values in the SCOPE model of 2000 and $10\left(\mathrm{~s} \mathrm{~m}^{-1}\right)$, respectively (Van der Tol et al., 2009b). In the third scenario, called "Landsat optical info/ $V_{\mathrm{cmax}}=\mathrm{f}\left(\mathrm{C}_{\mathrm{ab}}\right)$ ", we had almost the same settings as for the second scenario except for $V_{c m a x}$. Instead of considering a fixed typical value for $V_{\text {cmax }}$, we estimated its time series variation based on an empirical equation proposed between $V_{c m a x}$ and satellite retrieved $C_{a b}$ (Houborg et al., 2013). The goal was to see the changes of vegetation functioning when we are still relying on optical domain information both directly (from retrieved properties) and indirectly (from empirical relationships). In the last scenario, called "Landsat Optical/TIR Info", we added new information from the TIR domain to the simulations. For each day during the drought episode, a Look up Table (LUT) was generated with 28980 entries, of which the $5 \%$ were selected that matched best with the Landsat atmospherically corrected radiance in the TIR band. Each LUT consisted of values of $V_{\text {cmax }}$ (from 1-110 
$\mu \mathrm{mol} \mathrm{m} \mathrm{m}^{-2} \mathrm{~s}^{-1}$ with 5 increment), $m$ (from $1-20$ with 1 increment), $r_{\mathrm{ss}}$ (values of $100,200,500,1000,2000,5000,50000 \mathrm{~s} \mathrm{~m}^{-1}$ ) and $r_{\mathrm{bs}}$ (values of $1,10,50$, $\left.100,150,200,250,300,500 \mathrm{~s} \mathrm{~m}^{-1}\right)$. The model was run for all parameter combinations $(23 \times 20 \times 7 \times 9=28980$ simulations $)$ with all other meteorological inputs and parameters values of the overpass time, and the Landsat TIR radiance was simulated using the spectral response function of the Landsat thermal band. The average of the $5 \%$ best performing combinations of parameters was used as retrieved parameters rather than the single best, following Cambal et al (2003). Finally, we ran the SCOPE model using the interpolated parameters from the TIR data combined with the parameters retrieved from the optical domain, thus using all the information obtained from both optical and TIR to simulate daily GPP and ET.

Table 4.1. Vegetation properties obtained from literature to simulate daily GPP and ET for "Reference" scenario.

\begin{tabular}{lccc}
\hline Parameters & Unit & Value & References \\
\hline$L A I$ & $\mathrm{~m}^{2} \mathrm{~m}^{-2}$ & 2.88 & (Allen et al. 1998) \\
$C_{\mathrm{ab}}$ & $\mu \mathrm{g} \mathrm{cm}^{-2}$ & 49.66 & (Darvishzadeh et al. 2008) \\
$C_{\mathrm{w}}$ & $\mathrm{g} \mathrm{cm}^{-2}$ & 0.02 & (Darvishzadeh et al. 2008) \\
$C_{\mathrm{dm}}$ & $\mathrm{g} \mathrm{cm}^{-2}$ & 0.005 & (Darvishzadeh et al. 2008) \\
$C_{\mathrm{s}}$ & - & 0.02 & (Bayat et al., 2016a) \\
$L I D F_{\mathrm{a}}$ & - & -0.35 & (Van der Tol et al. 2009) \\
$L I D F_{\mathrm{b}}$ & - & -0.15 & (Van der Tol et al. 2009) \\
$V_{\mathrm{cmax}}$ & $\mathrm{umol} \mathrm{m}^{-2}$ & 98.27 & (Houborg et al., 2013) \\
$m$ & $\mathrm{~s}^{-1}$ & 10 & (Xu and Baldocchi, 2003) \\
$r_{\mathrm{ss}}$ & - & 500 & (Van der Tol et al. 2009) \\
$r_{\mathrm{bs}}$ & $\mathrm{s} \mathrm{m}^{-1}$ & 10 & (Van der Tol et al. 2009) \\
$r_{\mathrm{wc}}$ & $\mathrm{s} \mathrm{m}^{-1}$ & 70 & (Allen et al. 1998) \\
$h c$ & $\mathrm{~s} \mathrm{~m}^{-1}$ & 0.12 & (Allen et al. 1998) \\
\hline
\end{tabular}

\subsubsection{Crop factors}

We used the SCOPE model to compute a time series of reference ET (ETRef) following mostly the "FAO-56" (Allen et al., 1998) definition for reference hypothetical grass and also previous studies (Table 4.1). In addition, we defined and computed the reference value for GPP (GPPRef) from the same simulation, to establish the photosynthesis rate in the reference grass when there are no restrictions other than atmospheric demand. In fact, we used the same tool (SCOPE model) and, therefore, similar formulations for simulating $\mathrm{ET}_{\text {Ref }}$ and GPP Ref as the actual ET and GPP. The difference between the reference and actual quantities (ET and GPP) is due to the inputs we used in the SCOPE model for each case. For the case of reference ET and GPP, we used inputs describing the reference hypothetical grass extracted from "FAO-56" and 
literature (Table 4.1), however, for the case of actual ET and GPP we used Landsat derived information as the SCOPE inputs. We considered the net canopy photosynthesis $A_{n}$ as a proxy for flux tower footprint GPP, thus ignoring some conceptual differences between canopy photosynthesis and fluxpartitioned GPP. This is reasonable since previous studies have shown that the GPP estimated with the flux partitioning approach produced estimates that were fairly close to the canopy photosynthesis (Wohlfahrt and Gu, 2015). Finally we computed the crop coefficients as:

$$
\begin{aligned}
& K_{c E T}=\frac{E T}{E T_{\operatorname{Re} f}} \\
& K_{c G P P}=\frac{G P P}{G P P_{\operatorname{Re} f}}
\end{aligned}
$$

where $K_{\mathrm{c} \text { ET }}$ and $K_{\mathrm{c} \text { GPP }}$ are the crop factors (unitless) calculated for ET and GPP, respectively.

We also computed the dual crop factor and separate soil evaporation from canopy transpiration:

$$
\begin{gathered}
K_{c b}=\frac{T}{T_{\operatorname{Re} f}} \\
K_{e}=\frac{E}{E_{\operatorname{Re} f}}
\end{gathered}
$$

where $K_{\mathrm{cb}}$ is the basal crop coefficient (unitless) and describes the canopy transpiration, $K_{\mathrm{e}}$ is the soil evaporation (unitless) describing the evaporation component, $T$ is simulated transpiration $\left(\mathrm{mm} \mathrm{d}^{-1}\right), T_{\text {Ref }}$ is simulated reference transpiration $\left(\mathrm{mm} \mathrm{d}^{-1}\right), E$ is simulated evaporation $\left(\mathrm{mm} \mathrm{d}^{-1}\right)$ and $E_{\text {Ref }}$ is simulated reference evaporation $\left(\mathrm{mm} \mathrm{d}^{-1}\right)$. For comparison, we also calculated $\mathrm{ET}_{\text {Ref }}$ with the proposed model by FAO Penman-Monteith (PM) for the reference grass (Allen et al., 1998).

\subsubsection{Model performance evaluation}

The goodness-of-fit measures of $\mathrm{R}^{2}$ (coefficient of determination) and RMSE (root mean squared error) used for assessing model inversion performance. In addition, Taylor diagram (Taylor, 2001), was employed to evaluate the agreement between simulated and measured GPP, ET, $K_{c}$ GPP and $K_{\mathrm{C}} \mathrm{ET}$ in details. It is worth noting that in a Taylor diagram only two components of the error budget (the difference of the standard deviations and the correlation) are addressed and, therefore, the bias of the mean values is still missing. To consider also the bias, we decomposed the MSE (mean squared error) into three contributions, due to 1) unequal standard deviations, 2) a lack of (positive) correlation and 3 ) the bias in the mean values, as expressed in Eq. 4.8 and also shown in previous studies (Gupta et al., 2009). 


$$
M S E=\left(\sigma_{s}-\sigma_{g}\right)^{2}+2 \sigma_{s} \sigma_{g}(1-R)+(\bar{s}-\bar{g})^{2}
$$

where $\sigma_{\mathrm{s}}, \sigma_{\mathrm{g}}$ are standard deviations of the simulation and ground measurement, $\mathrm{R}$ is the correlation coefficient, $\bar{s}$ and $\bar{g}$ are the means of model simulation and ground measurement.

This decomposition has a considerable advantage. It expresses well that only positive correlations can contribute to accomplishing a lower MSE, whereas for instance $\mathrm{R}^{2}$ can also be high if the correlation is negative, so $\mathrm{R}^{2}$ alone is not a good measure of the correspondence between model and measurement.

\subsection{Results}

\subsubsection{Drought status at the site}

At the site, the monthly PDSI ranges between 0.44 to -3.26 from January to the end of August (Table 4.2). Several drought conditions, i.e. mild, moderate and severe, have been identified in the selected episode. PDSI values suggests near-normal conditions at the site from the first of January (DOY 1) until the end of February (DOY 60). During this near-normal period, grasses remained low in photosynthesis due to low temperatures. Drought with more severity, i.e., mild, moderate and severe were recorded from the first of March (DOY 61) till the end of August (DOY 244).

Table 4.2. PDSI variation for the selected episode at Vaira site

\begin{tabular}{llll}
\hline DOY & PDSI & Drought Status \\
\hline $1-31$ & 0.44 & Normal & Near normal \\
$32-60$ & 0.64 & & Near normal \\
\hline $61-91$ & -1.09 & & Mild drought \\
$92-121$ & -1.83 & & Mild drought \\
$122-152$ & -2.5 & Drought & Moderate drought \\
$153-182$ & -3 & & Severe drought \\
$183-213$ & -3.26 & & Severe drought \\
$214-244$ & -3.25 & & Severe drought
\end{tabular}

\subsubsection{TIR radiance variations}

The atmospherically corrected TIR radiance variation during the selected episode is presented in Fig. 4.3. Radiance in TIR band shows a global upward trend over time (from DOY 3 to DOY 187). However, at the end of the episode (from DOY 187 to DOY 219), TOC radiance of the TIR band started declining. 


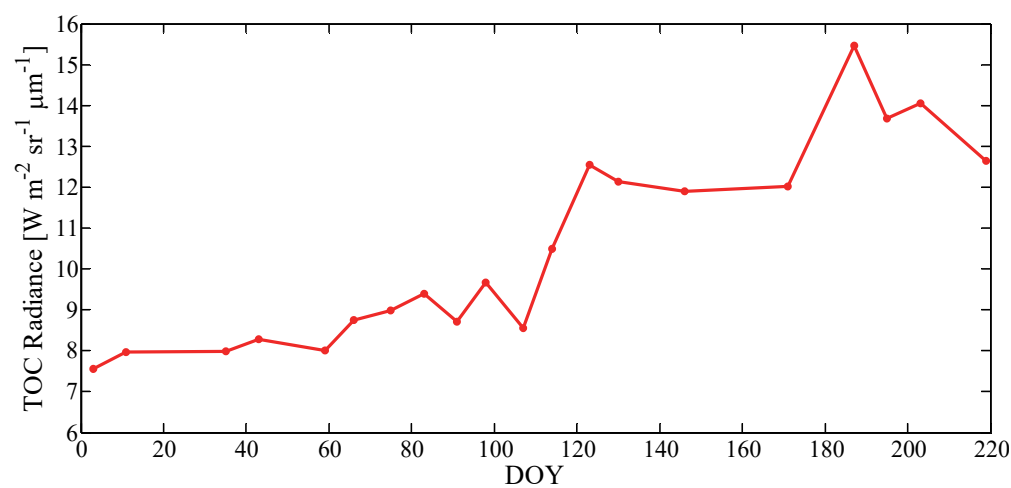

Figure 4.3. Landsat TOC radiance changes during drought episode as a function of time.

\subsubsection{Vegetation functioning (GPP and ET) variations}

Fig. 4.4 illustrates the daily GPP and ET variations in the selected episode at the site. GPP and ET followed almost the same trends in the episode. They are increasing initially (from DOY 1 till 90) and decreasing afterwards (from DOY 91 till 220). The minimum $\left(0.0 \mu \mathrm{mol} \mathrm{m} \mathrm{m}^{-2} \mathrm{~s}^{-1}\right)$ and the maximum $(8.8 \mu \mathrm{mol}$ $\mathrm{m}^{-2} \mathrm{~s}^{-1}$ ) GPP values were recorded at DOYs $150-220$ and 91 , respectively. Thus the range of GPP was $8.8\left(\mu \mathrm{mol} \mathrm{m} \mathrm{m}^{-2} \mathrm{~s}^{-1}\right)$. The minimum value of ET $(0.023$ $\mathrm{mm}$ day $^{-1}$ ) was recorded at the end of the episode, while the maximum value (3.12 $\mathrm{mm} \mathrm{day}^{-1}$ ) was recorded at DOY 101. Thus, the range of ET was $3.1 \mathrm{~mm}$ day $^{-1}$.

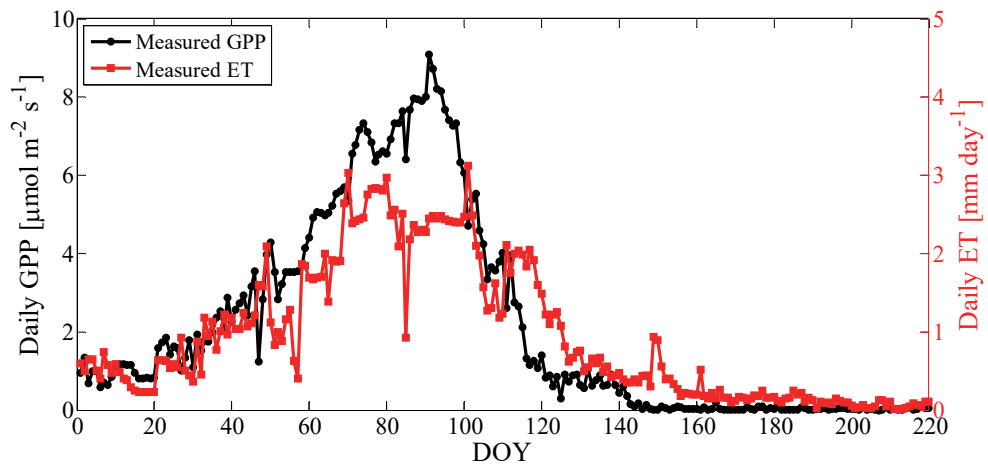

Figure 4.4. Vegetation functioning variations during the selected episode

\subsubsection{SCOPE (RTMt + energy balance) inversion against TIR spectra}

To measure the SCOPE model inversion performance in the TIR domain, the smallest squared error (SE) between the observed and simulated TIR band was used. Fig. 4.5 illustrates the observed TIR band (by Landsat) and the simulated one (by the SCOPE model) in a window of three by three pixels around the flux tower at the site on various days. The small squared error $(1.909<\mathrm{SE}<0.001)$ obtained through the LUT inversion showed that the 
SCOPE model was able to reproduce the observed TIR band with reasonable accuracy under different soil moisture conditions during the episode, although the last four simulations underestimated the observations.

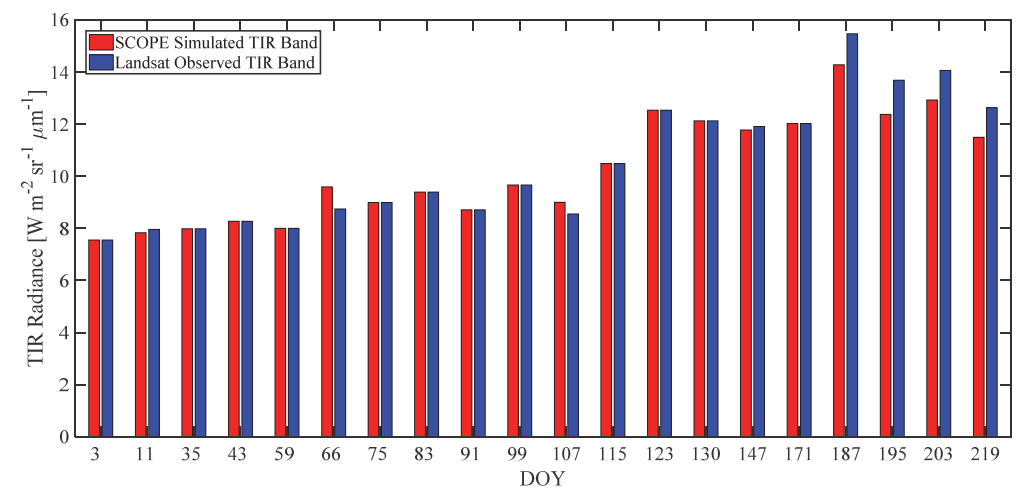

Figure 4.5. SCOPE simulated and Landsat observed TIR band at a $3 \times 3$ window around the flux tower at the site on different DOYs.

\subsubsection{TIR domain retrieved properties variations}

The variations of the retrieved vegetation properties from TIR domain during the episode are presented in Fig. 4.6. The results of retrieved properties from the TIR band showed a maximum value for $V_{\mathrm{cmax}}$ at the middle of the episode (DOY 100) and the minimum values obtained for the start and the end of the episode, while $r_{\text {ss }}$ showed the opposite trend compared to $V_{\text {cmax }}$ : it decreased first, was almost stable in the middle and increased at the end. Maximum $r_{\mathrm{ss}}$ was obtained at the end of the episode from DOY 120 till 219, while the minimum values were observed at the middle (DOYs 66 and 107). Although the $m$ parameter did not show a clear trend during the episode, some spikes observed in the middle of the season. The $r_{\mathrm{bs}}$ parameter, increased first (DOY 3 till DOY 35), declined in the middle (from DOY 35 till DOY 66) and slightly increased at the end of episode (from DOY 66 till DOY 219). Moreover, comparing the trends of derived properties from the TIR domain $\left(V_{\mathrm{cmax}}, m, r_{\mathrm{ss}}\right.$ and $r_{\mathrm{bs}}$ ), indicates that $r_{\mathrm{ss}}, r_{\mathrm{bs}}$ and $m$ started declining first (from DOY 35) while $V_{\text {cmax }}$ peaked later in the season (DOY 100). 
(a)

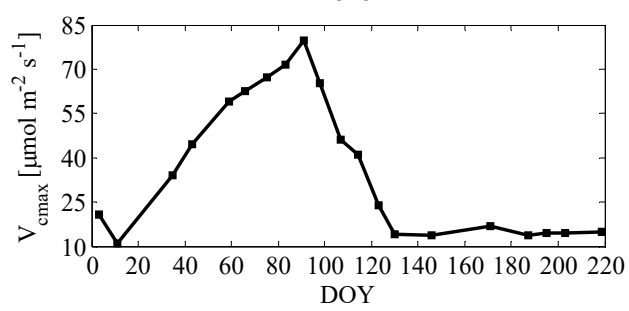

(c)

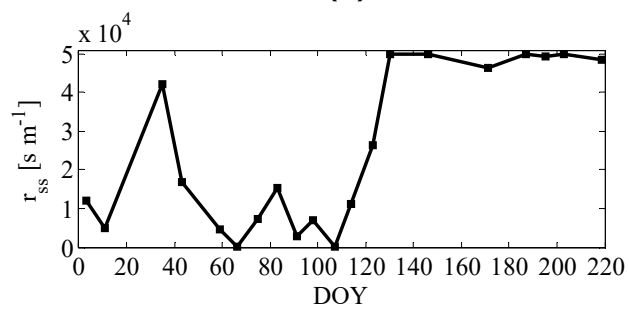

(b)

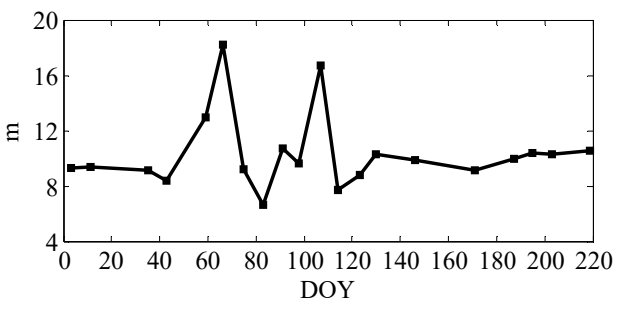

(d)

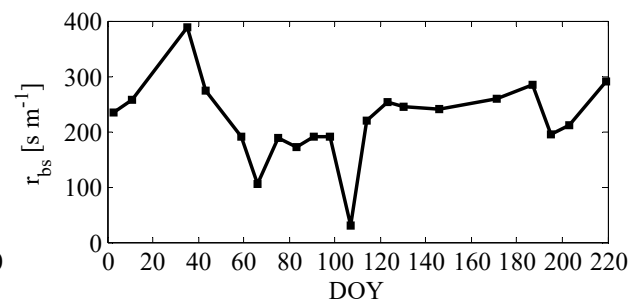

Figure 4.6. Landsat TIR domain retrieved properties variations during selected drought episode: (a) $V_{c m a x}$; (b) $m$; (c) $r_{s s}$; and (d) $r_{b s}$.

\subsubsection{Vegetation daily functioning simulation}

\subsubsection{Daily GPP}

Simulated actual GPP (with the inclusion of Landsat retrieved information) and reference GPP (GPPRef) are presented in Fig. 4.7. As expected, GPPRef, which represents GPP of hypothetical unstressed grass, increases throughout the season during the whole episode. The simulated actual GPP matched with the observed GPP for a part of the episode from DOY 1 to 70 when the information retrieved from optical domain of Landsat was used. For the rest of the episode the simulated GPP was underestimated (from DOY 70 till DOY 100) or overestimated (from DOY 110 till DOY 200) due to the fact that in SCOPE simulations a constant $m, V_{\mathrm{cmax}}$ and $r_{\mathrm{ss}}$ were applied. Estimating $V_{\mathrm{cmax}}$ changes as a function of $C_{a b}$, did not improve the results except for a small part of the episode (from DOY 120 till 190). However, the results of GPP simulations for almost the whole episode improved considerably when the retrieved information from the TIR band of Landsat was added. In other words, inclusion of time series information of $V_{\mathrm{cmax}}, m, r_{\mathrm{ss}}$ and $r_{\mathrm{bs}}$ makes the model better capture the GPP variation at the drought episode. 


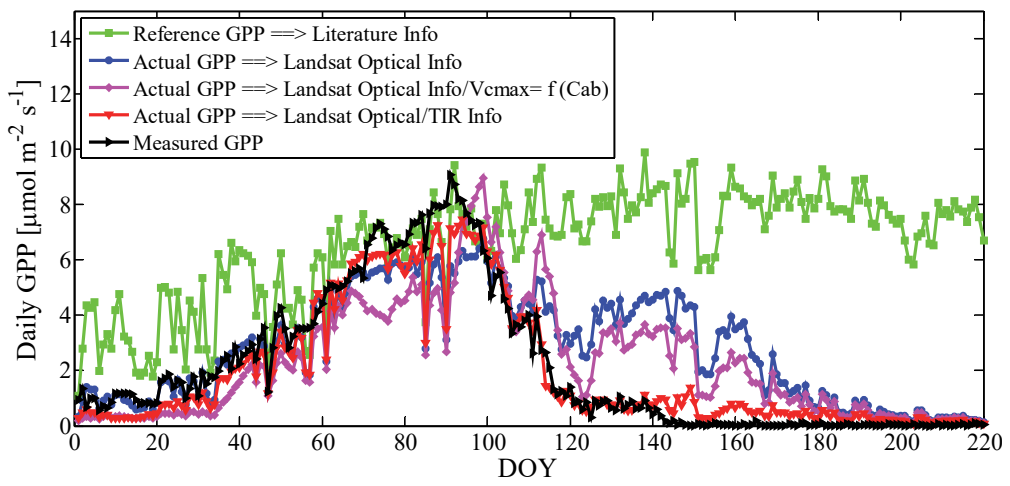

Figure 4.7. Time series of measured and simulated GPPs (actual and reference) at the site.

\subsubsection{Daily ET}

Simulated actual ET (with the inclusion of Landsat optical and TIR derived information) and reference $E T$ (ET Ref) are presented in Fig. 4.8. Similar to GPPRef, the $\mathrm{T}_{\text {Ref }}$ increases throughout the season during the whole episode. We also found good agreement between ET Ref simulated with SCOPE and ET Ref simulated with the FAO-PM model for the same period at the site (results not shown). For the actual ET, an acceptable match is observed between the simulated and measured ET for a part of the episode from DOY 1 to 70 when the information retrieved from the optical bands of Landsat was used. For the rest of the episode (DOY 70 to 220) the simulated ET was overestimated. Using Landsat retrieved properties from the optical bands plus $V_{c \max }=f\left(C_{a b}\right)$, resulted in small differences in ET compared to the situation when we used only information from the optical bands and fixed the $V_{\text {cmax }}$ value. The results improved considerably when the retrieved information from the TIR band of Landsat was added. However, adding TIR information did not improve the first part of the simulations (from DOY 1 to 110 ) and in some cases it made the match poorer. In summary, adding TIR information made the match better from DOY 110 to 220, it caused a slight underestimation from DOY 1 to 60 and overestimation from DOY 60 to 110 . 


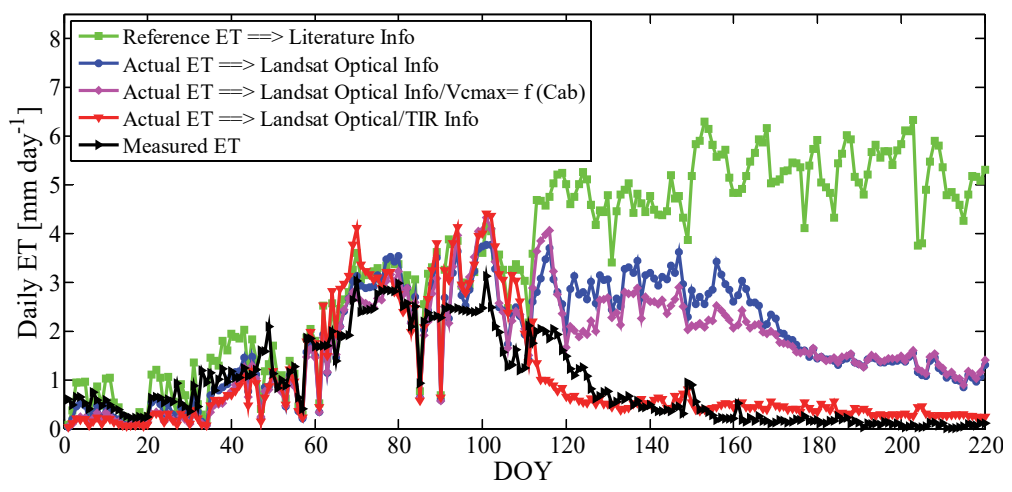

Figure 4.8. Time series of measured and simulated ET (actual and reference) at the site

An important aspect is the separation of transpiration $T$ and evaporation $E$ in SCOPE. The simulated $T_{\text {Ref }}$ shows an upward trend throughout the season, whereas the simulated actual $T$, within various scenarios, shows a peak in the middle of season from DOY 70 to DOY 110 (Fig 4.9a). Moreover, the simulated $E_{\text {Ref, actual }} E$ using Landsat optical information and actual $E$ using Landsat optical information plus $V_{\mathrm{cmax}}=\mathrm{f}\left(C_{\mathrm{ab}}\right)$ show upward trends during the whole episode (Fig. 4.9b) due to the fact that we kept the soil surface resistance for evaporation $r_{\mathrm{ss}}$ constant while $L A I$ decreased (and thus net radiation of the soil increased) during the drought episode. 
(a)

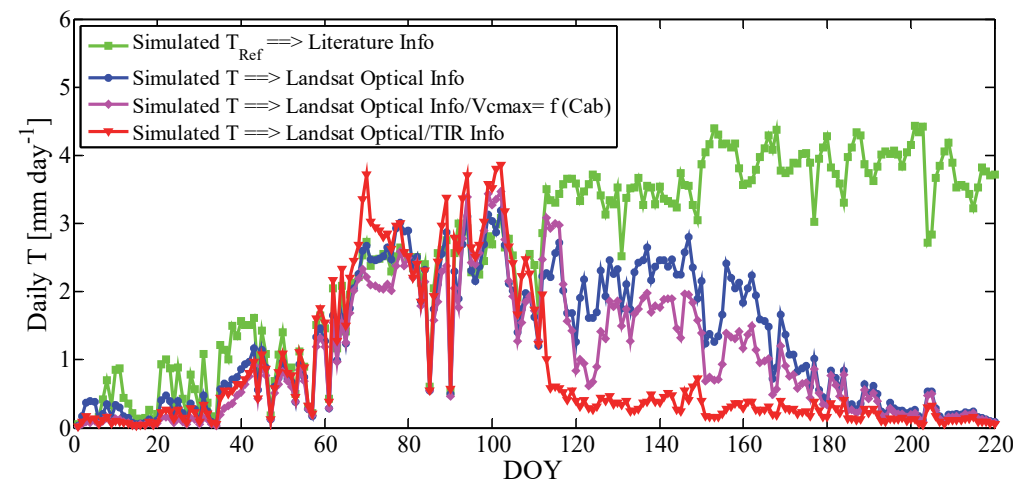

(b)

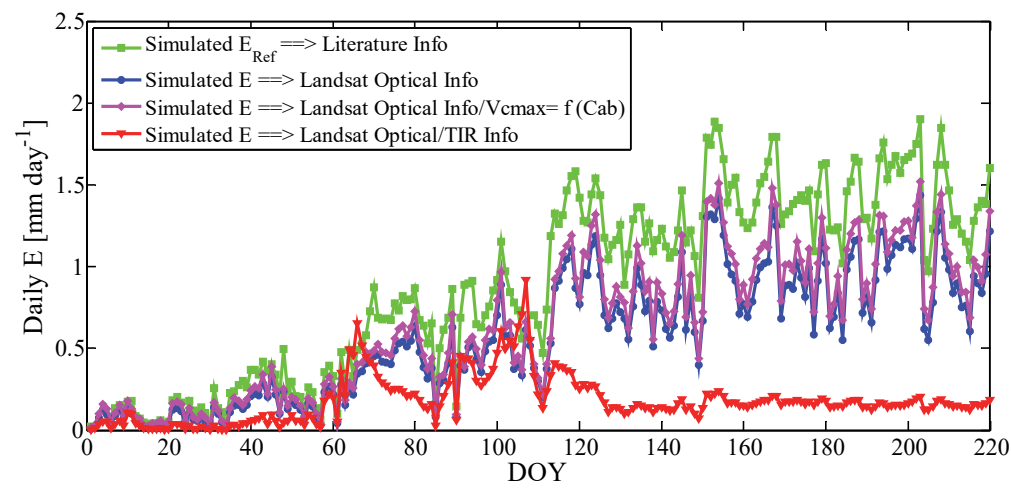

Figure 4.9. Time series of $T_{\text {Ref, }} T, E_{\text {Ref }}$ and $E ;$ (a) Simulated $T$, (b) Simulated $E$.

However, when we added Landsat TIR information and, therefore, retrieved $r_{\mathrm{ss}}, r_{\mathrm{bs}}, V_{\mathrm{cmax}}$ and $m$ parameter values, the simulated $E$ started declining from DOY 110-220. Thus constraining the SCOPE model by both optical and TIR information, the simulated $E$ shows a peak in the middle of season from DOY 70 to DOY 110 (Fig 4.9b).

\subsubsection{Daily Crop factors $\left(K_{c}\right)$}

Simulated crop factors ( $K_{\mathrm{C}}$ GPP and $K_{\mathrm{C}}$ ET) are presented in Figs. 4.10 and 4.11. The advantage of using crop factors is that drought effects appear more pronounced, thanks to the normalization by the reference scenario. The results show that the optical bands of Landsat could only explain a small part of the variations of $K_{\mathrm{C}}$ GPP (Fig 4.10), and for most of the period, $K_{\mathrm{C}}$ GPP was overestimated. This overestimate could not be alleviated by making $V_{\text {cmax }}$ a function of $C_{a b}$ (Fig 4.10) following Houborg et al (2013), which brings about only a slight improvement. This shows that the direct effect of the RTMo parameters (in SCOPE) cannot explain all drought effects on GPP. However, 
adding TIR information to the simulation, made substantial improvements in the model fit of $K_{c}$ GPP during the drought episode.

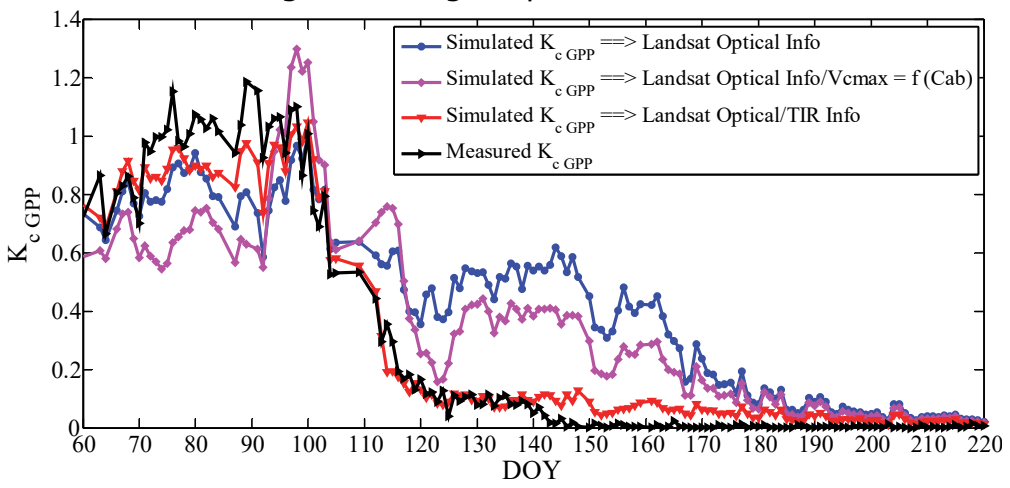

Figure 4.10. Time series of measured and simulated daily $\mathrm{K}_{\mathrm{c}}$ GPP.

Likewise a good match is observed between simulated and measured $K_{\mathrm{c}}$ ET (Fig. 4.11a) when we used both optical and TIR information during the drought episode. The benefit of using the TIR information is apparent at the end of drought episode when the water stress was most severe and the overestimate of $K_{\mathrm{c}}$ ET that occurs when only optical information is used, is alleviated. Making $V_{c m a x}$ a function of $C_{a b}$ following Houborg et al (2013), brings about a slight improvement of $K_{\mathrm{C}} \mathrm{ET}$ (Fig. 4.11a).

The causes for the overestimate of $K_{\mathrm{C}} \mathrm{ET}$ using optical information come from both soil evaporation ( $\left.K_{\mathrm{e}}, \mathrm{Fig} .4 .11 \mathrm{c}\right)$ and transpiration ( $K_{\mathrm{cb}}$, Fig. 4.11b). Clearly, the TIR information provided the necessary means to constrain the energy partitioning in the SCOPE model, after canopy structure ( $L A I$ and $L I D F$ ) and leaf composition ( $C_{a b}, C_{s}, C_{w}$ and $C_{d m}$ ) had been retrieved from optical data. It should be noted that no separate measurements of soil evaporation and transpiration were available, since flux tower measurements provide only the sum (Fig. 4.11bc). 
(a)

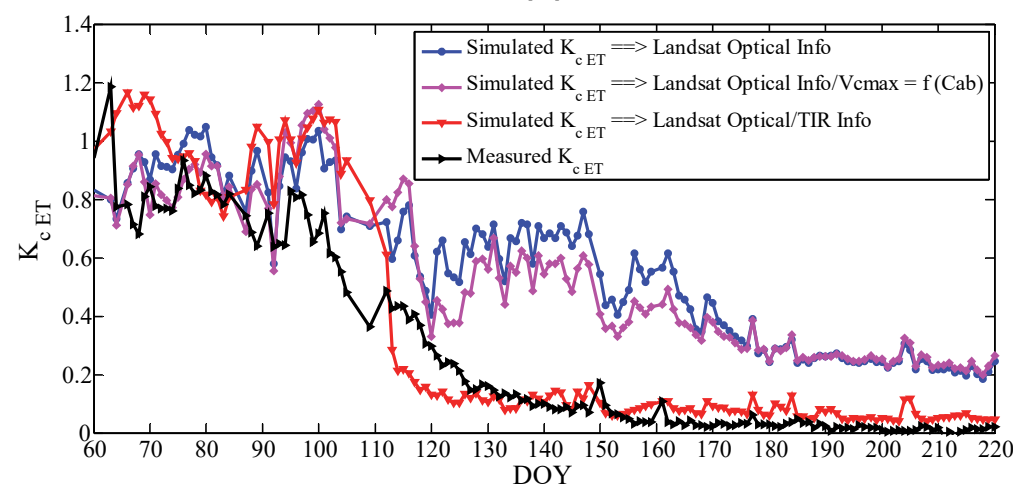

(b)

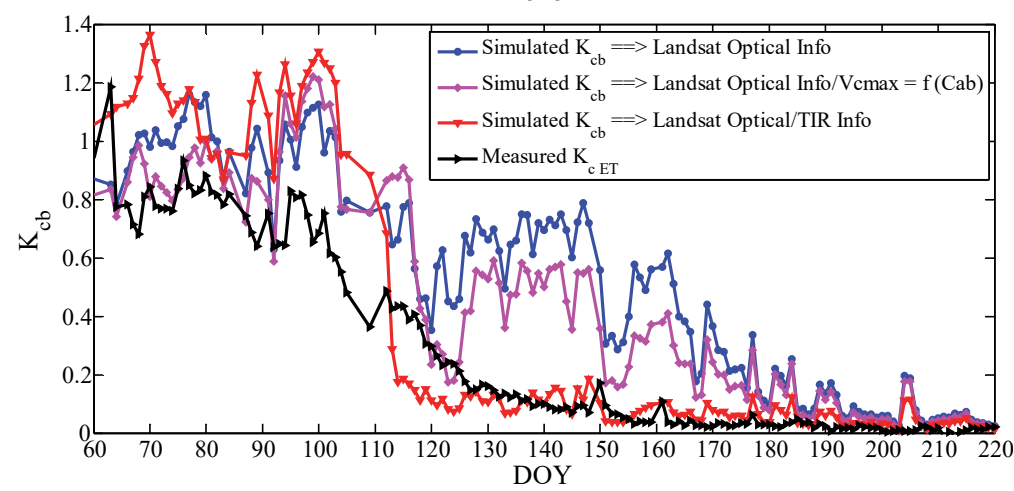

(c)

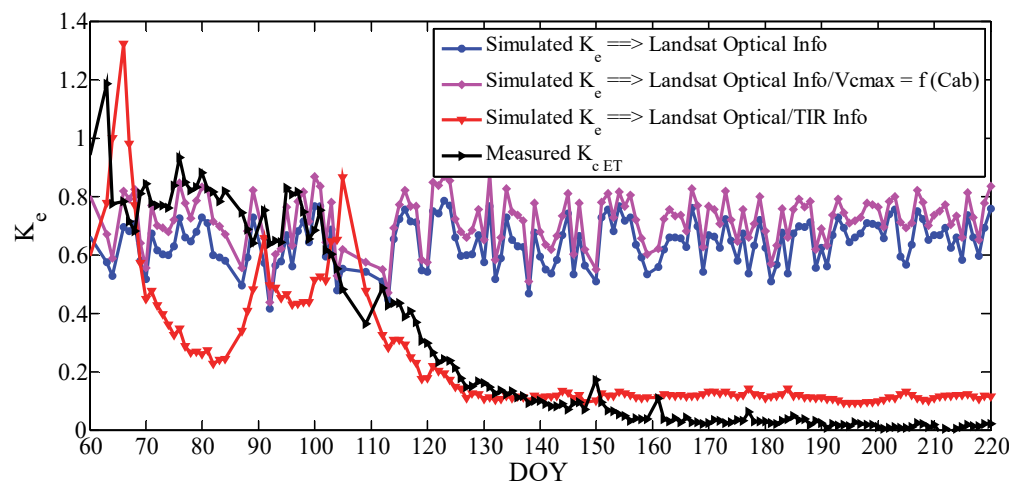

Figure 4.11. Time series of measured and simulated $\mathrm{K}_{c}$ in drought conditions. (a) Measured and simulated $\mathrm{K}_{\mathrm{c}}$ ET; (b) Measured $\mathrm{K}_{\mathrm{c}}$ ET and simulated $\mathrm{K}_{\mathrm{cb}}$ and (c) Measured $\mathrm{K}_{\mathrm{c}}$ ET and simulated $\mathrm{K}_{\mathrm{e}}$

\subsubsection{Intercomparison (GPP, ET and Kc)}

The statistics of the model fit for GPP, ET and $K_{c}$ are shown in Taylor diagrams in Fig. 4.12 and Table 4.3. Taylor diagrams illustrate that simulated 
daily GPP using Landsat optical information and optical plus $V_{\mathrm{cmax}}=\mathrm{f}\left(C_{\mathrm{ab}}\right)$, show a correlation coefficient $(R)$ of 0.78 and 0.80 , RMSE of 1.79 and 1.71 $\mu \mathrm{mol} \mathrm{m} \mathrm{m}^{-2} \mathrm{~s}^{-1}$ and a $\sigma$ of 2.11 and $2.19 \mu \mathrm{mol} \mathrm{m} \mathrm{m}^{-2} \mathrm{~s}^{-1}$. This shows that including $V_{\text {cmax }}$ information as a function of $C_{a b}$ causes a $\sigma$ that is closer to that of the measurements, a slightly lower (better) RMSE, and a higher (better) R. The Houborg et al (2013) model ( $B$ in Fig. 4.12a) could slightly better capture both the range of values and the day-to-day variations. The simulated GPP using optical and TIR information shows a high correlation $(R=0.98)$, low RMSE $\left(0.55 \mu \mathrm{mol} \mathrm{m} \mathrm{m}^{-2} \mathrm{~s}^{-1}\right)$ and variation range very close to that of measured GPP ( $\sigma$ $=2.55 \mu \mathrm{mol} \mathrm{m} \mathrm{m}^{-2} \mathrm{~s}^{-1}$ ). This indicates that combined use of optical/TIR information ( $\mathrm{C}$ in Fig. 4.12a) causes not only a $\sigma$ very close to that of the measurements, but also improves the $\mathrm{R}$ and RMSE considerably. Similar patterns are obtained for the simulated $K_{\mathrm{c}}$ GPP (Fig. 4.12b). Simulated $K_{\mathrm{c}}$ GPP for different scenarios, i.e., optical, optical/ $V_{\mathrm{cmax}}=\mathrm{f}\left(\mathrm{Cab}_{\mathrm{ab}}\right)$ and optical/TIR indicate a high $\mathrm{R}(0.834,0.835$ and 0.988$)$, low RMSE $(0.229,0.227$ and 0.07$)$ and low $\sigma(0.29,0.30$ and 0.36$)$ compared to the measured $K_{c} \operatorname{GPP}(1,0$ and 0.4$)$. Simulated daily ET using Landsat optical information and optical plus $V_{\mathrm{cmax}}=$ $f\left(C_{a b}\right)$, shows a low $R$ of 0.6 and 0.72 compared to the measured ET during the drought episode (Fig. 4.12c), due to the earlier mentioned increase in simulated $E$. Including $V_{\text {cmax }}$ information as a function of $C_{a b}$, causes a lower (better) RMSE of 0.7 compared to $0.82 \mathrm{~mm} \mathrm{day}^{-1}$, and a higher (better) $\mathrm{R}$ of 0.72 compared to 0.6. In addition, the ET simulation in which we used both optical and TIR information ( $C$ in Fig. 4.12c) shows improvements in $R(0.91)$ and RMSE (0.54 $\left.\mathrm{mm} \mathrm{day}^{-1}\right)$ compared to those of measured ET. Furthermore, simulated $K_{\mathrm{c}}$ et for different scenarios, i.e., optical, optical $/ V_{\mathrm{cmax}}=\mathrm{f}\left(C_{\mathrm{ab}}\right)$ and optical/TIR indicate similar patterns to ET with slightly different values of $\mathrm{R}$ $(0.85,0.88$ and 0.94$), \operatorname{RMSE}(0.17,0.15$ and 0.14$)$ and the variation range $(\sigma$ $=0.26,0.26$ and 0.4$)$ compared to the measured $K_{\mathrm{C}} \mathrm{ET}$ in the drought episode. In summary, both the Houborg et al (2013) model ( $B$ in Fig. 4.12d) and the combined use of optical/TIR information ( $\mathrm{C}$ in Fig. 4.12d) improved the relation between the measured and simulated $K_{\mathrm{C}} \mathrm{ET}$. 
(a)

A- Actual GPP $=>$ Landsat Optical Info

B- Actual GPP $=>$ Landsat Optical Info/Vc

C- Actual GPP $==>$ Landsat Optical/TIR Info

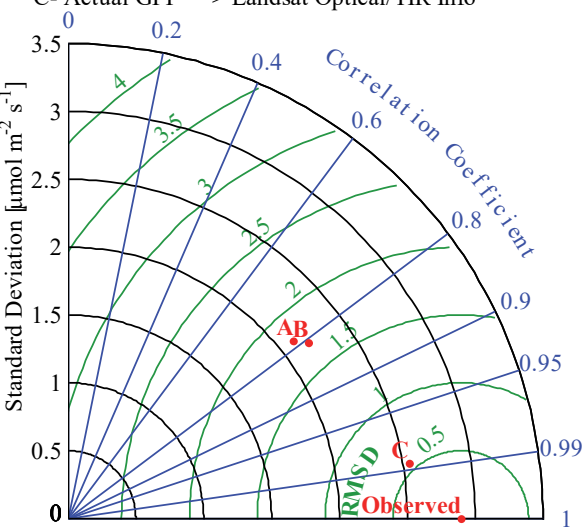

(c)

A- Actual ET $=\Rightarrow$ Landsat Optical Info

B- Actual ET $\Rightarrow$ Landsat Optical Info/Vcmax $=\mathrm{f}(\mathrm{Cab})$

C- Actual ET $=>$ Landsat Optical/TIR Info

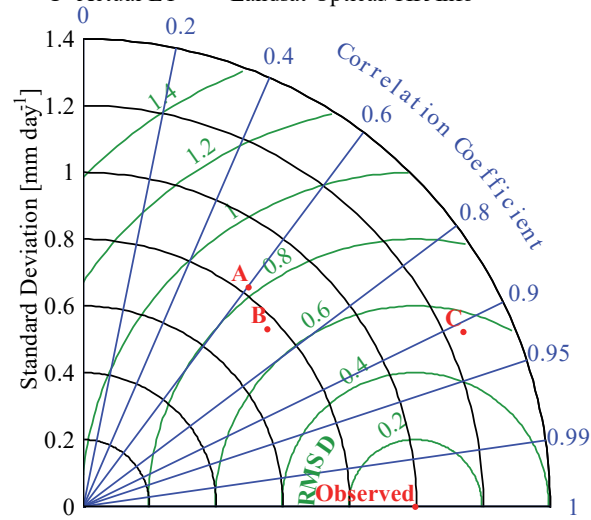

(b)

A- Actual $\mathrm{K}_{\mathrm{GPP}}=>$ Landsat Optical Info

B- Actual $\mathrm{K}=>$ Landsat Optical Info and Vcmax $=\mathrm{f}(\mathrm{Cab}$ C- Actual $\mathrm{K}_{\mathrm{c} \mathrm{GPP}}^{\mathrm{c} \mathrm{GPP}}=>$ Landsat Optical/TIR Info

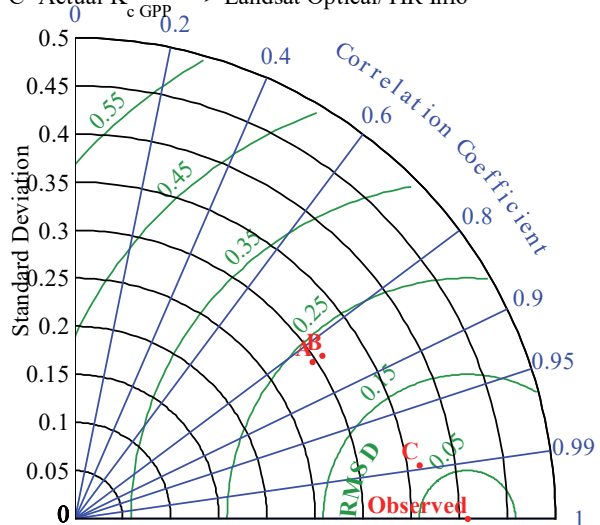

(d)

A- Actual $\mathrm{K}_{\mathrm{ET}}=>$ Landsat Optical Info

B- Actual $\mathrm{K}_{\mathrm{C}} \mathrm{ET}=>$ Landsat Optical Info and $\mathrm{Vcmax}=\mathrm{f}(\mathrm{Cab}$

C- Actual $\mathrm{K}_{\mathrm{c} \mathrm{ET}}^{\mathrm{cET}}=\Rightarrow$ Landsat Optical/TIR Info

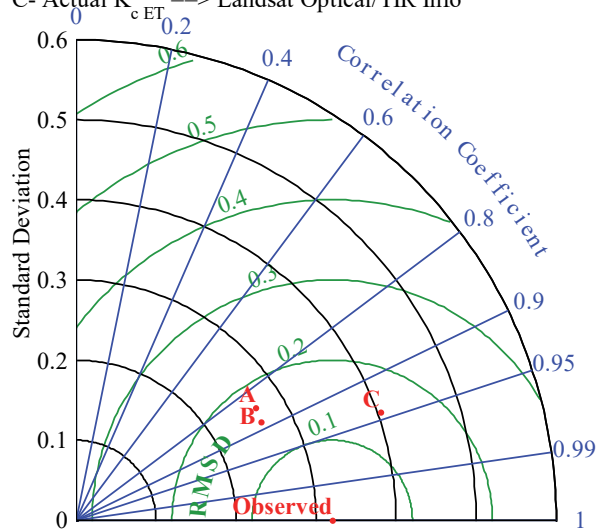

Figure 4.12. Taylor diagram illustrating the statistics between the observed (measured) and the simulated GPP, ET and $\mathrm{K}_{\mathrm{c}}$ during drought episode; (a) Measured and simulated GPP; (b) Measured and simulated $\mathrm{K}_{\mathrm{c}}$ GPP; (c) Measured and simulated ET; (d) Measured and simulated $\mathrm{K}_{\mathrm{c}} \mathrm{ET}$.

In addition, the results of computed MSE indicate that adding $V_{\text {cmax }}$ time series information, as a function of Landsat retrieved $C_{a b}$, slightly reduces the deviation of simulated from measured values in all scenarios (Table 4.3). The results show that the combined use of Landsat optical and TIR information gives an obvious reduction of the MSE, confirming a good agreement between the simulated and the measured variables (GPP, ET and $K_{c}$ ). Amongst all simulations, the dimensionless NRMSE (RMSE/range) show that the combined usage of Landsat optical and TIR information yields the best results for daily GPP and $K_{c}$ GPP simulations (NRMSE of 0.06 and 0.063 , respectively). 
Table 4.3. Statistical measures used for evaluation of simulation results

\begin{tabular}{|c|c|c|c|c|c|c|c|}
\hline \multirow[b]{2}{*}{ Variable } & \multirow[b]{2}{*}{ Scenario } & \multicolumn{6}{|c|}{ MSE contributions } \\
\hline & & $\begin{array}{l}\text { Unequal } \\
\text { standard } \\
\text { deviations }\end{array}$ & $\begin{array}{l}\text { Lack of } \\
\text { (positive) } \\
\text { correlation }\end{array}$ & $\begin{array}{l}\text { Bias } \\
\text { of mean } \\
\text { values }\end{array}$ & $\begin{array}{l}\text { Total } \\
\text { MSE }\end{array}$ & RMSE & NRMSE \\
\hline \multirow[t]{3}{*}{ GPP } & Landsat optical info & 0.61 & 2.62 & 1.15 & 4.38 & 2.09 & 0.23 \\
\hline & Landsat optical/Vcmax $=f(\mathrm{Cab})$ & 0.48 & 2.46 & 0.39 & 3.32 & 1.82 & 0.20 \\
\hline & Landsat optical + TIR info & 0.11 & 0.19 & 0.00 & 0.31 & 0.55 & 0.06 \\
\hline \multirow[t]{3}{*}{ ET } & Landsat optical info & 0.03 & 0.65 & 1.96 & 2.64 & 1.63 & 0.51 \\
\hline & Landsat optical/Vcmax $=f(\mathrm{Cab})$ & 0.05 & 0.43 & 1.51 & 1.99 & 1.41 & 0.45 \\
\hline & Landsat optical + TIR info & 0.07 & 0.23 & 0.06 & 0.36 & 0.60 & 0.19 \\
\hline \multirow[t]{3}{*}{$K_{\mathrm{C} \text { GPP }}$} & Landsat optical info & 0.013 & 0.040 & 0.018 & 0.071 & 0.266 & 0.224 \\
\hline & Landsat optical/Vcmax $=f(\mathrm{Cab})$ & 0.010 & 0.042 & 0.005 & 0.057 & 0.239 & 0.201 \\
\hline & Landsat optical + TIR info & 0.002 & 0.004 & 0.000 & 0.006 & 0.074 & 0.063 \\
\hline \multirow[t]{3}{*}{$K_{\text {С Ет }}$} & Landsat optical info & 0.003 & 0.026 & 0.084 & 0.113 & 0.336 & 0.282 \\
\hline & Landsat optical/Vcmax $=f(C a b)$ & 0.003 & 0.020 & 0.064 & 0.087 & 0.295 & 0.247 \\
\hline & Landsat optical + TIR info & 0.007 & 0.015 & 0.005 & 0.027 & 0.164 & 0.137 \\
\hline
\end{tabular}

The MSE decomposition results demonstrate that adding TIR information reduced the error in all components including standard deviation differences, lack of correlation and bias of the mean values in GPP and $K_{\mathrm{c}}$ GPP considerably. However, the dominant error contributor (relatively to total MSE) in GPP and $K_{\mathrm{C}}$ GPP simulation, which was lack of (positive) correlation, remained relatively similar in different scenarios, i.e. optical, optical $/ V_{c \max }=\mathrm{f}\left(C_{\mathrm{ab}}\right)$ and optical/TIR in GPP (with values of 2.62, 2.46 and 0.19 ) and $K_{\mathrm{C}}$ GPP (with values of 0.04 , 0.042 and 0.004 ) simulations.

The MSE components of the ET and $K_{\mathrm{C}}$ ET simulations showed that, although adding TIR information to the simulations reduced the error of correlation and bias of the mean values, the standard deviation error slightly increased for ET (from 0.03 to 0.07 ) and for $K_{\mathrm{C}}$ ET (from 0.003 to 0.007 ). Moreover, the dominant error contributor to the total MSE in ET and $K_{\mathrm{C}}$ ET simulation was the bias of the mean values in case only the optical information was used. The bias of mean values still remained the dominant one when additional information of $V_{c m a x}$ as a function of $C_{a b}$ was added, however, its value reduced for ET (from 1.96 to 1.51 ) and for $K_{\mathrm{C}} \mathrm{ET}$ (from 0.084 to 0.005 ). In the third scenario, when TIR information added to the ET and $K_{C}$ ET simulations, the lack of (positive) correlation dominated as the main error contributor.

\subsubsection{Spatio-temporal variations of GPP and ET}

Fig 4.13. present three representative maps of GPP generated by SCOPE model using optical and TIR information during the selected episode (for DOYs 
59, 75 and 203). At first glance, one can claim that the GPP maps generated by the SCOPE in which both optical and TIR information is used, could capture much higher spatial variability of GPP (Fig. 4.13b,d) in comparison to those generated from optical information through SCOPE (Fig. 4.13a,c). Moreover, the integrated use of optical and TIR information could map the low values of daily GPP in severe drought condition (DOY 203) compared to GPP map generated using only optical information (Fig. 4.13e,f).

(a)

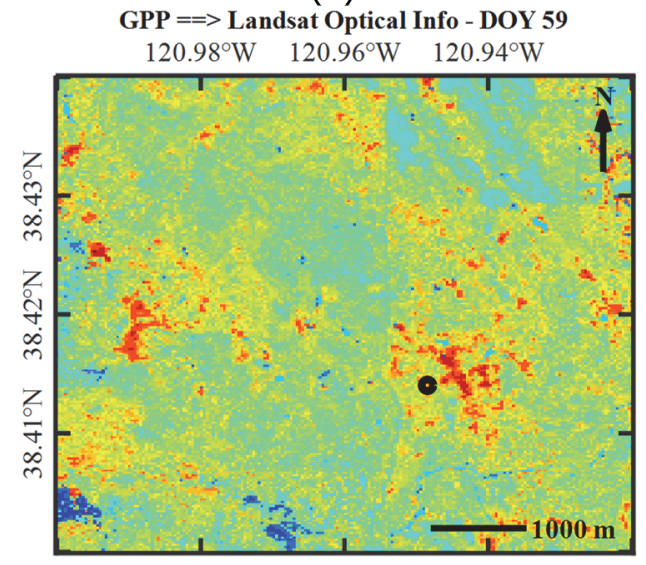

(c)

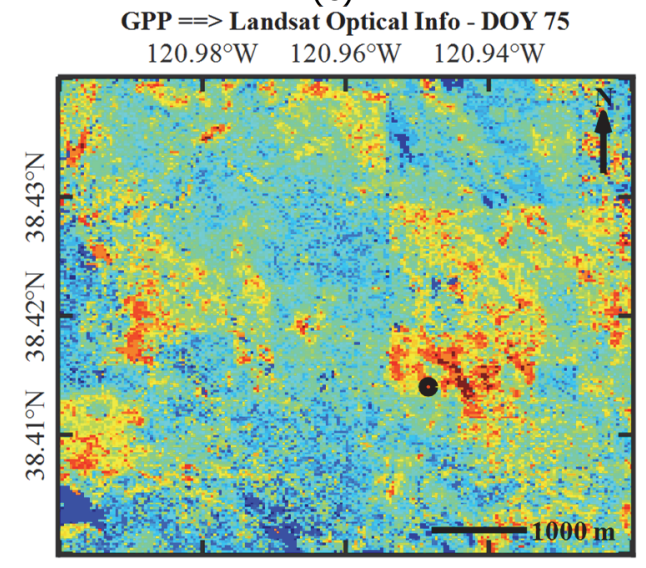

(b)

GPP $=\Rightarrow$ Landsat Optical/TIR Info - DOY 59 $120.98^{\circ} \mathrm{W} 120.96^{\circ} \mathrm{W} 120.94^{\circ} \mathrm{W} \quad \mu \mathrm{mol} \mathrm{m}^{-2} \mathrm{~s}^{-1}$

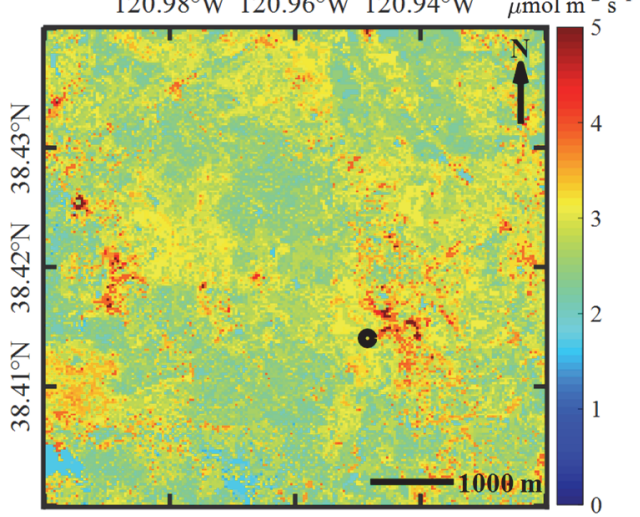

(d)

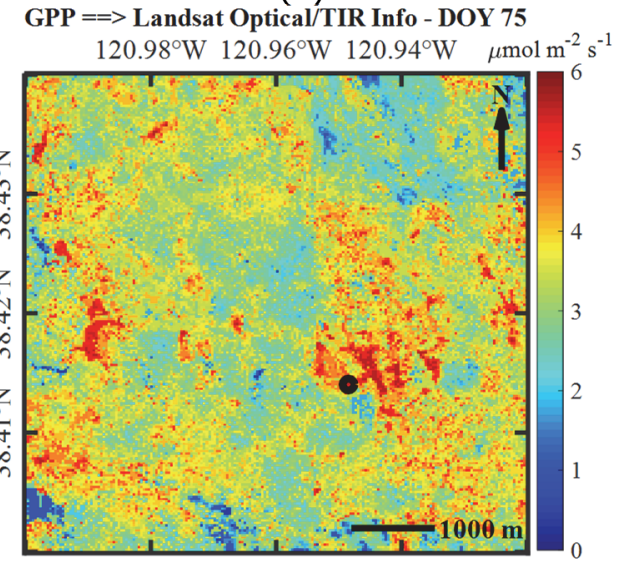


(e)

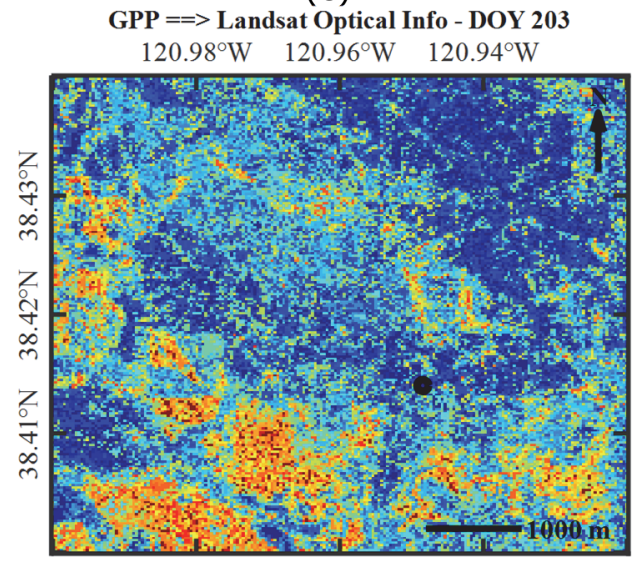

(f)

GPP $==>$ Landsat Optical/TIR Info - DOY 203 $120.98^{\circ} \mathrm{W} 120.96^{\circ} \mathrm{W} 120.94^{\circ} \mathrm{W} \quad \mu \mathrm{mol} \mathrm{m}^{-2} \mathrm{~s}^{-1}$

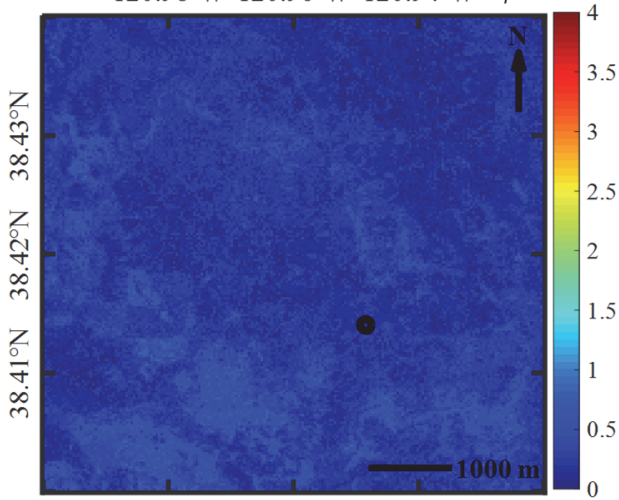

Figure 4.13. Daily GPP maps generated by use of optical and TIR information through SCOPE model during the selected episode on DOYs $59(\mathrm{a}, \mathrm{b}), 75(\mathrm{c}, \mathrm{d})$ and $203(\mathrm{e}, \mathrm{f})$ at Vaira site in 2004. The left panels (a, c, e) show GPP maps generated from optical information in SCOPE and the right panels (b, $d, f)$ show GPP maps generated from optical and TIR information in SCOPE. The black circle inside the maps show the location of Vaira Fluxnet site.

Similarly, Fig 4.14. present three representative maps of daily ET generated by SCOPE model using optical and TIR information during the selected episode (for DOYs 59, 75 and 203). As can be seen from these maps, the ET maps generated by the SCOPE in which both optical and TIR information is used could capture much higher spatial variability of ET (Fig. 4.14b,d) in comparison to those generated from optical information (Fig. 4.14a, C). In addition, the combined use of optical and TIR information could map the low values of daily ET in severe drought conditions (DOY 203) compared to ET map generated by SCOPE (Fig. 4.14f,e).

(a)

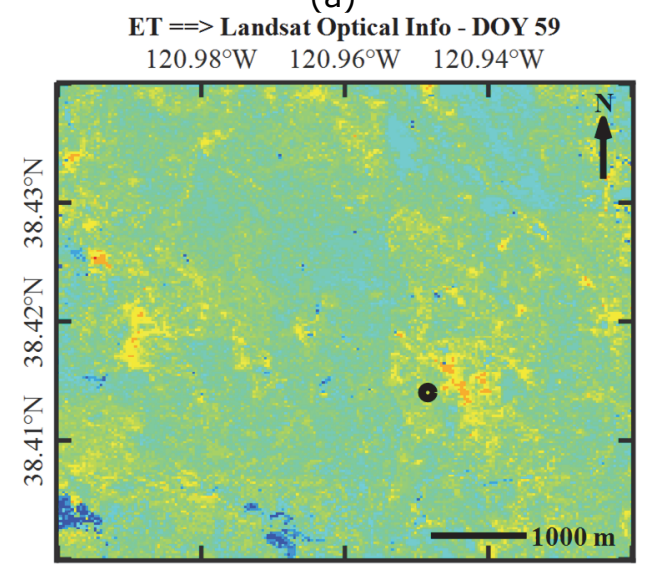

(b)

ET $==$ Landsat Optical/TIR Info - DOY 59 $120.98^{\circ} \mathrm{W} 120.96^{\circ} \mathrm{W} 120.94^{\circ} \mathrm{W} \mathrm{mm} \mathrm{day}^{-1}$

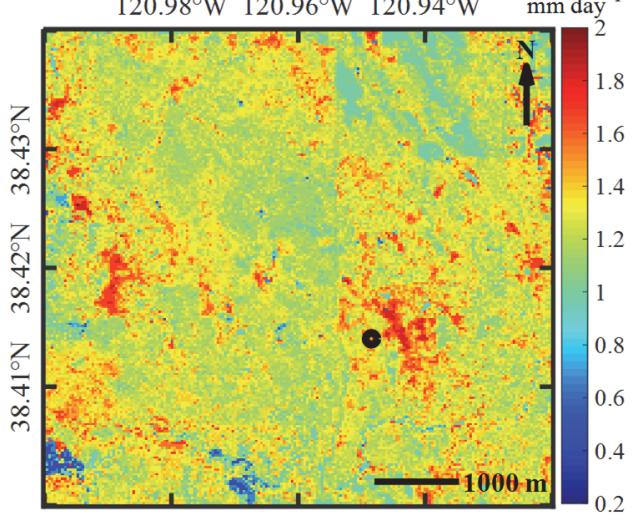


(c)

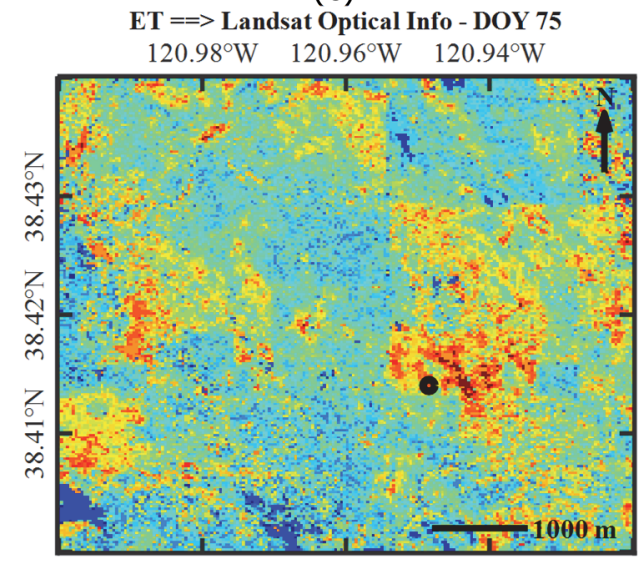

(e)

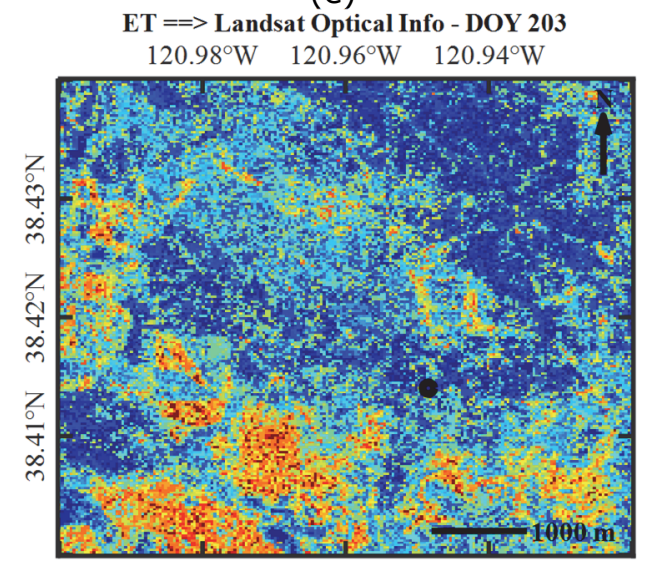

(d)

ET $==>$ Landsat Optical/TIR Info - DOY 75 $120.98^{\circ} \mathrm{W} 120.96^{\circ} \mathrm{W} 120.94^{\circ} \mathrm{W} \quad \mathrm{mm}$ day $^{-1}$

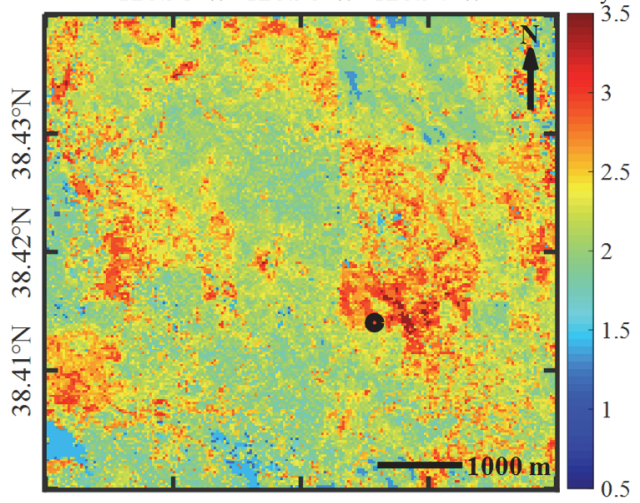

(f)

ET $==>$ Landsat Optical/TIR Info - DOY 203 $120.98^{\circ} \mathrm{W} 120.96^{\circ} \mathrm{W} 120.94^{\circ} \mathrm{W}$

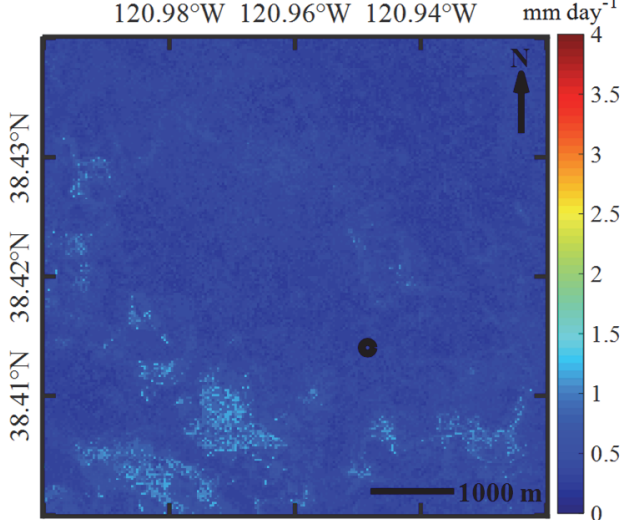

Figure 4.14. Daily ET maps generated by use of optical and TIR information through SCOPE model during the selected episode on DOYs $59(a, b), 75(c, d)$ and $203(e, f)$ at Vaira site in 2004. The left panels (a, c, e) show ET maps generated from optical information in SCOPE and the right panels $(b, d, f)$ show ET maps generated from optical and TIR information in SCOPE. The black circle inside the maps show the location of Vaira Fluxnet site.

\subsection{Discussion}

\subsubsection{TIR canopy spectra variation}

The TIR surface radiance increased under stress conditions especially from DOY 100 to 220 in our study site (Fig. 4.3), due to the seasonal cycle of land surface temperature and the partitioning of available energy to sensible and latent heat fluxes. The latter clearly reduced due to the decline in soil moisture (Mira et al., 2007) during the drought episode. Reduced transpiration is indirectly related to leaf optical reflectance via the (loss of) leaf water (Buitrago 
et al., 2016). Indeed the progressive decline of leaf water content (chapter 3, Fig. $3.17 \mathrm{c}$ ) is consistent with the decline in the soil moisture content observed at our study site. Our results are also in line with previous studies in which strong positive relationships were reported between leaf water content and the TIR radiance for different species under stress conditions (Buitrago et al., 2016; Fabre et al., 2011; Gerber et al., 2011; Ullah et al., 2012).

\subsubsection{Canopy properties and functioning variations}

Model inversion results indicate that the SCOPE model can reproduce TIR data under various soil moisture conditions with acceptable accuracy. Visual inspection shows that the retrieved $V_{\text {cmax }}$ correlates better with retrieved $C_{\mathrm{w}}$ (chapter 3, Fig. 3.17c) than with other retrieved properties from the optical bands during the drought episode. The relationship between $V_{\mathrm{cmax}}$ and $C_{\mathrm{w}}$ may be indirect: the leaf $V_{c m a x}$ is related to the leaf nitrogen content and fraction of leaf nitrogen in Rubisco (Evans, 1989; Xu and Baldocchi, 2003) and a significant relationship has been reported between leaf nitrogen content and leaf $C_{w}$ during the plant developmental stage in grass species. Thornton et al (1999) concluded that the decline in nitrogen concentration of $M$. caerulea, during a growth period, when dry mass was increasing, could mainly be explained by changes of $C_{w}$ (Thornton et al., 1999). Thus, the higher the $C_{w}$, the higher the leaf $\mathrm{N}$ and, consequently, the higher the leaf $V_{\mathrm{cmax}}$ will be and vice versa.

Furthermore, soil resistance-related parameters ( $r_{\mathrm{ss}}$ and $\left.r_{\mathrm{bs}}\right)$ reached the maximum values at the end of the episode when drought became severe. The soil boundary resistance $r_{\text {bs }}$ may change when vegetation structure changes, whereas $r_{\mathrm{ss}}$ is primarily a function of soil water potential. The increase in retrieved $r_{\text {ss }}$ can obviously be explained by the fact that the soil was extensively dry at the end of the episode. The fact that we included both resistances may cause the retrieval to be ill-posed (as the two resistances operate in series). We overcame this problem by selecting the best multiple solutions from the LUT by computing the average of 5 percent best solutions in the LUT.

Simulated daily GPP using Landsat optical bands (Fig. 4.7) could capture strong reductions in measured GPP during the drought episode. This can be explained by the reductions in the retrieved vegetation properties, especially a decline of $L A I$ and $C_{a b}$, which together determine the light absorbed by photosystems (sometimes referred to as 'green fAPAR' in the literature). These reductions are not related to $V_{\mathrm{cmax}}$ or stomatal regulation, which are often considered in models as the main regulation mechanisms of GPP (Egea et al., 2011; Keenan et al., 2010a; Zhou et al., 2013). The effect of introducing $V_{\text {cmax }}$ $=f\left(C_{a b}\right)$ is small. Note that we used the relationship of Houborg et al (2013) outside the range for which it was calibrated (at Cab $<10 \mathrm{ug} \mathrm{cm}^{-1}, V_{\text {cmax }}$ becomes negative). Our results suggest that $V_{\mathrm{cmax}}$ is better correlated to $C_{\mathrm{w}}$ than to $C_{a b}$. 
Combined use of optical and TIR domain information improved the daily GPP simulation considerably at the last part of the drought episode. In our case study (at Vaira grassland), the TIR information constrains soil evaporation, which cannot be estimated from optical information if the soil is covered with vegetation, and transpiration via $V_{\text {cmax. }}$. However, the dominant mechanisms to reduce evaporation and transpiration might be different in other ecosystems.

The overestimation of simulated actual ET in severe drought conditions when only optical information is used (Fig. 4.8) can be explained by the fact that in SCOPE, soil evaporation is parameterized with a single surface resistance value (2000 sm-1 in our simulation), and an aerodynamic resistance that depends on $L A I$, vegetation height, stability of the atmosphere and wind speed. SCOPE does not include a model for the unsaturated zone. The simplicity of the soil evaporation module also has an advantage: it makes it possible to retrieve the surface resistance from TIR data. This overestimation of ET disappeared almost completely when TIR domain information was added to the simulations (Fig. 4.8).

Overestimation of daily GPP and ET using optical data in our results matches with other studies which reported overestimation of water and carbon fluxes under severe water stress conditions. For instance, Gilabert et al (2015) estimated daily GPP in Mediterranean ecosystems in Spain (Las Majadas de Tietar site) using an optimized version of Monteith's approach with and without the inclusion of the water stress period in 2008-2011. They reported an overestimation of GPP from DOY 180 to DOY 300 when the water stress played a more important role. They came to the conclusion that the correlation between modelled and measured GPP decreases as water stress increases (Gilabert et al., 2015).

Spatio-temporal maps of GPP and ET generated by SCOPE model using optical and TIR information during the selected episode demonstrate that the maps generated by the SCOPE in which both optical and TIR information is used, could capture much higher spatial variability compared to those generated by optical provided information. Further, the integrated use of optical and TIR information could map the low values of ecosystem functioning in severe drought condition (DOY 203) compared to the map generated using only optical information.

Overall, the results of our study show that for estimating vegetation daily GPP and ET during a drought episode with good accuracy, we need to consider the effects of four major factors: (1) increased radiance over the whole spectrum, resulting in a reduced net radiation, (2) reduced absorbed photosynthetically active radiation by chlorophyll, and therefore a reduced photosynthesis and stomatal conductance, (3) reduced photosynthetic capacity $V_{\text {cmax }}$, and (4) reduced soil evaporation. Previous studies emphasized the necessity to consider stomatal, non-stomatal responses (Egea et al., 2011; Keenan et al., 2010a; Zhou et al., 2013) and soil evaporation reduction (Gökmen et al., 2012) when water and carbon fluxes are estimated under dry 
conditions. Here we show that the reduction in GPP and transpiration is not due to a change in the Ball-Berry parameter, but mainly because of a reduction in photosynthesis due to greenness and leaf area (optical data) and $V_{\text {cmax }}$ (TIR data).

The availability of a model like SCOPE that combines the optical and the thermal part of the spectrum with a SVAT scheme makes it possible to exploit the full potential of the optical and TIR domains of remote sensing observations, which is an advancement over the empirical use of VI's.

A limitation to the applicability of our approach to other ecosystems is that the RT scheme of the SCOPE model, which is essentially the PROSAIL (a wellestablished combination of PROSPECT leaf and canopy SAIL model), is a 1-D (vertical) RT model. This means that inhomogeneities in vegetation properties such as LAI in the horizontal direction within a pixel are not represented. The applicability of the model is therefore limited to homogeneous vegetation cover, where vertical variations in radiative and energy fluxes are much higher than the horizontal ones. The same holds for the thermal radiative transfer and the aerodynamic resistance scheme, which consider multiple sources (sunlit and shaded soil and vegetation), but is nevertheless 1-D. Therefore, we expect our approach to work for closed vegetation covers (e.g., grasslands, croplands, forest ecosystems) but in incomplete vegetation covers (e.g., row crops in an early growth stage, savanna ecosystems with closed understory and scattered trees, and boreal forest) our model representation may not be accurate.

\subsubsection{Operational use of Sentinel observations}

The results of this study have shown that from Landsat optical and TIR bands we can extract valuable information on canopy $T$, soil $E$ and GPP reductions. However, there is a great potential to improve the resolution (spatial, temporal and spectral) and, therefore, obtain details information, by exploiting the spectral data offered by the Sentinel-2 and 3 missions. Sentinel2 provides optical spectral information in 13 bands (covering VIS, NIR and SWIR regions) with spatial resolutions of 10, 20 and 60 meters and an average revisiting frequency of 5 days. Moreover, the Sentinel-3 provides optical and TIR spectral information through Sea and Land Surface Temperature Radiometer (SLSTR) covering 9 spectral bands (covering VIS - SWIR ( 6 bands) and TIR (3 bands) regions), with spatial resolutions of 500 (for VIS and SWIR bands) and 1000 (for TIR bands) meters and an average revisiting frequency of 1 day. Thus, our proposed approach is useful for estimation of vegetation properties and functioning changes from time series of sentinel-2 and 3 spectral data in an operational multi-sensor way.

\subsection{Conclusions}

The present analysis shows the potential of Landsat observations to reveal drought not only expressed as vegetation stomatal and non-stomatal effects, 
but also by its effect on soil evaporation. Non-stomatal effects could be revealed from the information provided by optical bands, but to reveal also stomatal effects and those of soil evaporation, the information contained in TIR bands is relevant. To exploit such spectral information in depth, specific tools are needed. In this study we used the SCOPE land surface model to enable the full exploitation of optical and TIR data from Landsat to simulate daily GPP and ET changes during a drought episode. The comparison between the simulated daily GPP and ET with those of the measured ones show evidence of a good agreement when optical and TIR spectral information are integrated. Therefore, the SCOPE model appears to be capable of estimating GPP and ET consistently during a prolonged drought episode when constrained with both satellite optical and TIR information. Moreover, our results also suggest that we can not only derive crop factors for ET but also for photosynthesis (GPP). This is possible when the SCOPE model is used since it enables to simulate photosynthesis for the hypothetical reference grass defined by FAO. In addition, retrieved vegetation properties from the optical and TIR domains of Landsat revealed that making $V_{c m a x}$ a function of $C_{a b}$ during a drought episode only gave slight improvements of the GPP and ET simulations. This might be improved if $V_{\text {cmax }}$ is linked to $C_{w}$ and/or to TIR spectra instead of to $C_{a b}$. Furthermore, generated time series of GPP and ET maps demonstrated that integrating optical and TIR information could map much higher spatial variability of GPP and ET in comparison to those using only optical information in mild stress. Integrating optical and TIR, could also capture the low values of daily GPP and ET in moderate and severe drought conditions. This study presents a promising approach in order to explore remote sensing observations in depth and underlines the feasibility of estimating substantial drought effects on ecosystem functioning. Although this study used Landsat optical and TIR observations to capture drought effects on grassland functioning only in California, we expect that such results will also be relevant for other closed vegetation covers (e.g., grasslands, croplands, forest ecosystems) during droughts mainly due to the RT scheme of the SCOPE model. 


\section{Chapter 5 Combined use of optical reflectance and soil moisture observations using SCOPE-SM model ${ }^{*}$}

\footnotetext{
* This chapter is based on:

Bayat, B., Van der Tol, C., Yang, P., Verhoef, W., 2018. Extending the SCOPE model to combine optical reflectance and soil moisture observations for remote sensing of ecosystem functioning under water stress conditions. Remote Sensing of Environment, 2018, 221, 286-301, https://doi.org/10.1016/j.rse.2018.11.021.
}

Bayat, B., Van der Tol, C., Verhoef, W., Raj, R., 2018. Spatio-temporal Estimation of Daily Photosynthesis in Drought Conditions using Remote Sensing Observations and Insitu Measurements, the $3^{\text {rd }}$ Integrated Carbon Observation Science ICOS 2018, Prague, Czech Republic, 11-13 September 2018. 


\section{ABSTRACT}

The model Soil-Canopy-Observation of Photosynthesis and Energy fluxes (SCOPE) relates remote sensing signals with plant functioning (i.e., photosynthesis and evapotranspiration). Relying on optical remote sensing data, the SCOPE model estimates photosynthesis and evapotranspiration, but these ecosystem-level fluxes may be significantly overestimated if water availability is the primary limiting factor for vegetation. In such cases, additional data sources are needed. In this study, we propose considering water stress in SCOPE by incorporating soil moisture in the model, besides using satellite optical information, to better capture vegetation functioning variations under drought conditions. A functional link between soil moisture, soil surface resistance, leaf water potential and carboxylation capacity is introduced as an extra element in SCOPE, resulting in a soil moisture integrated version of the model, SCOPE-SM. The modified model simulates additional state variables: (i) vapor pressure $\left(e_{i}\right)$, both in the soil pore space and leaf stomates in equilibrium with liquid water potential, (ii) the maximum carboxylation capacity $\left(V_{\text {cmax }}\right)$ by a soil moisture dependent stress factor and (iii) the soil surface resistance $\left(r_{\mathrm{ss}}\right)$ through approximation by a soil moisture dependent hydraulic conductivity. The new approach was evaluated at a Fluxnet site (US-Var) with dominant annual C3 grasses and covering a wet-todry episode from January to August 2004. By using the original SCOPE (version 1.61), we simulated half-hourly time steps GPP and ET via locally measured weather data and time series of Landsat (TM and ETM) retrieved vegetation properties from Chapter 3 [notably Leaf Area Index $(L A I)$, leaf chlorophyll content (Cab), leaf water content $\left(C_{\mathrm{w}}\right)$, leaf dry matter content $\left(C_{\mathrm{dm}}\right)$, the leaf inclination distribution function (LIDF) and the senescent material content $\left(C_{s}\right)$ ] after linear interpolation over time. Then, SCOPE-SM was applied to simulate half-hourly photosynthesis and evapotranspiration three times: first using time series of Landsat retrieved vegetation properties and modeled $e_{i}$, second using Landsat retrieved properties, modeled $e_{\mathrm{i}}$ and modeled $V_{\text {cmax }}$ and third using Landsat retrieved properties, modeled $e_{i}$, modeled $V_{\text {cmax }}$ and modeled $r_{s s}$. The outputs of all these four simulations (i.e., one original SCOPE and three SCOPESM simulations) were compared to flux tower photosynthesis and evapotranspiration measurements. The results indicate a significant improvement proceeding from the first to the fourth case in which we used both optical observations and soil moisture data. Our results show that the combined use of optical reflectance and soil moisture observations in SCOPE has great potential to capture variations of photosynthesis and evapotranspiration during drought episodes. Further, we found that the information contained in soil moisture observations can describe more variations of measured evapotranspiration compared to the information contained in thermal observations described in Chapter 4. 


\subsection{Introduction}

Process-based vegetation models are indispensable tools for understanding the link between vegetation appearance (i.e., canopy spectra) and ecosystem functioning (i.e., photosynthesis [gross primary production (GPP)] and evapotranspiration (ET)). Vegetation appearance can be described in a physically consistent way using different radiative transfer (RT) models (Jacquemoud and Baret, 1990; Verhoef, 1984, 1985) as a function of vegetation properties (e.g., leaf area index, leaf water, and chlorophyll content). In addition, coupled use of a leaf photosynthesis (Collatz et al., 1992; Farquhar et al., 1980) and an energy balance approach (Glenn et al., 2007; Liou and Kar, 2014; K. Zhang et al., 2016) besides the RT models allows to describe vegetation functioning variations through process-based descriptions. A process-based model can assist considerably to understand the light distribution within the canopy (by means of the RT module), the available energy consumption in photosynthesis (by means of the photosynthesis module) and partitioning of the energy into latent, sensible and ground heat fluxes (by means of the energy balance module).

Several process-based models have been applied for GPP (Cuddington et al., 2000; Mäkelä et al., 2000; Morales et al., 2005; Raj et al., 2018) and ET (Glenn et al., 2007; Liou and Kar, 2014; K. Zhang et al., 2016) estimation. The model CUPID (Kustas et al., 2007; Norman, 1979) is maybe the first one in which a reasonable RT model is implemented. Other remote sensing based models for ET or GPP typically do not include such detailed radiative transfer (reviews, see (K. Zhang et al., 2016) and (Anav et al., 2015)).

SCOPE (Soil-Canopy-Observation, Photochemistry, and Energy fluxes) is one of the process-based models which integrates soil-canopy spectral radiances, photosynthesis, and energy balance models (Van der Tol et al., $2009 b$ ) and, therefore, provides a valuable means to study the link between vegetation appearance and ecosystem functioning. Thus, in this study, the focus is on this model. SCOPE simulates canopy reflectance and fluorescence spectra in the observation direction, as well as photosynthesis, and evapotranspiration as functions of leaf optical properties, canopy structure, and weather variables. SCOPE has been widely used in various applications, all attempting to contribute to a better understanding and interpretation of remote sensing signals over vegetation by (1) quantifying and interpreting sun-induced chlorophyll fluorescence (Damm et al., 2015; Koffi et al., 2015; Verrelst et al., 2015; Yang and van der Tol, 2018; Zhang et al., 2014), (2) simulating multiple satellite radiances through coupling with atmosphere RT model (Bayat et al., 2018; Verhoef et al., 2018), (3) retrieving biophysical and biochemical properties (Bayat et al., 2016a; Van der Tol et al., 2016), (4) investigating directional effects of radiation in thermal infrared domain (Duffour et al., 2016, 2015), (5) estimating vegetation functioning variations and their biases (Bayat et al., 2018; Timmermans et al., 2013; Verrelst et al., 
2016). In addition, recently further extensions were proposed for the SCOPE model to advance its performance both at the leaf (Vilfan et al., 2018, 2016) and canopy (Yang et al., 2017) levels.

One shortcoming of SCOPE is that it does not keep track of the water budget in soil and vegetation, and does not contain an explicit parametrization of effects of soil moisture on the photosynthesis or stomatal parameters. Therefore, soil moisture effects are only manifest if the lack of soil moisture affects the optical or thermal appearance of the vegetation. The change of vegetation optical appearance as a result of soil moisture variations can only explain a small portion of the soil moisture effects (as described in chapter 4) and, therefore, the estimations of GPP and ET are considerably biased in water limited conditions. This makes a challenge for using SCOPE especially in ecosystems where water availability is the primary limiting factor for vegetation functioning, for instance, those located in arid and semi-arid areas. This challenge becomes even more relevant due to the fact that soil moisture deficit or "ecological drought" is expected to increase in both frequency and severity at nearly all ecosystems around the world (Wolf et al., 2013; Zhou et al., 2013). For instance, the impacts of seasonal stress as a result of soil water deficit are also reported in Mediterranean ecosystems (Jung et al., 2007; Ma et al., 2007; Morales et al., 2005; Xu and Baldocchi, 2003).

Remedying this shortcoming (i.e., biased estimations of GPP and ET) requires feeding additional and complementary information into SCOPE. Besides optical data sets, we need thermal observations or soil moisture information to effectively constrain canopy photosynthesis, transpiration and soil evaporation in water-limited ecosystems.

Integrated use of optical and thermal information in SCOPE has been addressed (in chapter 4 ) to estimate vegetation functioning during a drought episode. The energy balance and thermal radiative transfer routines of SCOPE, RTMt, have been inverted to retrieve the most sensitive parameters of SCOPE in the thermal domain [notably the maximum carboxylation capacity $\left(V_{c m a x}\right)$, the Ball-Berry stomatal conductance parameter $(m)$, soil surface resistances $\left(r_{\mathrm{ss}}\right)$ and boundary resistances $\left(r_{\mathrm{bs}}\right)$ ] by means of look-up tables. Based on this approach, there is no need for extra modifications of the original SCOPE (version 1.61) since it is already simulating thermal signals and, therefore, making a look-up table for the thermal simulations is sufficient.

However, the potential of a combined use of optical and soil moisture observations is still unexplored and has not been dealt with in depth. It is unclear how much information one can get from soil moisture observations to improve SCOPE estimations in water-limited ecosystems. More importantly, how different is the information in thermal observations from that of soil moisture provided. To address these questions, we need to add functional links between soil moisture and vegetation properties in SCOPE. We speculate that by the combined use of satellite optical information and soil moisture data, one can see the majority of drought effects on leaf photosynthesis, transpiration, 
and soil evaporation respectively. In other words, incorporating water stress in the SCOPE model will allow to combine reflectance optical information and soil moisture data improving our understanding of GPP and ET variations in waterlimited ecosystems.

The water stress (i.e., soil moisture deficit) has been incorporated in different photosynthesis-conductance models to enhance photosynthesis and transpiration estimation, using experimental data sets collected in a laboratory effort, field works and field campaigns. The inclusion of soil water constraints on photosynthesis parameters could lead to considerable improvements of photosynthesis and transpiration simulations (Egea et al., 2011; Keenan et al., 2010a, 2009; Verhoef and Egea, 2014). Further, water stress was integrated into the widely-used energy balance SEBS [surface energy balance system (Su, 2002)] model using soil moisture products to improve evapotranspiration estimations in water-limited regions in Turkey (Gökmen et al., 2012).

In the current study, we propose a simple update for SCOPE, hereafter called SCOPE-SM, to allow us to use soil moisture data together with remote sensing optical observations in order to correct GPP and ET estimations under water stress conditions. In the SCOPE-SM model, the soil moisture information is taken into account through the formulation of canopy and soil heat fluxes (via vapor pressure parameter $e_{i}$ ), leaf stomatal resistance (via maximum carboxylation rate parameter $V_{c m a x}$ ) and soil surface resistance (via soil surface resistance parameter $r_{\mathrm{ss}}$ ). The performance of SCOPE-SM was preliminarily evaluated by the comparison of its outputs with both the original SCOPE outputs and the field measurements during a wet-to-dry episode (from January to August 2004) at a Fluxnet site (US-Var). Next, the performance of SCOPESM was compared with previous results (described in chapter 4) in which optical and thermal observations used to constrain SCOPE in a wet-to-dry episode to enhance vegetation functioning estimation. This is important since it can show the information content and possible differences of soil moisture data and thermal observations.

The structure of this chapter is as follows. After this introduction (section 5.1), a general overview of the SCOPE model is provided. Here, we briefly describe the methodology that SCOPE adopts to quantify GPP and ET (section 5.2.1). Then, we provide insights into our proposed approach, SCOPE-SM, to correct GPP and ET estimations (section 5.2.2). In section 5.3, we evaluate the performance of both SCOPE and SCOPE-SM models at the Vaira Ranch site (section 5.3.1.2). Next, the GPP and ET simulation results from both models are presented and compared with those of measured GPP and ET (sections 5.3.4.1, 5.3.4.2 and 5.3.4.3). The comparison of soil moisture and thermal information provided to constrain the SCOPE model is also presented (section 5.3.4.4) and finally, the most important results are discussed and conclusions are drawn (section 5.4). 


\subsection{Model description}

\subsubsection{SCOPE model brief overview}

SCOPE is an integrated soil-canopy spectral radiances, photochemistry and energy balance model (Van der Tol et al., 2009b) which combines radiative transfer theory with plant physiology and micrometeorological approaches. There are three radiative transfer models, one photosynthesis model and one energy balance model integrated into SCOPE. The radiative transfer models of SCOPE cover the 0.4 to $50 \mu \mathrm{m}$ wavelength range. RTMo, which is mainly based on the Fluspect (Vilfan et al., 2016) and SAIL (Verhoef, 1984, 1985) models, is the radiative transfer model handling the incident solar and sky radiation and it simulates canopy reflectance and radiation distribution inside a canopy. RTMt is the radiative transfer model in the thermal domain for internally emitted radiation $(2.5-50 \mu \mathrm{m})$. Another radiative transfer model is RTMf that simulates canopy fluorescence $(0.64-0.85 \mu \mathrm{m})$. SCOPE spectral outputs have sampling intervals of $1 \mathrm{~nm}$ in the optical domain, of $0.1 \mu \mathrm{m}$ in the thermal domain, and of $1 \mu \mathrm{m}$ in the longwave domain.

Further, in SCOPE, a vegetation canopy is divided into 60 leaf layers assuming a maximum LAI of 0.1 per layer, and one soil surface is defined under the vegetation layers. There are 468 classes of leaf orientation, composed of all combinations of 13 the leaf's normal zenith angles and 36 leaf azimuth angles. The orientations are of great importance because solar flux interception and scattering by leaves is a function of their orientation relative to the sun's position.

RTMo computes the radiation that interacts with each leaf and the scattered and absorbed radiation. Likewise, RTMt simulates the distribution of thermal emitted radiation within the canopy. The net radiation outputs of RTMo and RTMt are used as an input to the energy balance module to estimate skin temperature, while the computed skin temperature from the energy balance is an input of RTMt. The skin temperature is solved by iteration of RTMt and the energy balance module. Such an iteration continues until the energy balance is closed for all the elements described above.

Both the aerodynamic and stomatal resistances are modified during the iteration due to the fact that atmospheric stability and vegetation photosynthesis are influenced by leaf temperatures. The aerodynamic resistance depends on the LAI, canopy height, wind speed and the atmospheric stability (Wallace and Verhoef, 2000), whereas the stomatal resistance depends on net assimilation rate of the leaves, vapor pressure deficit in the ambient air and air pressure. Furthermore, the photosynthesis of C3 (Farquhar et al., 1980), C4 vegetation (Collatz et al., 1992), stomatal resistance (Collatz et al., 1992, 1991) and chlorophyll fluorescence (Van der Tol et al., 2009a) are computed by the biochemical routine of the model. 
In the original SCOPE model, one has to consider constant values for maximum carboxylation capacity, leaf water potential, soil water potential and soil surface resistance (these parametrizations are described in Appendix A). Considering constant values for such parameters in SCOPE works when soil moisture deficit is not the primary limiting factor (e.g., humid regions) for vegetation functioning or if its effect is known a-priori and specified as inputs. However, this is problematic for application in time series during drought conditions specifically or at water-limited ecosystems in general. Therefore, we proposed a simple extension for the SCOPE (section 5.2.2) to overcome this challenge mainly through three steps; (i) the maximum carboxylation capacity $\left(V_{\text {cmax }}\right)$ is modeled by a soil moisture dependent stress factor, (ii) vapor pressure $\left(e_{i}\right)$ is modeled both in the soil pore space and leaf stomates in equilibrium with liquid water potential and, and (iii) the soil surface resistance $\left(r_{\mathrm{ss}}\right)$ approximated by a soil moisture dependent hydraulic conductivity. However, the Ball-Berry stomatal parameter is not modified compared to the original SCOPE model. The three steps are described in section 5.2.2.

\subsubsection{SCOPE-SM model}

\subsubsection{Modeling maximum carboxylation capacity}

When estimating GPP during a drought episode by the original SCOPE model, using the set of formulations (i.e., given in Eqs. 5.A1 to 5.A5 in Appendix $\mathrm{A}$ ), one has to consider a constant $V_{\mathrm{cmax}}$ as an input. In other words, regardless of water stress phase or even the seasonal cycle, $V_{\text {cmax }}$ is always either kept as constant during the drought episode or prescribed as time series input. This will not only result in an overestimation of GPP directly but also make stomatal resistance and, consequently, transpiration estimation, biased. To tackle this issue, we propose to consider water stress level in the $V_{\text {cmax }}$ parameter based on soil water availability to correct GPP estimation. We therefore defined a soil moisture (SM) dependent stress factor (SF) to modify $V_{c m a x}$ during the episode through an S-shaped membership function in MATLAB as follows:

$$
V_{c \text { max }}=S F \times V_{c \text { max }}
$$

where: 


$$
S F= \begin{cases}0 & S M<a \\ 2\left(\frac{S M-a}{b-a}\right)^{2} & a \leq S M \leq \frac{a+b}{2} \\ 1-2\left(\frac{S M-b}{b-a}\right)^{2} & \frac{a+b}{2}<S M<b \\ 1 & S M \geq b\end{cases}
$$

where, $a$ and $b$ are the coefficients of the membership function corresponding to soil moisture at permanent wilting point and field capacity, respectively.

The S-shaped membership function was selected because (1) in this function two coefficients (i.e., $a$ and $b$ ) are used to locate the left and right extremes of the sloped portion of the curve. This provides a good fit to the conceptual framework for vegetation functioning in water-limited areas in which two thresholds (i.e., permanent wilting point and field capacity) are considered (Seneviratne et al., 2010, 2006b), and (2) by increase of SM values the function increases from 0 to 1 . This reasonably scales $V_{\text {cmax }}$ and, therefore, generate lower values for dry conditions (SM approaching 0 ) and higher values for wet conditions (higher SM).

The coefficients ( $a$ and $b$ ) are soil dependent and can be obtained for a desired soil using a soil moisture retention curve. Paired measurements of pressure head and volumetric soil moisture content are needed to generate the soil moisture retention curve (Tuller and Or, 2004). We obtained 35 paired measurements at the Vaira site (Miller et al., 2010; Xu et al., 2004) and fitted the widely used parametric model proposed by Van Genuchten (1980) to such measurements. Then, we considered the $\mathrm{pF}$ ( $\log$ of the negative water potential, in $\mathrm{cm}$ ) of 2.6 (corresponding to a soil moisture of $0.29 \mathrm{~m}^{3} \mathrm{~m}^{-3}$ ) for the onset of water stress effects and $\mathrm{pF}$ of 4.2 (corresponding to soil moisture of $0.06 \mathrm{~m}^{3} \mathrm{~m}^{-3}$ ) for the permanent wilting point, following Feddes et al (1976). Thus, in our study $a=0.07$ and $b=0.29$ were obtained for the Vaira site.

\subsubsection{Modeling vapor pressure}

In the original SCOPE model, the vapor pressure in the stomatal pore space $e_{i}$ is considered to be in equilibrium with the liquid water potential of the leaf, and is, therefore, a function of temperature and water potential (see Eq. 5.A8 in Appendix A). In practice, however, water potential has been set to zero and the humidity in the pore space to saturation, because the water potential is not calculated as a state variable. This is reasonable under conditions without water stress (e.g., soil moisture around field capacity), but in a dry episode 
the leaf water potentials could be so low, that the assumption of saturation in the stomata is not justified anymore. To take this into account, we incorporated the water potential gradient from soil to leaf in SCOPE by describing the SoilPlant-Atmosphere Continuum (SPAC), the pathway for water movement from the soil through the plant to the atmosphere. The process of water movement can be divided into three sub-processes; (1) root extraction (from soil to root xylem), (2) plant water flux (from roots to leaves) and (3) transpiration (from leaves into the atmosphere). The first two processes have been added to the model by using additional resistances for liquid flow (Fig. 5.1), root radial resistance $\left(r_{\mathrm{r}}\right)$ and root axial resistance $\left(r_{\mathrm{x}}\right)$.

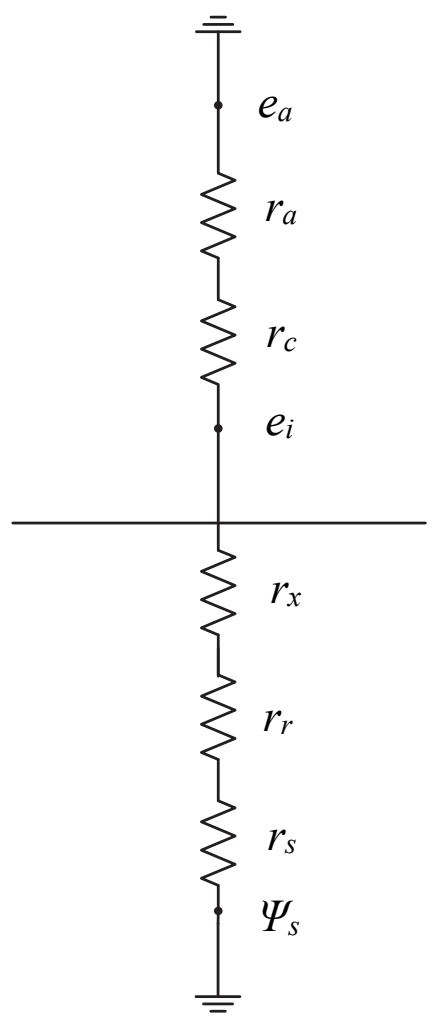

Figure 5.1. Simple Soil-Plant-Atmosphere Continuum (SPAC) scheme. The $\psi_{\mathrm{s}}$ is soil water potential $(\mathrm{m}), r_{\mathrm{s}}$ is soil hydraulic resistance $\left(\mathrm{s} \mathrm{m}^{-1}\right), r_{\mathrm{r}}$ is resistance to water flow radially across the roots $\left(\mathrm{s} \mathrm{m}^{-1}\right), r_{\mathrm{x}}$ is plant axial resistance to flow from the soil to the leaves ( $\mathrm{s}$ $\left.\mathrm{m}^{-1}\right), e_{\mathrm{i}}$ is leaf (soil) vapor pressure $(\mathrm{hPa}), r_{\mathrm{c}}$ is leaf stomatal (soil surface) resistance (s $\left.\mathrm{m}^{-1}\right), r_{\mathrm{a}}$ is aerodynamic resistance $\left(\mathrm{s} \mathrm{m}^{-1}\right)$ and $e_{\mathrm{a}}$ is atmospheric vapor pressure $(\mathrm{hPa})$.

We assumed that changes in storage (roots, xylem and leaves) are negligible, such that the fluxes $(q)$ are equal: 


$$
q_{s, r}=q_{r, l}=q_{s, l}
$$

where subscript / stands for leaf, $r$ for root and $s$ for soil. Therefore, the flux from soil to leaf $q_{s, l}$ can be described as:

$$
q_{s, l}=\frac{\psi_{s}-\psi_{l}}{r_{s}+r_{r}+r_{x}}
$$

where $\psi_{\mathrm{s}}$ is soil water potential $(\mathrm{m}), \psi_{\mathrm{l}}$ is leaf water potential $(\mathrm{m}), r_{\mathrm{s}}, r_{\mathrm{r}}$ and $r_{\mathrm{x}}$ are soil hydraulic resistance $\left(\mathrm{s} \mathrm{m}^{-1}\right)$, resistance to water flow radially across the roots $\left(\mathrm{s} \mathrm{m}^{-1}\right)$ and plant axial resistance to flow from the soil to the leaves $\left(\mathrm{s} \mathrm{m}^{-1}\right)$, respectively.

The liquid flow to the leaf is equal to the transpiration rate $T$, because we assumed that changes in leaf water storage are negligible.

$T\left(\mathrm{~m} \mathrm{~s}^{-1}\right)$ can be obtained by the method of bulk vapor transfer (Deardorff, 1978) as follows:

$$
T=\rho_{a}\left(\frac{q_{l}-q_{a}}{r_{c}+r_{a}}\right)
$$

where $q_{\mathrm{l}}$ and $q_{\mathrm{a}}$ are specific humidity $\left(\mathrm{kg} \mathrm{kg}^{-1}\right)$ of leaf and the atmosphere, $\rho_{\mathrm{a}}$ is the density of dry air $\left(\mathrm{kg} \mathrm{m}^{-3}\right)$, respectively. The specific humidity is obtained from the vapor pressure as $q=0.622 / p \times e_{i}$, where $p$ is the atmospheric pressure and 0.622 the ratio of the molar mass of water to air.

The relation between the liquid water potential and the atmospheric vapor gradient then becomes:

$$
\frac{\psi_{s}-\psi_{l}}{r_{s}+r_{r}+r_{x}}=\frac{0.622}{p} \frac{\rho_{a}}{\rho_{w}}\left(\frac{e_{l}-e_{a}}{r_{c}+r_{a}}\right)
$$

The term on the left side of Eq. (6) is called root extraction $(S)$ and the right side term is transpiration $(T)$. The coefficients $\rho_{\mathrm{a}}$ and $\rho_{\mathrm{w}}$ [the density of water vapour $\left.\left(\mathrm{kg} \mathrm{m}^{-3}\right)\right]$ are considered as constant values, $e_{\mathrm{a}}$ and $p$ as inputs, $r_{\mathrm{s}}, r_{\mathrm{r}}, r_{\mathrm{x}}$ are parameterized, and $\psi_{\mathrm{l}}, r_{\mathrm{a}}$ [aerodynamic resistance $\left(\mathrm{s} \mathrm{m}^{-1}\right)$ ], $r_{\mathrm{c}}$ [leaf stomatal resistance $\left.\left(\mathrm{s} \mathrm{m}^{-1}\right)\right]$, and $e_{\mathrm{i}}$ are solved by iteration of the energy balance calculation in the SCOPE model. It should be noted that a direct arithmetic solution for $\psi_{1}$, is not possible.

$\psi_{\mathrm{s}}$ is described as a function of soil moisture with Van Genuchten (1980):

$$
\begin{aligned}
& \psi_{s}=\frac{\left(S_{e}^{-1 / m}-1\right)^{1 / n}}{\alpha} \\
& S_{e}=\frac{\left(\theta-\theta_{r}\right)}{\left(\theta_{\text {sat }}-\theta_{r}\right)}
\end{aligned}
$$




$$
m=1-\frac{1}{n}
$$

where $\theta, \theta_{\text {sat, }}$ and $\theta_{r}$ is soil moisture $\left(\mathrm{m}^{3} \mathrm{~m}^{-3}\right)$, saturated soil moisture $\left(\mathrm{m}^{3} \mathrm{~m}^{-}\right.$ ${ }^{3}$ ) and residual soil moisture content $\left(\mathrm{m}^{3} \mathrm{~m}^{-3}\right), a$ and $n$ are soil-dependent parameters. We fitted the Van Genuchten model with the measurements and obtained $0.38,0.0,1.66$ and 1.5 for $\theta_{\text {sat }}, \theta_{r}, a$, and $n$, respectively.

$r_{\mathrm{s}}$ can be obtained by (Reid and Huck, 1990):

$$
r_{s}=\frac{1}{B K L_{V} \Delta z}
$$

$B$ is the root length activity factor, $K$ is hydraulic conductivity of soil $\left(\mathrm{m} \mathrm{s}^{-1}\right), L \mathrm{v}$ is root density $\left(\mathrm{m} \mathrm{m}^{-3}\right)$, and $\Delta \mathrm{z}$ is the thickness of the soil layer $(\mathrm{m}) . B$ is calculated as:

$$
B=\frac{2 \pi}{\ln \left[\left(\pi L_{V}\right)^{-1 / 2} / r\right]}
$$

where $r$ is root radius $(m) . K$ is calculated as:

$$
K=K_{s a l} S_{e}^{l}\left[1-\left(1-S_{e}^{1 / m}\right)^{m}\right]^{2}
$$

where $K_{\text {sat }}$ is the hydraulic conductivity at air entry potential $\left(\mathrm{m} \mathrm{s}^{-1}\right)$, and $/$ is an empirical pore-connectivity parameter. The other parameters are defined in Eq. 5.7 and 5.9.

$r_{r}$ is estimated as (Reid and Huck, 1990):

$$
r_{r}=\frac{P_{r}\left(\theta_{\text {sat }} / \theta\right)}{L_{V} \Delta z}
$$

where $P_{\mathrm{r}}$ is root radical resistivity $\left(\mathrm{s} \mathrm{m}^{-1}\right)$.

The xylem resistance $r_{\mathrm{x}}$ is estimated as (Klepper et al., 1983):

$$
r_{x}=\frac{P_{a} z}{0.5 f L_{V}}
$$

where $P_{a}$ is root axial resistivity $\left(\mathrm{s} \mathrm{m}^{-3}\right), z$ depth of the midpoint of soil layer considered as $0.2, f$ is a fraction, and it is defined for a specific depth as the number of roots which connect directly to the stem base to total roots crossing a horizontal plane at that depth. We can consider it equals 0.22 based on (Klepper et al., 1983).

The iteration to solve $\psi_{1}$ and $e_{i}$ uses an initial value of $\psi_{l}=\psi_{\mathrm{s}}$. This value is recomputed after calculation of the transpiration flux, and this continues until 
convergence of consecutive $\psi_{1}$ (a difference less than $1 \mathrm{~cm}$ ). This iteration loop is nested in the energy balance loop that resolves leaf temperature.

\subsubsection{Modeling soil surface resistance}

In the original SCOPE model, there is another relevant parameter which controls the soil resistance to evaporation from soil pore space " $r_{\mathrm{ss}}$ ". This parameter is also considered as a constant value (the default value in the model is $500 \mathrm{~s} \mathrm{~m}^{-1}$ for moist conditions). In fact, the $r_{\mathrm{ss}}$ is used in Eq. (6A) instead of $r_{\mathrm{c}}$ for the computation of soil latent heat flux. Thus, in the original model this parameter is parameterized for different conditions and, therefore, it does not respond to soil moisture conditions. To have a better estimation of $r_{\text {ss, }}$ hydrological evaporation models might be used. However, this makes the study more complex and one has to introduce a substantial additional number of parameters into the SCOPE model. In this study, we propose to simply approximate the $r_{\mathrm{ss}}$ based on a soil moisture dependent hydraulic conductivity (Verhoef and Egea, 2014) as follows:

$$
r_{s s}=r_{s s \min }\left(K_{s a t} / K_{\theta}\right)
$$

where $r_{\text {ssmin }}$ is the minimum soil surface resistance for wet conditions ( $\mathrm{m} \mathrm{s}^{-}$ ${ }^{1}$ ), and the other parameters are defined before (in Eqs. 5.7-5.9 and 5.12).

\subsection{Evaluation of the model}

Time series of GPP and ET were simulated using both the original and the extended SCOPE model (Fig. 5.2). A number of parameters were retrieved from Landsat optical observations (described in chapter 3), and these were used in both versions of SCOPE, together with half-hourly time step weather inputs [notably TOC incoming shortwave radiation from 0.3 to $2.5 \mu \mathrm{m}\left(R_{\text {in }}\right)$, TOC incoming long wave radiation from 2.5 to $50 \mu \mathrm{m}\left(R_{\mathrm{li}}\right)$, air pressure $(p)$, air temperature $\left(T_{a}\right)$, actual vapor pressure $\left(e_{a}\right)$, and wind speed $\left.(u)\right]$. For the extended SCOPE, we further used the near-surface soil moisture as measured in the field. 


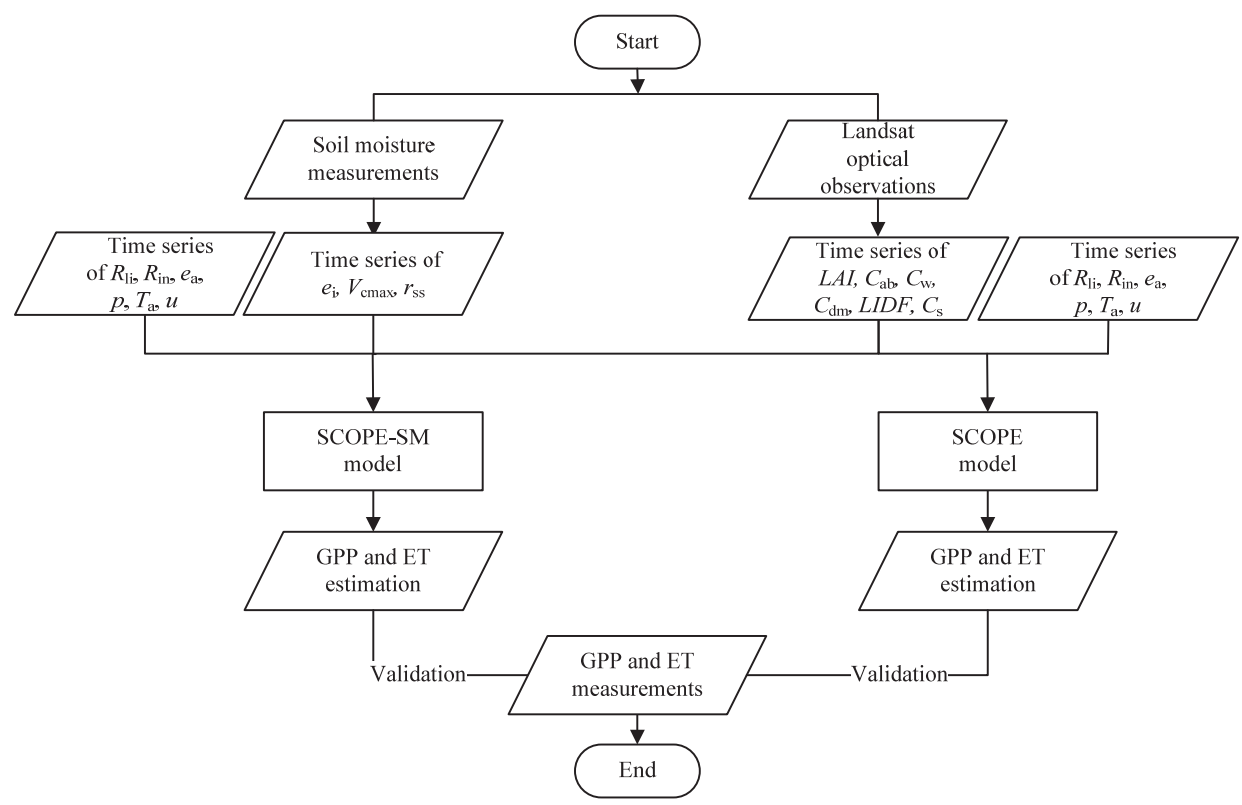

Figure 5.2. The main phases of the methodology

\subsubsection{Study site and data}

\subsubsection{Vaira Ranch (US-Var) Fluxnet site description}

The study site is an annual grassland known as Vaira Ranch (US-Var) in the Ameriflux and Fluxnet network, USA (Boden et al., 2013). The site is located on the lower foothills of the Sierra Nevada Mountains, California (Vaira Ranch, $38.4133^{\circ} \mathrm{N} ; 120.9508^{\circ} \mathrm{W}$ ) with an average elevation of $129 \mathrm{~m}$ (Xu et al., 2004). This study area often faces drought. One of the driest year in the site was 2004 according to the Palmer Drought Severity Index (PDSI) dataset (www.ncdc.noaa.gov/temp-and-precip/drought/historical-palmers) and a pervious on-site study (Ma et al., 2007). In our study, we focused on this driest year and used the months from January to August 2004 for modeling and validation purposes. The dominant grass species of the site include Brachypodium distachyon, Erodium cicutarium, Bromus hordeaceous, Hypochaeris glabra, Trifolium dubium Sibth, Trifolium hirtum, Erodium botrys and Dichelostemma volubile (Xu and Baldocchi, 2004). They are all C3 plants and are originally from the Mediterranean basin (Xu and Baldocchi, 2004).

\subsubsection{Remote sensing observations}

Remote sensing optical observations can be used to retrieve vegetation properties to feed the SCOPE model together with locally measured weather data to simulate GPP and ET. In the current study we used time series of Landsat-retrieved vegetation properties (chapter 3, Fig. 3.17) during the selected period at the Vaira site. For the days with a satellite overpass, the 
Landsat-retrieved properties were used. For the other days during the episode in which Landsat observations were not available, a linear interpolation was applied and, therefore, a continuous set of retrieved properties ( $L A I, C_{a b}, C_{\mathrm{w}}$, $C_{\mathrm{dm}}, L I D F$, and $C_{\mathrm{s}}$ ) obtained for all days during the episode was used in SCOPE.

\subsubsection{Ground measurements}

Volumetric soil moisture data were collected by an array of calibrated frequency domain reflectometry sensors at three different depths of 2, 10 and $20 \mathrm{~cm}$ (Theta Probe model ML2-X, Delta-T Devices, Cambridge, UK), calibrated by gravimetric measurements. In this study, we used soil moisture measurements at $10 \mathrm{~cm}$ depth. The required meteorological inputs, including solar radiation fluxes, air temperature, relative humidity, air pressure and wind speed, were collected with a half-hourly time step.

Radiation fluxes were recorded above the canopy using upward and downward facing quantum sensors (PAR Lite, Kipp, and Zonen, Delft, Netherlands), a pyranometer (CM 11, Kipp and Zonen, Delft, Netherlands), and one net radiometer (NR Lite, Kipp and Zonen, Delft, Netherlands). Temperature and relative humidity were collected by a resistance thermometer and a solid-state humicap (model HMP-45A, Vaisala, Helsinki, Finland). Air pressure was recorded by capacitance barometers (model PTB101B, Vaisala, Helsinki, Finland). Furthermore, an Eddy Covariance (EC) system was used to measure fluxes (Wind master Pro, Gill Instruments, Lymington, UK plus LI7500, LICOR, Lincoln, NE, USA). For more details of these measurements, the reader is referred to previous studies (Baldocchi et al., 2004; Ma et al., 2007; Xu and Baldocchi, 2004).

\subsubsection{Error statistics}

Various error statistics were employed to investigate the performance of the SCOPE and SCOPE-SM models in simulating daily GPP and ET against the Vaira Fluxnet site derived GPP and ET. The coefficient of determination $\left(R^{2}\right)$, the root mean square error (RMSE) and the normalized root mean square error (NRMSE) were used to evaluate the agreement between simulated and measured GPP and ET in each case. Moreover, we decomposed the MSE into three components (Gupta et al., 2009) to describe the contributions due to 1) unequal standard deviations, 2) lack of (positive) correlation and 3) the bias in the mean values for SCOPE and SCOPE-SM simulations as follows:

$$
R^{2}=1-\frac{\sum_{i=1}^{n}\left(g_{i}-s_{i}\right)^{2}}{\sum_{i=1}^{n}\left(g_{i}-\bar{g}\right)^{2}}
$$




$$
\begin{aligned}
& \text { RMSE }=\sqrt{\frac{1}{n} \sum_{i=1}^{n}\left(s_{i}-g_{i}\right)^{2}} \\
& N R M S E=\left(\frac{R M S E}{g_{\text {max }}-g_{\text {min }}}\right) \\
& \text { MSE }=\left(\sigma_{s}-\sigma_{g}\right)^{2}+2 \sigma_{s} \sigma_{g}(1-R)+(\bar{s}-\bar{g})^{2}
\end{aligned}
$$

where $s_{i}$ and $g_{i}$ are the model simulation and the ground measurement, $n$ is number of samples, $g_{\max }$ and $g_{\min }$ are maximum and minimum values of measurements, $\sigma_{\mathrm{s}}$ and $\sigma_{\mathrm{g}}$ are standard deviation of the simulation and ground measurement, the over bars represent the mean values of model simulation (

$\bar{S})$ and ground measurement $(\bar{g})$ and $R$ is the correlation coefficient.

The advantages of MSE decomposition are that (1) one can investigate the bias in the mean values as well as the difference in the standard deviations between model simulations and ground measurements, and (2) one can better interpret the computed $R^{2}$ due to the fact that only a positive correlation can contribute to accomplishing a low value of MSE. The first is relevant because in case of large difference in the standard deviations or in the mean values (bias), the MSE will still be high, even if the model correlates well with the measurements. The second is necessary to avoid misinterpretation of a higher $R^{2}$ between model simulation and ground measurement in the case of a negative correlation.

\subsubsection{Information content of optical, thermal and soil moisture observations}

Similar error statistics (as of section 5.3.2) were utilized to compare the SCOPE (constrained only by optical observations), SCOPE-SM (constrained by optical and soil moisture observations), and SCOPE (constrained by optical and thermal observations) performances. Further, we used a crop factor analysis, described in chapter 4 , to better interpret the added value of each observation (i.e., optical, thermal and soil moisture) for GPP and ET simulation and, therefore, to understand the differences between the information each observation can provide. The crop factor is the ratio of actual over potential (unlimited, defined for green grass with ample soil moisture) GPP and ET. 


\subsubsection{Simulation results}

\subsubsection{Daily GPP simulation}

Simulated daily GPP results from the original SCOPE and the updated version of the model (SCOPE-SM) are presented in Fig. 5.3. In the original SCOPE case (Fig. 5.3a) we only used Landsat-retrieved information. As shown, the simulated GPP by the SCOPE model was in good agreement with the Fluxnet measured GPP only for a part of the selected episode from DOY 1 to 70, when soil moisture was relatively high. However, there is considerable inconsistency in the simulated GPP compared to the measured one for the rest of the episode (e.g., DOY 100 till DOY 200). The SCOPE-SM simulation results showed that estimating $V_{c \max }$ changes as a function of soil moisture accomplished a considerable improvement of GPP (Fig. 5.3c). In addition, the results showed that modifying $e_{\mathrm{i}}$ and $r_{\mathrm{ss}}$ based on available soil moisture data (Fig. 5.3b and 5.3d) did not change GPP simulations. Overall, comparison of the original SCOPE performance (Fig. 5.3a) with that of SCOPE-SM (Fig. 5.3c) demonstrated the value of combining Landsat observations and soil moisture data in the accurate estimation of daily GPP.

(a)

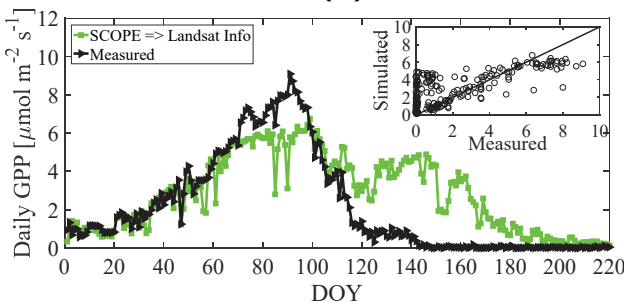

(c)

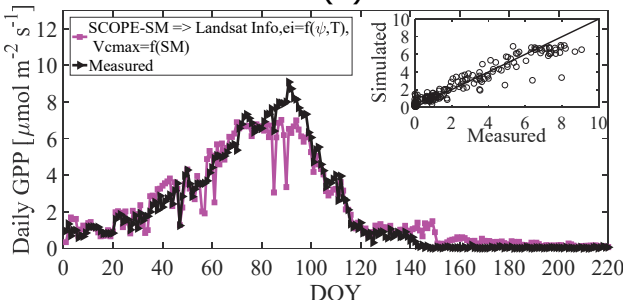

(b)

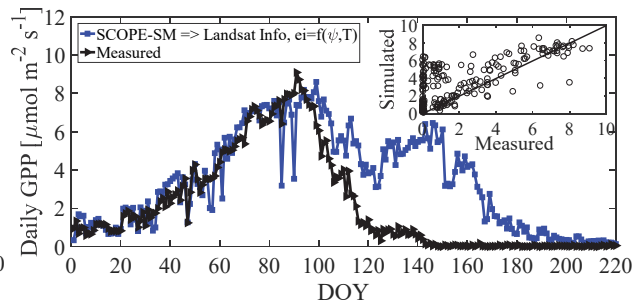

(d)

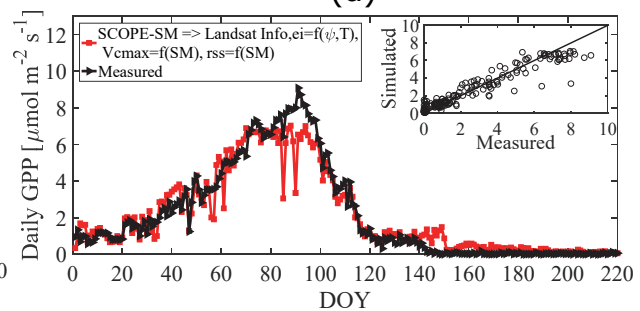

Figure 5.3. Model simulated and Fluxnet measured daily GPP at the Vaira site during the drought episode in 2004; (a) GPP simulated by original SCOPE using only Landsat retrieved vegetation properties, (b) GPP simulated by SCOPE-SM using Landsat retrieved properties and updated vapor pressure information, (c) GPP simulated by SCOPE-SM using Landsat retrieved properties, updated vapor pressure and $V_{\text {cmax }}$ information, and (d) GPP simulated by SCOPE-SM using Landsat retrieved vegetation properties, updated vapor pressure, updated $V_{\mathrm{cmax}}$ and updated $r_{\mathrm{ss}}$ information. Figure insets represent the scatter plot between simulated and measured GPP for each case (for more details of error statistics see section 5.3.4.3). 


\subsubsection{Daily ET simulation}

Simulated daily ET results from the original SCOPE and the updated version of the model in this study are presented in Fig. 5.4. Similar to GPP estimation, we found good agreement between the SCOPE simulated ET, and Fluxnet measured ET (Fig. 5.4a) for the first part of the episode (i.e., from DOY 1 to 70 ) in which soil moisture was relatively high. However, for the other days during the episode (i.e., DOY 71 to 220) the simulated ET is considerably overestimated. Using information from Landsat plus soil moisture data in the form of updated $e_{i}$ through SCOPE-SM (Fig. 5.4b) did not improve ET simulations comparing to that of the original SCOPE (Fig. 5.4a). However, the performance of SCOPE-SM in estimating ET improved when we made $V_{\text {cmax }}$ a function of soil moisture (Fig. 5.4c). Moreover, the results of ET simulations by SCOPE-SM significantly improved for the whole episode when the time series of $r_{\mathrm{ss}}$ information is also added (Fig. 5.4d). That is to say, the performance of SCOPE-SM improved for the whole episode when we combined Landsat information (in the form of retrieved vegetation properties) with soil moisture data (in the form of modified $V_{\text {cmax }}$ and $r_{\text {ss }}$ ).

(a)

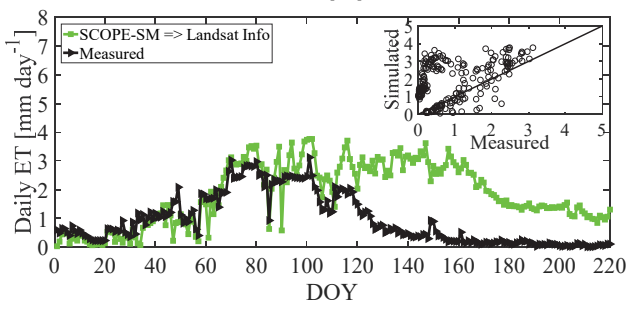

(c)

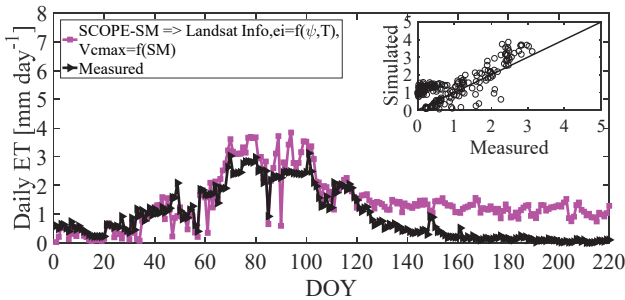

(b)

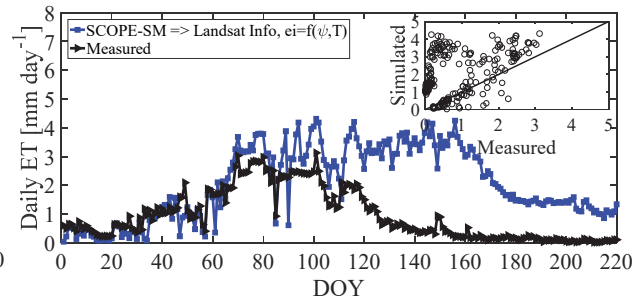

(d)

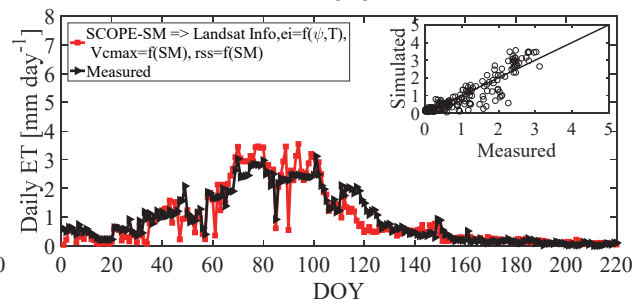

Figure 5.4. Model simulated and Fluxnet measured daily ET at the Vaira site during the drought episode in 2004; (a) ET simulated by original SCOPE using only Landsat retrieved vegetation properties, (b) ET simulated by SCOPE-SM using Landsat retrieved vegetation properties and updated vapor pressure information, (c) ET simulated by SCOPE-SM using Landsat retrieved vegetation properties, updated vapor pressure and $V_{\text {cmax }}$ information, and (d) ET simulated by SCOPE-SM using Landsat retrieved vegetation properties, updated vapor pressure, updated $V_{\mathrm{cmax}}$ and updated $r_{\mathrm{ss}}$ information. Figure insets represent the scatter plot between simulated and measured ET for each case (for more details of error statistics see section 5.3.4.3).

With the SCOPE model, one can separate canopy transpiration $T$ and soil evaporation $E$. This is crucial since we can explore the added value of using 
various dataset on simulated $T$ and $E$ separately. The results of canopy $T$ and soil $E$ are presented in Fig. 5.5. As can be seen from Fig. 5.5ab, satellite information could explain the majority of canopy $T$ reduction at the end of the episode and, therefore, it peaked in the middle of the episode. However, canopy $E$ showed an upward trend during the selected episode and, therefore, peaked at the end of episode, due to reducing LAI (Fig. 5.5ab).

Moreover, simulation results of SCOPE-SM in which $V_{\text {cmax }}$ is modified besides using updated $e_{i}$ and Landsat retrieved properties (Fig. 5.5c), reveal more drought effects on simulated canopy $T$, without affecting $E$. Making $r_{\mathrm{ss}}$ a function of soil moisture reduces $E$ at the end of episode when soil moisture was lowest, so that $E$ peaked in the middle and decreased at the end of the episode (Fig. 5.5d).

(a)

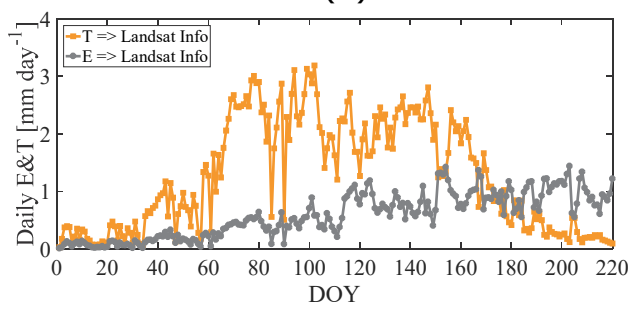

(c)

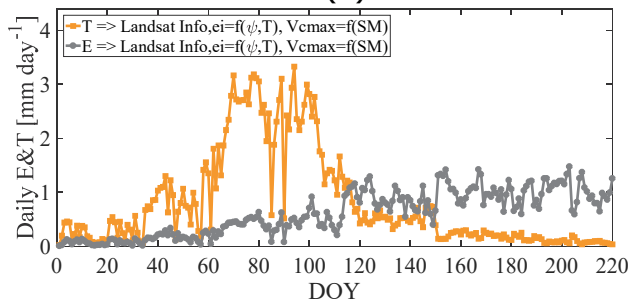

(b)

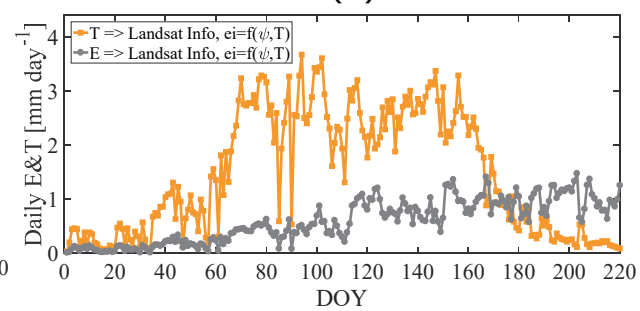

(d)

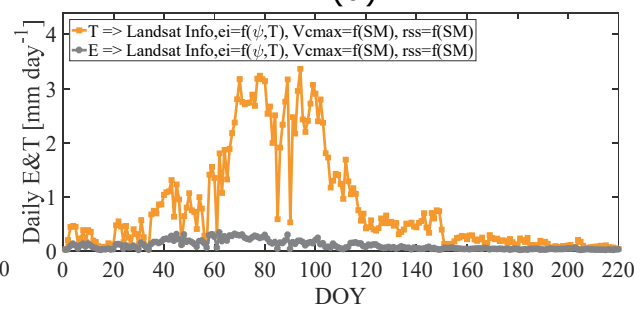

Figure 5.5. Model simulated soil $E$ and canopy $T$ at the Vaira site during the drought episode in 2004; (a) $E$ and $T$ simulated by original SCOPE using only Landsat retrieved vegetation properties, (b) $E$ and $T$ simulated by SCOPE-SM using Landsat retrieved vegetation properties and updated vapor pressure information, (c) $E$ and $T$ simulated by SCOPE-SM using Landsat retrieved vegetation properties, updated vapor pressure and $V_{\text {cmax }}$ information, and (d) $E$ and $T$ simulated by SCOPE-SM using Landsat retrieved vegetation properties, updated vapor pressure, updated $V_{\mathrm{cmax}}$ and updated $r_{\mathrm{ss}}$ information.

\subsubsection{Performance evaluation}

The results of performance evaluation for model simulations and ground measurements of GPP and ET are presented in Table 5.1. As can be seen from the table, the performance of SCOPE-SM for simulating GPP (i.e., RMSE $=0.6$, MSE $\left.=0.36, R^{2}=0.98\right)$ was improved considerably compared to the original SCOPE (i.e., RMSE $=2.09, \mathrm{MSE}=4.38, \mathrm{R}^{2}=0.79$ ) during the drought episode . The decrease of the MSE in GPP simulation during the drought episode by SCOPE-SM can be attributed to the lower (improved) value of standard 
deviations error (from 0.61 to 0.13 ), lower (improved) value of lack of positive correlation (from 2.62 to 0.23 ), and a lower (improved) value of bias in the mean (from 1.15 to 0 ). Thus, all of the error contributions decreased and, therefore, resulted in a lower value of the total MSE. More importantly, the results indicate that the dominant error contributor $(\sim 60 \%)$ to total MSE for both cases (i.e, SCOPE and SCOPE-SM simulated GPP) was the lack of positive correlation. Therefore, the values of $R^{2}$ for GPP simulations by both SCOPE and SCOPE-SM contribute considerably to the total MSE and, therefore, it can be considered a major source of error. This also means that using $R^{2}$ as an error measure makes sense in this case and improving the correlation would be of great help to decrease total MSE. Similar contributions of error budgets detected for GPP simulation during the whole episode as well (see the values within parentheses in Table 5.1).

Table 5.1. MSE components, RMSE, NRMSE and $\mathrm{R}^{2}$ comparison between the original SCOPE and SCOPE-SM performance for simulating daily GPP and ET. Model simulation results were compared with Vaira Fluxnet GPP and ET measurements. The table values without parentheses present the statistics only for drought conditions (from DOY 60 to 220) while the values within parentheses present the statistics for the whole episode (i.e., from DOY 1 to 220) covering both near normal and drought conditions. Different configurations of SCOPE-SM are shown as (C1: Landsat information plus updated $\left.e_{i}\right)$, (C2: Landsat information, updated $e_{i}$, updated $V_{\text {cmax }}$ ) and (C3: Landsat information, updated $e_{\mathrm{i}}$, updated $V_{\mathrm{cmax}}$ and updated $r_{\mathrm{ss}}$ ). The original SCOPE and SCOPE-SM (C3) statistics are shown in bold

\begin{tabular}{|c|c|c|c|c|c|c|c|c|}
\hline \multirow[b]{2}{*}{ Variable } & \multirow[b]{2}{*}{ Model } & \multicolumn{3}{|c|}{ MSE components } & \multirow[b]{2}{*}{$\begin{array}{l}\text { Total } \\
\text { MSE }\end{array}$} & \multirow[b]{2}{*}{ RMSE } & \multirow[b]{2}{*}{ NRMSE } & \multirow[b]{2}{*}{$R^{2}$} \\
\hline & & $\begin{array}{l}\text { Unequal } \\
\text { standard } \\
\text { deviations }\end{array}$ & $\begin{array}{l}\text { Lack } \\
\text { of positive } \\
\text { correlation }\end{array}$ & $\begin{array}{l}\text { Bias } \\
\text { in the } \\
\text { mean }\end{array}$ & & & & \\
\hline \multirow{4}{*}{ GPP } & SCOPE & $\begin{array}{l}\mathbf{0 . 6 1} \\
(0.38)\end{array}$ & $\begin{array}{l}\mathbf{2 . 6 2} \\
(2.57)\end{array}$ & $\begin{array}{l}1.15 \\
(0.44)\end{array}$ & $\begin{array}{l}\mathbf{4 . 3 8} \\
(3.40)\end{array}$ & $\begin{array}{l}\mathbf{2 . 0 9} \\
(1.84)\end{array}$ & $\begin{array}{l}\mathbf{0 . 2 3} \\
(0.20)\end{array}$ & $\begin{array}{l}\mathbf{0 . 7 9} \\
(0.74)\end{array}$ \\
\hline & $\begin{array}{l}\text { SCOPE-SM } \\
=>\mathrm{C} 1\end{array}$ & $\begin{array}{l}0.03 \\
(0.01)\end{array}$ & $\begin{array}{l}3.49 \\
(3.48)\end{array}$ & $\begin{array}{l}3.33 \\
(1.67)\end{array}$ & $\begin{array}{l}6.84 \\
(5.16)\end{array}$ & $\begin{array}{l}2.62 \\
(2.27)\end{array}$ & $\begin{array}{l}0.29 \\
(0.25)\end{array}$ & $\begin{array}{l}0.78 \\
(0.72)\end{array}$ \\
\hline & $\begin{array}{l}\text { SCOPE-SM } \\
=>\mathrm{C} 2\end{array}$ & $\begin{array}{l}0.14 \\
(0.12)\end{array}$ & $\begin{array}{l}0.23 \\
(0.44)\end{array}$ & $\begin{array}{l}0.00 \\
(0.00)\end{array}$ & $\begin{array}{l}0.37 \\
(0.56)\end{array}$ & $\begin{array}{l}0.61 \\
(0.75)\end{array}$ & $\begin{array}{l}0.07 \\
(0.08)\end{array}$ & $\begin{array}{l}0.98 \\
(0.96)\end{array}$ \\
\hline & $\begin{array}{l}\text { SCOPE-SM } \\
=>\mathrm{C} 3\end{array}$ & $\begin{array}{l}\mathbf{0 . 1 3} \\
(0.12) \\
\end{array}$ & $\begin{array}{l}0.23 \\
(0.44) \\
\end{array}$ & $\begin{array}{l}\mathbf{0 . 0 0} \\
(0.00)\end{array}$ & $\begin{array}{l}\mathbf{0 . 3 6} \\
(0.55) \\
\end{array}$ & $\begin{array}{l}\mathbf{0 . 6 0} \\
(0.74) \\
\end{array}$ & $\begin{array}{l}\mathbf{0 . 0 7} \\
(0.08) \\
\end{array}$ & $\begin{array}{l}\mathbf{0 . 9 8} \\
(0.96) \\
\end{array}$ \\
\hline \multirow{4}{*}{ ET } & SCOPE & $\begin{array}{c}\mathbf{0 . 0 3} \\
(0.04)\end{array}$ & $\begin{array}{l}\mathbf{0 . 6 7} \\
(1.05)\end{array}$ & $\begin{array}{l}1.93 \\
(0.79)\end{array}$ & $\begin{array}{l}\mathbf{2 . 6 3} \\
(1.89)\end{array}$ & $\begin{array}{l}\mathbf{1 . 6 2} \\
(1.37)\end{array}$ & $\begin{array}{l}\mathbf{0 . 5 2} \\
(0.44)\end{array}$ & $\begin{array}{l}\mathbf{0 . 5 9} \\
(0.44)\end{array}$ \\
\hline & $\begin{array}{l}\text { SCOPE-SM } \\
=>\mathrm{C} 1\end{array}$ & $\begin{array}{l}0.00 \\
(0.15)\end{array}$ & $\begin{array}{l}0.91 \\
(1.26)\end{array}$ & $\begin{array}{l}2.77 \\
(1.21)\end{array}$ & $\begin{array}{l}3.68 \\
(2.62)\end{array}$ & $\begin{array}{l}1.92 \\
(1.62)\end{array}$ & $\begin{array}{l}0.62 \\
(0.52)\end{array}$ & $\begin{array}{l}0.55 \\
(0.42)\end{array}$ \\
\hline & $\begin{array}{l}\text { SCOPE-SM } \\
=>\mathrm{C} 2\end{array}$ & $\begin{array}{l}0.02 \\
(0.00)\end{array}$ & $\begin{array}{l}0.12 \\
(0.36)\end{array}$ & $\begin{array}{l}0.59 \\
(0.22)\end{array}$ & $\begin{array}{l}0.73 \\
(0.57)\end{array}$ & $\begin{array}{l}0.86 \\
(0.79)\end{array}$ & $\begin{array}{l}0.28 \\
(0.24)\end{array}$ & $\begin{array}{l}0.93 \\
(0.77)\end{array}$ \\
\hline & $\begin{array}{l}\text { SCOPE-SM } \\
=>\mathrm{C} 3\end{array}$ & $\begin{array}{l}\mathbf{0 . 0 2} \\
(0.01)\end{array}$ & $\begin{array}{l}0.12 \\
(0.14)\end{array}$ & $\begin{array}{l}\mathbf{0 . 0 0} \\
(0.00)\end{array}$ & $\begin{array}{l}0.14 \\
(0.16)\end{array}$ & $\begin{array}{l}\mathbf{0 . 3 7} \\
(0.40)\end{array}$ & $\begin{array}{l}0.12 \\
(0.13)\end{array}$ & $\begin{array}{l}\mathbf{0 . 9 5} \\
(0.92)\end{array}$ \\
\hline
\end{tabular}

Comparing ET simulations from SCOPE and SCOPE-SM demonstrated that the performance of SCOPE-SM for simulating ET (i.e., RMSE $=0.37$, MSE $=$ $\left.0.14, R^{2}=0.95\right)$ was improved considerably compared to the original SCOPE (i.e., $\mathrm{RMSE}=1.62, \mathrm{MSE}=2.63, \mathrm{R}^{2}=0.59$ ) during the drought episode. Using SCOPE-SM, the lower (improved) MSE error for the ET simulation resulted from lower (improved) error budgets of MSE components including standard deviation differences (from 0.03 to 0.02 ), lack of correlation (from 0.67 to 0.12 ), and bias of the mean values (from 1.93 to 0.0 ) during the drought 
episode. Furthermore, the results indicated that the dominant error contributor ( 73\%) to total MSE for ET simulated by SCOPE was the bias in the mean. Therefore, the (relatively) lower value of $R^{2}(0.59)$ for ET simulations by SCOPE contributed less to the total MSE $(\sim 25 \%)$ and therefore cannot be considered a major source of error. This also means that $R^{2}$ as an error measure is rather meaningless in this case. Improving the correlation would not help much here since the greatest contribution to the MSE decomposition for SCOPE ET simulation originates from the bias in the mean values. However, the dominant error contributor ( 85\%) in total MSE for ET simulated by SCOPE-SM was the lack of positive correlation. The value of $\mathrm{R}^{2}$ for ET simulation by SCOPE-SM contributes considerably to the total MSE and, therefore, it can be considered a major determinant of the error. Thus, using $R^{2}$ as an error measure does make sense in this case.

Furthermore, NRMSE results showed that the performance of SCOPE in simulating daily GPP was better than ET (NRMSE of 0.23 compared to 0.52 ). Similar results were obtained for the case of SCOPE-SM for GPP and ET simulations (NRMSE of 0.07 compared to 0.12 ). This confirms that SCOPE (and also SCOPE-SM) performs more accurate simulations for GPP compared to ET.

\subsubsection{Comparison of optical, soil moisture and thermal information content}

As described in section 5.1, besides using the optical data sets, there are two other sources of information which can be employed to constrain the SCOPE model effectively, to estimate vegetation functioning in water-limited ecosystems: either using thermal observations or soil moisture data. To understand how the information in thermal observation is different from the information in the soil moisture, we compared these two simulations resulting from using various observations in Table 5.2. It should be noted that the GPP and ET simulations in which the optical and thermal observations were utilized are described in chapter 4.

Table 5.2. Comparison of the information content of various observations to simulate GPP and ET using the SCOPE model. The statistical measures are obtained compared to the ground measured values of GPP and ET at the Vaira site.

\begin{tabular}{|c|c|c|c|c|c|c|c|}
\hline \multirow[b]{2}{*}{ Variable } & \multirow[b]{2}{*}{ Observations } & \multicolumn{3}{|c|}{ MSE components } & \multirow{2}{*}{$\begin{array}{l}\text { Total } \\
\text { MSE }\end{array}$} & \multirow[t]{2}{*}{ RMSE } & \multirow[t]{2}{*}{$\mathrm{R}^{2}$} \\
\hline & & $\begin{array}{l}\text { Unequal } \\
\text { standard } \\
\text { deviations }\end{array}$ & $\begin{array}{l}\text { Lack } \\
\text { of positive } \\
\text { correlation }\end{array}$ & $\begin{array}{l}\text { Bias } \\
\text { in the } \\
\text { mean }\end{array}$ & & & \\
\hline \multirow{3}{*}{ GPP } & Optical & 0.61 & 2.62 & 1.15 & 4.38 & 2.09 & 0.79 \\
\hline & Optical and thermal & 0.11 & 0.19 & 0.00 & 0.31 & 0.55 & 0.96 \\
\hline & Optical and soil moisture & 0.13 & 0.23 & 0.00 & 0.36 & 0.60 & 0.98 \\
\hline \multirow{3}{*}{ ET } & Optical & 0.03 & 0.67 & 1.93 & 2.63 & 1.62 & 0.59 \\
\hline & Optical and thermal & 0.07 & 0.23 & 0.06 & 0.36 & 0.60 & 0.83 \\
\hline & Optical and soil moisture & 0.02 & 0.12 & 0.00 & 0.14 & 0.37 & 0.95 \\
\hline
\end{tabular}


From Table 5.2 it can be seen that we do need to employ supplementary information besides using only optical observations to constrain the SCOPE model. Comparing the statistical measures for GPP simulations demonstrates that the combined use of optical and thermal observations can provide slightly more information (i.e., RMSE $=0.55, \mathrm{MSE}=0.31$ ) compared to the combined use of optical and soil moisture observations (i.e., RMSE $=0.60$, MSE $=0.36$ ) to capture photosynthesis variations. This slight difference might be attributed to the seasonal variations of the maximum carboxylation capacity which apparently can better be captured by thermal observations. However, this is reverse for the ET simulations. The results of ET simulations show that the combined use of optical and soil moisture observations provides considerably more information (i.e., RMSE $=0.37$, MSE $=0.14$ ) compared to the combined use of optical and thermal observations (i.e., RMSE $=0.60$, MSE $=0.36$ ) to capture ET variations. This may be attributed to the fact that the soil surface resistance was approximated by a mechanistic model as a function of soil moisture content in SCOPE-SM, whereas in the original SCOPE this resistance was kept constant.

Further, crop factor $\left(\mathrm{K}_{c}\right)$ analysis performed to show the differences between thermal and soil moisture provided data for simulating GPP (Fig. 5.6) and ET (Fig. 5.7) visually. 
(a)

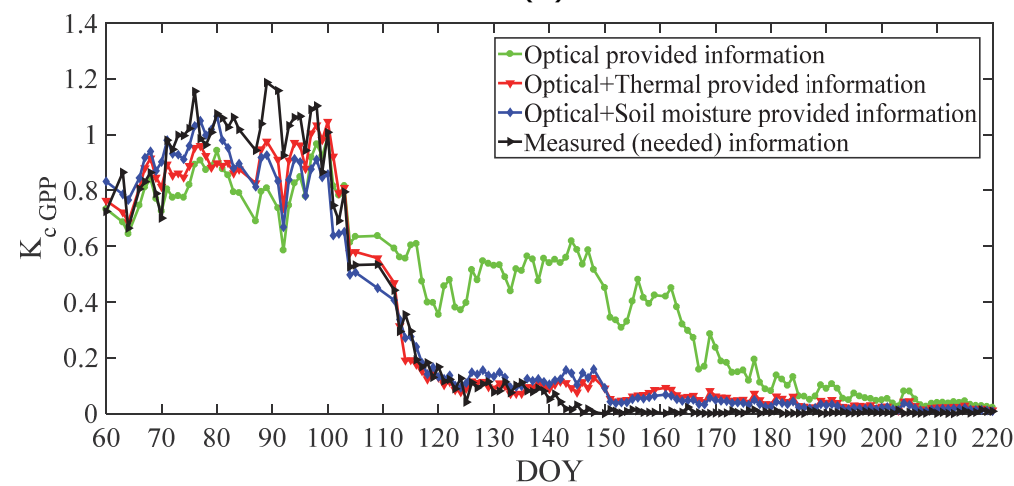

(b)

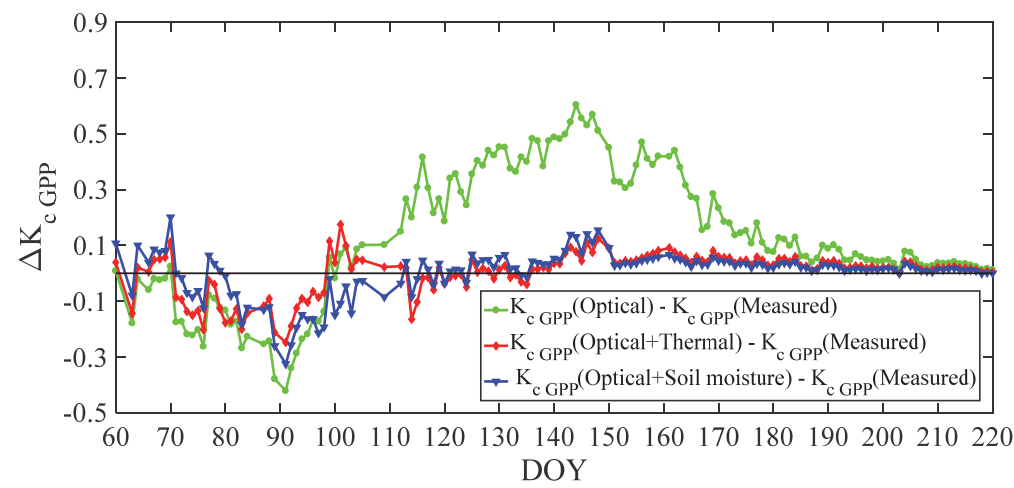

Figure 5.6. Time series of measured and simulated $K_{C}$ GPP and $\Delta K_{c}$ GPP in drought conditions. (a) Simulated and measured $\mathrm{K}_{\mathrm{c}}$ GPP comparing the information content provided by each observation; (b) The difference between simulated and measured $\mathrm{Kc}$ GPP computed for each observation.

The results of crop factor analysis for GPP simulation indicate that thermal observations could better capture the needed information for a part of the episode (e.g., DOY 90 to 110), while, for the rest of episode the information of this thermal observations are comparable with those of soil moisture data (Fig. 5.6ab). However, crop factor analysis for ET shows different results. Except for a part of the episode (from DOY 120 to DOY 150) in which the same information was obtained from both thermal and soil moisture observations, for the rest of episode, soil moisture observations provided more information for ET simulation (Fig. 5.7ab). 
(a)

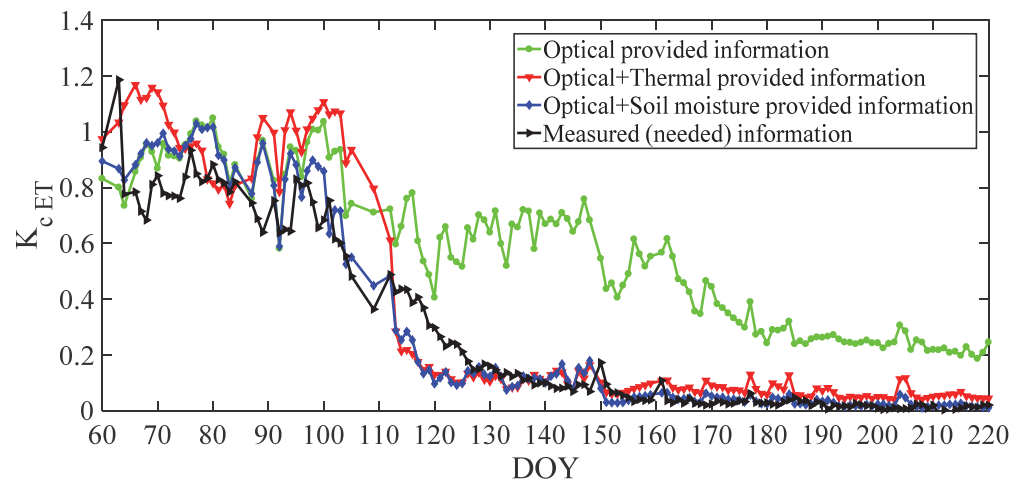

(b)

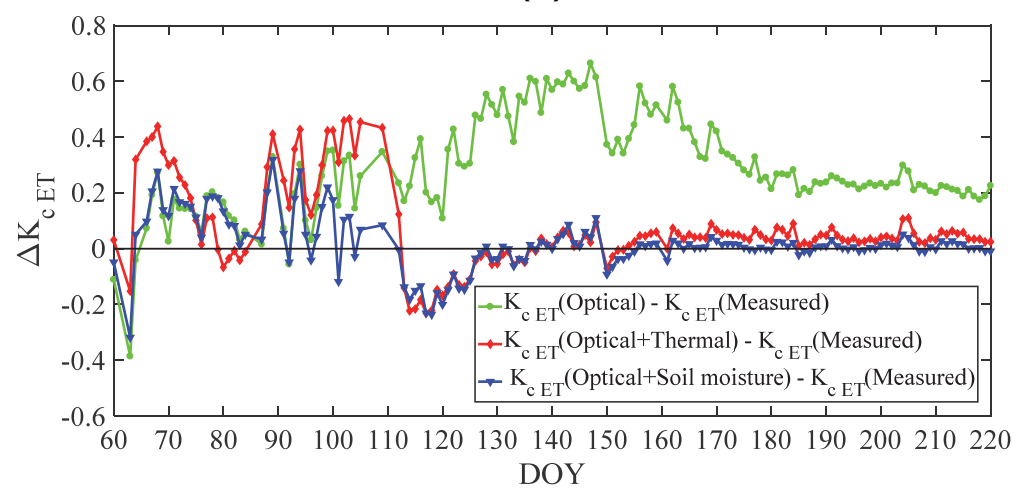

Figure 5.7. Time series of measured and simulated $\mathrm{K}_{\mathrm{C} \text { ET }}$ and $\Delta \mathrm{K}_{\mathrm{C} E \mathrm{ET}}$ in drought conditions. (a) Simulated and measured $\mathrm{K}_{\mathrm{C}}$ et comparing the information content provided by each observation; (b) The difference between simulated and measured $\mathrm{K}_{\mathrm{c}}$ Eт computed for each observation.

\subsection{Discussion and conclusions}

Using the SCOPE model for estimating daily GPP and ET in semi-arid regions, experiencing prolonged drought episodes, is challenging because water availability is the primary limiting factor for vegetation. In such conditions, the GPP and ET simulated by SCOPE are often considerably overestimated. The SCOPE-SM model is proposed in this study to allow the combined use of satellite-derived optical information and a soil moisture dataset for improving daily GPP and ET estimations in water-limited ecosystems. Therefore, SCOPE-SM could alleviate the overestimation of GPP and ET during the stress period.

Satellite optical information was used by radiative transfer model routines of SCOPE-SM to estimate net radiation similar to the original SCOPE model. This is a significant advancement of the SCOPE model since one can use its radiative transfer modules to exploit satellite observations to their full extent. SCOPE provides a powerful tool that enables using all bands information 
together. However, supplementary soil moisture data were utilized in this study by SCOPE-SM to estimate time series of maximum carboxylation capacity, leaf and soil vapor pressure, and soil surface resistance during a drought episode. All these parameters are assumed constant in the original SCOPE model. This leads to substantial systematic errors of both GPP and ET simulations during the soil moisture deficit in a drought episode. The higher the soil moisture deficit is, the larger the errors of GPP and ET simulations in the original SCOPE will be.

It was also shown that some of the soil moisture deficit induced changes can be seen in the Landsat optical bands through the SCOPE model. For instance, the decline of transpiration was observed in the case of using only Landsat information through original SCOPE (Fig. 5.5ab). However, soil moisture deficit effects on maximum carboxylation capacity and soil evaporation remain undetected using only the Landsat optical bands. This indicates the importance of using supplementary information to regulate leaf carboxylation capacity and soil evaporation. There are two possibilities to provide such supplementary information: (1) using thermal observations or (2) using a soil moisture dataset to constrain the SCOPE model. We described the option of using thermal observations, using Landsat thermal information (in chapter 4) to retrieve maximum carboxylation and soil resistance besides utilizing the optical bands information in the SCOPE model. We concluded that using thermal information can effectively constrain the SCOPE model for simulating GPP and ET in water-limited regions. However, the information in the soil moisture dataset had not been explored yet. This study was aimed at investigating the information content of the soil moisture dataset. The results show that the combined use of optical and soil moisture data can improve the GPP and ET simulations considerably. Our current study reveals that soil moisture data is another good supplementary source of information that can assist in regulating maximum carboxylation capacity and soil evaporation parameters with SCOPE-SM (Fig 5cd). Further, to understand the differences between thermal and soil moisture information in simulating GPP and ET, we compared the impacts of soil moisture information with those of thermal information through the crop factor method. Our comparison demonstrates that there is more information embedded in the soil moisture dataset compared to the thermal information for ET simulations in water-limited ecosystems. This can be explained by the fact that approximation of soil evaporation as a function of soil moisture is more efficient than its retrieval from thermal observations. However, crop factor results show that GPP estimates constrained by thermal data are slightly better than GPP estimates constrained by soil moisture data. This might be due to the efficiency of maximum carboxylation capacity estimation from thermal observations compared to soil moisture data. An obvious way forward is to use both soil moisture and thermal data in a synergistic and complementary way. Soil moisture observations can be used to constrain soil evaporation effectively and, therefore, improve ET 
estimation, while thermal observations can constrain maximum carboxylation capacity effectively and improve GPP estimation. This is practically possible and promising due to the facts that (1) soil moisture information can be retrieved from contemporary satellite observations (e.g., Sentinel 1) in addition to the ground data which is routinely measured at flux tower sites, and (2) satellite thermal information is partly available (e.g., Landsat and Sentinel 3). The synergistic use also has an advantage for reducing the uncertainty in the retrieval process by avoiding ill-posedness [i.e., multiple solutions of the inversion which yield similar spectra (Combal et al., 2003)] in the retrieval of parameters from the thermal domain since some parameters can be estimated from soil moisture observations.

There are two relevant parameters in the (Farquhar-Ball-Berry type) photosynthesis-conductance module in SCOPE affecting the simulation of GPP and ET; (1) the maximum carboxylation (biochemical) parameter $V_{\text {cmax }}$ and Ball-Berry (stomatal) conductance parameter $m$. The question is, which one plays a more important role in explaining drought effects on GPP and ET simulations; biochemical limitations $\left(V_{\mathrm{cmax}}\right.$ decline) or stomatal limitation ( $m$ decline), or mesophyll conductance limitation, the latter of which is not parameterized in SCOPE. This is still a topic of discussion in the research community. On the one hand, the majority of studies suggest imposing the biochemical limitation in the model while considering a constant value for $m$ to sufficiently capture water stress effects on the simulated GPP and ET. For instance, no trend (constant behavior) has been reported for $m$ but a clear declining trend for $V_{\text {cmax }}$ as soil moisture deficit develops (Colello et al., 1998; Sellers et al., 1996). This is confirmed later by follow-up investigations from both field and model experiments during water stress (Calvet et al., 2004; Gimeno et al., 2016; Keenan et al., 2009; Krinner et al., 2005; Moorcroft et al., 2001; Reichstein et al., 2002; Xu and Baldocchi, 2003). These findings are also consistent with a recently published study demonstrating no seasonal changes in $m$ during water stress conditions using experimental data over a sunflower field (Miner and Bauerle, 2017) and, therefore, support the use of a constant value for $m$ parameter during stress condition. Based on the conclusions from these studies, in case of not considering a $V_{\text {cmax }}$ decline in water stress periods, the simulated photosynthesis will significantly be overestimated. On the other hand, a water stress response has been reported in some other studies mostly for $m$ (Harley and Tenhunen, 1991; Heroult et al., 2013; Sala and Tenhunen, 1996) and, therefore, the possibility of considering less limitation of the biochemical parameter.

Further, other studies suggested considering both limitations (i.e., stomatal and biochemical) together (Egea et al., 2011; Keenan et al., 2010b; Zhou et al., 2013). However, in these studies conflicting conclusions have been drawn on the highest limitation strength. For instance, one (Zhou et al., 2013) reported greater impacts of biochemical limitation compared to stomatal limitation, while, another (Egea et al., 2011) found greater impact of imposing 
stomatal limitation compared to the biochemical. Keenan et al (2010a) reconciled these conflicting conclusions on the relative contributions of stomatal and biochemical limitations for carbon and water fluxes simulations at a Mediterranean Quercus ilex forest during a water stress episode, by attributing the stress effects to mesophyll conductance. They imposed limitations on biochemical, stomatal and mesophyll conductance through various scenarios to understand each contribution. They demonstrated that by considering only biochemical limitations one can reproduce drought effects on carbon and water fluxes accurately. Although neither stomatal nor mesophyll conductance limitations alone could reproduce carbon and water fluxes with acceptable accuracy, by posing limitations on both (stomatal and mesophyll together), the carbon and water fluxes during water stress were reproduced too (Keenan et al., 2010a). This reveals that posing limitation on biochemical parameters during water stress can produce equivalent results to that of posing limitation on both 'stomatal and mesophyll conductance' together.

In our study, we have chosen the option (i.e., imposing a soil moisture limitation on the biochemical $V_{\text {cmax }}$ parameter) that is most compatible with the original SCOPE, which does not include mesophyll conductance. This choice is also consistent with our previous results (described in chapter 4 ) in which both $V_{\text {cmax }}$ and $m$ were tuned against thermal data and only the $V_{\text {cmax }}$ response to soil moisture deficit has been observed, while, no significant changes were observed for $m$ during the stress episode. Similar trends were obtained for $V_{\text {cmax }}$ (declining) and $m$ (constant) in the field measurements for blue oak at same climatic region ( $\mathrm{Xu}$ and Baldocchi, 2003) during a severe summer drought. They attributed their findings (of varying $V_{c m a x}$ and constant $m$ ) to the relation between photosynthesis demand and stomatal conductance.

Our results showed that making vapor pressure a function of temperature and water potential did not bring improvements to the simulations of GPP and ET during the drought episode (Fig 5.3b and 5.4b). This can be explained by the variations (in both soil and leaf) of water potential and temperature during the drought episode. As one could expect, there is a direct relationship between vapor pressure and temperature. Therefore, an increase of temperature will result in a vapor pressure increase and vice versa. Similarly, the relation between vapor pressure and water potential is also direct, so that an increase of water potential will increase vapor pressure and vice versa. However, our analysis demonstrated that vapor pressure computation in the SCOPE model is more affected by temperature change than by water potential. For instance, the results show that a 5 -degree increase in temperature produces a 35 percent increase of vapor pressure, while a $5 \mathrm{~m}$ increase in water potential (of water or soil) gives only a 0.001 percent increase in vapor pressure. Consequently, making vapor pressure a function of temperature and water potential did not improve the GPP and ET simulations during this episode.

The variable $r_{\mathrm{ss}}$, which controls the evaporation rate, is better constrained by soil moisture than by thermal data. This was to be expected because the 
evaporation rate is mostly controlled by water availability (supply) in drought conditions. Thus, soil moisture data has rich information to constrain the $r_{\mathrm{ss}}$ parameter. This is in agreement with previous studies, for instance, Camillo and Gurney (1986) reported that considering a soil moisture-dependent resistance could remove overestimation of daily cumulative evaporation under soil moisture deficit conditions (Camillo and Gurney, 1986). It is stated that evaporation occurs at the potential rate following the atmospheric demand until soil moisture supply is depleted considerably and, therefore, surface resistance increases (Wetzel and Chang, 1987). Thus, considering a constant $r_{\text {ss }}$ in SCOPE for simulation of ET results in overestimation of soil evaporation (see Fig. 5.5 $a b c$ ). This upward trend of soil evaporation is due to the fact that we kept the $r_{\text {ss }}$ parameter constant while LAI was decreasing during the episode. This caused an increase in net radiation over the soil, which later translated into a high latent heat value for soil in the simulation. This issue of soil $E$ was solved when we made $r_{\mathrm{ss}}$ a function of soil moisture in SCOPE-SM by means of an approximation through soil hydraulic conductivity.

We evaluated the performance of SCOPE-SM by comparing simulated GPP and ET with Vaira Fluxnet site GPP and ET measurements in 2004. Our results show remarkable agreement between SCOPE-SM model simulations and ground measured daily GPP and ET. SCOPE-SM better captured the low values of daily GPP and ET in moderate and severe drought condition than SCOPE did. The ability of SCOPE-SM to capture ET variations during a water stress period is in good agreement with Gökmen et al (2012) study who integrated soil moisture data into the SEBS model to better represent ET variations during water stress in Turkey.

Overall, the idea of using soil moisture observations for improving the estimation of GPP and ET in dry conditions might be useful and can also be applied for other process-based models. However, the way which should be employed for such a model modification may vary from one model to another based on their specific parametrizations. For instance, water stress levels were implemented in the widely-used SEBS model (Su, 2002) in the computation of sensible heat flux by means of a modified $\mathrm{kB}^{-1}$ parameter, which controls aerodynamic resistance to heat transfer compared to momentum transfer (Gökmen et al., 2012). Thus, special attention should be paid to investigate the parametrization of a desired model to find the most important and sensitive parameter before implementing further modifications.

The SCOPE-SM model offers the opportunity for continuous time-series estimation of GPP and ET variations in arid and semi-arid regions with a remarkable accuracy using various remote sensing optical observations, soil moisture products. This can contribute to a better understanding of carbon and water fluxes, vegetation functioning and water productivity in water-limited ecosystems.

It should further be emphasized that the performance of the SCOPE-SM model in simulating GPP and ET was only preliminarily assessed at the Vaira 
site. Thus, although we speculate that the model would have implications for its use with other closed vegetation covers (e.g., grasslands, croplands, forest ecosystems) in water-limited ecosystems, much effort is still needed to evaluate SCOPE-SM's performance in other ecosystems, and also with different satellite data sets. 
Appendix A. The main features of GPP and ET formulations in the SCOPE model.

The C3 Photosynthesis is calculated in the SCOPE model as the minimum of two processes (Farquhar et al., 1980); (1) carboxylation rate limited by Ribulose biphosphate-carboxylase-oxygenase activity (known as Rubisco (enzyme)-limited, $V_{c}$, described in Eq. (5.A1)), or (2) carboxylation rate limited by Ribulose 1-5 bisphosphate regeneration rate (known as RuBP (electron transport/light)-limited, $V_{\mathrm{e}}$, described in Eq. (5.A2)):

$$
\begin{aligned}
& V_{c}=V_{c \max } \frac{C_{i}-\Gamma^{*}}{C_{i}+K_{c}\left(1+O_{i} / K_{o}\right)} \\
& V_{e}=\frac{J\left(C_{i}-\Gamma^{*}\right)}{4\left(C_{i}+2 \Gamma^{*}\right)} \\
& C_{i}=C_{s}\left(1-\frac{1}{m R H}\right)
\end{aligned}
$$

where $V_{\mathrm{cmax}}$ is the maximum carboxylation rate $\left(\mu \mathrm{mol} \mathrm{m} \mathrm{m}^{-2} \mathrm{~s}^{-1}\right), C_{\mathrm{i}}$ is the internal $\mathrm{CO}_{2}$ concentration $\left(\mu \mathrm{mol} \mathrm{m}{ }^{-3}\right), \Gamma^{*}$ is the $\mathrm{CO}_{2}$ compensation point in the absence of mitochondrial respiration, $K_{c}$ and $K_{0}$ are the Michaelis-Menten constants for carboxylation and oxygenation, respectively $\left(\mu \mathrm{mol} \mathrm{m} \mathrm{m}^{-3}\right), O_{\mathrm{i}}$ is the

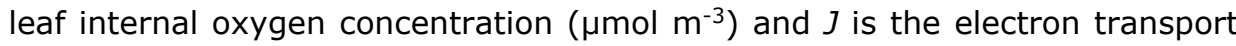
rate $\left(\mu \mathrm{mol} \mathrm{m} \mathrm{m}^{-2} \mathrm{~s}^{-1}\right), C_{\mathrm{s}}$ is $\mathrm{CO}_{2}$ concentration in the boundary layer $\left(\mu \mathrm{mol} \mathrm{m} \mathrm{m}^{-3}\right.$ ), $m$ is Ball-Berry parameter (unitless) and $\mathrm{RH}$ is relative humidity at the leaf surface (\%).

Furthermore, leaf stomatal resistance $r_{\mathrm{c}}\left(\mathrm{s} \mathrm{m}^{-1}\right)$ is calculated as:

$$
r_{c}=\frac{0.625\left(C_{s}-C_{i}\right)}{A_{n}} \frac{\rho_{a}}{M_{a}} \frac{10^{12}}{p}
$$

where $\rho_{a}$ is specific mass of air $(\mathrm{kg} \mathrm{m}-3), M_{a}$ is molecular mass of dry air ( $\mathrm{g}$ $\mathrm{mol}^{-1}$ ), and $p$ is atmospheric pressure (hPa).

Furthermore, the latent heat flux $(L E)$ in the SCOPE model is calculated for leaf and soil elements as follows:

$$
L E=\lambda \frac{q_{i}-q_{a}}{r_{a}+r_{c}}
$$


where $\lambda$ is vaporization heat of water $\left(\mathrm{J} \mathrm{kg}^{-1}\right), q_{\mathrm{i}}$ is the humidity in stomata (in case of leaf) or soil pores (in case of soil) $\left(\mathrm{kg} \mathrm{m}^{-3}\right), q_{\mathrm{a}}$ is the humidity above the canopy $\left(\mathrm{kg} \mathrm{m}^{-3}\right), r_{\mathrm{a}}$ is aerodynamic resistance $\left(\mathrm{s} \mathrm{m}^{-1}\right)$ calculated based on the Wallace and Verhoef two-source model (Wallace and Verhoef, 2000), $r_{c}$ is stomatal (eq. 5.A5) or soil surface resistance $\left(\mathrm{s} \mathrm{m}^{-1}\right)$. The $q_{\mathrm{i}}$ for leaf and soil is obtained from:

$$
q_{i}=e_{i} \frac{M_{w} / M_{a}}{p}
$$

where $e_{\mathrm{i}}$ is vapor pressure ( $\left.\mathrm{hPa}\right)$ and $M_{\mathrm{w}}$ is molecular mass of water $\left(\mathrm{g} \mathrm{mol}^{-1}\right)$. The $e_{i}$ is computed as:

$$
\begin{aligned}
& e_{i}=e_{\text {sat }} \exp \left(\frac{0.001 \Psi \frac{M_{w}}{R}}{T_{i}+273.15}\right) \\
& e_{\text {sat }}=6.107 \times 10^{\left(\frac{7.5 T_{i}}{237.3+T_{i}}\right)}
\end{aligned}
$$

where $e_{\text {sat }}$ is the saturated vapor pressure at temperature $T_{\mathrm{i}}(\mathrm{hPa}), \psi$ is the leaf and soil water potential $\left(\mathrm{J} \mathrm{kg}^{-1}\right), R$ is molar gas constant $\left(\mathrm{J} \mathrm{mol}^{-1} \mathrm{~K}^{-1}\right), T_{\mathrm{i}}$ is leaf and soil temperature $\left({ }^{\circ} \mathrm{C}\right)$. 
Chapter 6 Concluding remarks and prospects 
Exploiting the information content of available optical, thermal and soil moisture observations from different sensors to the full extent, and investigating the potential of combined use of such observations, can provide new opportunities to quantify ecosystem functioning variations during different environmental conditions. However, concerning satellite observations, two main challenges should be tackled: (1) translating the satellite radiance data to important surface properties information about the ecosystem, and (2) obtaining knowledge on biophysical, biochemical and biological processes that take place in the vegetated ecosystem. Thus, it is not enough to only retrieve surface optical properties from satellite TOA radiance data, but further a step is needed to relate these optical properties information to vegetation processes in the ecosystem. One potential approach adopted in this dissertation is the combined use of RT models with surface energy balance and photosynthesis models, through the SCOPE model, to fully exploit satellite spectral information and soil moisture observations describing vegetation functioning.

\subsection{Summary of conclusions}

Using RT models makes it possible to use all available data from different sensors in a consistent way and monitor vegetation properties variations in the ecosystem. RT model inversion against time series of hyperspectral data during a drought experiment in the laboratory is very promising to quantify drought effects. Further, the first spectral signs of stress in spectra and vegetation properties are detectable using spectroscopic techniques (Chapter 2).

It is also possible to invert coupled RT models in the "real world" against satellite multispectral radiance observations to monitor vegetation properties in response to drought. By coupling various RT models, one can describe the soil, vegetation and the atmosphere contributions in a "bottom-up" approach and, thereby, simulate TOA spectral radiance data comparable to satelliteobserved TOA radiances. This makes it possible to retrieve vegetation properties directly from TOA radiances rather than from atmospherically corrected TOC reflectance data (Chapter $\mathbf{3}$ ). This is significant since (1) the retrieval of surface properties by model inversion of TOA radiance data, instead of using surface reflectances obtained by atmospheric correction, is the best way to remove systematic effects related to the solar zenith angle and the atmospheric conditions, since RT models can take these effects implicitly into account, (2) simulated TOA radiance spectra can be sampled by the spectral response functions for all the bands of arbitrary hyperspectral and multispectral sensor in space. This means that a multitude of optical sensors can give their combined inputs for time series of retrieved biophysical surface properties, thus creating a much denser temporal sampling than would be possible for separate single sensors, (3) the TOA radiance approach allows even taking into account the spatial structure of the Earth's surface, since the forward modeling can include the simulation of the adjacency effect for the 
assumed spatial distribution of surface properties, and (4) one can also take into account the surface anisotropy effect in time series image analysis applied to satellite data.

Retrieval of vegetation properties from satellite observations (either from TOA radiance or atmospherically corrected TOC reflectance) is a challenging task mainly due to the ill-posedness problem (multiple sets of surface characteristics can explain the same observation) and high computational demands. However, a greater challenge, as compared to the retrieval, is how to obtain vegetation processes (i.e., GPP and ET) information from satellite optical and thermal observations. This is a fact that farmers and scientists are more interested in physical processes of the land surface and not only optical properties of surface and the atmosphere itself. Coupled use of a RT model and a SVAT model, like in SCOPE, makes it possible to obtain spatio-temporal variations of GPP and ET during different environmental conditions (Chapter 4). By constraining the SCOPE model with the optical and thermal observations of various sensors one can consider the effects of four major factors: (1) increased reflectance over the whole spectrum, resulting in a reduced net radiation, (2) reduced absorbed photosynthetically active radiation by chlorophyll, and therefore a reduced photosynthesis and stomatal conductance, (3) reduced photosynthetic capacity $V_{\text {cmax }}$, and (4) reduced soil evaporation. The availability of a model like SCOPE that combines the optical and the thermal part of the spectrum with a SVAT scheme makes it possible to exploit the full potential of the optical and TIR domains of remote sensing observations, which is an advancement over the empirical use of vegetation indices.

The majority of SVAT models like SCOPE does not take water stress explicitly into account due to the fact that they do not model the water balance. It is possible to simply extend such models to allow combined use of satellite optical data together with soil moisture products to improve their performance in water-limited ecosystems (Chapter 5). It is shown that using optical remote sensing data is an adequate approach to simulate physical processes via the SCOPE model if only the available energy is limiting vegetation functioning. However, the model does not perform well when water availability becomes the primary limiting factor for vegetation and, consequently, the estimations will be significantly biased. In this dissertation, we propose considering water stress in SCOPE by incorporating soil moisture in the model, besides using satellite optical information, to better capture vegetation functioning variations during drought conditions. Satellite optical information is used to estimate total net radiation, similar to the original SCOPE. However, the added soil moisture information is used to model (i) vapor pressure computation both in the soil and the leaf by taking water potential variations into account, (ii) the maximum carboxylation capacity by defining a soil moisture dependent stress factor and (iii) the soil surface resistance through approximation by a soil moisture dependent hydraulic conductivity. 


\subsection{Implications}

The adopted approaches and the extended SCOPE model (i.e., SCOPE-SM) described in this dissertation can play an important role to demonstrate the potential of combining data from different sensors (with different spatial, spectral and temporal resolution) and in-situ observations into higher-level surface products. This can be beneficial for both academic (e.g., remote sensing, eco-hydrology, and plant physiology communities) and application oriented (e.g., agriculture and farming) sectors to understand the vegetation response to climate change.

By exploiting hyperspectral observations using RT model inversion and a statistical approach, the drought effects on vegetation properties and the spectra are detected. Further, spectroscopic techniques and RT model inversion show a promising potential of detecting stress on the spectral reflectance and vegetation properties before they become visibly apparent. This has an important implication for drought "early detection" purposes (Chapter 2).

A forward modeling TOA radiance approach can be used to accurately simulate satellite radiance data and directly retrieve vegetation properties in different environmental conditions in space and time. This approach is useful for successful retrieval of vegetation properties and to produce maps of land surface properties and monitor vegetation properties variations in a straightforward operational way. The approach can also be easily adapted for conducting multi-sensor time-series studies, creating a much denser temporal sampling than would be possible for separate single sensors. This has an important implication for multi-sensor time series synergy studies (Chapter 3).

This dissertation indicates that inverting RT models against TOA radiance spectra (Chapter 3 ) in the optical domain can provide insight into vegetation biophysical and biochemical properties (LAI, $C_{\mathrm{ab}}, C_{\mathrm{w}}, C_{\mathrm{dm}}, \operatorname{LIDF}$ and $C_{\mathrm{s}}$ ) variations during a drought episode. However, it is still possible to add information from the thermal part of the spectrum in the SCOPE model to retrieve spatio-temporal maps of maximum carboxylation capacity and soil surface resistance to be used for land surface processes simulations. In other words, it is shown that non-stomatal effects could be revealed from the information provided by optical bands, but to reveal also stomatal effects and those of soil evaporation, the information contained in the TIR bands is relevant. This has an important implication for integrating optical and thermal sensor data to better capture drought effects on ecosystem functioning from space to benefit farmers (Chapter $\mathbf{4}$ ).

Finally, the extended SCOPE model, SCOPE-SM, can serve as a tool which allows using soil moisture information together with remote sensing optical observations to correct GPP and ET overestimations under water stress conditions. This indicates that soil moisture data is another valuable 
supplementary source of information that can assist in regulating maximum carboxylation capacity and soil evaporation parameters with SCOPE-SM.

Comparing simulations in which thermal and soil moisture data are used separately demonstrates that there is more information embedded in the soil moisture dataset compared to the thermal information for ET simulations in water-limited ecosystems. SCOPE-SM has an important potential application in precision agriculture for providing continuous time-series mapping of ecosystem functioning variations in arid and semi-arid regions with remarkable accuracy (Chapter 5).

\subsection{Challenges and future research}

During the course of this research, several challenges were encountered. Although considerable efforts have been made to tackle them to a certain extent, they have not been resolved completely.

First, the difficulty of obtaining ground data for validation of model simulations (e.g., soil evaporation, canopy transpiration, biophysical and biochemical properties) at both laboratory and field levels. Although destructive measurements have been conducted during the laboratory experiment for $L A I$ and $C_{a b}$ (described in chapter 2 ), it was not an easy task to obtain all the needed measurements of other vegetation properties (i.e., $C_{w}$, $C_{\mathrm{dm}}, C_{\mathrm{s}}$, and LIDF) at such a small set for validation purposes. Further, it is interesting to take leaf spectral measurements for both reflectance and chlorophyll fluorescence as well in such a drought experiment to compare the leaf spectral behavior with those of the canopy.

Second, the inversion of the coupled RT model against satellite TOA radiances provides a useful tool to accurately simulate time series of satellite data and to retrieve vegetation properties, but it may be considered computationally expensive (it takes about 4 seconds per pixel for Landsat images on a normal PC). There might be three solutions for reducing the time of computations in operational applications; (1) changing the inversion method from optimization to using look-up tables, (2) applying advanced statistical methods (e.g., emulators) and machine learning tools to generate acceptable results, (3) parallel processing or running the model on supercomputers. Moreover, retrieval of vegetation properties from satellite images may sometimes be ill-posed. Various methods (e.g., using a priori information, the mean of 5 percent best solutions in the look-up table method, and using a normalized cost function) were used in this research to stabilize the solutions. Also, the response of the inverse model to a possible change of the sensor signals by one standard deviation due to noise has been investigated. However, the retrieval uncertainty has not been fully quantified, which deserves further research.

Third, the integration of optical/thermal observations or combined use of optical and soil moisture observations to better simulate vegetation functioning 
in a drought episode was only performed for a grassland site. Although we expect our approach to work for all closed vegetation covers (e.g., grasslands, croplands, forest ecosystems), its representation may not be accurate enough for incomplete vegetation covers (e.g., row crops in an early growth stage, savanna ecosystems with closed understory and scattered trees, and boreal forest).

Fourth, it was shown that there is more information in the soil moisture observations than in thermal data for ET estimation. An obvious way forward is to use both soil moisture and thermal data in a synergistic and complementary way. In such a synergic approach, we suggest using thermal data to constrain maximum carboxylation capacity and soil moisture observations to constrain the soil surface resistance parameter in the SCOPE model.

Fifth, this dissertation investigates the effects of water stress (drought) on vegetation functioning. It is also interesting to study the effects of radiation stress (direct and diffuse radiation variations) on vegetation functioning. This might be facilitated by designing different scenarios for the atmospheric conditions through RT models, for instance MODTRAN, and simulate the resulting radiation spectra. Then one can utilize these radiation spectra in SCOPE and simulate vegetation functioning variations.

To conclude, this dissertation describes several approaches to exploit satellite optical/TIR observations and soil moisture dataset to quantify vegetation properties and functioning in a drought episode with remarkable accuracy. Further work may be directed to investigate the information content of the sun-induced chlorophyll fluorescence signal regarding photosynthesis and transpiration estimation in water-limited ecosystems. 


\title{
سنجش از دور كمّى خصوصيات و عملكرد كياهان تحت شرايط

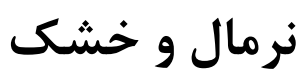

\author{
باقر بيات \\ رساله \\ جهت اخذ درجه دكترى در دانشكده علوم و مشاهدات زمينى (اى تى سى) \\ دانشخاه توئنته \\ انسخده - هلند
}

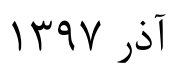


جككيده

دادههاى سرى زمانى ايتيكى، حرارتى و رطوبت خاك حاوى اطلاعات بسيار مفيدى در مورد

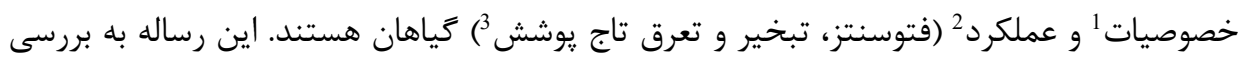

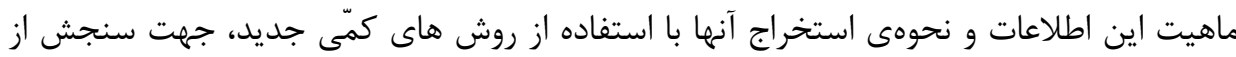

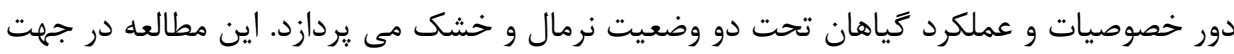

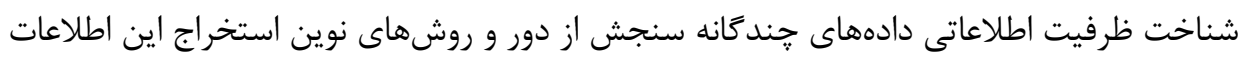

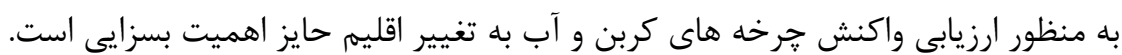
رساله حاضر از شش فصل تشكيل شده است. فصل اول توضيحات مقدماتى بوده كه در آن به آنه

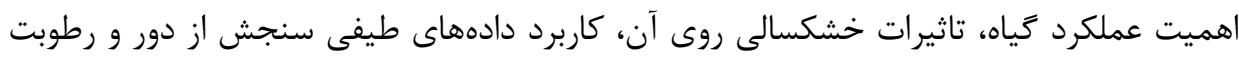

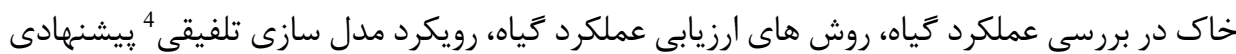
و اهداف تحقيق يرداخته شده است.

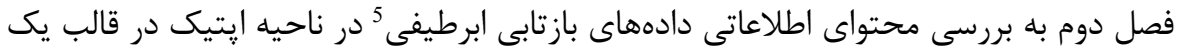

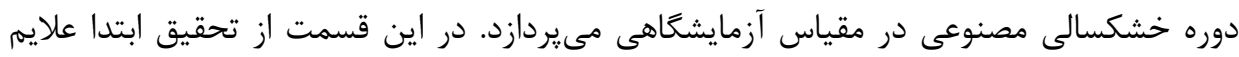

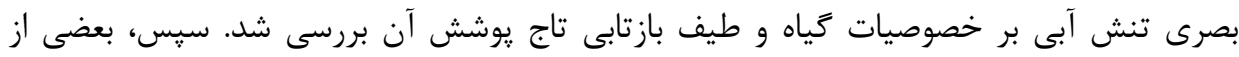

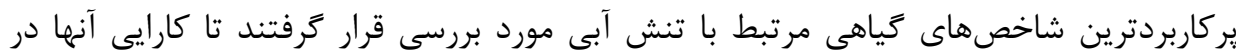

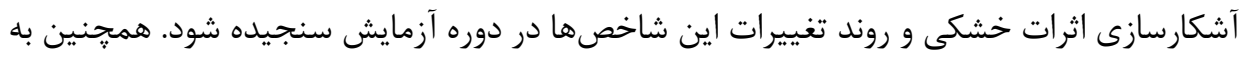

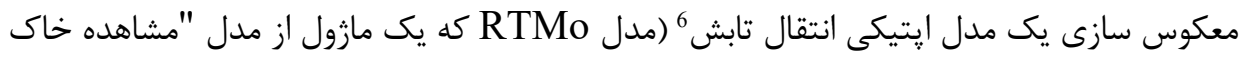
- تاج يوشش فتوسنتز و شار انرزى 7" (SCOPE) مى باشد) در مقابل دادههاى ابرطيفى جمع آورى

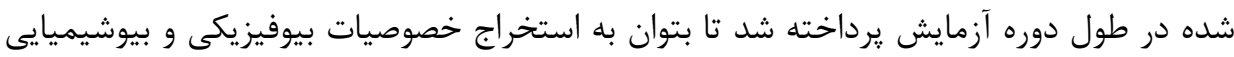

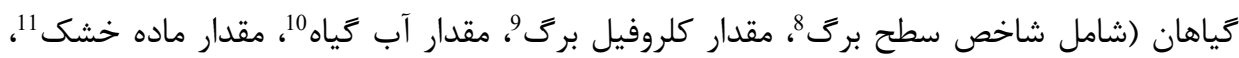

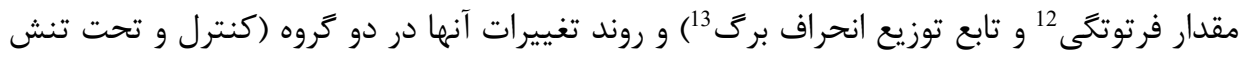

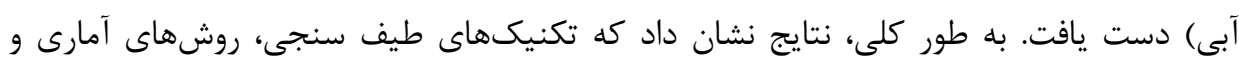

${ }^{1}$ Properties

2 Functioning

3 Canopy

${ }^{4}$ Coupled modeling approach

${ }^{5}$ Hyperspectral reflectance

${ }^{6}$ Radiative transfer

7 Soil-Canopy Observation of Photosynthesis and Energy fluxes

8 Leaf area index

9 Leaf chlorophyll content

10 Leaf water content

11 Leaf dry matter content

12 Senescent material

13 Leaf inclination distribution function 
معكوس سازى مدل ' إتيكى انتقال تابش، يتانسيلهاى نويد بخشى جهت بهره بردارى از دادههاى

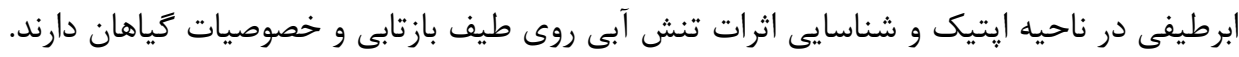

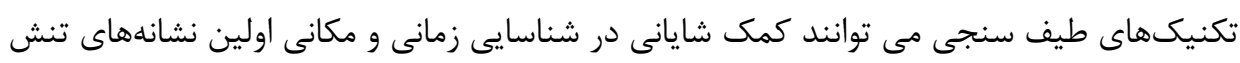

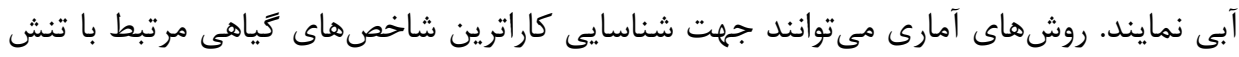

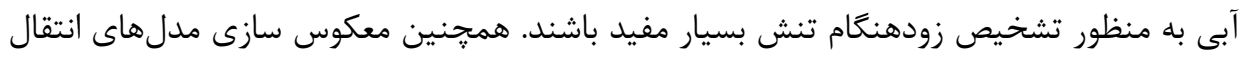

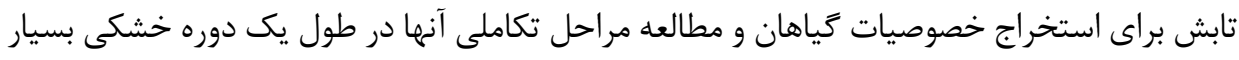
1اهخشا است.

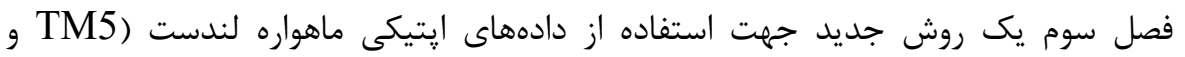

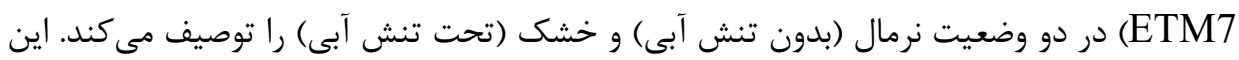

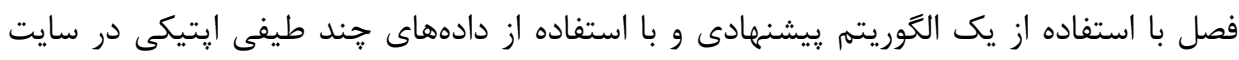

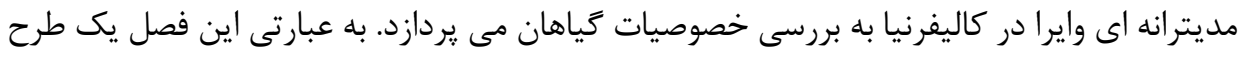

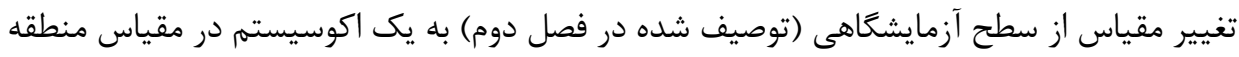

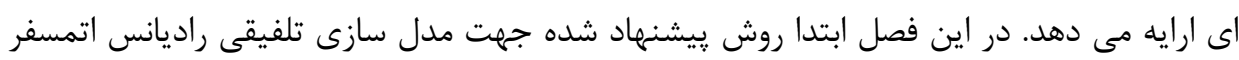

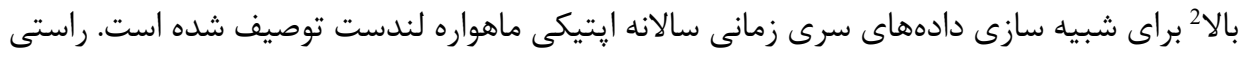

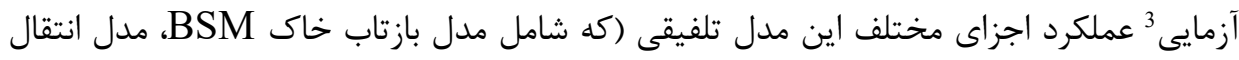

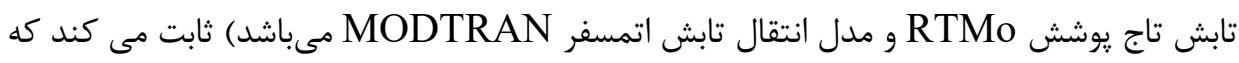

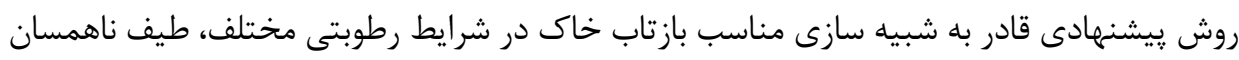

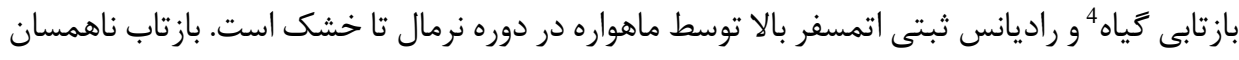

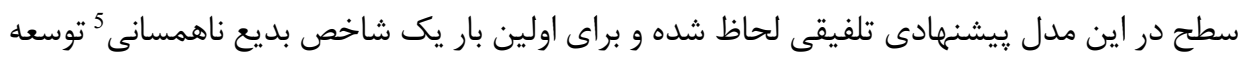

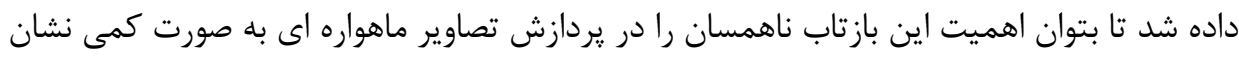

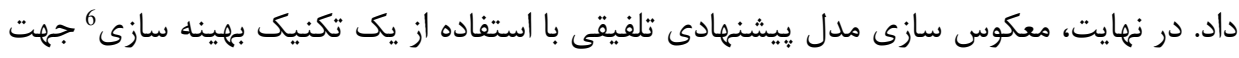

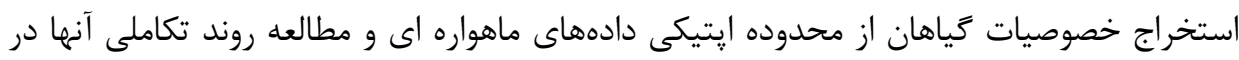

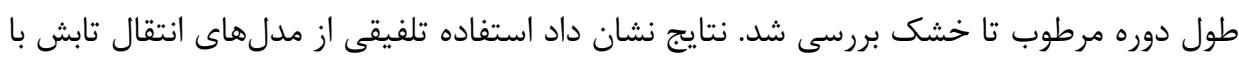

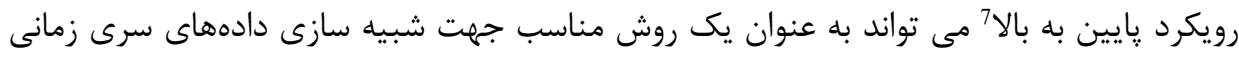

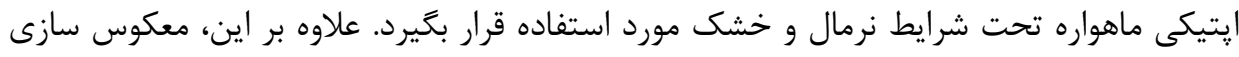

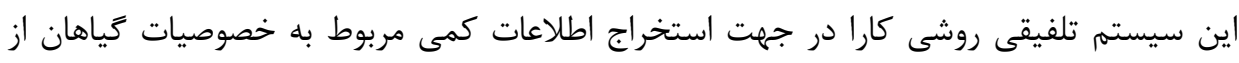

1 Model inversion

2 Top-of-atmosphere radiance

3 Validation

${ }^{4}$ Anisotropic vegetation reflectance spectra

${ }^{5}$ Anisotropy index

6 Optimization technique

7 "bottom-up" approach 
دادهاى سرى زمانى راديانس ثبت شده با ماهواره در اتمسفر بالا ارايه مى دهد. اطلاعات استخراج

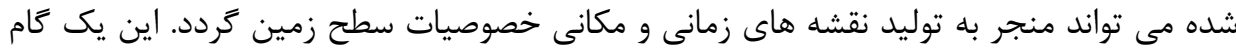

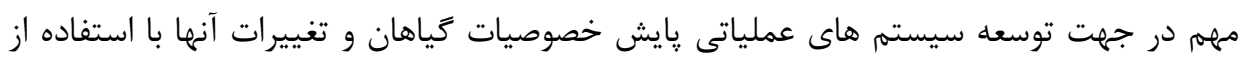

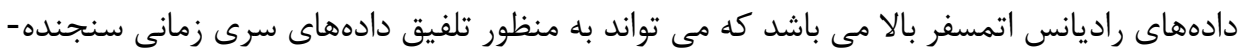

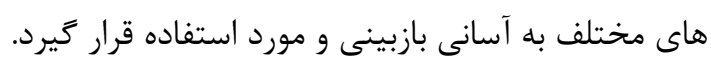

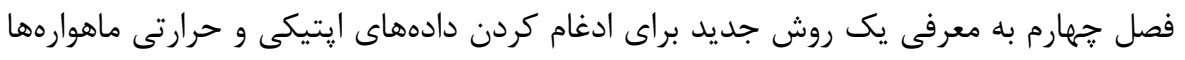
به منظور افزايش اطلاعات مفيد قابل استخراج در جهت تخمين عملكرد كياهان تحت شرايط نرمال

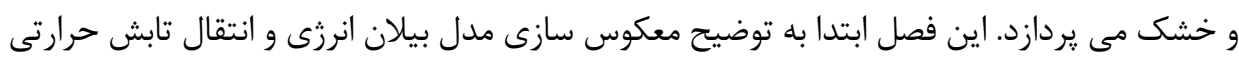

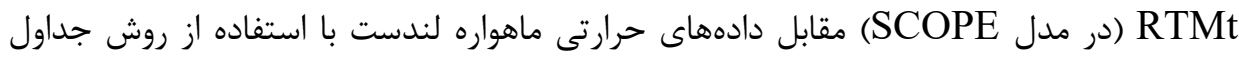

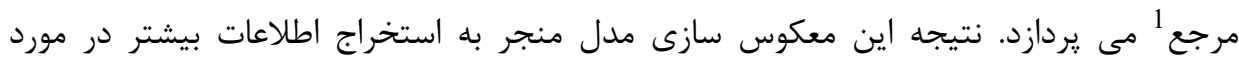

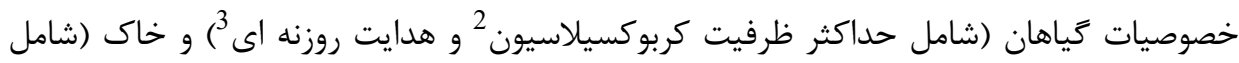

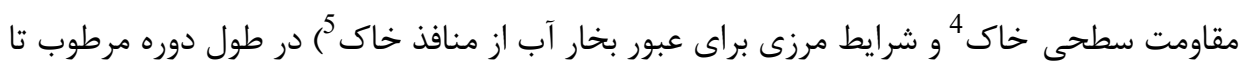

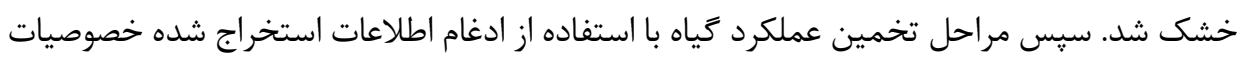

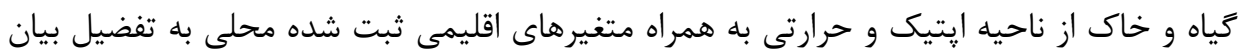

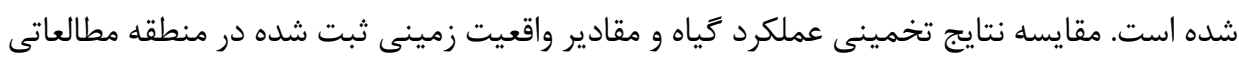

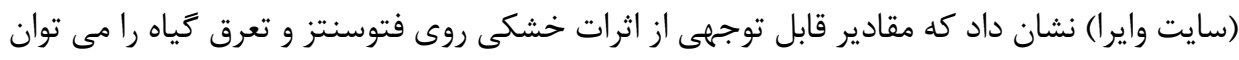

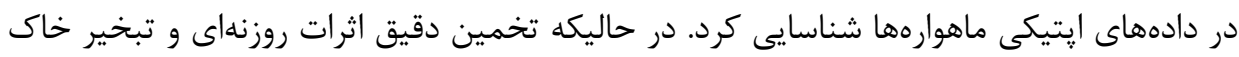

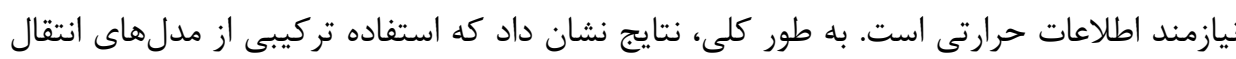

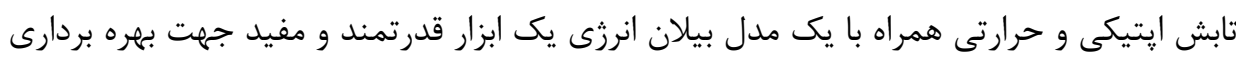

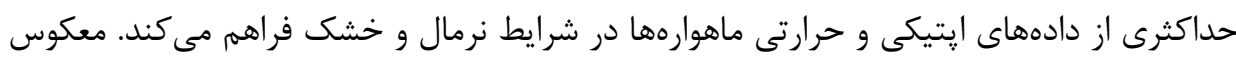

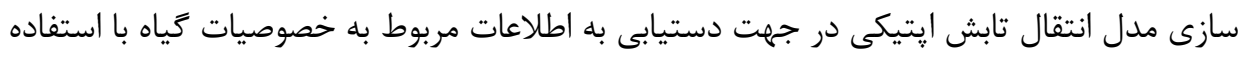

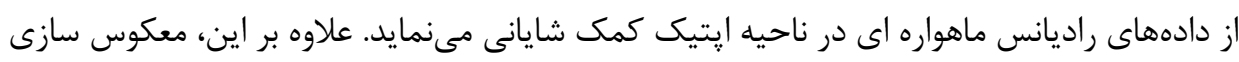

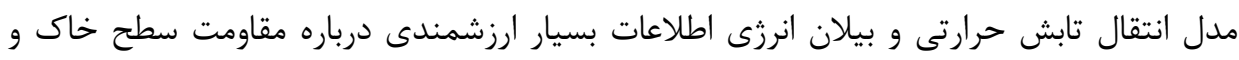

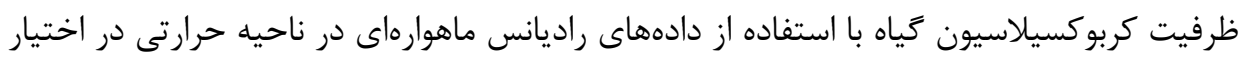

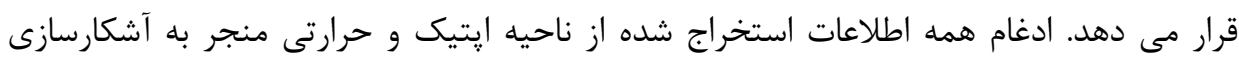

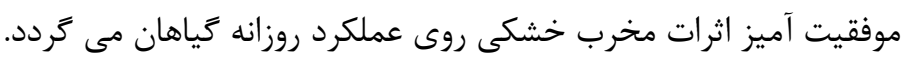

${ }^{1}$ Look-up tables

2 Maximum carboxylation capacity

3 Stomatal conductance

${ }^{4}$ Soil surface resistances

5 Soil boundary resistance 
در فصل ينجم به بررسى ارزش افزوده تركيب كردن دادههاى ايتيكى و رطوبت خاك براى

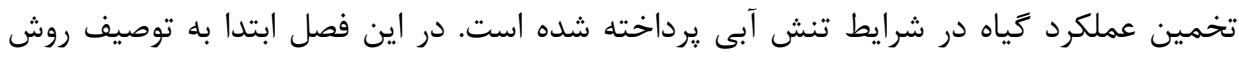

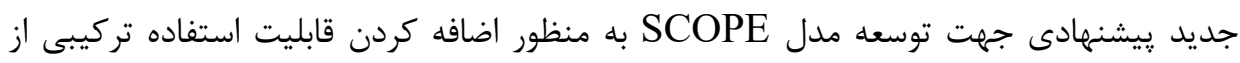

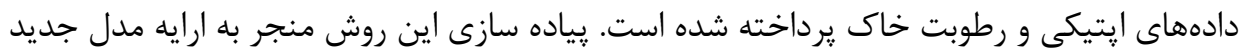

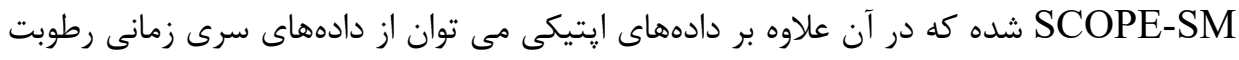

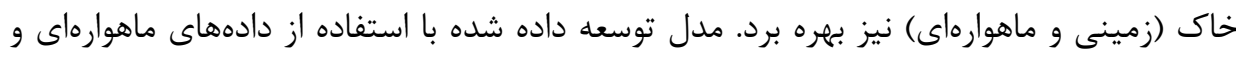

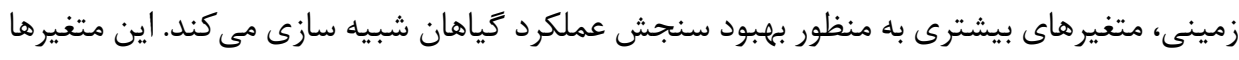

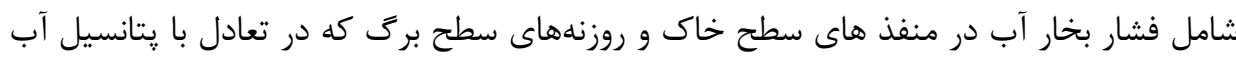

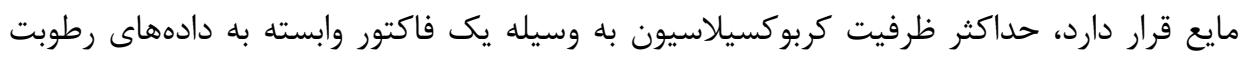

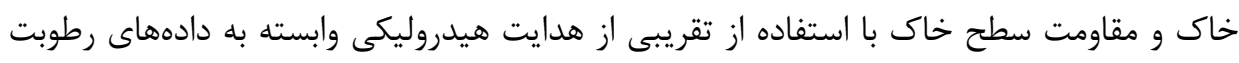

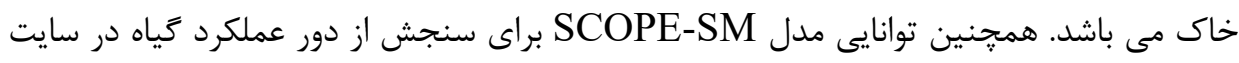

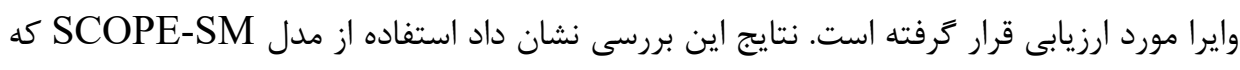

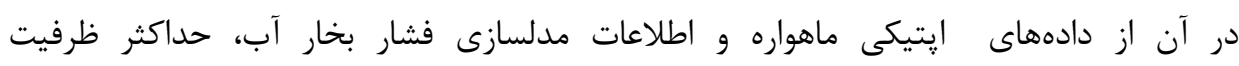

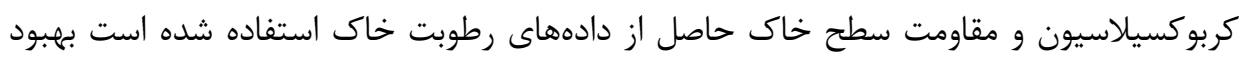

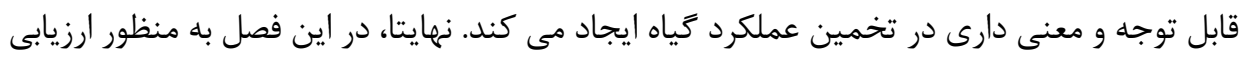

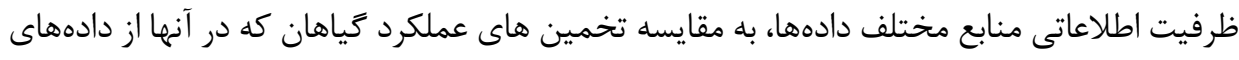

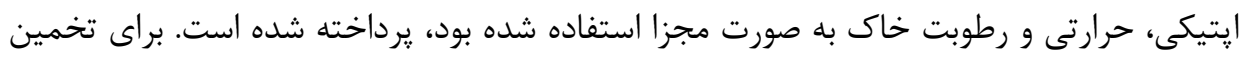

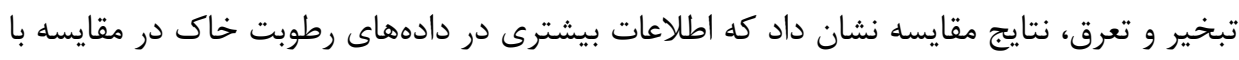

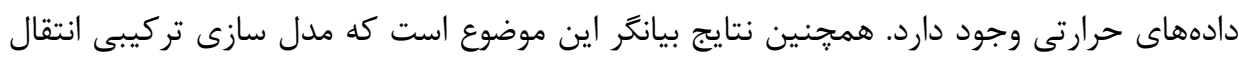

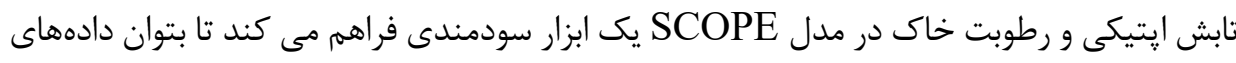

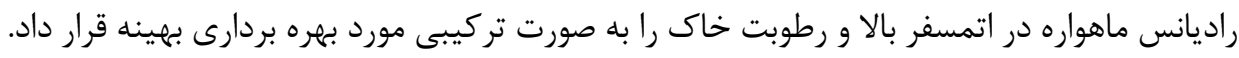

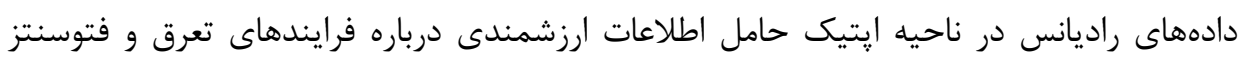

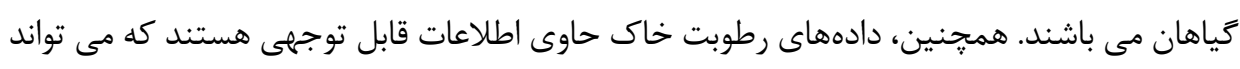

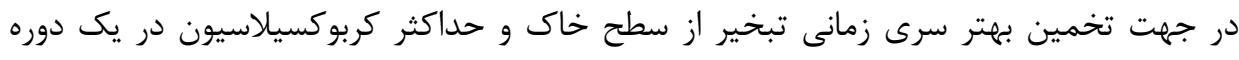

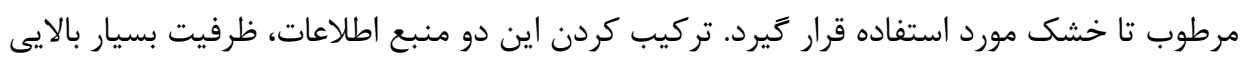

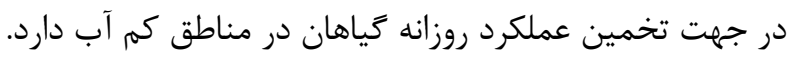

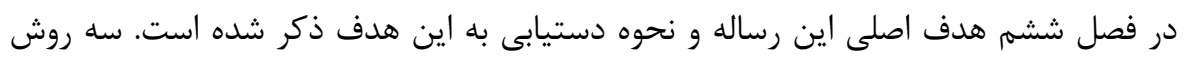

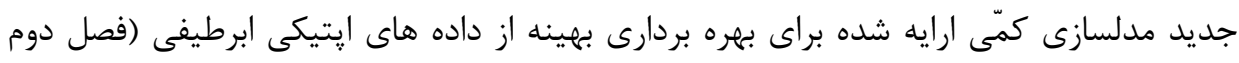

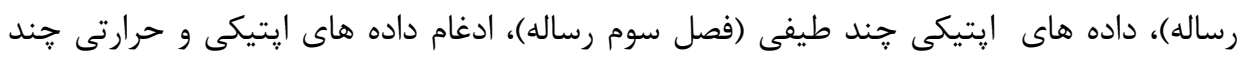

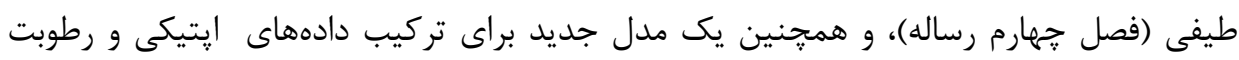

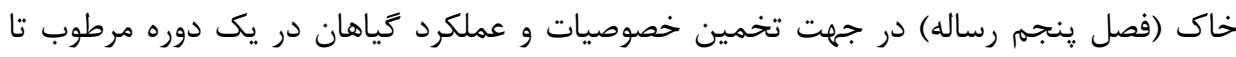


خشك مورد بحث و بررسى قرار كرفته است. روش ها و مدل ويشننهاد شده در اين رساله امكان

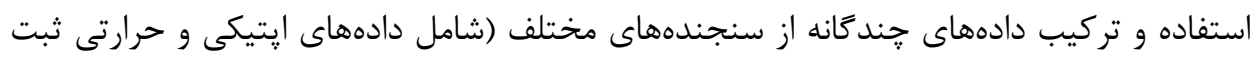

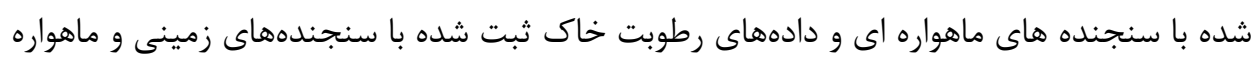

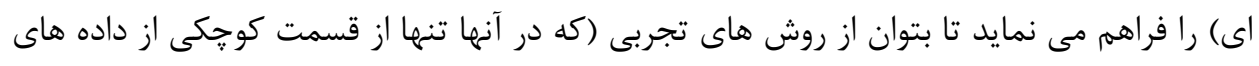

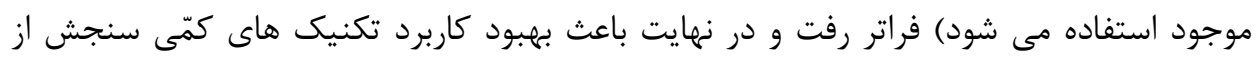

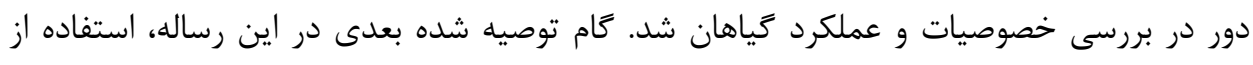

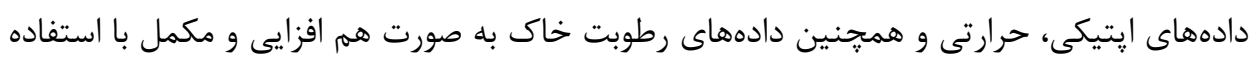

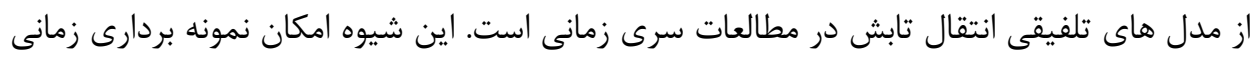

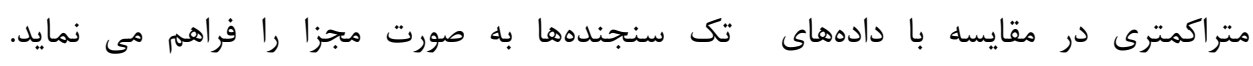

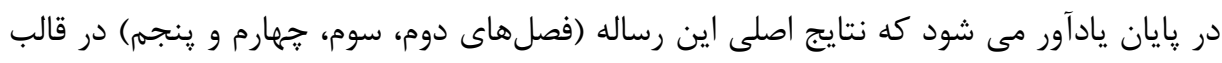

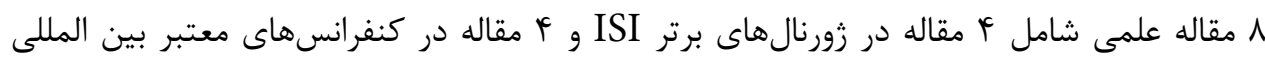

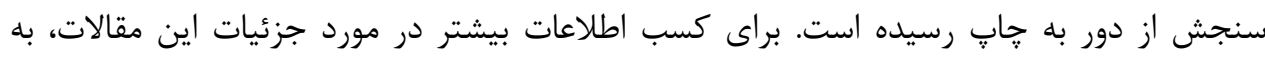

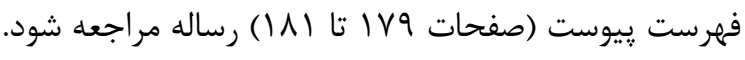




\section{Bibliography}

Adams, J., 2009. Vegetation-climate interaction: how plants make the global environment. Springer Science \& Business Media.

Allen, R.G., Pereira, L.S., Raes, D., Smith, M., 1998. Crop evapotranspiration: Guidelines for computing crop requirements. Irrig. Drain. Pap. No. 56, FAO 300. doi: 10.1016/j.eja.2010.12.001

Allen, R.G., Tasumi, M., Trezza, R., 2007. Satellite-Based Energy Balance for Mapping Evapotranspiration with Internalized Calibration (METRIC)Model. J. Irrig. Drain. Eng. 133, 380-394. doi:10.1061/(ASCE)07339437(2007)133:4(380)

Alley, W.M., 1984. The Palmer drought severity index: limitations and assumptions. J. Clim. Appl. Meteorol. 23, 1100-1109.

Anav, A., Friedlingstein, P., Beer, C., Ciais, P., Harper, A., Jones, C., MurrayTortarolo, G., Papale, D., Parazoo, N.C., Peylin, P., others, 2015. Spatiotemporal patterns of terrestrial gross primary production: A review. Rev. Geophys. 53, 785-818.

Anderson, M.C., Norman, J.M., Mecikalski, J.R., Otkin, J.A., Kustas, W.P., 2007a. A climatological study of evapotranspiration and moisture stress across the continental United States based on thermal remote sensing: 1. Model formulation. J. Geophys. Res. Atmos. 112.

Anderson, M.C., Norman, J.M., Mecikalski, J.R., Otkin, J.A., Kustas, W.P., 2007b. A climatological study of evapotranspiration and moisture stress across the continental United States based on thermal remote sensing: 2. Surface moisture climatology. J. Geophys. Res. Atmos. 112.

Asner, G.P., 1998. Biophysical and biochemical sources of variability in canopy reflectance. Remote Sens. Environ. 64, 234-253. doi:10.1016/S00344257(98)00014-5

Asner, G.P., Nepstad, D., Cardinot, G., Ray, D., 2004. Drought stress and carbon uptake in an Amazon forest measured with spaceborne imaging spectroscopy. Proc Natl Acad Sci U S A 101, 6039-6044. doi:10.1073/pnas.0400168101

Atkinson, P.M., Jeganathan, C., Dash, J., Atzberger, C., 2012. Intercomparison of four models for smoothing satellite sensor time-series data to estimate vegetation phenology. Remote Sens. Environ. 123, 400-417.

Atzberger, C., Richter, K., Vuolo, F., Darvishzadeh, R., Schlerf, M., 2011. Why confining to vegetation indices? Exploiting the potential of improved spectral observations using radiative transfer models. Proc. SPIE 8174, 81740Q. doi: 10.1117/12.898479

Atzberger, C., Darvishzadeh, R., Immitzer, M., Schlerf, M., Skidmore, A., le Maire, G., 2015. Comparative analysis of different retrieval methods for mapping grassland leaf area index using airborne imaging spectroscopy. Int. J. Appl. Earth Obs. Geoinf. 43, 19-31. doi:10.1016/j.jag.2015.01.009 
Aubinet, M., Vesala, T., Papale, D., 2012. Eddy covariance: a practical guide to measurement and data analysis. Springer Science \& Business Media.

Babar, M.A., Reynolds, M.P., Van Ginkel, M., Klatt, A.R., Raun, W.R., Stone, M.L., 2006. Spectral reflectance indices as a potential indirect selection criteria for wheat yield under irrigation. Crop Sci. 46, 578-588.

Bach, H., Verhoef, W., 2003. Sensitivity studies on the effect of surface soil moisture on canopy reflectance using the radiative transfer model GeoSAIL. IGARSS 2003. 2003 IEEE Int. Geosci. Remote Sens. Symp. Proc. (IEEE Cat. No.03CH37477) 3, 1679-1681. doi:10.1109/IGARSS.2003.1294215

Baldocchi, D., Meyers, T., 1998. On using eco-physiological, micrometeorological and biogeochemical theory to evaluate carbon dioxide, water vapor and trace gas fluxes over vegetation: A perspective. Agric. For. Meteorol. 90, 1-25. doi:10.1016/S0168-1923(97)00072-5

Baldocchi, D., Falge, E., Gu, L.H., Olson, R., Hollinger, D., Running, S., Anthoni, P., Bernhofer, C., Davis, K., Evans, R., Fuentes, J., Goldstein, A., Katul, G., Law, B., Lee, X.H., Malhi, Y., Meyers, T., Munger, W., Oechel, W., U, K.T.P., Pilegaard, K., Schmid, H.P., Valentini, R., Verma, S., Vesala, T., Wilson, K., Wofsy, S., 2001. FLUXNET: A new tool to study the temporal and spatial variability of ecosystem-scale carbon dioxide, water vapor, and energy flux densities. Bull. Am. Meteorol. Soc. 82, 2415-2434. doi:Doi 10.1175/1520-0477(2001)082

Baldocchi, D.D., 2003. Assessing the eddy covariance technique for evaluating carbon dioxide exchange rates of ecosystems: past, present and future. Glob. Chang. Biol. 9, 479-492. doi:10.1046/j.1365-2486.2003.00629.x

Baldocchi, D.D., Xu, L., Kiang, N., 2004. How plant functional-type, weather, seasonal drought, and soil physical properties alter water and energy fluxes of an oak-grass savanna and an annual grassland. Agric. For. Meteorol. 123, 13-39. doi:10.1016/j.agrformet.2003.11.006

Baret, F., Buis, S., 2008. Estimating canopy characteristics from remote sensing observations: Review of methods and associated problems, in: Advances in Land Remote Sensing. Springer, pp. 173-201.

Barton, C.V.M., 2011. Advances in remote sensing of plant stress. Plant Soil 354, 41-44. doi:10.1007/s11104-011-1051-0

Bastiaanssen, W.G.M., 2000. SEBAL-based sensible and latent heat fluxes in the irrigated Gediz Basin, Turkey. J. Hydrol. 229, 87-100.

Bastiaanssen, W., Noordman, E.J.., Pelgrum, H., Davids, G., Thoreson, B.., Allen, R.G., 2005. SEBAL model with remotely sensed data to improve water-resources management under actual field conditions. J. Irrig. Drain. Eng. 131, 2. doi:10.1061/(ASCE)0733-9437(2005)131

Bayat, B., van der Tol, C., Verhoef, W., 2016a. Remote sensing of grass response to drought stress using spectroscopic techniques and canopy reflectance model inversion. Remote Sens. 8, 557. doi: $10.3390 /$ rs8070557 
Bayat, B., van der Tol, C., Verhoef, W., 2016b. Monitoring soil moisture deficit effects on vegetation parameters using radiative transfer models inversion and hyperspectral measurements under controlled conditions, in: Living Planet Symposium. The European Space Agency (ESA), Prague, the Czech Republic, p. 107.

Bayat, B., van der Tol, C., Verhoef, W., 2018. Integrating satellite optical and thermal infrared observations for improving daily ecosystem functioning estimations in a drought episode. Remote Sens. Environ. 209, 375-394. doi:10.1016/j.rse.2018.02.027

Bayat, B., Tol, C. Van Der, Verhoef, W., 2018b. Retrieval of land surface properties from an annual time series of Landsat TOA radiances during a drought episode using coupled radiative transfer models. Remote Sens. Environ, doi:10.1016/j.rse.2018.09.030.

Beer, C., Reichstein, M., Tomelleri, E., Ciais, P., Jung, M., Carvalhais, N., Rödenbeck, C., Arain, M.A., Baldocchi, D., Bonan, G.B., others, 2010. Terrestrial gross carbon dioxide uptake: global distribution and covariation with climate. Science (80-. ). 329, 834-838.

Berjón, A.J., Cachorro, V.E., Zarco-Tejada, P.J., Frutos, A., 2013. Retrieval of biophysical vegetation parameters using simultaneous inversion of high resolution remote sensing imagery constrained by a vegetation index. Precis. Agric. 14, 541-557. doi:10.1007/s11119-013-9315-8

Berk, A., Anderson, G.P., Acharya, P.K., Shettle, E.P., 2008. MODTRAN 5.2.0.0 User's Manual. Hanscom AFB: Air Force Research Labora- tory, Space Vehicles Directorate, Air Force Materiel Command, MA 01731-3010, 97 pp.

Bicheron, P., Leroy, M., 1999. A method of biophysical parameter retrieval at global scale by inversion of a vegetation reflectance model. Remote Sens. Environ. 67, 251-266.

Boden, T.A., Krassovski, M., Yang, B., 2013. The AmeriFlux data activity and data system: an evolving collection of data management techniques, tools, products and services. Geosci. Instrumentation, Methods Data Syst. 2, 165-176.

Bonan, G., 2015. Ecological climatology: concepts and applications. Cambridge University Press.

Börner, A., Wiest, L., Keller, P., Reulke, R., Richter, R., Schaepman, M., Schläpfer, D., 2001. SENSOR: a tool for the simulation of hyperspectral remote sensing systems. ISPRS J. Photogramm. Remote Sens. 55, 299312.

Borzuchowski, J., Schulz, K., 2010. Retrieval of Leaf Area Index (LAI) and Soil Water Content (WC) Using Hyperspectral Remote Sensing under Controlled Glass House Conditions for Spring Barley and Sugar Beet. Remote Sens. 2, 1702-1721. doi: 10.3390/rs2071702

Bosch, J.M., Hewlett, J.D., 1982. A review of catchment experiments to determine the effect of vegetation changes on water yield and 
evapotranspiration. J. Hydrol. 55, 3-23. doi:10.1016/00221694(82)90117-2

Bowyer, P., Danson, F.M., 2004. Sensitivity of spectral reflectance to variation in live fuel moisture content at leaf and canopy level. Remote Sens. Environ. 92, 297-308. doi:10.1016/j.rse.2004.05.020

Brunsell, N.A., Gillies, R.R., 2003. Scale issues in land--atmosphere interactions: implications for remote sensing of the surface energy balance. Agric. For. Meteorol. 117, 203-221.

Buitrago, M.F., Groen, T.A., Hecker, C.A., Skidmore, A.K., 2016. Changes in thermal infrared spectra of plants caused by temperature and water stress. ISPRS J. Photogramm. Remote Sens. 111, 22-31. doi:10.1016/j.isprsjprs.2015.11.003

Calvet, J.-C., Rivalland, V., Picon-Cochard, C., Guehl, J.-M., 2004. Modelling forest transpiration and $\mathrm{CO} 2$ fluxes-response to soil moisture stress. Agric. For. Meteorol. 124, 143-156.

Camillo, P.J., Gurney, R.J., 1986. A resistance parameter for bare-soil evaporation models. Soil Sci. 141, 95-105.

Carter, G.A., 1991. Primary and secondary effects of water content on the spectral reflectance of leaves. Am. J. Bot. 78, 916-924. doi: $10.2307 / 2445170$

Carter, G.A., 1994. Ratios of leaf reflectances in narrow wavebands as indicators of plant stress. Remote Sens. 15, 697-703.

Carter, G.A., Miller, R.L., 1994. Early Detection of Plant Stress by Digital Imaging within Narrow Stress-Sensitive Wavebands 5 3. Remote Sens. Environ. 302, 295-301.

Ceccato, P., Flasse, S., Tarantola, S., Jacquemoud, S., Grégoire, J.-M., 2001. Detecting vegetation leaf water content using reflectance in the optical domain. Remote Sens. Environ. 77, 22-33.

Ceccato, P., 2002. Designing a spectral index to estimate vegetation water content from remote sensing data: Part 1 Theoretical approach. Remote Sens. Environ. 82, 188-197. doi:10.1016/S0034-4257(02)00037-8

Ceccato, P., Gobron, N., Flasse, S., Pinty, B., Tarantola, S., 2002. Designing a spectral index to estimate vegetation water content from remote sensing data: Part 2. Validation and applications. Remote Sens. Environ. 82, 198207. doi:10.1016/S0034-4257(02)00036-6

Chaerle, L., Van Der Straeten, D., 2001. Seeing is believing: Imaging techniques to monitor plant health. Biochim. Biophys. Acta - Gene Struct. Expr. 1519, 153-166. doi:10.1016/S0167-4781(01)00238-X

Chávez, R.O., Clevers, J.G.P.W., Herold, M., Ortiz, M., Acevedo, E., 2013. Modelling the spectral response of the desert tree Prosopis tamarugo to water stress. Int. J. Appl. Earth Obs. Geoinf. 21, 53-65. doi: $10.1016 /$ j.jag.2012.08.013

Chen, D., Huang, J., Jackson, T.J., 2005. Vegetation water content estimation for corn and soybeans using spectral indices derived from MODIS near- 
and short-wave infrared bands. Remote Sens. Environ. 98, 225-236. doi: $10.1016 /$ j.rse.2005.07.008

Chongya, J., Hongliang, F., 2012. Modeling soil reflectance using a global spectral library, in: AGU Fall Meeting, 3-7 December. San Francisco, USA.

Cleugh, H.A., Leuning, R., Mu, Q., Running, S.W., 2007. Regional evaporation estimates from flux tower and MODIS satellite data. Remote Sens. Environ. 106, 285-304. doi:10.1016/j.rse.2006.07.007

Clevers, J.G.P.W., Kooistra, L., Schaepman, M.E., 2010. Estimating canopy water content using hyperspectral remote sensing data. Int. J. Appl. Earth Obs. Geoinf. 12, 119-125. doi:10.1016/j.jag.2010.01.007

Coates, A.R., Dennison, P.E., Roberts, D.A., Roth, K.L., 2015. Monitoring the impacts of severe drought on southern California Chaparral species using hyperspectral and thermal infrared imagery. Remote Sens. 7, 1427614291. doi: $10.3390 /$ rs71114276

Colello, G.D., Grivet, C., Sellers, P.J., Berry, J.A., 1998. Modeling of energy, water, and $\mathrm{CO} 2$ flux in a temperate grassland ecosystem with SiB2: May-October 1987. J. Atmos. Sci. 55, 1141-1169.

Collatz, G.J., Ball, J.T., Grivet, C., Berry, J.A., 1991. Physiological and environmental regulation of stomatal conductance, photosynthesis and transpiration: a model that includes a laminar boundary layer. Agric. For. Meteorol. 54, 107-136.

Collatz, G.J., Ribas-Carbo, M., Berry, J.A., 1992. Coupled photosynthesisstomatal conductance model for leaves of C4 plants. Funct. Plant Biol. 19, 519-538.

Combal, B., Baret, F., Weiss, M., Trubuil, A., Mace, D., Pragnere, A., Myneni, R., Knyazikhin, Y., Wang, L., 2003. Retrieval of canopy biophysical variables from bidirectional reflectance: Using prior information to solve the ill-posed inverse problem. Remote Sens. Environ. 84, 1-15.

Crow, W.T., Kustas, W.P., Prueger, J.H., 2008. Monitoring root-zone soil moisture through the assimilation of a thermal remote sensing-based soil moisture proxy into a water balance model. Remote Sens. Environ. 112, 1268-1281. doi:10.1016/j.rse.2006.11.033

Dai, A., 2011. Drought under global warming: A review. Wiley Interdiscip. Rev. Clim. Chang. 2, 45-65. doi:10.1002/wcc.81

Damm, A., Guanter, L., Paul-Limoges, E., der Tol, C., Hueni, A., Buchmann, N., Eugster, W., Ammann, C., Schaepman, M.E., 2015. Far-red suninduced chlorophyll fluorescence shows ecosystem-specific relationships to gross primary production: An assessment based on observational and modeling approaches. Remote Sens. Environ. 166, 91-105.

Damm, A., Paul-Limoges, E., Haghighi, E., Simmer, C., Morsdorf, F., Schneider, F.D., van der Tol, C., Migliavacca, M., Rascher, U., 2018. Remote sensing of plant-water relations: An overview and future perspectives. J. Plant Physiol. 1-17. doi:10.1016/j.jplph.2018.04.012

Darvishzadeh, R., Skidmore, A., Schlerf, M., Atzberger, C., 2008. Inversion of 
a radiative transfer model for estimating vegetation LAI and chlorophyll in a heterogeneous grassland. Remote Sens. Environ. 112, 2592-2604. doi: $10.1016 /$ j.rse.2007.12.003

Darvishzadeh, R., Atzberger, C., Skidmore, A., Schlerf, M., 2011. Mapping grassland leaf area index with airborne hyperspectral imagery: A comparison study of statistical approaches and inversion of radiative transfer models. ISPRS J. Photogramm. Remote Sens. 66, 894-906. doi:10.1016/j.isprsjprs.2011.09.013

Daughtry, C., 2000. Estimating Corn Leaf Chlorophyll Concentration from Leaf and Canopy Reflectance. Remote Sens. Environ. 74, 229-239. doi:10.1016/S0034-4257(00)00113-9

De Jong, S.M., Addink, E. a., Hoogenboom, P., Nijland, W., 2012. The spectral response of Buxus sempervirens to different types of environmental stress - A laboratory experiment. ISPRS J. Photogramm. Remote Sens. 74, 56-65. doi:10.1016/j.isprsjprs.2012.08.005

Deardorff, J.W., 1978. Efficient prediction of ground surface temperature and moisture, with inclusion of a layer of vegetation. J. Geophys. Res. 83. doi: 10.1029/JC083iC04p01889

Dong, J., Xiao, X., Wagle, P., Zhang, G., Zhou, Y., Jin, C., Torn, M.S., Meyers, T.P., Suyker, A.E., Wang, J., Yan, H., Biradar, C., Moore, B., 2015. Comparison of four EVI-based models for estimating gross primary production of maize and soybean croplands and tallgrass prairie under severe drought. Remote Sens. Environ. 162, 154-168. doi:10.1016/j.rse.2015.02.022

Dorigo, W.A., Zurita-Milla, R., de Wit, A.J.W., Brazile, J., Singh, R., Schaepman, M.E., 2007. A review on reflective remote sensing and data assimilation techniques for enhanced agroecosystem modeling. Int. J. Appl. Earth Obs. Geoinf. 9, 165-193. doi:10.1016/j.jag.2006.05.003

Dorigo, W., Richter, R., Baret, F., Bamler, R., Wagner, W., 2009. Enhanced Automated Canopy Characterization from Hyperspectral Data by a Novel Two Step Radiative Transfer Model Inversion Approach. Remote Sens. 1, 1139-1170. doi:10.3390/rs1041139

Dorman, M., Svoray, T., Perevolotsky, A., Sarris, D., 2013. Forest performance during two consecutive drought periods: diverging long-term trends and short-term responses along a climatic gradient. For. Ecol. Manage. 310, 1-9.

Dorman, M., Perevolotsky, A., Sarris, D., Svoray, T., 2015. The effect of rainfall and competition intensity on forest response to drought: lessons learned from a dry extreme. Oecologia 177, 1025-1038.

Drusch, M., Del Bello, U., Carlier, S., Colin, O., Fernandez, V., Gascon, F., Hoersch, B., Isola, C., Laberinti, P., Martimort, P., Meygret, A., Spoto, F., Sy, O., Marchese, F., Bargellini, P., 2012. Sentinel-2: ESA's Optical HighResolution Mission for GMES Operational Services. Remote Sens. Environ. 120, 25-36. doi:10.1016/j.rse.2011.11.026 
Duan, S.-B., Li, Z.-L., Wu, H., Tang, B.-H., Ma, L., Zhao, E., Li, C., 2014. Inversion of the PROSAIL model to estimate leaf area index of maize, potato, and sunflower fields from unmanned aerial vehicle hyperspectral data. Int. J. Appl. Earth Obs. Geoinf. 26, 12-20. doi: $10.1016 /$ j.jag.2013.05.007

Duffour, C., Olioso, A., Demarty, J., Van der Tol, C., Lagouarde, J.P., 2015. An evaluation of SCOPE: A tool to simulate the directional anisotropy of satellite-measured surface temperatures. Remote Sens. Environ. 158, 362-375. doi:10.1016/j.rse.2014.10.019

Duffour, C., Lagouarde, J.-P., Olioso, A., Demarty, J., Roujean, J.-L., 2016. Driving factors of the directional variability of thermal infrared signal in temperate regions. Remote Sens. Environ. 177, 248-264.

Earl, H.J., Davis, R.F., 2003. Effect of drought stress on leaf and whole canopy radiation use efficiency and yield of maize. Agron. J. 95, 688-696.

Egea, G., Verhoef, A., Vidale, P.L., 2011. Towards an improved and more flexible representation of water stress in coupled photosynthesis-stomatal conductance models. Agric. For. Meteorol. 151, 1370-1384. doi: 10.1016/j.agrformet.2011.05.019

Elmetwalli, A.M.H., Tyler, A.N., Hunter, P.D., Salt, C.A., 2012. Detecting and distinguishing moisture- and salinity-induced stress in wheat and maize through in situ spectroradiometry measurements. Remote Sens. Lett. 3, 363-372. doi: 10.1080/01431161.2011.599346

Evans, J.R., 1989. Photosynthesis and nitrogen relationship in leaves of C3 plants. Oecologia 78, 9-19. doi:10.1007/BF00377192

Fabre, S., Lesaignoux, A., Olioso, A., Briottet, X., 2011. Influence of water content on spectral reflectance of leaves in the $3-15-\mu \mathrm{m}$ domain 8 , 143-147. doi:10.1109/LGRS.2010.2053518

Fang, Y., Sun, G., Caldwell, P., Mcnulty, S.G., Noormets, A., Domec, J.C., King, J., Zhang, Z., Zhang, X., Lin, G., Zhou, G., Xiao, J., Chen, J., 2016. Monthly land cover-specific evapotranspiration models derived from global eddy flux measurements and remote sensing data. Ecohydrology 9, 248-266. doi:10.1002/eco.1629

Farquhar, G.D., von Caemmerer, S. von, Berry, J.A., 1980. A biochemical model of photosynthetic $\mathrm{CO} 2$ assimilation in leaves of $\mathrm{C} 3$ species. Planta 149, 78-90.

Faurtyot, T., Baret, F., 1997. Vegetation water and dry matter contents estimated from top-of-the-atmosphere reflectance data: a simulation study. Remote Sens. Environ. 61, 34-45.

Fedotov, Y., Bullo, O., Belov, M., Gorodnichev, V., 2016. Experimental Research of Reliability of Plant Stress State Detection by Laser-Induced Fluorescence Method. Internatinal J. Opt. 2016, 6.

Gamon, J. a., Peñuelas, J., Field, C.B., 1992. A narrow-waveband spectral index that tracks diurnal changes in photosynthetic efficiency. Remote Sens. Environ. 41, 35-44. doi:10.1016/0034-4257(92)90059-S 
Gang, C., Wang, Z., Chen, Y., Yang, Y., Li, J., Cheng, J., Qi, J., Odeh, I., 2016. Drought-induced dynamics of carbon and water use efficiency of global grasslands from 2000 to 2011. Ecol. Indic. 67, 788-797. doi: 10.1016/j.ecolind.2016.03.049

Gao, B.C., 1996. NDWI - A normalized difference water index for remote sensing of vegetation liquid water from space. Remote Sens. Environ. 58, 257-266. doi:10.1016/S0034-4257(96)00067-3

Gastellu-Etchegorry, J.-P., Demarez, V., Pinel, V., Zagolski, F., 1996. Modeling radiative transfer in heterogeneous 3-D vegetation canopies. Remote Sens. Environ. 58, 131-156.

Gastellu-Etchegorry, J.P., Martin, E., Gascon, F., 2004. DART: a 3D model for simulating satellite images and studying surface radiation budget. Int. J. Remote Sens. 25, 73-96.

Gastellu-Etchegorry, J.-P., 2008. 3D modeling of satellite spectral images, radiation budget and energy budget of urban landscapes. Meteorol. Atmos. Phys. 102, 187.

Genc, L., Inalpulat, M., Kizil, U., Mirik, M., Smith, S.E., Mendes, M., 2013. Determination of water stress with spectral reflectance on sweet corn (Zea mays L.) using classification tree (CT) analysis. ZemdirbysteAgriculture 100, 81-90. doi:10.13080/z-a.2013.100.011

Gerber, F., Marion, R., Olioso, A., Jacquemoud, S., Ribeiro da Luz, B., Fabre, S., 2011. Modeling directional-hemispherical reflectance and transmittance of fresh and dry leaves from $0.4 \mu \mathrm{m}$ to $5.7 \mu \mathrm{m}$ with the PROSPECT-VISIR model. Remote Sens. Environ. 115, 404-414. doi: $10.1016 /$ j.rse.2010.09.011

Gerstl, S.A.W., Simmer, C., 1986. Radiation physics and modelling for off-nadir satellite-sensing of non-Lambertian surfaces. Remote Sens. Environ. 20, 1-29.

Gilabert, M.A., Moreno, A., Maselli, F., Martinez, B., Chiesi, M., Sanchez-Ruiz, S., Garcia-Haro, F.J., Perez-Hoyos, A., Campos-Taberner, M., PerezPriego, O., Serrano-Ortiz, P., Carrara, A., 2015. Daily GPP estimates in Mediterranean ecosystems by combining remote sensing and meteorological data. ISPRS J. Photogramm. Remote Sens. 102, 184-197. doi: 10.1016/j.isprsjprs.2015.01.017

Gimeno, T.E., Crous, K.Y., Cooke, J., O'Grady, A.P., Ósvaldsson, A., Medlyn, B.E., Ellsworth, D.S., 2016. Conserved stomatal behaviour under elevated $\mathrm{CO} 2$ and varying water availability in a mature woodland. Funct. Ecol. 30, 700-709.

Gitelson, A.A., Peng, Y., Arkebauer, T.J., Schepers, J., 2014. Relationships between gross primary production, green LAI, and canopy chlorophyll content in maize: Implications for remote sensing of primary production. Remote Sens. Environ. 144, 65-72. doi:10.1016/j.rse.2014.01.004

Glenn, E.P., Huete, A.R., Nagler, P.L., Hirschboeck, K.K., Brown, P., 2007. Integrating remote sensing and ground methods to estimate 
evapotranspiration. CRC. Crit. Rev. Plant Sci. 26, 139-168. doi: $10.1080 / 07352680701402503$

Glenn, E.P., Huete, A.R., Nagler, P.L., Nelson, S.G., 2008. Relationship between remotely-sensed vegetation indices, canopy attributes and plant physiological processes: What vegetation indices can and cannot tell us about the landscape. Sensors 8, 2136-2160. doi:10.3390/s8042136

Glenn, E.P., Nagler, P.L., Huete, A.R., 2010. Vegetation index methods for estimating evapotranspiration by remote sensing. Surv. Geophys. 31, 531-555. doi:10.1007/s10712-010-9102-2

GloVis, URL https://glovis.usgs.gov/ (accessed 9.7.17).

Gökmen, M., Vekerdy, Z., Verhoef, A., Verhoef, W., Batelaan, O., van der Tol, C., 2012. Integration of soil moisture in SEBS for improving evapotranspiration estimation under water stress conditions. Remote Sens. Environ. 121, 261-274. doi:DOI 10.1016/j.rse.2012.02.003

Gonzalez-Dugo, M.P., Neale, C.M.U., Mateos, L., Kustas, W.P., Prueger, J.H., Anderson, M.C., Li, F., 2009. A comparison of operational remote sensingbased models for estimating crop evapotranspiration. Agric. For. Meteorol. 149, 1843-1853. doi:10.1016/j.agrformet.2009.06.012

Govender, M., Dye, P., Weiersbye, I., Witkowski, E., F, A., 2009. Review of commonly used remote sensing and ground-based technologies to measure plant water stress. Water SA 35, 741-752.

Gupta, H. V., Kling, H., Yilmaz, K.K., Martinez, G.F., 2009. Decomposition of the mean squared error and NSE performance criteria: Implications for improving hydrological modelling. J. Hydrol. 377, 80-91. doi: 10.1016/j.jhydrol.2009.08.003

Haboudane, D., Miller, J.R., Pattey, E., Zarco-Tejada, P.J., Strachan, I.B., 2004. Hyperspectral vegetation indices and novel algorithms for predicting green LAI of crop canopies: Modeling and validation in the context of precision agriculture. Remote Sens. Environ. 90, 337-352. doi: $10.1016 /$ j.rse.2003.12.013

Harley, P.C., Tenhunen, J.D., 1991. Modeling the Photosynthetic Response of C 3 Leaves to Environmental Factors. Model. Crop Photosynth. - from Biochem. to Canopy 19, 53711.

Heady, H.F., 1958. Vegetational changes in the California annual type. Ecology $39,402-416$.

Heim, R.R., others, 2000. Drought indices: a review. Drought a Glob. Assess. 159-167.

Heim, R.R., 2005. Computing the monthly Palmer Drought Index on a weekly basis: A case study comparing data estimation techniques. Geophys. Res. Lett. 32, 1-4. doi:10.1029/2004GL022118

Heroult, A., LIN, Y.-S., Bourne, A., Medlyn, B.E., Ellsworth, D.S., 2013. Optimal stomatal conductance in relation to photosynthesis in climatically contrasting Eucalyptus species under drought. Plant. Cell Environ. 36, 262-274. 
Historical Palmer Drought Indices | Temperature, Precipitation, and Drought | National Centers for Environmental Information (NCEI) [WWW Document], n.d. URL https://www.ncdc.noaa.gov/temp-andprecip/drought/historical-palmers/ (accessed 9.7.17).

Houborg, R., Soegaard, H., Boegh, E., 2007. Combining vegetation index and model inversion methods for the extraction of key vegetation biophysical parameters using Terra and Aqua MODIS reflectance data. Remote Sens. Environ. 106, 39-58.

Houborg, R., Cescatti, A., Migliavacca, M., Kustas, W.P., 2013. Satellite retrievals of leaf chlorophyll and photosynthetic capacity for improved modeling of GPP. Agric. For. Meteorol. 177, 10-23. doi:10.1016/j.agrformet.2013.04.006

Huete, A.R., 1987. Soil and sun angle interactions on partial canopy spectra. Int. J. Remote Sens. 8, 1307-1317.

Hunt Jr, E.R., Rock, B.N., 1989. Detection of changes in leaf water content using Near- and Middle-Infrared reflectances. Remote Sens. Environ. 30, 43-54. doi:10.1016/0034-4257(89)90046-1

Jackson, L.E., 1985. Ecological origins of California's Mediterranean grasses. J. Biogeogr. 349-361.

Jackson, T.J., Chen, D., Cosh, M., Li, F., Anderson, M., Walthall, C., Doriaswamy, P., Hunt, E.R., 2004. Vegetation water content mapping using Landsat data derived normalized difference water index for corn and soybeans. Remote Sens. Environ. 92, 475-482. doi:10.1016/j.rse.2003.10.021

Jacquemoud, S., Baret, F., 1990. PROSPECT: A model of leaf optical properties spectra. Remote Sens. Environ. 34, 75-91. doi:10.1016/00344257(90)90100-Z

Jacquemoud, S., Baret, F., Andrieu, B., Danson, F.M., Jaggard, K., 1995. Extraction of vegetation biophysical parameters by inversion of the PROSPECT+ SAIL models on sugar beet canopy reflectance data. Application to TM and AVIRIS sensors. Remote Sens. Environ. 52, 163172.

Jacquemoud, S., Ustin, S.L., Verdebout, J., Schmuck, G., Andreoli, G., Hosgood, B., 1996. Estimating leaf biochemistry using the PROSPECT leaf optical properties model. Remote Sens. Environ. 56, 194-202. doi: 10.1016/0034-4257(95)00238-3

Jacquemoud, S., Verhoef, W., Baret, F., Bacour, C., Zarco-Tejada, P.J., Asner, G.P., François, C., Ustin, S.L., 2009. PROSPECT+SAIL models: A review of use for vegetation characterization. Remote Sens. Environ. 113, S56S66. doi:10.1016/j.rse.2008.01.026

Jung, M., Le Maire, G., Zaehle, S., Luyssaert, S., Vetter, M., Churkina, G., Ciais, P., Viovy, N., Reichstein, M., 2007. Assessing the ability of three land ecosystem models to simulate gross carbon uptake of forests from boreal to Mediterranean climate in Europe. Biogeosciences 4, 647-656. 
Keenan, T., Garcia, R., Friend, A.D., Zaehle, S., Gracia, C., Sabate, S., 2009. Improved understanding of drought controls on seasonal variation in Mediterranean forest canopy CO 2 and water fluxes through combined in situ measurements and ecosystem modelling. Biogeosciences 6.

Keenan, T., Sabate, S., Gracia, C., 2010a. Soil water stress and coupled photosynthesis-conductance models: Bridging the gap between conflicting reports on the relative roles of stomatal, mesophyll conductance and biochemical limitations to photosynthesis. Agric. For. Meteorol. 150, 443-453. doi:DOI 10.1016/j.agrformet.2010.01.008

Keenan, T., Sabate, S., Gracia, C., 2010b. The importance of mesophyll conductance in regulating forest ecosystem productivity during drought periods. Glob. Chang. Biol. 16, 1019-1034. doi:10.1111/j.13652486.2009.02017.x

Klepper, B., Rickman, R.W., Taylor, H.M., 1983. Farm management and the function of field crop root systems. Agric. Water Manag. 7, 115-141.

Kneizys, F.X., Shettle, E.P., Abreu, L.W., Chetwynd, J.H., Anderson, G.P., 1988. Users guide to LOWTRAN 7.

Knipling, E.B., 1970. Physical and physiological basis for the reflectance of visible and near-infrared radiation from vegetation. Remote Sens. Environ. 1, 155-159.

Koffi, E.N., Rayner, P.J., Norton, A.J., Frankenberg, C., Scholze, M., 2015. Investigating the usefulness of satellite-derived fluorescence data in inferring gross primary productivity within the carbon cycle data assimilation system. Biogeosciences 12, 4067-4084. doi:10.5194/bg-124067-2015

Koster, R.D., Dirmeyer, P.A., Guo, Z., Bonan, G., Chan, E., Cox, P., Gordon, C.T., Kanae, S., Kowalczyk, E., Lawrence, D., others, 2004. Regions of strong coupling between soil moisture and precipitation. Science (80-. ). 305, 1138-1140.

Krinner, G., Viovy, N., de Noblet-Ducoudré, N., Ogée, J., Polcher, J., Friedlingstein, P., Ciais, P., Sitch, S., Prentice, I.C., 2005. A dynamic global vegetation model for studies of the coupled atmosphere-biosphere system. Global Biogeochem. Cycles 19.

Kustas, W.P., Norman, J.M., 1996. Use of remote sensing for evapotranspiration monitoring over land surfaces. Hydrol. Sci. J. 41, 495516. doi:10.1080/02626669609491522

Kustas, W.P., Norman, J.M., 1999. Evaluation of soil and vegetation heat flux predictions using a simple two-source model with radiometric temperature for partial canopy cover. Agric. For. Meteorol. 94, 13-29.

Kustas, W.P., Anderson, M.C., Norman, J.M., Li, F., 2007. Utility of radiometric-aerodynamic temperature relations for heat flux estimation. Boundarylayer Meteorol. 122, 167-187.

Kuusk, A., 1991. The hot spot effect in plant canopy reflectance, in: PhotonVegetation Interactions. Springer, pp. 139-159. 
Kuusk, A., 1998. Monitoring of vegetation parameters on large areas by the inversion of a canopy reflectance model. Int. J. Remote Sens. 19, 28932905. doi: $10.1080 / 014311698214334$

Laio, F., Porporato, A., Fernandez-Illescas, C.., Rodriguez-Iturbe, I., 2001. Plants in water-controlled ecosystems: active role in hydrologic processes and response to water stress II. Probabilistic soil moisture dynamics. Adv. Water Resour. 24, 745-762. doi:10.1016/S0309-1708(01)00007-0

Larcher, W., 2003. Physiological plant ecology: ecophysiology and stress physiology of functional groups. Springer Science \& Business Media, New York, USA.

Laurent, V.C.E., Verhoef, W., Clevers, J.G.P.W., Schaepman, M.E., 2011 a. Inversion of a coupled canopy-atmosphere model using multi-angular top-of-atmosphere radiance data: A forest case study. Remote Sens. Environ. 115, 2603-2612. doi:10.1016/j.rse.2011.05.016

Laurent, V.C.E., Verhoef, W., Clevers, J.G.P.W., Schaepman, M.E., 2011 b. Estimating forest variables from top-of-atmosphere radiance satellite measurements using coupled radiative transfer models. Remote Sens. Environ. 115, 1043-1052. doi:10.1016/j.rse.2010.12.009

Le Maire, G., Marsden, C., Verhoef, W., Ponzoni, F.J., Lo Seen, D., Bégué, A., Stape, J.-L., Nouvellon, Y., 2011. Leaf area index estimation with MODIS reflectance time series and model inversion during full rotations of Eucalyptus plantations. Remote Sens. Environ. 115, 586-599. doi: $10.1016 /$ j.rse.2010.10.004

Lee, S.-J., Cho, J., Hong, S., Ha, K.-J., Lee, H., Lee, Y.-W., 2016. On the relationships between satellite-based drought index and gross primary production in the North Korean croplands, 2000-2012. Remote Sens. Lett. 7, 790-799. doi:10.1080/2150704X.2016.1187315

Lewinska, K.E., Ivits, E., Schardt, M., Zebisch, M., 2016. Alpine forest drought monitoring in South Tyrol: PCA based synergy between scpdsi data and MODIS derived NDVI and NDII7 time series. Remote Sens. 8. doi: $10.3390 /$ rs8080639

Li, F., Kustas, W.P., Prueger, J.H., Neale, C.M.U., Jackson, T.J., 2005. Utility of remote sensing based two-source energy balance model under low and high vegetation cover conditions. J. Hydrometeorol 6, 878-891. doi: $10.1175 / J H M 464.1$

Lidon, Z.Z., Cebola, F., 2012. An overview on drought induced changes in plant growth, water relations and photosynthesis. Emirates J. Food Agric. 24, 57-72.

Liou, Y.A., Kar, S.K., 2014. Evapotranspiration estimation with remote sensing and various surface energy balance algorithms-a review. Energies 7, 2821-2849. doi:10.3390/en7052821

Long, D., Singh, V.P., 2012. A modified surface energy balance algorithm for land (M-SEBAL) based on a trapezoidal framework. Water Resour. Res. 48. doi:10.1029/2011WR010607 
Loveland, T.R., Dwyer, J.L., 2012. Landsat: Building a strong future. Remote Sens. Environ. 122, 22-29. doi:10.1016/j.rse.2011.09.022

Loveland, T.R., Irons, J.R., 2016. Landsat 8: The plans, the reality, and the legacy. Remote Sens. Environ. 185, 1-6. doi:10.1016/j.rse.2016.07.033

Ma, S., Baldocchi, D.D., Xu, L., Hehn, T., 2007. Inter-annual variability in carbon dioxide exchange of an oak/grass savanna and open grassland in California. Agric. For. Meteorol. 147, 157-171.

Ma, S., Baldocchi, D.D., Mambelli, S., Dawson, T.E., 2011. Are temporal variations of leaf traits responsible for seasonal and inter-annual variability in ecosystem CO2 exchange? Funct. Ecol. 25, 258-270. doi:10.1111/j.1365-2435.2010.01779.x

Ma, S., Baldocchi, D., Wolf, S., Verfaillie, J., 2016. Slow ecosystem responses conditionally regulate annual carbon balance over 15 years in Californian oak-grass savanna. Agric. For. Meteorol. 228, 252-264.

Ma, S., Osuna, J.L., Verfaillie, J., Baldocchi, D.D., 2017. Photosynthetic responses to temperature across leaf-canopy-ecosystem scales: a 15year study in a Californian oak-grass savanna. Photosynth. Res. 132, 277-291.

Markwell, J., Osterman, J., Mitchell, J., 1995. Calibration of the Minolta SPAD502 leaf chlorophyll meter. Photosynth. Res. 467-472.

Maselli, F., Papale, D., Puletti, N., Chirici, G., Corona, P., 2009. Combining remote sensing and ancillary data to monitor the gross productivity of water-limited forest ecosystems. Remote Sens. Environ. 113, 657-667. doi: $10.1016 /$ j.rse.2008.11.008

McNaughton, S.J. t, 1968. Structure and function in California grasslands. Ecology 49, 962-972.

Meroni, M., Colombo, R., Panigada, C., 2004. Inversion of a radiative transfer model with hyperspectral observations for LAI mapping in poplar plantations. Remote Sens. Environ. 92, 195-206. doi: $10.1016 /$ j.rse.2004.06.005

Merzlyak, M.N., Chivkunova, O.B., Melø, T.B., Naqvi, K.R., 2002. Does a leaf absorb radiation in the near infrared (780-900 $\mathrm{nm}$ ) region? A new approach to quantifying optical reflection, absorption and transmission of leaves. Photosynth. Res. 72, 263-270. doi:10.1023/A:1019823303951

Miller, G.R., Chen, X., Rubin, Y., Ma, S., Baldocchi, D.D., 2010. Groundwater uptake by woody vegetation in a semiarid oak savanna. Water Resour. Res. 46, 1-14. doi:10.1029/2009WR008902

Miner, G.L., Bauerle, W.L., 2017. Seasonal variability of the parameters of the Ball-Berry model of stomatal conductance in maize (Zea mays L.) and sunflower (Helianthus annuus L.) under well-watered and water-stressed conditions. Plant Cell Environ. 40, 1874-1886. doi:10.1111/pce.12990

Mira, M., Valor, E., Boluda, R., Caselles, V., Coll, C., 2007. Influence of soil water content on the thermal infrared emissivity of bare soils: Implication for land surface temperature determination. J. Geophys. Res. Earth Surf. 
112, 1-11. doi:10.1029/2007JF000749

Monteith, J.L., 1972. Solar radiation and productivity in tropical ecosystems. J. Appl. Ecol. 9, 747-766.

Moorcroft, P.R., Hurtt, G.C., Pacala, S.W., 2001. A method for scaling vegetation dynamics: the ecosystem demography model (ED). Ecol. Monogr. 71, 557-586.

Morales, P., Sykes, M.T., Prentice, I.C., Smith, P., Smith, B., Bugmann, H., Zierl, B., Friedlingstein, P., Viovy, N., Sabate, S., others, 2005. Comparing and evaluating process-based ecosystem model predictions of carbon and water fluxes in major European forest biomes. Glob. Chang. Biol. 11, 2211-2233.

Nagler, P.L., Cleverly, J., Glenn, E., Lampkin, D., Huete, A., Wan, Z., 2005. Predicting riparian evapotranspiration from MODIS vegetation indices and meteorological data. Remote Sens. Environ. 94, 17-30. doi: 10.1016/j.rse.2004.08.009

Noomen, M.F., Smith, K.L., Colls, J.J., Steven, M.D., Skidmore, a. K., Van Der Meer, F.D., 2008. Hyperspectral indices for detecting changes in canopy reflectance as a result of underground natural gas leakage. Int. J. Remote Sens. 29, 5987-6008. doi:10.1080/01431160801961383

Norman, J.M., 1979. "Modelling the complete crop canopy",'Modification of the Aerial Environment of Plants'. Am. Soc. Agr. Eng. Monogr. 2, 249-277.

Norman, J.M., Kustas, W.P., Humes, K.S., 1995. Source approach for estimating soil and vegetation energy fluxes in observations of directional radiometric surface temperature (vol 77, pg 263, 1995). Agric. For. Meteorol. 80, 297. doi:10.1016/0168-1923(96)02344-1

Norman, J.M., Kustas, W.P., Prueger, J.H., Diak, G.R., 2000. Surface flux estimation using radiometric temperature: A dual-temperature-difference method to minimize measurement errors. Water Resour. Res. 36, 22632274. doi: $10.1029 / 2000 W R 900033$

Olioso, A., Chauki, H., Courault, D., Wigneron, J.-P., 1999. Estimation of evapotranspiration and photosynthesis by assimilation of remote sensing data into SVAT models. Remote Sens. Environ. 68, 341-356.

Palmer, W.C., 1965. Meteorological drought. US Department of Commerce, Weather Bureau Washington, DC.

Peng, Y., Gitelson, A.A., Keydan, G., Rundquist, D.C., Moses, W., 2011. Remote estimation of gross primary production in maize and support for a new paradigm based on total crop chlorophyll content. Remote Sens. Environ. 115, 978-989. doi:10.1016/j.rse.2010.12.001

Penuelas, J., Baret, F., Filella, I., 1995. Semiempirical Indexes to Assess Carotenoids Chlorophyll-a Ratio from Leaf Spectral Reflectance. Photosynthetica.

Pitt, M.D., Heady, H.F., 1978. Responses of annual vegetation to temperature and rainfall patterns in northern California. Ecology 59, 336-350.

Pu, R., Ge, S., Kelly, N.M., Gong, P., 2003. Spectral absorption features as 
indicators of water status in coast live oak (Quercus agrifolia) leaves. Int. J. Remote Sens. 24, 1799-1810. doi:10.1080/01431160210155965

Rahman, H., Verstraete, M.M., Pinty, B., 1993. Coupled surface-atmosphere reflectance (CSAR) model: 1. Model description and inversion on synthetic data. J. Geophys. Res. Atmos. 98, 20779-20789.

Rana, G., Katerji, N., 2000. Measurement and estimation of actual evapotranspiration in the field under Mediterranean climate: A review. Eur. J. Agron. 13, 125-153. doi:10.1016/S1161-0301(00)00070-8

Reddy, A.R., Chaitanya, K.V., Vivekanandan, M., 2004. Drought-induced responses of photosynthesis and antioxidant metabolism in higher plants. J. Plant Physiol. 161, 1189-1202.

Reichstein, M., Falge, E., Baldocchi, D., Papale, D., Aubinet, M., Berbigier, P., Bernhofer, C., Buchmann, N., Gilmanov, T., Granier, A., Grünwald, T., Havrànkovà, K., Ilvesniemi, H., Janous, D., Knohl, A., Laurila, T., Lohila, A., Loustau, D., Matteucci, G., Meyers, T., Miglietta, F., Ourcival, J.M., Pumpanen, J., Rambal, S., Rotenberg, E., Sanz, M., Tenhunen, J., Seufert, G., Vaccari, F., Vesala, T., Yakir, D., Valentini, R., 2005. On the separation of net ecosystem exchange into assimilation and ecosystem respiration: Review and improved algorithm. Glob. Chang. Biol. 11, 1424-1439. doi:10.1111/j.1365-2486.2005.001002.x

Reichstein, M., Tenhunen, J.D., Roupsard, O., Ourcival, J., Rambal, S., Miglietta, F., Peressotti, A., Pecchiari, M., Tirone, G., Valentini, R., 2002. Severe drought effects on ecosystem $\mathrm{CO} 2$ and $\mathrm{H} 2 \mathrm{O}$ fluxes at three Mediterranean evergreen sites: revision of current hypotheses? Glob. Chang. Biol. 8, 999-1017.

Reichstein, M., Bahn, M., Mahecha, M.D., Kattge, J., Baldocchi, D.D., 2014. Linking plant and ecosystem functional biogeography. Proc. Natl. Acad. Sci. 111, 13697-13702. doi:10.1073/pnas.1216065111

Reid, J.B., Huck, M.G., 1990. Diurnal variation of crop hydraulic resistance: a new analysis. Agron. J. 82, 827-834.

Richter, K., Atzberger, C., Hank, T.B., Mauser, W., 2012. Derivation of biophysical variables from Earth observation data: validation and statistical measures. J. Appl. Remote Sens. 6, 063557-1. doi: $10.1117 / 1 . J$ RS.6.063557

Running, S.W., Nemani, R.R., Peterson, D.L., Band, L.E., Potts, D.F., Pierce, L.L., Spanner, M.A., Peterson, D.L., 1989. Mapping Regional Forest Evapotranspiration and Photosynthesis by Coupling Satellite Data with Ecosystem Simulation. Ecology 70, 1090-1101.

Running, S.W., 2012. A measurable planetary boundary for the biosphere. Science (80-. ). 337, 1458-1459.

Sadava, D.E., Hillis, D.M., Heller, H.C., Berenbaum, M., 2009. Life: the science of biology. Macmillan.

Sala, A., Tenhunen, J.D., 1996. Simulations of canopy net photosynthesis and transpiration in Quercus ilex L. under the influence of seasonal drought. 
Agric. For. Meteorol. 78, 203-222.

Saltelli, A., Chan, K., Scott, E.M., others, 2000. Sensitivity analysis. Wiley New York.

Sánchez, J.M., Scavone, G., Caselles, V., Valor, E., Copertino, V.A., Telesca, V., 2008. Monitoring daily evapotranspiration at a regional scale from Landsat-TM and ETM+ data: Application to the Basilicata region. J. Hydrol. 351, 58-70. doi:10.1016/j.jhydrol.2007.11.041

Schaepman-Strub, G., Schaepman, M.E., Painter, T.H., Dangel, S., Martonchik, J. V, 2006. Reflectance quantities in optical remote sensing-definitions and case studies. Remote Sens. Environ. 103, 27-42. doi: $10.1016 /$ j.rse.2006.03.002

Sellers, P.J., Randall, D.A., Collatz, G.J., Berry, J.A., Field, C.B., Dazlich, D.A., Zhang, C., Collelo, G.D., Bounoua, L., 1996. A revised land surface parameterization (SiB2) for atmospheric GCMs. Part I: Model formulation. J. Clim. doi:10.1175/1520-0442(1996)009<0676:ARLSPF>2.0.CO;2

Sellers, P.J., Dickinson, R.E., Randall, D.A., Betts, A.K., Hall, F.G., Berry, J.A., Collatz, G.J., Denning, A.S., Mooney, H.A., Nobre, C.A., others, 1997. Modeling the exchanges of energy, water, and carbon between continents and the atmosphere. Science (80-. ). 275, 502-509.

Seneviratne, S.I., Lüthi, D., Litschi, M., Schär, C., 2006a. Land-atmosphere coupling and climate change in Europe. Nature 443, 205-209. doi: $10.1038 /$ nature05095

Seneviratne, S.I., Lüthi, D., Litschi, M., Schär, C., 2006b. Land--atmosphere coupling and climate change in Europe. Nature 443, 205.

Seneviratne, S.I., Corti, T., Davin, E.L., Hirschi, M., Jaeger, E.B., Lehner, I., Orlowsky, B., Teuling, A.J., 2010. Investigating soil moisture--climate interactions in a changing climate: A review. Earth-Science Rev. 99, 125161.

Serbin, S.P., Singh, A., McNeil, B.E., Kingdon, C.C., Townsend, P.A., 2014. Spectroscopic determination of leaf morphological and biochemical traits for northern temperate and boreal tree species. Ecol. Appl. 24, 16511669. doi:10.1890/13-2110.1

Serbin, S.P., Singh, A., Desai, A.R., Dubois, S.G., Jablonski, A.D., Kingdon, C.C., Kruger, E.L., Townsend, P.A., 2015. Remotely estimating photosynthetic capacity, and its response to temperature, in vegetation canopies using imaging spectroscopy. Remote Sens. Environ. 167, 7887. doi:10.1016/j.rse.2015.05.024

Sheffield, J., Wood, E.F., 2008. Global trends and variability in soil moisture and drought characteristics, 1950-2000, from observation-driven simulations of the terrestrial hydrologic cycle. J. Clim. 21, 432-458. doi:10.1175/2007JCLI1822.1

Sheffield, J., Andreadis, K.M., Wood, E.F., Lettenmaier, D.P., 2009. Global and continental drought in the second half of the twentieth century: Severityarea-duration analysis and temporal variability of large-scale events. J. 
Clim. 22, 1962-1981. doi:10.1175/2008JCLI2722.1

Sobrino, J.A., Jiménez-Muñoz, J.C., Sòria, G., Romaguera, M., Guanter, L., Moreno, J., Plaza, A., Martínez, P., 2008. Land surface emissivity retrieval from different VNIR and TIR sensors. IEEE Trans. Geosci. Remote Sens. 46, 316-327. doi:10.1109/TGRS.2007.904834

Song, C., Dannenberg, M.P., Hwang, T., 2013. Optical remote sensing of terrestrial ecosystem primary productivity. Prog. Phys. Geogr. 37, 834854. doi: $10.1177 / 0309133313507944$

Su, Z., 2002. The Surface Energy Balance System ( SEBS ) for estimation of turbulent heat fluxes. Hydrol. Earth Syst. Sci. 6, 85-99. doi: 10.5194/hess-6-85-2002

Su, H., McCabe, M.F., Wood, E.F., Su, Z., Prueger, J.H., 2005. Modeling evapotranspiration during SMACEX: Comparing two approaches for localand regional-scale prediction. J. Hydrometeorol. 6, 910-922. doi:10.1175/JHM466.1

Suárez, L., Zarco-Tejada, P.J., Berni, J. a. J., González-Dugo, V., Fereres, E., 2009. Modelling PRI for water stress detection using radiative transfer models. Remote Sens. Environ. 113, 730-744. doi: $10.1016 /$ j.rse.2008.12.001

Sun, G., Alstad, K., Chen, J., Chen, S., Ford, C.R., Lin, G., Liu, C., Lu, N., McNulty, S.G., Miao, H., others, 2011. A general predictive model for estimating monthly ecosystem evapotranspiration. Ecohydrology 4, 245255.

Taylor, K.E., 2001. in a Single Diagram. J. Geophys. Res. 106, 7183-7192. doi: $10.1029 / 2000$ JD900719

Thornton, B., Lemaire, G., Millard, P., Duff, E.I., 1999. Relationships between nitrogen and water concentration in shoot tissue of molinia caerulea during shoot development. Ann. Bot. 83, 631-636. doi:10.1006/anbo.1999.0872

Timmermans, J., Su, Z., van der Tol, C., Verhoef, A., Verhoef, W., 2013. Quantifying the uncertainty in estimates of surface-atmosphere fluxes through joint evaluation of the SEBS and SCOPE models. Hydrol. Earth Syst. Sci. 17, 1561-1573. doi:10.5194/hess-17-1561-2013

Tucker, C.J., 1980. Remote sensing of leaf water content in the near infrared. Remote Sens. Environ. 10, 23-32. doi:10.1016/0034-4257(80)90096-6

Tuller, M., Or, D., 2004. Retention of water in soil and the soil water characteristic curve. Encycl. soils Environ. 4, 278-289.

Tuzet, A., Perrier, A., Leuning, R., 2003. A coupled model of stomatal conductance, photosynthesis and transpiration. Plant Cell Environ. 26, 1097-1116. doi:DOI 10.1046/j.1365-3040.2003.01035.x

Ullah, S., Skidmore, A.K., Naeem, M., Schlerf, M., 2012. An accurate retrieval of leaf water content from mid to thermal infrared spectra using continuous wavelet analysis. Sci. Total Environ. 437, 145-152. doi:10.1016/j.scitotenv.2012.08.025 
USGS, 1998. Landsat 7 science data users handbook. USGS Unnumbered Ser. Gen. Interes. Publ. Report 430-15-01-003-0.

Ustin, S.L., Gitelson, A.A., Jacquemoud, S., Schaepman, M., Asner, G.P., Gamon, J.A., Zarco-Tejada, P., 2009. Retrieval of foliar information about plant pigment systems from high resolution spectroscopy. Remote Sens. Environ. 113, S67-S77. doi:10.1016/j.rse.2008.10.019

Valor, E., Caselles, V., 1996. Mapping Land Surface Emissivity from NDVI: application to European, African, and South American Area. Remote Sens. Environ. 57, 167-184. doi:10.1016/0034-4257(96)00039-9

Van der Tol, C., Verhoef, W., Rosema, A., 2009a. A model for chlorophyll fluorescence and photosynthesis at leaf scale. Agric. For. Meteorol. 149, 96-105. doi:DOI 10.1016/j.agrformet.2008.07.007

Van der Tol, C., Verhoef, W., Timmermans, J., Verhoef, A., Su, Z., 2009b. An integrated model of soil-canopy spectral radiances, photosynthesis, fluorescence, temperature and energy balance. Biogeosciences 6, 31093129.

Van der Tol, C., Rossini, M., Cogliati, S., Verhoef, W., Colombo, R., Rascher, U., Mohammed, G., 2016. A model and measurement comparison of diurnal cycles of sun-induced chlorophyll fluorescence of crops. Remote Sens. Environ. 186, 663-677. doi:10.1016/j.rse.2016.09.021

Van Genuchten, M.T., 1980. A closed-form equation for predicting the hydraulic conductivity of unsaturated soils. Soil Sci. Soc. Am. J. 44, 892-898.

Verhoef, A., Allen, S.J., 2000. A SVAT scheme describing energy and CO2 fluxes for multi-component vegetation: calibration and test for a Sahelian savannah. Ecol. Modell. 127, 245-267.

Verhoef, A., Egea, G., 2014. Modeling plant transpiration under limited soil water: Comparison of different plant and soil hydraulic parameterizations and preliminary implications for their use in land surface models. Agric. For. Meteorol. 191, 22-32. doi:10.1016/j.agrformet.2014.02.009

Verhoef, W., 1984. Light scattering by leaf layers with application to canopy reflectance modeling: The SAIL model. Remote Sens. Environ. 16, 125141. doi: $10.1016 / 0034-4257(84) 90057-9$

Verhoef, W., 1985. Earth observation modeling based on layer scattering matrices. Remote Sens. Environ. 17, 165-178. doi:10.1016/00344257(85) $90072-0$

Verhoef, W., 1998. Theory of radiative transfer models applied in optical remote sensing of vegetation canopies. Wageningen University. doi:ISBNL 90-5485-804-4

Verhoef, W., Bach, H., 2003a. Remote sensing data assimilation using coupled radiative transfer models. Phys. Chem. Earth, Parts A/B/C 28, 3-13. doi: 10.1016/S1474-7065(03)00003-2

Verhoef, W., Bach, H., 2003b. Simulation of hyperspectral and directional radiance images using coupled biophysical and atmospheric radiative transfer models. Remote Sens. Environ. 87, 23-41. doi:10.1016/s0034- 
4257(03)00143-3

Verhoef, W., Bach, H., 2007. Coupled soil-leaf-canopy and atmosphere radiative transfer modeling to simulate hyperspectral multi-angular surface reflectance and TOA radiance data. Remote Sens. Environ. 109, 166-182. doi:10.1016/j.rse.2006.12.013

Verhoef, W., Jia, L., Xiao, Q., Su, Z., 2007. Unified optical-thermal four-stream radiative transfer theory for homogeneous vegetation canopies. IEEE Trans. Geosci. Remote Sens. 45, 1808-1822. doi:10.1109/TGRS.2007.895844

Verhoef, W., Bach, H., 2012. Simulation of Sentinel-3 images by four-stream surface-atmosphere radiative transfer modeling in the optical and thermal domains. Remote Sens. Environ. 120, 197-207. doi: $10.1016 /$ j.rse.2011.10.034

Verhoef, W., van der Tol, C., Middleton, E.M., 2018. Hyperspectral radiative transfer modeling to explore the combined retrieval of biophysical parameters and canopy fluorescence from FLEX - Sentinel-3 tandem mission multi-sensor data. Remote Sens. Environ. 204, 942-963. doi: $10.1016 /$ j.rse.2017.08.006

Verma, M., Friedl, M.A., Law, B.E., Bonal, D., Kiely, G., Black, T.A., Wohlfahrt, G., Moors, E.J., Montagnani, L., Marcolla, B., Toscano, P., Varlagin, A., Roupsard, O., Cescatti, A., Arain, M.A., D'Odorico, P., 2015. Improving the performance of remote sensing models for capturing intra- and interannual variations in daily GPP: An analysis using global FLUXNET tower data. Agric. For. Meteorol. 214-215, 416-429. doi: $10.1016 /$ j.agrformet.2015.09.005

Verrelst, J., Schaepman, M.E., Koetz, B., Kneubühler, M., 2008. Angular sensitivity analysis of vegetation indices derived from CHRIS/PROBA data. Remote Sens. Environ. 112, 2341-2353.

Verrelst, J., Rivera, J.P., Van Der Tol, C., Magnani, F., Mohammed, G., Moreno, J., 2015. Global sensitivity analysis of the SCOPE model: What drives simulated canopy-leaving sun-induced fluorescence? Remote Sens. Environ. 166, 8-21. doi:10.1016/j.rse.2015.06.002

Verrelst, J., van der Tol, C., Magnani, F., Sabater, N., Rivera, J.P., Mohammed, G., Moreno, J., 2016. Evaluating the predictive power of sun-induced chlorophyll fluorescence to estimate net photosynthesis of vegetation canopies: A SCOPE modeling study. Remote Sens. Environ. 176, 139151.

Vicca, S., Balzarolo, M., Filella, I., Granier, A., Herbst, M., Knohl, A., Longdoz, B., Mund, M., Nagy, Z., Pintér, K., Rambal, S., Verbesselt, J., Verger, A., Zeileis, A., Zhang, C., Peñuelas, J., 2016. Detection of effects of extreme droughts on gross primary production using satellite data. Nat. Publ. Gr. 1-13. doi:10.1038/srep28269

Vile, D., Garnier, E., Shipley, B., Laurent, G., Navas, M.-L., Roumet, C., Lavorel, S., Díaz, S., Hodgson, J.G., Lloret, F., Midgley, G.F., Poorter, H., 
Rutherford, M.C., Wilson, P.J., Wright, I.J., 2005. Specific leaf area and dry matter content estimate thickness in laminar leaves. Ann. Bot. 96, 1129-36. doi:10.1093/aob/mci264

Vilfan, N., van der Tol, C., Muller, O., Rascher, U., Verhoef, W., 2016. Fluspect$B$ : A model for leaf fluorescence, reflectance and transmittance spectra. Remote Sens. Environ. 186, 596-615. doi:10.1016/j.rse.2016.09.017

Vilfan, N., der Tol, C., Yang, P., Wyber, R., Malenovsk'y, Z., Robinson, S.A., Verhoef, W., 2018. Extending Fluspect to simulate xanthophyll driven leaf reflectance dynamics. Remote Sens. Environ. 211, 345-356.

Wagle, P., Xiao, X., Torn, M.S., Cook, D.R., Matamala, R., Fischer, M.L., Jin, C., Dong, J., Biradar, C., 2014. Sensitivity of vegetation indices and gross primary production of tallgrass prairie to severe drought. Remote Sens. Environ. 152, 1-14. doi:10.1016/j.rse.2014.05.010

Wagle, P., Xiao, X., Suyker, A.E., 2015. Estimation and analysis of gross primary production of soybean under various management practices and drought conditions. ISPRS J. Photogramm. Remote Sens. 99, 70-83. doi:10.1016/j.isprsjprs.2014.10.009

Wallace, J.S., Verhoef, A., 2000. Modelling interactions in mixed-plant communities: light, water and carbon dioxide. Leaf Dev. Canopy Growth 204, 250.

Wetzel, P.J., Chang, J.-T., 1987. Concerning the Relationship between Evapotranspiration and Soil Moisture. J. Clim. Appl. Meteorol. doi: 10.1175/1520-0450(1987)026<0018:CTRBEA>2.0.CO;2

Wilcox, B.P., 2010. Ecohydrology Bearing - Invited Commentary Transformation ecosystem change and ecohydrology: ushering in a new era for watershed management. Ecohydrology 130, 126-130. doi: $10.1002 /$ eco

Wohlfahrt, G., Gu, L., 2015. The many meanings of gross photosynthesis and their implication for photosynthesis research from leaf to globe. Plant Cell Environ. 38, 2500-2507. doi:10.1111/pce.12569

Wolf, A., Akshalov, K., Saliendra, N., Johnson, D.A., Laca, E.A., 2006. Inverse estimation of $\mathrm{Vc}(\max )$, leaf area index, and the Ball-Berry parameter from carbon and energy fluxes. J. Geophys. Res. 111. doi:Artn D08s08\rDoi 10.1029/2005gd005927

Wolf, S., Eugster, W., Ammann, C., Häni, M., Zielis, S., Hiller, R., Stieger, J., Imer, D., Merbold, L., Buchmann, N., 2013. Contrasting response of grassland versus forest carbon and water fluxes to spring drought in Switzerland. Environ. Res. Lett. 8, 035007. doi:10.1088/17489326/8/3/035007

Wu, C., Niu, Z., Tang, Q., Huang, W., Rivard, B., Feng, J., 2009. Remote estimation of gross primary production in wheat using chlorophyll-related vegetation indices. Agric. For. Meteorol. 149, 1015-1021. doi: $10.1016 /$ j.agrformet.2008.12.007

Wu, C., Chen, J.M., Huang, N., 2011. Predicting gross primary production from 
the enhanced vegetation index and photosynthetically active radiation: Evaluation and calibration. Remote Sens. Environ. 115, 3424-3435. doi: $10.1016 /$ j.rse.2011.08.006

Wulder, M.A., White, J.C., Goward, S.N., Masek, J.G., Irons, J.R., Herold, M., Cohen, W.B., Loveland, T.R., Woodcock, C.E., 2008. Landsat continuity: Issues and opportunities for land cover monitoring. Remote Sens. Environ. 112, 955-969. doi:10.1016/j.rse.2007.07.004

Wulder, M.A., Masek, J.G., Cohen, W.B., Loveland, T.R., Woodcock, C.E., 2012. Opening the archive: How free data has enabled the science and monitoring promise of Landsat. Remote Sens. Environ. 122, 2-10. doi: $10.1016 /$ j.rse.2012.01.010

Wullschleger, S.D., 1993. Biochemical limitations to carbon assimilation in C3 plants-a retrospective analysis of the A/Ci curves from 109 species. J. Exp. Bot. 44, 907-920.

Xiao, X., Hollinger, D., Aber, J., Goltz, M., Davidson, E.A., Zhang, Q., Moore, B., 2004a. Satellite-based modeling of gross primary production in an evergreen needleleaf forest. Remote Sens. Environ. 89, 519-534. doi: $10.1016 /$ j.rse.2003.11.008

Xiao, X., Zhang, Q., Braswell, B., Urbanski, S., Boles, S., Wofsy, S., Moore, B., Ojima, D., 2004b. Modeling gross primary production of temperate deciduous broadleaf forest using satellite images and climate data. Remote Sens. Environ. 91, 256-270. doi:10.1016/j.rse.2004.03.010

Xu, L., Baldocchi, D.D., 2003. Seasonal trends in photosynthetic parameters and stomatal conductance of blue oak (Quercus douglasii) under prolonged summer drought and high temperature. Tree Physiol. 23, 86577. doi: $10.1093 /$ treephys/23.13.865

Xu, L., Baldocchi, D.D., 2004. Seasonal variation in carbon dioxide exchange over a Mediterranean annual grassland in California. Agric. For. Meteorol. 123, 79-96. doi:10.1016/j.agrformet.2003.10.004

Xu, L., Baldocchi, D.D., Tang, J., 2004. How soil moisture, rain pulses, and growth alter the response of ecosystem respiration to temperature. Global Biogeochem. Cycles 18, 1-10. doi:10.1029/2004GB002281

Yang, P., Verhoef, W., van der Tol, C., 2017. The mSCOPE model: A simple adaptation to the SCOPE model to describe reflectance, fluorescence and photosynthesis of vertically heterogeneous canopies. Remote Sens. Environ. 201, 1-11. doi:10.1016/j.rse.2017.08.029

Yang, P., van der Tol, C., 2018. Linking canopy scattering of far-red suninduced chlorophyll fluorescence with reflectance. Remote Sens. Environ. 209, 456-467. doi:10.1016/j.rse.2018.02.029

Yi, Q., Bao, A., Luo, Y., Zhao, J., 2012. Measuring cotton water status using water-related vegetation indices at leaf and canopy levels. J. Arid Land 4, 310-319. doi:10.3724/SP.J.1227.2012.00310

Zarco-Tejada, P.J., Rueda, C. a., Ustin, S.L., 2003. Water content estimation in vegetation with MODIS reflectance data and model inversion methods. 
Remote Sens. Environ. 85, 109-124. doi:10.1016/S00344257(02)00197-9

Zarco-Tejada, P.J., Berjón, A., López-Lozano, R., Miller, J.R., Martín, P., Cachorro, V., González, M.R., De Frutos, A., 2005. Assessing vineyard condition with hyperspectral indices: Leaf and canopy reflectance simulation in a row-structured discontinuous canopy. Remote Sens. Environ. 99, 271-287.

Zarco-Tejada, P.J., González-Dugo, V., Williams, L.E., Suárez, L., Berni, J.A.J., Goldhamer, D., Fereres, E., 2013. A PRI-based water stress index combining structural and chlorophyll effects: Assessment using diurnal narrow-band airborne imagery and the CWSI thermal index. Remote Sens. Environ. 138, 38-50. doi:10.1016/j.rse.2013.07.024

Zhang, K., Kimball, J.S., Running, S.W., 2016. A review of remote sensing based actual evapotranspiration estimation. Wiley Interdiscip. Rev. Water 3. doi:10.1002/wat2.1168

Zhang, Q., Xiao, X., Braswell, B., Linder, E., Baret, F., Moore, B., 2005. Estimating light absorption by chlorophyll, leaf and canopy in a deciduous broadleaf forest using MODIS data and a radiative transfer model. Remote Sens. Environ. 99, 357-371. doi:10.1016/j.rse.2005.09.009

Zhang, Y., Peng, C.H., Li, W.Z., Fang, X.Q., Zhang, T.L., Zhu, Q.A., Chen, H., Zhao, P.X., 2013. Monitoring and estimating drought-induced impacts on forest structure, growth, function, and ecosystem services using remotesensing data: recent progress and future challenges. Environ. Rev. 21, 103-115. doi:Doi 10.1139/Er-2013-0006

Zhang, Y., Guanter, L., Berry, J.A., Joiner, J., Tol, C., Huete, A., Gitelson, A., Voigt, M., Köhler, P., 2014. Estimation of vegetation photosynthetic capacity from space-based measurements of chlorophyll fluorescence for terrestrial biosphere models. Glob. Chang. Biol. 20, 3727-3742.

Zhang, Y., Song, C., Sun, G., Band, L.E., McNulty, S., Noormets, A., Zhang, Q., Zhang, Z., 2016. Development of a coupled carbon and water model for estimating global gross primary productivity and evapotranspiration based on eddy flux and remote sensing data. Agric. For. Meteorol. 223, 116-131. doi:10.1016/j.agrformet.2016.04.003

Zhao, X., Wei, H., Liang, S., Zhou, T., He, B., Tang, B., Wu, D., 2015. Responses of natural vegetation to different stages of extreme drought during 2009-2010 in Southwestern China. Remote Sens. 7, 1403914054. doi: $10.3390 /$ rs71014039

Zhou, S., Duursma, R. a., Medlyn, B.E., Kelly, J.W.G., Prentice, I.C., 2013. How should we model plant responses to drought? An analysis of stomatal and non-stomatal responses to water stress. Agric. For. Meteorol. 182183, 204-214. doi:10.1016/j.agrformet.2013.05.009 


\section{Author's biography and $\mathrm{PhD}$ publications}

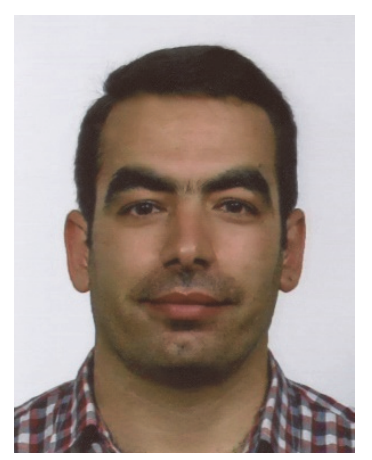

Bagher Bayat was born on the $21^{\text {st }}$ of November 1984 in Malayer, Hamedan province, Iran. In 2008, he received his BSc degree in Natural Resources Engineering - Watershed Management from Gorgan University, Iran. In 2011, he obtained his MSc degree in Remote Sensing and Geographic Information System (RS - GIS) from Shahid Beheshti University, Tehran, Iran. He graduated from both universities with first-class honours [BSC GPA: 17.98 and MSc GPA: 18.45 out of 20]. Accordingly, he was succeeded to achieve a permanent position in the Iranian National Talent Foundation and was exempted from doing the military service obligation through "Elite Students Military Exemption Program". From 2011 to 2013, he was working as RS - GIS specialist at Soil Conservation and Watershed Management Research Institute (SCWMRI), Tehran, Iran. During this period, he was involved in two national projects related to RS and GIS applications in water resources monitoring. In August 2013, he moved to the Netherlands to pursue his PhD degree at WRS department of the Faculty of Geo-Information Science and Earth Observation (ITC), University of Twente, which resulted in this dissertation. His research interests focus on surface-atmosphere radiative transfer models, remote sensing of vegetation properties and functioning, drought effects, earth observation and Eco-hydrology, GIS spatial analysis and data visualization.

A list of Author's publications during his PhD at the University of Twente is as follows:

\section{ISI Journal Articles:}

Bayat, B., Van der Tol, C., Verhoef, W., 2016. Remote Sensing of Grass Response to Drought Stress Using Spectroscopic Techniques and Canopy Reflectance Model Inversion. Remote Sensing, 2016, 8, 557, https://doi.org/10.3390/rs8070557.

Bayat, B., Van der Tol, C., Verhoef, W., 2018. Integrating Satellite Optical and Thermal Infrared Observations for Improving Daily Ecosystem Functioning Estimations during a Drought Episode. Remote Sensing of Environment, 2018, 209, 375-394, https://doi.org/10.1016/j.rse.2018.02.027.

Bayat, B., Van der Tol, C., Verhoef, W., 2018. Retrieval of Land Surface Properties from an Annual Time Series of Landsat TOA Radiances during a 
Drought Episode using Coupled Radiative Transfer Models. Remote Sensing of Environment, 2018, https://doi.org/10.1016/j.rse.2018.09.030.

Bayat, B., Van der Tol, C., Yang, P., Verhoef, W., 2018. Extending the SCOPE model to combine optical reflectance and soil moisture observations for remote sensing of ecosystem functioning under water stress conditions. Remote Sensing of Environment, 2018, 221, 286-301, https:// doi.org/10.1016/j.rse.2018.11.021.

\section{International conferences Articles:}

Bayat, B., Van der Tol, C., Verhoef, W., 2016. Monitoring Soil Moisture Deficit Effects on Vegetation Parameters Using Radiative Transfer Models Inversion and Hyperspectral Measurements under Controlled Conditions. Living Planet Symposium 2016, 9-13 May 2016, Prague, Czech Republic.

Arabi, B., Salama, M. S., Bayat, B., Verhoef, W. (2016). One Decade Monitoring of Water Turbidity in the Wadden Sea Using Coupled WaterAtmosphere Radiative Transfer Models and Remote Sensing Observations. American Geophysical Unit (AGU) Ocean sciences Meeting 2016, 21-26 February 2016, New Orleans, LA, USA.

Bayat, B., Verhoef, W., Van der Tol, C., 2017. MOD-PROSAIL: a Coupled Atmosphere-canopy Radiative Transfer Model for the Retrieval of Vegetation Properties from Remote Sensing Observations with Application to Drought Effects Detection. The $5^{\text {th }}$ International Symposium on Recent Advances in Quantitative Remote Sensing (RAQRS'V) 2017, 18-22 September 2017, Valencia, Spain.

Nangira Wandera, L., Van der Tol, C., Mallick, K., Bayat, B., Verbeiren, B., van Griensven, A., Verhoef, W., Suliga, J., Miguel Barrios, J., Chormanski, J., Kleniewska, M., 2017. Retrieval of Spatio-temporal Evaporation by Integrating Landsat OLI Optical and Thermal Data, American Geophysical Unit (AGU) Fall Meeting 2017, 11-15 December 2017, New Orleans, LA, USA.

Bayat, B., Van der Tol, C., Verhoef, W., Raj, R., 2018. Spatio-temporal Estimation of Daily Photosynthesis in Drought Conditions using Remote Sensing Observations and In-situ Measurements, the $3^{\text {rd }}$ Integrated Carbon Observation Science (ICOS) 2018, 11-13 September 2018, Prague, Czech Republic.

Bayat, B., Van der Tol, C., Verhoef, W., 2018. Estimation of Vegetation Functioning in a Drought Episode from Optical and Thermal Remote Sensing. IEEE International Geoscience and Remote Sensing Symposium (IGARSS) 2018, 22-27 July 2018, Valencia, Spain. 
Van der Tol, C., Vilfan, N., Yang, P., Bayat, B., Verhoef, W., 2018. Modeling Reflectance, Fluorescence and Photosynthesis: Development of the SCOPE Model. IEEE International Geoscience and Remote Sensing Symposium (IGARSS) 2018, 22-27 July 2018, Valencia, Spain.

Raj, R., Lukes, P., Homolova, L., Brovkina, O., Sigut, L., Bayat, B., 2018. Integration of flux tower data and remotely sensed data into the SCOPE simulator: A Bayesian approach, the 3rd Integrated Carbon Observation Science (ICOS) 2018, 11-13 September 2018, Prague, Czech Republic. 